\title{
Heparins in Thrombosis and Cancer
}

Citation for published version (APA):

Vignoli, A. V. (2018). Heparins in Thrombosis and Cancer: Effects on the Vascular Endothelium. [Doctoral Thesis, Maastricht University]. Maastricht University. https://doi.org/10.26481/dis.20181116av

Document status and date:

Published: 01/01/2018

DOI:

10.26481/dis.20181116av

Document Version:

Publisher's PDF, also known as Version of record

\section{Please check the document version of this publication:}

- A submitted manuscript is the version of the article upon submission and before peer-review. There can be important differences between the submitted version and the official published version of record.

People interested in the research are advised to contact the author for the final version of the publication, or visit the DOI to the publisher's website.

- The final author version and the galley proof are versions of the publication after peer review.

- The final published version features the final layout of the paper including the volume, issue and page numbers.

Link to publication

\footnotetext{
General rights rights.

- You may freely distribute the URL identifying the publication in the public portal. please follow below link for the End User Agreement:

www.umlib.nl/taverne-license

Take down policy

If you believe that this document breaches copyright please contact us at:

repository@maastrichtuniversity.nl

providing details and we will investigate your claim.
}

Copyright and moral rights for the publications made accessible in the public portal are retained by the authors and/or other copyright owners and it is a condition of accessing publications that users recognise and abide by the legal requirements associated with these

- Users may download and print one copy of any publication from the public portal for the purpose of private study or research.

- You may not further distribute the material or use it for any profit-making activity or commercial gain

If the publication is distributed under the terms of Article $25 \mathrm{fa}$ of the Dutch Copyright Act, indicated by the "Taverne" license above, 
Heparins in Thrombosis and Cancer:

Effects on the Vascular Endothelium 
(C) Alfonso Vittorio Vignoli,

Maastricht University/Bergamo "Papa Giovanni XXIII" Hospital, 2018.

All rights reserved. No part of this book may be reproduced, stored in a retrieval system or transmitted in any form or by any means without prior written permission by the author or, when appropriate, by the publishers of the publications.

ISBN: see back cover.

Cover Art and Design: Marina Marchetti, Alfonso Vittorio Vignoli.

Printing: Printing Facility of the Bergamo "Papa Giovanni XXIII" Hospital. 


\title{
Heparins in Thrombosis and Cancer: Effects on the Vascular Endothelium
}

\author{
Dissertation
}

to obtain the degree of Doctor at the Maastricht University, on the authority of the Rector Magnificus

Prof. Dr. Rianne M. Letschert

in accordance with the decision of the Board of Deans, to be defended in public on Friday $16^{\text {th }}$ November, 2018, at 12.45 P.M.

by

Alfonso Vittorio Vignoli 


\section{Promotors}

Prof. Dr. Hugo ten Cate

Prof. Dr. Anna Falanga (University of Bergamo)

\section{Co-promotor}

Dr. Marina Marchetti (University of Bergamo)

\section{Assessment committee}

Prof. Dr. Chris P.M. Reutelingsperger (Chairman)

Dr. Henri M.H. Spronk

Prof. Dr. Harry C. Schouten

Prof. Dr. Henri H. Versteeg (Leiden University Medical Center)

Dr. Marina Panova-Noeva (Center for Thrombosis and Haemostasis, Gutenberg University, Mainz)

The research described in this thesis has been partially supported by grants from the Italian Association for Cancer Research (AIRC, Milan, Italy), Regione Lombardia (Italy) and Italian Ministry of Health. 
"Once you eliminate the impossible, whatever remains, no matter how improbable, must be the truth." (Arthur Conan Doyle, from "Sherlock Holmes") 



\section{Table of Contents}

Chapter 1: General Introduction................................

Outline of the Thesis.............................22

\section{PART ONE Overview on Hemostasis and Cancer}

Chapter 2: Coagulation and Cancer: Biological and Clinical Aspects. 35

Chapter 3: Mechanisms and risk factors of thrombosis in cancer.

PART TWO Heparin Actions on Endothelial Cell Hemostatic Properties

Chapter 4: Differential effect of the low-molecularweight-heparin, dalteparin, and unfractionated heparin on microvascular endothelial cells hemostatic properties 59

PART THREE Heparin Effects on Tumor Cell-Endothelial Cell Interactions

Chapter 5: Heparins inhibit the endothelial prothrombotic features induced by tumor cells................71

Chapter 6: Endothelial capillary tube formation and cell proliferation induced by tumor cells are affected by 
low molecular weight heparins and unfractionated heparin................................................................. 77

Chapter 7: LMWH Bemiparin and ULMWH RO-14 reduce the endothelial angiogenic features elicited by leukemia, lung cancer, or breast cancer cells

Chapter 8: Comparative assessment of lowmolecular-weight-heparins in cancer from the perspective of patient outcome and survival...........101

Chapter 9: Acute promyelocytic leukemia cell adhesion to vascular endothelium is reduced by heparins.............................................................. 117

Chapter 10: General discussion and summary ......127

Appendix: Valorisation....................................... 145

Curriculum Vitae..............................151

Publications.....................................155

Acknowledgements...........................161 


\section{Chapter 1}

General Introduction 


\section{Thrombosis and Cancer: a Mutual Relationship}

In our days, thrombotic and malignant diseases account for a major portion of human deaths in developed countries. According to the statistical agency of the European Union, Eurostat, this is particularly relevant in Europe, where deaths due to cardiovascular diseases are immediately followed by cancers as leading causes of death (1-2).

Of note, although the presence of a mechanistic connection between cardiovascular and malignant diseases was suggested 150 years ago by Trousseau in France and by Billroth in Austria (3-4), only during the last two decades it has become clear that thrombosis and cancer are mutually connected in a two-way relationship (5).

On the one hand, the presence of a tumor causes a derangement of the hemostatic system which renders cancer patients prone to develop thrombosis (and also bleeding). In general, cancer inflicts an activation of blood coagulation with the appearance of a hypercoagulable state or chronic disseminated intravascular coagulation (DIC) in these patients. Coagulation test abnormalities are commonly detected in the blood of cancer patients, even in the absence of overt thrombosis and/or bleeding: these haemostatic alterations may include high levels of plasma by-products of clotting reactions (i.e. prothrombin fragment $1+2$, 
fibrinopeptide A, thrombin-antithrombin complex, and DDimer), an acquired protein $C$ resistance, as well as high levels of circulating microparticles (MP) shed by tumour cells and platelets (6). The pathogenesis of blood coagulation activation in cancer is complex and multifactorial (7). Indeed, in malignancy, a key role is played by tumour cell-associated clot promoting properties. These properties lead to the activation of the clotting cascade, with the generation of thrombin and fibrin, and the stimulation of platelets, leukocytes, and endothelial cells, expressing cellular procoagulant features.

On the other hand, haemostatic proteins and reactions interdigitate the process of tumour progression (8). In general, tumour growth and aggressiveness largely rely on cancer cell capacity to promote neoangiogenesis and metastasis (9). In these processes, a contribution of different components of the haemostatic system, including Tissue Factor (TF) and FVIla, FXa, thrombin and fibrinogen as well as vascular cells, has been clearly documented by both in vitro and in vivo tumour models. Mechanisms described include both clotting-dependent activities of these molecules, culminating in platelet activation and fibrin deposition, as well as clotting-independent properties $(5,7)$. Moreover, the prothrombotic and proangiogenic factors of circulating MP 
shed by tumour cells and stimulated platelets are considered important players in supporting tumour growth (10).

Since cancer cells can activate the coagulation system and the haemostatic factors play a role in tumour progression, the road is paved for the development of bifunctional therapeutic approaches that are both capable of attacking the malignant process and resolving the coagulation impairment. In this setting, heparins may offer a fundamental contribution.

\section{Heparins: Generalities}

Heparins, naturally-occurring glycosaminoglycans, are a mixture of sulfated polysaccharide chains of different molecular weight. Heparins are synthesized by mast cells and distributed widely throughout the organs of mammalian species. Heparin preparations are heterogeneous with respect to molecular size, anticoagulant activity, and pharmacokinetic properties. The molecular weight (MW) of unfractionated heparin (UFH) ranges from 3 to $30 \mathrm{kDa}$, with a mean MW of $15 \mathrm{kDa}$ (about 45 monosaccharide chains). In medicine, heparins are used as antithrombotic drugs. Heparins exert their major anticoagulant activity in blood by binding to and potentiating the activity of the natural anticoagulant antithrombin (AT) through a unique glucosamine unit contained within a pentasaccharide sequence (11). The heparin-AT complex inactivates a 
number of coagulation enzymes, including thrombin and the activated forms of Factor X, Factor IX, Factor XI, and Factor XII. Thrombin and activated Factor X (FXa) are the most responsive to inhibition, and human thrombin is about 10-fold more sensitive than FXa to inhibition by the heparin-AT complex. For thrombin inhibition, heparin must bind to both the coagulation enzyme and AT, whereas binding of heparin to the enzyme is not required for inhibition of FXa. The formation of a ternary complex between AT, thrombin, and heparin results in the inactivation of thrombin. For this reason, heparin's activity against thrombin is size-dependent, the ternary complex requiring at least 18 saccharide units for efficient formation. In contrast, anti-FXa activity requires only the pentasaccharide binding site. The heparin molecules with fewer than 18 saccharides lack the chain length to bridge thrombin and AT and therefore are unable to inhibit thrombin. In contrast, very small heparin fragments containing the highaffinity pentasaccharide sequence catalyze inhibition of $\mathrm{FXa}$ by AT. This size difference has led to the development of low molecular weight heparins (LMWH) as anticoagulant drugs. LMWH target preferably FXa activity rather than thrombin (Ila) activity, with the aim of facilitating a more subtle regulation of coagulation and an improved therapeutic index. LMWH can be obtained by controlled chemical, enzymatic, physical, and radiochemical depolymerization of UFH. They possess a mean MW between 3 and $6 \mathrm{kDa}$ and chain 
lengths of 12 to 18 saccharide units. Different LMWH show distinct structural differences and MW component distribution, which determine differences in their chemical and biological activities, particularly, different anti-FXa and anti-Flla activities which translates in a particular antiFXa/anti-Flla ratio (12).

Compared to UFH, LMWH have an increased anti-Xa/anti-Ila activity ratio, reduced plasma protein binding, lower tendency to bind to endothelial cells (13), decreased interaction with platelets and platelet factor 4 , a prolonged half-life and increased bioavailability after s.c. administration. All these characteristics translate in a more consistent and predictable absorption rate and bioavailability pattern as compared to UFH. Bioavailability of LMWH preparations is different according to molecule features, ranging from $87 \%$ to $98 \%$ (12-13).

UFH and LMWH are metabolized by depolymerization and desulfation (13-14). After being degraded by the liver, heparins are eliminated by the kidneys as metabolites retaining their biologic activity (14). The clearance of LMWH does not change as a function of administered dose (unlike that of UFH, which is dose dependent), which may be attributed to the lower cellular uptake of LMWH compared with UFH (15). 


\section{Heparins: Clinical Uses}

\section{-Prophylaxis of Thrombosis}

The efficacy of prophylactic strategies to prevent Venous ThromboEmbolism (VTE) in at risk hospitalized patients has been well demonstrated. For example, pharmacological prophylaxis with $\mathrm{LMWH}$ reduces the risk of Pulmonary Embolism (PE) by $75 \%$ in general surgical patients (16) and by $57 \%$ in medical patients (17). It has been shown that cancer patients undergoing surgery benefit from effective pharmacological prophylaxis (18), and that extended duration of thromboprophylaxis with LMWH is beneficial to patients undergoing major abdominal or pelvic surgery (19). This is reflected in current guidelines which recommend that all cancer patients undergoing major surgery should receive heparin-based prophylaxis for a minimum of 7-10 days, with supportive mechanical prophylaxis in those patients at highest risk (20). Clinical trials have demonstrated the benefit of VTE prophylaxis either with low-dose UFH or LMWH in hospitalized general medical patients, including patients with cancer. Differently from hospitalized cancer patients, primary prevention of thrombosis in ambulatory cancer patients is still debated, although there is evidence that LMWH is effective in reducing VTE in selected outpatients receiving chemotherapy. 


\section{-Treatment of Thrombosis}

Today, the standard treatment regimen for a first acute VTE episode in patients without cancer consists of an initial therapy with heparins, followed by a long-term therapy with a Vitamin $\mathrm{K}$ antagonist (i.e. warfarin) agent for 3 to 6 months, or with a direct oral anticoagulant (DOAC), with or without prior LMWH. However, in patients with cancer related VTE monotherapy with $\mathrm{LMWH}$ is preferred and recommended for 6 months or longer, although comparative trials of $\mathrm{LMWH}$ against DOAC are being done in this population (21-22). A recently published $\mathrm{LMWH}$ controlled clinical trial suggests that the DOAC edoxaban would be an effective alternative to LMWH with an acceptable bleeding risk profile (23).

\section{Heparins: Effect on Survival of Cancer Patients}

Since the early 1980's, a beneficial effect of heparins on overall survival in cohorts of cancer patients enrolled in randomized clinical trials (RCT) of perioperative prophylaxis with UFH versus no prophylaxis was reported by both retrospective and prospective evaluations (24-25). However, a later systematic review of all methodologically correct clinical trials in cancer patients without VTE and comparing UFH with placebo or no treatment failed to provide 
convincing evidence of either positive or negative effects of UFH on cancer survival (26).

In the meanwhile, the use of LMWH progressively increased. In 1999, a meta-analysis of all clinical trials testing the efficacy of LMWH versus UFH for the initial treatment of VTE showed a pooled odds ratio for 3-month mortality in cancer patients of $0.61(95 \% \mathrm{Cl}, 0.40$ to 0.93$)$ in favor of LMWH (27). Positive suggestions came also from the CLOT study; a post-hoc analysis of this trial found an advantage in survival in the subgroup of patients with limited disease receiving long-term LMWH dalteparin compared to warfarin (28). This indication, together with the known advantages of LMWH administration and the feasibility of long term treatment, have prompted researchers to continue to investigate the potential role of $\mathrm{LMWH}$ as antineoplastic agent. Prospective RCT have therefore been designed to address the survival of cancer patients receiving LMWH as primary efficacy end-point (29-32). The results of these trials didn't provide any clear evidence in favor of a beneficial effect of heparins on cancer survival, until, in 2007, Kuderer et al. performed the first systematic review and meta-analysis of all RCT of the efficacy and safety of anticoagulants (LMWH, UFH and VKA) in the treatment of patients with cancer without VTE (33). The results obtained from 11 eligible trials showed that the administration of any sort of anticoagulation significantly decreased overall 1-year 
mortality with a relative risk of $0.905(95 \% \mathrm{Cl}, 0.85-0.97$, $\mathrm{p}=0.003$ ) compared to no anticoagulation. Interestingly, for LMWH the relative risk of mortality was $0.88(95 \% \mathrm{Cl}, 0.79$ $0.98, p=0.015)$, compared with a non-significant effect of warfarin, resulting in an absolute risk difference of $8 \%$ for $\mathrm{LMWH}$, with also less major bleeding events in the LMWH group compared to warfarin. These findings have been confirmed in subsequent reviews (34). Since then, other studies that incorporate as secondary objective the effect of LMWH on cancer survival, have been started or published (35-39).

\section{Heparins: Effects on Cancer Biology}

The suggestions coming from clinical trials of a beneficial effect of LMWH on survival from cancer, have triggered basic research to investigate the potential antitumor effects of LMWH in vitro and in animal models. Several different and possibly interrelated biological mechanisms have been proposed, including both coagulation -dependent and independent activities (40). Indeed, it has been demonstrated that heparin can interfere with tumor progression by inhibiting: 1) heparin-binding growth factors that drive malignant cell growth; 2) tumor angiogenesis; 3) tumor cell heparanase that mediates tumor cell invasion and metastasis; 4) cell surface selectin-mediated tumor cell 
metastasis; and 5) blood coagulation activation that may provide an environment leading to tumor growth. Particularly, the inhibitory effects of heparins on angiogenesis have been actively investigated in both in vivo and in vitro systems (41).

\section{The roles of Vascular Endothelium in Thrombosis and Cancer}

In the cancer and thrombosis setting, the vascular endothelium appears to have a key role. Indeed, vascular endothelium is not a simple, just inert layer of cells that form the inner surface of the blood vessels, endowed with just mechanical, protective functions. On the contrary, endothelial cells take an active part in several physiological and pathological functions, including the hemostatic system, where it can play both procoagulant and anticoagulant roles, and tumor progression, particularly in the angiogenesis and metastatic processes. Angiogenesis, the formation of new vessels, has a major role in tumor growth, dissemination and metastasis in both solid and hematological tumors [25]. Angiogenesis is driven by microvascular EC, which upon activation by angiogenic growth factors degrade their basement membrane, migrate into the interstitial matrix, proliferate, and form new capillary-like structures [14]. The angiogenic switch in cancer is a highly complex event that involves several tumor-derived factors. Inhibition of 
angiogenesis is one of the proposed strategies to control cancer.

The aggressive potential of a tumor is also largely dependent on its capacity to spread and metastasize at distant sites. Hematogenous metastasis is a multi-step process in which tumor cells enter the blood circulation, evade recognition and elimination by immune system, adhere to the vascular endothelium of distant organs, extravasate and finally colonize a tissue in a site distant from the initial tumor. The adhesion of tumor cells to the endothelium and its matrix, particularly in the microvascular bed, is a crucial step in the metastatic process (42). Some findings demonstrate that hematogenous cancer metastases originate from intravascular growth of endothelium-attached rather than extravasated cancer cells (43), suggesting a key role of tumor-endothelial cell contact in cancer metastasis.

Therefore, drugs able to target both the prothrombotic and proangiogenic features of endothelial cells in the setting of malignancy, could indeed help to slow down/inhibit cancer progression. 


\section{Outline of the thesis}

Chapter 1 is the General Introduction to the work described in this thesis.

It provides the background to the mutual relationship between the tumor biology and the hemostatic system activation (thrombosis), and how heparins may play a role in breaking this vicious cycle.

\section{Part One}

Chapters $2 \& 3$ are two up-to-date reviews that summarize the most important biological and clinical aspects connected to the hemostasis and cancer relationships.

In particular, Chapter 2 provides an extensive overview of the hemostatic complications in cancer, together with the main insights into the interaction between hemostasis and cancer biology. It also reviews the assessment of the risk of thrombohemorrhagic events in cancer patients, and the prophylaxis and treatment of such manifestations. Chapter 3 extends this discussion and gives an update on the biological mechanisms that underlie the cancer-associated coagulopathy, in particular the role of tumor cells in promoting activation of the coagulation system.

\section{Part two}

Chapter 4 is a study that evaluates the in vitro antithrombotic effects of a LMWH, i.e. dalteparin, and UFH on both 
microvascular (human microvascular endothelial cells [HMEC-1]) and macrovascular (human umbilical vein endothelial cells [HUVEC]) endothelial cells, stimulated by bacterial endotoxin.

\section{Part three}

Chapter 5 presents the results of a study that shows that heparins are able to counteract the endothelial prothrombotic features elicited by tumor cell derived products, as well as by standard cytokines.

Chapter 6 shows that endothelial cell proliferation and capillary-like tube formation, i.e. two main steps of the angiogenesis process, induced by the exposure to tumor cell cytokines are both inhibited by heparins.

Chapter 7 reports how also "second generation" LMWH and Ultra-Low-MWH are able to inhibit the angiogenic response of microvascular endothelial cells stimulated by tumor cell conditioned media in vitro.

Chapter 8 reviews data from clinical studies showing that LMWH may have a beneficial effect on the outcomes and survival of cancer patients. It also reports our data showing that heparins not only are able to counteract endothelial angiogenesis elicited by tumor cells (in this case of pancreatic tumor origin), but that are able to inhibit the proliferation/migration of tumor cells themselves. 
Chapter 9 presents data on the effect of heparins on another step of tumor progression, in particular, that these drugs are able to impair the adhesion of leukemic cells to the vascular wall.

Chapter 10 is the general discussion and summary of the thesis findings. 


\section{References}

1. Eurostat. Causes of Death Statistics. 2016 [cited 20164 October 2016]; Available from: http://ec.europa.eu/eurostat/statistics-

explained/index.php?title=Causes_of_death_statistics\&oldid $=292956$

2. Yach D, Hawkes C, Gould CL, Hofman KJ. The global burden of chronic diseases: overcoming impediments to prevention and control. Jama. 2004 Jun 2;291(21):2616-22.

3. Trousseau A. Phlegmasia alba dolens. Clinique Medicale de l'Hotel-Dieu: J.B. Bailliere, Paris., 1865:654-712. 4. Billroth $T$. Lectures on surgical pathology and therapeutics: a handbook for students and practitioners.: The New Sydenham Society, London, 1878:1877-8.

5. Falanga $A$, Marchetti $M$, Vignoli $A$. Coagulation and cancer: biological and clinical aspects. J Thromb Haemost. 2013 Feb;11(2):223-33.

6. Falanga A, Russo L. Epidemiology, risk and outcomes of venous thromboembolism in cancer. Hamostaseologie. 2012;32(2):115-25.

7. Falanga A, Marchetti M, Vignoli A, Balducci D. Clotting mechanisms and cancer: implications in thrombus formation and tumor progression. Clin Adv Hematol Oncol. 2003 Nov;1(11):673-8. 
8. Rickles FR, Falanga A. Activation of clotting factors in cancer. Cancer Treat Res. 2009;148:31-41.

9. Falanga A, Panova-Noeva M, Russo L. Procoagulant mechanisms in tumour cells. Best Pract Res Clin Haematol. 2009 Mar;22(1):49-60.

10. Falanga $A$, Tartari $C J$, Marchetti M. Microparticles in tumor progression. Thrombosis Research. 2012;129 (Suppl. 1):S132-S6.

11. Hirsh J, Warkentin TE, Shaughnessy SG, Anand SS, Halperin JL, Raschke R, et al. Heparin and low-molecularweight heparin: mechanisms of action, pharmacokinetics, dosing, monitoring, efficacy, and safety. Chest. 2001 Jan;119(1 Suppl):64S-94S.

12. Fareed J, Hoppensteadt D, Schultz C, Ma Q, Kujawski MF, Neville B, et al. Biochemical and pharmacologic heterogeneity in low molecular weight heparins. Impact on the therapeutic profile. Curr Pharm Des. 2004;10(9):983-99.

13. Samama MM, Gerotziafas GT. Comparative pharmacokinetics of LMWHs. Semin Thromb Hemost. 2000;26 Suppl 1:31-8.

14. Frydman A. Low-molecular-weight heparins: an overview of their pharmacodynamics, pharmacokinetics and metabolism in humans. Haemostasis. 1996;26 Suppl 2:2438. 
15. Bara L, Samama M. Pharmacokinetics of low molecular weight heparins. Acta Chir Scand Suppl. 1988;543:65-72.

16. Mismetti P, Laporte S, Darmon JY, Buchmuller A, Decousus $\mathrm{H}$. Meta-analysis of low molecular weight heparin in the prevention of venous thromboembolism in general surgery. Br J Surg. 2001 Jul;88(7):913-30.

17. Dentali F, Douketis JD, Gianni M, Lim W, Crowther MA. Meta-analysis: anticoagulant prophylaxis to prevent symptomatic venous thromboembolism in hospitalized medical patients. Annals of internal medicine. $2007 \mathrm{Feb}$ 20;146(4):278-88.

18. Efficacy and safety of enoxaparin versus unfractionated heparin for prevention of deep vein thrombosis in elective cancer surgery: a double-blind randomized multicentre trial with venographic assessment. ENOXACAN Study Group. The British journal of surgery. 1997 Aug;84(8):1099-103.

19. Bergqvist D, Agnelli G, Cohen AT, Eldor A, Nilsson PE, Le Moigne-Amrani A, et al. Duration of prophylaxis against venous thromboembolism with enoxaparin after surgery for cancer. N Engl J Med. 2002 Mar 28;346(13):97580.

20. Khorana AA, Streiff $M B$, Farge $D$, Mandala $M$, Debourdeau $P$, Cajfinger $F$, et al. Venous thromboembolism prophylaxis and treatment in cancer: a consensus statement 
of major guidelines panels and call to action. J Clin Oncol. 2009 Oct 10;27(29):4919-26.

21. Lyman GH, Khorana AA, Falanga A, Clarke-Pearson $D$, Flowers $C$, Jahanzeb $M$, et al. American Society of Clinical Oncology guideline: recommendations for venous thromboembolism prophylaxis and treatment in patients with cancer. J Clin Oncol. 2007 Dec 1;25(34):5490-505.

22. Kearon C, Kahn SR, Agnelli G, Goldhaber S, Raskob GE, Comerota AJ. Antithrombotic therapy for venous thromboembolic disease: American College of Chest Physicians Evidence-Based Clinical Practice Guidelines (8th Edition). Chest. 2008 Jun;133(6 Suppl):454S-545S.

23. Raskob GE, van Es N, Verhamme P, Carrier M, Di Nisio M, Garcia D, et al. Edoxaban for the Treatment of Cancer-Associated Venous Thromboembolism. N Engl J Med. 2018 Feb 15;378(7):615-24.

24. Kakkar A, Hedges $\mathrm{R}$, Williamson $\mathrm{R}$, Kakkar $\mathrm{V}$. Perioperative heparin-therapy inhibits late death from metastatic cancer. Int J Oncol. 1995 Apr;6(4):885-8.

25. Lebeau B, Chastang C, Brechot JM, Capron F, Dautzenberg B, Delaisements $C$, et al. Subcutaneous heparin treatment increases survival in small cell lung cancer. "Petites Cellules" Group. Cancer. 1994 Jul 1;74(1):38-45.

26. Smorenburg SM, Hettiarachchi RJ, Vink R, Buller HR.

The effects of unfractionated heparin on survival in patients 
with malignancy--a systematic review. Thromb Haemost. 1999 Dec;82(6):1600-4.

27. Hettiarachchi RJ, Smorenburg SM, Ginsberg J, Levine M, Prins MH, Buller HR. Do heparins do more than just treat thrombosis? The influence of heparins on cancer spread. Thromb Haemost. 1999 Aug;82(2):947-52.

28. Lee AY, Rickles FR, Julian JA, Gent M, Baker RI, Bowden C, et al. Randomized comparison of low molecular weight heparin and coumarin derivatives on the survival of patients with cancer and venous thromboembolism. J Clin Oncol. 2005 Apr 1;23(10):2123-9.

29. Falanga $A$. The effect of anticoagulant drugs on cancer. J Thromb Haemost. 2004 Aug;2(8):1263-5.

30. Kakkar AK, Levine MN, Kadziola Z, Lemoine NR, Low $\mathrm{V}$, Patel HK, et al. Low molecular weight heparin, therapy with dalteparin, and survival in advanced cancer: the fragmin advanced malignancy outcome study (FAMOUS). J Clin Oncol. 2004 May 15;22(10):1944-8.

31. Altinbas M, Coskun HS, Er O, Ozkan M, Eser B, Unal $A$, et al. A randomized clinical trial of combination chemotherapy with and without low-molecular-weight heparin in small cell lung cancer. J Thromb Haemost. 2004 Aug;2(8):1266-71.

32. Klerk CP, Smorenburg SM, Otten HM, Lensing AW, Prins $\mathrm{MH}$, Piovella $\mathrm{F}$, et al. The effect of low molecular 
weight heparin on survival in patients with advanced malignancy. J Clin Oncol. 2005 Apr 1;23(10):2130-5.

33. Kuderer NM, Khorana AA, Lyman GH, Francis CW. A meta-analysis and systematic review of the efficacy and safety of anticoagulants as cancer treatment: impact on survival and bleeding complications. Cancer. 2007;110(5):1149-61.

34. Lazo-Langner A, Goss GD, Spaans JN, Rodger MA. The effect of low-molecular-weight heparin on cancer survival. A systematic review and meta-analysis of randomized trials. J Thromb Haemost. 2007 Apr;5(4):729-37. 35. Icli $F$, Akbulut $H$, Utkan $G$, Yalcin $B$, Dincol $D$, Isikdogan $A$, et al. Low molecular weight heparin (LMWH) increases the efficacy of cisplatinum plus gemcitabine combination in advanced pancreatic cancer. J Surg Oncol. 2007 May 1;95(6):507-12.

36. van Doormaal FF, Di Nisio M, Otten HM, Richel DJ, Prins M, Buller HR. Randomized trial of the effect of the low molecular weight heparin nadroparin on survival in patients with cancer. J Clin Oncol. 2011 May 20;29(15):2071-6.

37. Riess H, Pelzer U, Hilbig A, Stieler J, Opitz B, Scholten $\mathrm{T}$, et al. Rationale and design of PROSPECTCONKO 004: a prospective, randomized trial of simultaneous pancreatic cancer treatment with enoxaparin and chemotherapy). BMC Cancer. 2008;8:361. 
38. Maraveyas A, Waters J, Roy R, Propper D, Fyfe D, Lofts $F$, et al. Gemcitabine with or without prophylactic weight-adjusted dalteparin in patients with advanced or metastatic pancreatic cancer (APC): a multicentre, randomised phase IIB trial (the UK FRAGEM study) European Journal of Cancer Supplements. 2009;7(2):362.

39. Griffiths GO, Burns S, Noble SI, Macbeth FR, Cohen D, Maughan TS. FRAGMATIC: a randomised phase III clinical trial investigating the effect of fragmin added to standard therapy in patients with lung cancer. BMC Cancer. 2009;9:355.

40. Falanga A, Vignoli A, Diani E, Marchetti $M$. Comparative assessment of low-molecular-weight heparins in cancer from the perspective of patient outcomes and survival. Patient Relat Outcome Meas. 2011 Jul;2:175-88.

41. Norrby K. Low-molecular-weight heparins and angiogenesis. Apmis. 2006 Feb;114(2):79-102.

42. Orr FW, Wang HH. Tumor cell interactions with the microvasculature: a rate-limiting step in metastasis. Surg Oncol Clin N Am. 2001;10:357-81.

43. Al-Mehdi AB, Tozawa K, Fisher AB, Shientag L, Lee $A$, Muschel RJ. Intravascular origin of metastasis from the proliferation of endothelium-attached tumor cells: a new model for metastasis. Nature Med. 2000;6:100-2. 


\section{PART ONE}

\section{Overview on Hemostasis and Cancer}




\title{
Chapter 2
}

\author{
Coagulation and \\ Cancer: Biological and \\ Clinical Aspects.
}

Falanga A, Marchetti $M$, Vignoli A.Coagulation and cancer: biological and clinical aspects. Journal Thrombosis Haemostasis 2013;11(2):223-33. 


\title{
Coagulation and cancer: biological and clinical aspects
}

\author{
A. FALANGA, M. MARCHETTI and A. VIGNOLI \\ Division of Immunohematology and Transfusion Medicine, Ospedali Riuniti, Bergamo, Italy
}

To cite this article: Falanga A, Marchetti M, Vignoli A. Coagulation and cancer: biological and clinical aspects. J Thromb Haemost 2013; 11: $223-33$

\begin{abstract}
Summary. Malignancy affects the hemostatic system and the hemostatic system affects malignancy. In cancer patients there are a number of coagulation abnormalities which provide the background for an increased tendency of these patients to both thrombosis and hemorrhage. The causes of this coagulation impairment rely on general risk factors which are common to other categories of patients, and other factors which are specific to cancer, such as tumor type and disease stage. In addition, data from basic research indicate that the hemostatic components and the cancer biology are interconnected in multiple ways. Notably, while cancer cells are able to activate the coagulation system, the hemostatic factors play a role in tumor progression. This opens the way to the development of bifunctional therapeutic approaches that are both capable of attacking the malignant process and resolving the coagulation impairment. On the other hand, the management of thrombosis and hemorrhages in cancer patients can be different. To approach these problems, some guidelines have been released by prominent international scientific societies. Also actively investigated is the issue of identifying new biomarkers to classify the subjects at a higher risk, thus improving the prevention of thrombohemorrhagic events in these patients. Finally, novel prophylactic and therapeutic approaches are currently under development. This review provides an overview of the hemostatic complications in cancer, together with new insights into the interaction between hemostasis and cancer biology. We also review the assessment of the risk of thrombohemorrhagic events in cancer patients, and the prophylaxis and treatment of such manifestations.
\end{abstract}

Keywords: cancer, thrombosis, hemorrhage, prophylaxis, lowmolecular-weight heparins, tissue factor

\section{Introduction}

Malignancy is characterized by a derangement of the hemostatic system which predisposes cancer patients to both

Correspondence: Anna Falanga, Division of Immunohematology and Transfusion Medicine and "Hemostasis and Thrombosis" Center, Ospedali Riuniti, Largo Barozzi 1, 24128 Bergamo, Italy.

Tel.: + 39035 266540; fax: + 39035266659 .

E-mail: annafalanga@yahoo.com thrombosis and hemorrhage. Although traditionally described more in patients with solid tumors, thrombotic events are now also recognized as important complications in hematological malignancies, with a thrombotic rate similar to that observed in solid tumors at a high risk of thrombosis. Hemorrhages and uncompensated disseminated intravascular coagulation (DIC) further complicate the spectrum of hemostatic complications in malignancy and can be fatal, as observed in acute leukemia [1].

The close relationship between cancer and thrombosis has been known since 1865, when Armand Trousseau first described a clinical association between thrombosis and a yet undiagnosed cancer. Cancer favors the activation of blood coagulation with the appearance of a hypercoagulable state or chronic DIC in these patients. Abnormalities in one or more coagulation tests are common in cancer patients, even without overt thrombotic and/or hemorrhagic manifestations. The results of laboratory tests demonstrate that a process of fibrin formation and fibrinolysis parallels the development of malignancy, increasingly in those with metastases [2]. Particularly, subtle hemostatic alterations are detected, such as high levels of plasma by-products of clotting reactions (i.e. prothrombin fragment $1+2[\mathrm{~F} 1+2]$, fibrinopeptide A [FPA], thrombinantithrombin complex [TAT] and D-dimer), or an acquired protein $\mathrm{C}$ resistance, as well as high levels of circulating microparticles (MP) shed by tumor cells and platelets [3]. On the other hand, hemostatic proteins and reactions interdigitate the process of tumor growth and dissemination [4].

The pathogenesis of blood coagulation activation in cancer is complex and multifactorial. However, a unique feature in malignancy is the role played by the expression of tumor cell-associated clot promoting properties. These properties lead to the activation of the clotting cascade, with the generation of thrombin and fibrin, and the stimulation of platelets, leukocytes and endothelial cells which expose their cellular procoagulant features. Several of these mechanisms can contribute to tumor development and progression [4], particularly MP-enriched prothrombotic and proangiogenic factors are new important players in supporting tumor growth [5]. In the last decade, our knowledge grew after the discovery of a complex scenario in which oncogenic events drive the procoagulant conversion of tumor cells [6]. 
Although cancer patients can experience both venous and arterial thrombosis, the thrombotic venous occlusions have been studied more extensively. The risk of developing venous thromboembolism (VTE) in this population is increased up to seven-fold compared with the general population [7]. This rate has grown in recent years as a consequence of improved oncology outcomes, the use of more thrombogenic therapy regimens and an aging population. Finally, thrombosis can be the first sign of a malignant disease, preceding the clinical detection of cancer by months or even years [8]. Many factors can increase the thrombotic risk in cancer patients, including general risk factors, such as immobility, old age and surgery, and risk factors specific of cancer, such as the cancer type, advanced disease stage and anti-cancer therapies. To help clinicians in the prevention and management of thrombotic and hemorrhagic events in cancer patients, a number of guidelines have been released from international scientific societies $[9,10]$.

In this review, we provide an overview of the hemostatic complications in cancer and new insights into the interactions between the hemostatic factors and cancer biology. Finally, the assessment of the patient risk factors for thrombohemorrhagic manifestations, and the prevention and treatment of such manifestations will also be summarized.

\section{The spectrum of hemostatic complications in cancer}

Although Trousseau's original report was about venous thrombosis in patients with gastric cancer, now the term 'Trousseau's syndrome' is used to indicate any type of thromboembolic manifestation occurring in cancer. These include arterial and venous thrombosis, non-bacterial thrombotic endocarditis (NBTE), thrombotic microangiopathy (TMA) and veno-occlusive disease (VOD).

In the venous bed, deep venous thrombosis (DVT) of the lower limbs is the most common manifestation, followed by upper-limb DVT, pulmonary embolism (PE), cerebral sinus thrombosis and migratory superficial thrombophlebitis. Large retrospective and prospective population studies show an overall VTE incidence ranging from $0.6 \%$ up to $7.8 \%$ [11]. This wide range is because of the presence of many and different factors that contribute to the global VTE risk, the most important being cancer type [11]. An unusual high prevalence of splanchnic (i.e. Budd-Chiari syndrome and portal vein thrombosis) and cerebral vein thrombosis is reported among patients with myeloproliferative neoplasms (MPN), and these events are often the presenting feature of the disease, before diagnosis [12].

Data regarding arterial thromboembolic events (ATE) are more limited $[13,14]$. In cancer patients, a variety of arterial thrombotic syndromes have been reported and the sites most commonly involved are the peripheral blood circulation of the upper and lower extremities and cerebral vessels [15]. The mesenteric vessels, kidney and liver represent other unusual sites of ATE. Nevertheless, ATE incidence in cancer may be estimated around $2-5 \%$, accounting for $10-30 \%$ of total thrombotic complications. In a recent retrospective analysis in ambulatory cancer patients receiving chemotherapy, the incidence of symptomatic ATE was $0.27 \%$ [14].

In patients with MPN, major thromboses occur in $10-40 \%$ of patients, of these up to $70 \%$ are as a result of ATE events, including ischemic stroke, acute myocardial infarction and peripheral arterial occlusion [16]. In addition to ATE and VTE, MPN patients may present with perturbances of the microcirculation, leading to erythromelalgia, TIA, visual or hearing transitory defects, recurrent headache and peripheral paresthesia [16]. NBTE is particularly common in MPN but can also be observed in solid tumors. NBTE, detected in $0.9-1.3 \%$ of patients dying of cancer, is the cardiac manifestation of systemic hemostatic activation resulting in the formation of platelet and fibrin vegetations on cardiac valves [13]. These vegetations can cause ATE after dislodgement, leading to strokes, splenic infarctions and acute limb ischemia

Other thrombotic manifestations observed in cancer are TMA and VOD. TMA represents a heterogeneous group of diseases characterized by microangiopathic hemolytic anemia, peripheral thrombocytopenia and organ failure of variable severity. TMA in cancer is a rare but severe complication with a short-term life-threatening prognosis, and can manifest as thrombotic thrombocytopenic purpura (TTP) and hemolytic uremic syndrome (HUS). TMA has been described in association with the use of specific chemotherapeutic agents, particularly mitomycin, gemcitabine and, recently, also with some targeted cancer agents, for example immunotoxins, monoclonal antibodies and tyrosine kinase inhibitors [17] Cancer-associated TMA displays typical features at presentation, which should alert clinicians of the possibility of an underlying malignancy in a patient with a newly diagnosed TMA. [18].

VOD is a serious liver disease characterized by obstruction of small intrahepatic central venules by microthrombi and fibrin deposition [19], and is observed in approximately 50 $60 \%$ of allogeneic hematopoietic stem cell transplanted patients. In its severe form, whose incidence varies from $0 \%$ to $77 \%$ of all VOD cases, this complication is associated with a mortality rate close to $85 \%$, as a consequence of multiorgan failure [20]. Risk factors for VOD include hepatic damage, high-dose chemotherapy drugs, abdominal irradiation, female gender and donor-recipient HLA disparity. The deoxyribonucleic acid derivative defibrotide has proven successful for the prevention and treatment of VOD: the underlying mechanisms of action include a protective role of this drug on the microvascular endothelium, as suggested by in vitro studies [21].

Thrombosis can also represent the earliest clinical manifestation of an occult cancer [22]. Indeed, patients with idiopathic VTE show a four- to seven-fold increased risk of being diagnosed with cancer in the first year after thrombosis, as compared with patients with VTE secondary to known causes, and the risk of cancer is even higher in patients with recurrent thromboembolism and in those with bilateral VTE. Whether extensive screening for occult malignancy in patients with 
idiopathic VTE is recommendable or not is still being debated [23]. Indeed, only two previous studies have compared limited vs. extensive screening, with no conclusive results [24,25].

Finally, on the other side of the spectrum are the hemorrhagic manifestations. Indeed, in cancer patients, abnormal bleeding represents an important cause of mortality, observed in about $10 \%$ of patients with solid tumors and in a higher proportion in patients with hematologic malignancies [26]. Bleeding manifestations include melena, hematuria, hematemesis, hematochezia, hemoptysis, epistaxis, vaginal bleeding or ulcerated skin lesions. Ecchymoses, petechiae or bruising are also described. Hemorrhage may occur as an acute catastrophic event, episodic major bleeds, or an ongoing low-degree emission. Potential causes include thrombocytopenia, decreased synthesis of coagulation factors owing to liver dysfunction or vitamin $\mathrm{K}$ deficiency, oral anticoagulation, pre-existing mild coagulation factor deficiencies, congenital von Willebrand disease (VWD), vessel wall erosion, DIC and, rarely, acquired inhibitors against blood clotting factors. In MPN, high platelet counts (i.e. above $1000 \times 10^{9}$ per L) are associated with acquired VWD [27], this results from the adsorption of von Willebrand factor (vWF) multimers onto platelets. A similar mechanism is observed in lymphoproliferative diseases, where vWF multimers bind onto malignant cells [27].

DIC is a syndrome characterized by systemic intravascular activation of coagulation, leading to widespread occurrence of (micro)vascular thrombosis contributing to organ failure. In addition, laboratory assessments show activation of fibrinolysis and non-specific proteolysis systems. The ongoing consumption of clotting factors and platelets, together with hyperfibrinolysis and other proteolytic effects result in bleeding from various sites. Important in this context is the measurement of D-dimer, the lysis product of cross-linked fibrin, which shows hyperfibrinolysis in response to clotting activation and fibrin formation. Severe DIC is particularly associated with acute leukemias, causing severe hemorrhages. Intracerebral and pulmonary hemorrhages are relatively common life-threatening complications in acute promyelocytic leukemia (APL), and are the most frequent cause of early death during induction therapy, although can also occur before APL diagnosis and the start of therapy. APL patients with concomitant risk factors have a higher risk of developing a fatal hemorrhage [10]. In contrast to leukemias, scarce data exist on the impact of DIC in patients with solid tumors. One study that evaluated DIC occurrence in 1117 patients with solid tumors reported a 7\% incidence [28]; however, this single study is not sufficient to draw any definitive conclusion.

Finally, acquired hemophilia is a rare but potentially fatal bleeding complication caused by the development of autoantibodies directed against plasma coagulation factors, most frequently FVIII (i.e. acquired hemophilia A). As acquired hemophilia can result in significant morbidity and mortality, the differential diagnosis when evaluating the cancer patient with unexplained bleeding should always be considered [26].

\section{Pathogenesis of coagulation alterations}

The pathogenesis of the coagulation system imbalance in cancer is complex and involves multiple factors, both clinical and biological.

\section{Clinical factors}

Clinical factors can be grouped in three main categories (Table 1): (i) patient-related characteristics, (ii) cancer-related features and (iii) anti-cancer therapies. The first category comprises many risk factors that are not exclusive of but frequent amongst cancer patients, and include advanced age, prolonged immobility, a prior history of thrombosis, high leukocyte and platelet counts, obesity, immobility, and also comorbid conditions such as heart disease, acute infection and respiratory disease [29-32].

Considering the second category, large epidemiological studies have recognized malignant brain tumors, hematological malignancies and adenocarcinoma of the pancreas, stomach, ovary, uterus, lung and kidney as having the highest VTE risk [33]. Among hematological malignancies, multiple myeloma, non-Hodgkin's lymphoma and Hodgkin's disease showed the highest VTE incidence [34]. Moreover, advanced, metastatic cancer has been shown to be associated with an increased risk of VTE compared with localized tumors [33]. Last, active anticancer treatments, including chemotherapy, hormonal therapy, antiangiogenic agents, combination regimens and surgery have a pro-thrombotic effect [35]. The direct injury of endothelial cells by chemotherapeutic agents, or by tumorderived products, leading to a loss of antithrombotic properties is thought to play a role in the increased VTE risk.

An important finding is also the elevation in the expression of procoagulant tissue factor (TF) and/or phosphatydilserine (PS) exposure and the release of MPs after treatment caused by different chemotherapeutic agents [36]. The appearance of several novel anti-cancer agents carrying a thrombogenic effect brings this issue to the forefront of cancer medicine.

\section{Biological mechanisms}

Beyond clinical factors, biological pathways probably play an important role in the pathogenesis of hemostatic alterations in cancer. Cancer cells can activate the hemostatic system through the expression of procoagulant proteins, exposure of procoagulant lipids, release of inflammatory cytokines and MPs, and adhesion to host vascular cells [37] (Fig. 1). The most characterized tumor procoagulant is TF.

Constitutively expressed on the malignant cell surface, TF can lead to the formation of both localized, as well as systemic procoagulant states. TF activity on tumor cells can be potentiated by the expression of anionic phospholipids (i.e. PS) on the outer leaflet of the cell membrane [38,39] and the secretion of heparanase. The main function of heparanase is to degrade heparan sulfates of the extracellular matrix, thereby promoting tumor invasion and metastasis. However, heparanase 
Table 1 Thrombotic risk factors in cancer patients

\begin{tabular}{lll}
\hline Patient related & Cancer related & Treatment related \\
\hline Older age & Site of cancer: brain, pancreas, kidney, stomach, lung, & Hospitalization \\
Bed rest & bladder, gynecologic, hematologic malignancies & Surgery \\
Obesity & Stage of cancer: advanced stage and initial period after diagnosis & Chemo- and hormonal therapy \\
Previous thrombosis & & Anti-angiogenic therapy \\
Prothrombotic mutations & & Erythropoiesis stimulating agents \\
High leukocyte and platelet counts & & Blood transfusions \\
Comorbidities & & CVC \\
& & Radiations
\end{tabular}

CVC, central venous catheters.

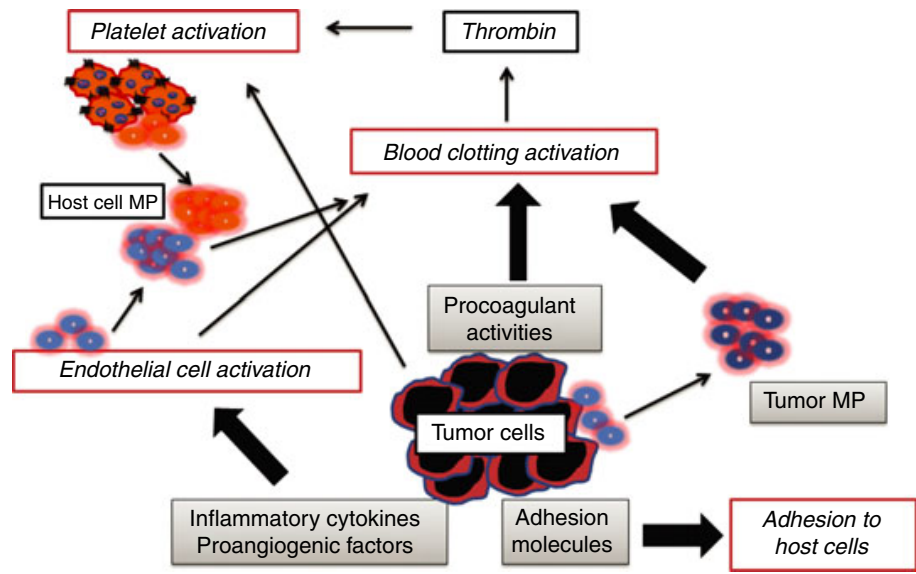

Fig. 1. Tumor-hemostatic system interactions. Tumor cells activate the hemostatic system in multiple ways. Tumor cells may release procoagulant tissue factor, cancer procoagulant and microparticles (MP) that can directly activate the coagulation cascade. Tumor cells may also activate the host's hemostatic cells (endothelial cells and platelets), by either release of soluble factors or by direct adhesive contact, thus further enhancing clotting activation.

can also interact with the TF pathway inhibitor (TFPI) on the cell surface, leading to dissociation of TFPI from the cell membrane of endothelial and tumor cells which results in an increased cell surface TF activity [40].

Another tumor procoagulant is cancer procoagulant (CP) that, unlike TF, directly activates FX independently of FVII. $\mathrm{CP}$ has been detected in various tumor cells, and in amnionchorion tissues but not in normally differentiated cells. In patients with APL, CP, expressed by bone marrow blast cells at the onset of disease, disappears when remission is reached [37]. $\mathrm{CP}$ has also been studied also in patients with different types of solid tumors $[41,42]$.

$\mathrm{TF}$ can be actively released by tumor cells in a cell membrane-associated form represented by TF-bearing MPs [43]. MPs are plasma membrane vesicles of $0.1-1 \mu \mathrm{m}$ in diameter produced by active vesiculation of virtually all type of cells [5]. PS expressed on MP surfaces provides a suitable anionic phospholipid surface for the assembly of tenase and prothrombinase complexes, thereby promoting the coagulation cascade. This capacity can be further enhanced by the concomitant expression of TF (Fig. 2). Low plasma MP levels are present in healthy subjects, the majority being of a platelet origin $(>80 \%)$, but in pathological conditions an overall increment in MP occurs and a significant amount of MP of other vascular sources, including tumor cells, can be detected. Elevated levels of MPs (bearing or not TF) have been described in patients with both solid [5] and hematological malignancies [44 46]. MPs of a platelet origin were found higher in stage IV vs. I and II/III gastric cancer, showing the highest diagnostic accuracy for metastasis prediction [47]. Finally, the pathogenetic role of MPs in cancer-associated thrombosis has been demonstrated by the development of a DIC-like syndrome in mice after intravenous injection of highly TF-positive MPs of a tumor origin [5].

Tumor cells are also capable of interacting with the host fibrinolytic system, owing to the expression of plasminogen activators (uPA and t-PA), their inhibitors (PAI-1 and PAI-2) and receptors such as uPAR [37], and of annexin II, a coreceptor for plasminogen and tissue plasminogen activator (tPA). In APL, the increased annexin II expression has been linked to an excessive activation of fibrinolysis [48]. Likely, depending on which side, pro- or anti-fibrinolytic, prevails, the 


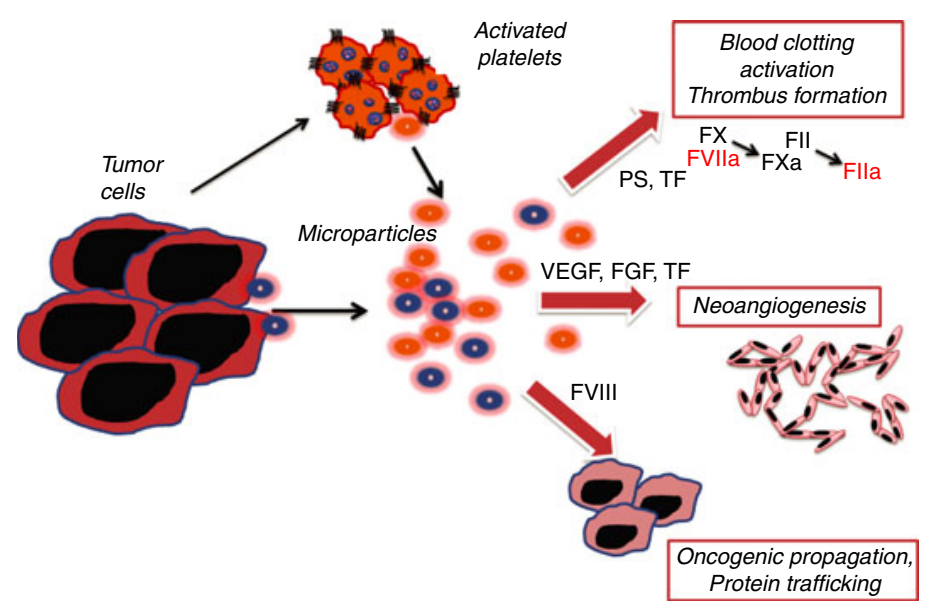

Fig. 2. Microparticle (MP) production and activities in cancer. Tumor cells actively release MP but also promote MP formation by platelets. Tissue factor (TF) and phosphatidylserine (PS) expression on the surfaces of both platelet- and tumor-derived MP are involved in blood clotting activation and thrombus formation. On the other hand, the elevated content of proangiogenic factors in platelet-derived MP (VEGF, vascular endothelial growth factor, FGF, fibroblast growth factor, PDGF, platelet-derived growth factor), render these elements also important mediators of the neangiogenesis process. Finally, intracellular transfer of MP may occur between cancer cells, leading to a horizontal propagation of oncogenes and amplification of their angiogenic phenotype.

clinical manifestations of fibrinolysis system alterations may be quite different, from bleeding symptoms as observed in leukemia, to VTE evidenced in solid tumors.

Furthermore, tumor cells release a variety of soluble proinflammatory (i.e. tumor necrosis factor-alpha $[\mathrm{TNF}-\alpha]$ and interleukin-1beta [IL-1 $\beta]$ ) and proangiogenic (i.e. vascular endothelial growth factor [VEGF] and basic fibroblast growth factor [bFGF]) factors [37], which can stimulate the prothrombotic features of vascular cells. In endothelial cells, these molecules induce TF expression, stimulate PAI-1 production, downregulate thrombomodulin and promote cell-adhesion molecules upregulation [37]. The capacity of tumor cells to adhere to vascular endothelium favors localized blood clotting activation and thrombus formation.

In the last decade, molecular studies of experimental models of human cancer have demonstrated that oncogene and repressor gene-mediated neoplastic transformation activate clotting as an integral feature of neoplastic transformation [49]. Genome-wide expression profiling of mouse hepatocytes expressing the MET oncogene have demonstrated a significant upregulation of PAI-1 and cyclooxygenase-2 (COX-2). The inactivation of the tumor suppressor gene PTEN was linked to TF gene induction in human astrocytoma cells. In non-small cell lung cancer specimens, TF mRNA expression was found to be increased in samples presenting either tumor protein p 53 (TP53) and PTEN mutations; the concomitant presence of mutations in three tumor suppressor genes further dramatically increased TF expression [50]. Finally, in a colorectal cancer model, activation of K-ras and inactivation of $\mathrm{p} 53$ resulted in increased tumor cell TF expression and enhanced release of TF-bearing MPs [49].

\section{Role of hemostatic proteins in tumor progression}

Coagulation activation and tumor progression are closely linked. Tumor growth and aggressiveness largely rely on cancer cell capacity to promote neoangiogenesis and metastasis [37]. In these processes, a contribution of different components of the hemostatic system, including thrombin, TF and FVIIa, FXa, fibrinogen and vascular cells, has been clearly documented by both in vitro and in vivo tumor models. Mechanisms described include both clotting-dependent activities of these molecules, culminating in platelet activation and fibrin deposition, as well as clotting-independent properties.

\section{Clotting-dependent mechanisms}

Fibrin deposited within the tumor vasculature facilitates angiogenesis by providing an excellent scaffold for new vessel formation. Furthermore, this fibrin matrix binds and sequesters a number of growth factors (bFGF, VEGF and insulin-like growth factor-1) and protects them from proteolytic degradation [37]. Localized fibrin deposition favors the metastatic process by stabilizing tumor cell adhesion or tumor cellassociated emboli to the endothelium.

However, the fibrin matrix present in tumors is in a dynamic state, undergoing simultaneous deposition and dissolution by the fibrinolytic system to be replaced by mature connective tissue stroma. This highlights a crucial role of fibrinolysis in tumor biology and the relevance of fibrinolytic protein expression by neoplastic cells in promoting cell mobility and motility. Although fibrinogen deficiency does not impair growth and angiogenesis of the primary tumor in animal 
models, it significantly reduces lung metastases, probably owing to diminished adhesion and stability of metastatic cells [51].

Independently from thrombin, platelets can be directly activated by tumor cells through the release of pro-aggregating substances or adhesion mechanisms. For example, the binding of podoplanin, expressed on tumor cells' surfaces, to CLEC-2, expressed by platelets, induces platelet activation and aggregation [52]. The formation of tumor cell-platelet thrombi may support metastasis formation by preventing interactions between tumor and innate immune cells [53].

\section{Clotting-independent mechanisms}

Thrombin and $T F$ participate to tumor progression through clotting-independent mechanisms, as a result of interactions with specific receptors belonging to the family of proteaseactivated receptors (PAR) expressed by platelets, tumor cells, endothelial cells, vascular smooth muscle cells and macrophages [37]. Thrombin cleaved-PAR-1 stimulates growth factors, chemokines, and extracellular proteins release that promote tumor cell proliferation and migration [54]. In endothelial cells, thrombin upregulates many angiogenesisrelated genes, including VEGF, VEGFR, bFGF and metalloproteinase (MMP)-2. Both thrombin and FXa can induce the angiogenesis-promoting gene Cyr61 and connective tissue growth factor (CTGF) expression [55]. Finally, thrombinactivated platelets become highly proangiogenic by releasing proangiogenic factors from their granule contents, including VEGF [56] and platelet-derived growth factor (PDGF) [57]. The pro-metastatic activity of thrombin has been demonstrated by experimental models, in which lung metastasis was increased by pre-treatment of tumor cells with thrombin [37].

Binding of FVII to TF generates downstream signaling cascades that promote increased endothelial cell adhesion and migration. Furthermore, TF in complex with FVIIa and FXa activates one or more PARs, including endothelial PAR-2 to support angiogenesis in vivo [58]. Recent studies have focused on a possible role of the alternatively spliced TF (asTF), a soluble isoform of circulating TF, in cancer progression [59]. The suggestive hypothesis coming from research is that both asTF and flTF contribute to tumor progression, but through different ways: the first acting directly on the proliferative tumor side, and the second on the angiogenic side with the contribution of FVIIa and PAR-2.

Platelet MPs display high proangiogenic activity owing to their unique content of angiogenesis-stimulating agents derived from platelet alpha-granules, together with the expression of adhesion molecules, and the capacity to induce pro-angiogenic factor release by tumor cells [5]. TF expression by MPs might represent another important mechanism involving MPs in tumor progression [5]. Moreover, intracellular transfer of MPs may occur between cancer cells, leading to a horizontal propagation of oncogenes and their associated transforming phenotype [60] (Fig. 2).
Finally, leucocytes have been involved in tumor growth and metastasis [37]. Neutrophils, activated in the tumor microenviroment by locally generated inflammatory mediators (i.e. TNF- $\alpha$ ), can adhere to tumor cells and facilitate their migration across the endothelial barrier. By releasing metalloproteinases, they can hydrolyze endothelial cell matrix components and favor cancer cell motility [61].

\section{Anticoagulation and tumor progression}

The above evidence taken together suggests that reducing coagulation activation in cancer patients may not only prevent hemostatic complications but also improve cancer survival [62]. Indeed, clinical trials with anticoagulant drugs were started in the early 1980 s to test the effects of anticoagulation on cancer survival. A recent meta-analysis [63] overall suggested a favorable impact of anticoagulation on the survival of cancer patients, particularly with low-molecular-weight heparins (LMWH). In recent years, prospective randomized controlled trials (RCTs) have been designed to address as a primary endpoint the survival of cancer patients receiving LMWH, but the results available so far have not provided clear conclusions yet $[64,65]$. Ongoing studies on VTE prevention in cancer patients incorporate as a secondary end-point the impact of LMWH on cancer survival [66-68]. These results will be available in the next few years.

Several previous in vitro and in vivo studies have demonstrated that the potential beneficial effects of heparins on survival may rely on some direct anticancer properties. These include: inhibition of tumor-induced angiogenesis, tumor cell heparanase, cell surface selectin-mediated tumor cell metastasis and blood coagulation activation [62]

The impact of natural anticoagulant proteins, such as activated protein $\mathrm{C}$ and thrombomodulin, on tumor biology is under active investigation as well $[69,70]$.

\section{Prevention and treatment of thrombosis and bleeding}

\section{Thromboprophylaxis}

With regard to arterial thrombosis, cancer patients share the same general risk factors with non-cancer patients (i.e. arterial hypertension, diabetes, dislipidemia and obesity); additional risk factors are co-morbidities including pulmonary disease, renal disease, infection, blood transfusion and chemotherapy. Older age ( $>60$ years) and previous thrombosis are wellestablished cardiovascular risk factors for thrombosis in MPN which identify the so-called high-risk patients. There is great deal of attention in moving beyond these recognized risk factors, particularly in the young or asymptomatic low- and intermediate-risk individuals at risk of thrombosis. Recently, the impact of new risk factors, such as leukocytosis and JAK2V617F mutational status and/or mutational burden, is under active investigation [71]. Today, no guidelines or recommendations are available for ATE prophylaxis in the cancer setting. An exception is represented by MPN, in which 
aspirin, in association or not with hydroxyurea, anagrelide and/ or phlebotomy, has proven useful to significantly reduce the risk of cardiovascular events [72].

More certainty is available for VTE primary prophylaxis. Thromboprophylaxis with either unfractionated heparin or LMWH has been shown to be safe and effective in high-risk settings such as hospitalization for medical illness and the postsurgical period. Current European and American guidelines found a good level of consensus on VTE prevention with LMWH in the surgical oncology setting [73-77], particularly in cancer patients undergoing 'high-risk' major abdominal or pelvic surgery $[78,79]$. However, the duration of post-surgical prophylaxis is still being debated.

The international consensus is lower in the medical setting, in which two high-risk situations can be identified: the first involves patients hospitalized or bedridden for prolonged periods of time, and the second relates to ambulatory patients receiving chemotherapy or radiation. Cancer patients hospitalized for an acute medical illness are at risk for thrombosis. They should be considered for thromboprophylaxis with prophylactic doses of LMWH or fondaparinux, but the duration of thromboprophylaxis is yet undefined. Moreover, to date, no evidences exist that the highest risk patients should receive adjusted drug doses for prophylaxis.

Most VTE occur in the outpatients setting; however, the guideline panels agree on not recommending routine thromboprophylaxis in ambulatory cancer patients. Nevertheless, in recent years, RCTs have been conducted to evaluate the impact of thromboprophylaxis in ambulatory patients with solid tumors receiving systemic chemotherapy [80-82]. Overall, these studies suggest that outpatient thromboprophylaxis is feasible, safe and effective. Notably, the VTE low rates observed in these studies suggest the importance of patient selection and disagree on a wide application of prophylaxis. In line with this, the most recent guidelines of the National Comprehensive Cancer Network emphasize the need for VTE risk assessment in ambulatory cancer patients and the need of RCTs for patients with a favorable risk-benefit ratio [83]. Other areas of uncertainty include prophylaxis in patients who receive chemo-, radio- or hormone therapy and have a history of VTE, patients with cerebral cancer, patients undergoing surgery other than abdominal or pelvic procedures, or patients undergoing laparoscopy procedures lasting more than $30 \mathrm{~min}$ [79].

Unlike solid tumor experience, no ad hoc studies or guidelines are available to help clinicians with best practices for prophylaxis of VTE in hematologic malignancies [84]. In patients with acute leukemia and lymphoma, some information on thromboprophylaxis comes from two studies [85,86], while more data are available in multiple myeloma [87]. Given the higher VTE risk during treatment of multiple myeloma patients with thalidomide or lenalidomide in combination with dexamethasone or multi-agent chemotherapy, thromboprophylaxis is recommended. However, which is the best prophylactic scheme in this setting is an issue of debate. The results of prospective randomized trials of GIMEMA studies, comparing the efficacy of LMWH, warfarin (fixed low-dose or full dose) and aspirin for prophylactic anticoagulation, showed only a trend for a more effective thromboprophylaxis with LMWH $[88,89]$. The guidelines of the American Society of Clinical Oncology (ASCO), the European Society of Medical Oncology (ESMO) and the Italian Society for Haemostasis and Thrombosis (SISET) recommend prophylaxis with LMWH or adjusted-dose warfarin (International Normalized Ratio 2-3) [79,90,91]. The International Myeloma Working Group proposes different thromboprophylactic strategies based on stratification of the patient's risk of VTE [92].

Current research is focusing on the design of VTE risk models to identify high-risk patients who might benefit from primary thromboprophylaxis. The score-model proposed by Khorana et al. is based on five simple predictive clinical and laboratory parameters in cancer patients: cancer site, platelet count, hemoglobin level or the use of erythropoiesis-stimulating agents, leukocyte count and body mass index. This model has been shown to predict the short-term risk of symptomatic VTE accurately in patients undergoing chemotherapy [93]. Recently, the inclusion of P-selectin and D-Dimer quantification to this model improved the risk stratification strategy [94]. Emerging biomarkers are represented by plasma TF and MPs [95].

\section{Treatment of thrombosis}

The treatment of ATE in cancer patients relies on anti-platelet and anticoagulant/fibrinolytic agents according to the same protocols recommended for secondary prophylaxis for stroke and myocardial infarction in the non-cancer population. However, specific protocols have been developed for acute VTE treatment, which has replaced the traditional regimens based on initial therapy with UFH, LMWH or fondaparinux followed by long-term therapy with a vitamin $\mathrm{K}$ antagonist (VKA). Data from various RCTs, comparing LMWH with VKA in the long-term VTE therapy in cancer [96-99], show the superiority of LMWH monotherapy, which is now endorsed by international guidelines $[90,100]$. For patients who develop a recurrence while on $\mathrm{LMWH}$, dose escalation of $\mathrm{LMWH}$ is often effective, whereas for patients who develop a recurrence on VKA therapy, the recommended practice is to switch to LMWH. Raising the intensity of VKA therapy is not recommended because of the potential for increasing bleeding $[101,102]$. There are limited data on the use, safety and longterm outcome of vena cava filters. Today, the use of these devices can be considered as an alternative to prevent PE (as filters are not effective in reducing DVT risk) only in patients who have a contraindication to anticoagulation [103].

Novel oral anticoagulants (i.e. dabigatran, rivaroxaban and apixaban) may change the therapeutic scenario in patients with cancer. These agents, which achieve rapid inhibition of activated factor $\mathrm{X}$ or thrombin, may offer an easier solution than LMWH but studies focusing on treatment of cancer-associated thrombosis with these agents are lacking. To date, some of these agents have shown 
comparable efficacy and safety compared with traditional anticoagulants in RCTs that included primarily patients without cancer [104,105]. Given the higher risk of recurrent thrombosis and bleeding in cancer patients, further research is needed to understand the antithrombotic impact of these new agents in this setting [106].

\section{Prophylaxis and treatment of bleeding}

On the bleeding side, the most important issue is represented by the prophylaxis and treatment of the fatal hemorrhagic syndrome in APL. However, the management of this syndrome is particularly difficult. Recent recommendations indicate that three simultaneous actions must be immediately undertaken when a diagnosis of APL is suspected: the start of ATRA therapy, the administration of supportive care with transfusions of plasma and platelets, and the confirmation of molecular diagnosis [107,108]. According to current recommendations, a prophylactic platelet transfusion is an essential part of supportive care, with the aim to maintain a platelet count above $20 \times 10^{9}$ per $\mathrm{L}$ in non-bleeding patients and above $50 \times 10^{9}$ per $\mathrm{L}$ in those with active bleeding $[71,84]$. The role of heparin in the treatment of the coagulopathy is undefined. No systematic studies have been reported on the use of LMWH or any of the newer anticoagulants (i.e. FXa and IIa inhibitors, hirudin, fondaparinux) to treat the thrombohemorrhagic syndrome of APL. Other types of therapeutic regimens, including antifibrinolytic agents or protease inhibitors (i.e. aprotinin), have been suggested, but no data from RCTs are available. Interestingly, the occurrence of thromboembolic events was reported during antifibrinolytic agent administration in combination with ATRA. A lack of efficacy of tranexamic acid on the hemorrhageassociated mortality in APL was shown in the large PETHEMA trial [109].

\section{Conclusions}

Cancer disease is associated with a high risk of both thrombotic and hemorrhagic complications. Preventing these complications is clinically relevant because they significantly contribute to the morbidity and mortality of these patients. The efforts of the research have significantly elucidated the clinical and the biological mechanisms underlying the hemostatic derangement caused by cancer. Interestingly, direct oncogene activation and or tumor suppressor gene impairment, may result in the stimulation of blood clotting and/or suppression of fibrinolysis, which can produce thrombosis and/or DIC in some in vivo models.

Some of the factors involved in the multiple interconnections existing between the hemostatic system and cancer biology may prove useful for establishing risk assessment models, not only for thrombosis but also for cancer prognosis. The hope is that our accrued knowledge in the field will help us to establish more accurate and appropriate interventions for the management of hemostatic complications. Meanwhile, we can rely on the guidelines issued by the relevant international scientific societies.

\section{Acknowledgements}

The authors wish to thank Associazione Italiana per la Ricerca sul Cancro (A.I.R.C., grants IG10558 and '5 per mille' 12237) and Regione Lombardia (grant 'Piano Regionale Sangue 20102012') for their support.

\section{Disclosure of Conflict of Interest}

The authors state that they have no conflicts of interest

\section{References}

1 Falanga A, Marchetti M. Venous thromboembolism in the hematologic malignancies. J Clin Oncol 2009; 27: 4848-57.

2 Falanga A, Marchetti M, Vignoli A, Balducci D. Clotting mechanisms and cancer: implications in thrombus formation and tumor progression. Clin Adv Hematol Oncol 2003; 1: 673-8.

3 Falanga A, Russo L. Epidemiology, risk and outcomes of venous thromboembolism in cancer. Hamostaseologie 2012; 32: 115-25.

4 Rickles FR, Falanga A. Activation of clotting factors in cancer. Cancer Treat Res 2009; 148: 31-41.

5 Falanga A, Tartari CJ, Marchetti M. Microparticles in tumor progression. Thromb Res 2012; 129(Suppl. 1): S132-6.

6 Garnier D, Magnus N, D’Asti E, Hashemi M, Meehan B, Milsom C, Rak J. Genetic pathways linking hemostasis and cancer. Thromb Res 2012; 129(Suppl. 1): S22-9.

7 Lee AY, Levine MN. Venous thromboembolism and cancer: risks and outcomes. Circulation 2003; 107: I17-21.

8 Prandoni P, Falanga A, Piccioli A. Cancer and venous thromboembolism. Lancet Oncol. 2005; 6: 401-10.

9 Khorana AA, Streiff MB, Farge D, Mandala M, Debourdeau P, Cajfinger F, Marty M, Falanga A, Lyman GH. Venous thromboembolism prophylaxis and treatment in cancer: a consensus statement of major guidelines panels and call to action. J Clin Oncol 2009; 27: 4919-26.

10 Sanz MA, Grimwade D, Tallman MS, Lowenberg B, Fenaux P, Estey EH, Naoe T, Lengfelder E, Buchner T, Dohner H, Burnett AK, Lo-Coco F. Management of acute promyelocytic leukemia: recommendations from an expert panel on behalf of the European LeukemiaNet. Blood 2009; 113: 1875-91.

11 Khorana AA, Connolly GC. Assessing risk of venous thromboembolism in the patient with cancer. J Clin Oncol 2009; 27: 4839-47.

12 Reikvam H, Tiu RV. Venous thromboembolism in patients with essential thrombocythemia and polycythemia vera. Leukemia 2012; 26: $563-71$.

13 Sanon S, Lenihan DJ, Mouhayar E. Peripheral arterial ischemic events in cancer patients. Vasc Med 2011; 16: 119-30.

14 Di Nisio M, Ferrante N, Feragalli B, De Tursi M, Iacobelli S, Cuccurullo F, Porreca E. Arterial thrombosis in ambulatory cancer patients treated with chemotherapy. Thromb Res 2011; 127: 382-3.

15 Arboix A. [Cerebrovascular disease in the cancer patient]. Rev Neurol 2000; 31: 1250-2.

16 Landolfi R, Di Gennaro L, Falanga A. Thrombosis in myeloproliferative disorders: pathogenetic facts and speculation. Leukemia 2008; 22: 2020-8.

17 Blake-Haskins JA, Lechleider RJ, Kreitman RJ. Thrombotic microangiopathy with targeted cancer agents. Clin Cancer Res 2011; 17: $5858-66$.

18 Oberic L, Buffet M, Schwarzinger M, Veyradier A, Clabault K, Malot S, Schleinitz N, Valla D, Galicier L, Bengrine-Lefevre L, Gorin 
NC, Coppo P. Cancer awareness in atypical thrombotic microangiopathies. Oncologist 2009; 14: 769-79.

19 Kansu E. Thrombosis in stem cell transplantation. Hematology 2012; 17(Suppl. 1): S159-62.

20 Coppell JA, Richardson PG, Soiffer R, Martin PL, Kernan NA, Chen A, Guinan E, Vogelsang G, Krishnan A, Giralt S, Revta C, Carreau NA, Iacobelli M, Carreras E, Ruutu T, Barbui T, Antin JH, Niederwieser D. Hepatic veno-occlusive disease following stem cell transplantation: incidence, clinical course, and outcome. Biol Blood Marrow Transplant 2010; 16: 157-68.

21 Falanga A, Vignoli A, Marchetti M, Barbui T. Defibrotide reduces procoagulant activity and increases fibrinolytic properties of endothelial cells. Leukemia 2003; 17: 1636-42.

22 Aderka D, Brown A, Zelikovski A, Pinkhas J. Idiopathic deep vein thrombosis in an apparently healthy patient as a premonitory sign of occult cancer. Cancer 1986; 57: 1846-9.

23 Rosovsky R, Lee AY. Evidence-based mini-review: should all patients with idiopathic venous thromboembolic events be screened extensively for occult malignancy? Hematology Am Soc Hematol Educ Program 2010; 2010: 150-2.

24 Piccioli A, Lensing AW, Prins MH, Falanga A, Scannapieco GL, Ieran M, Cigolini M, Ambrosio GB, Monreal M, Girolami A, Prandoni P. Extensive screening for occult malignant disease in idiopathic venous thromboembolism: a prospective randomized clinical trial. J Thromb Haemost 2004; 2: 884-9.

25 van Doormaal FF, Terpstra W, van Der Griend R, Prins MH, Nijziel MR, van de Ree MA, Buller HR, Dutilh JC, ten Cate-Hoek A, van den Heiligenberg SM, van der Meer J, Otten JM. Is extensive screening for cancer in idiopathic venous thromboembolism warranted? J Thromb Haemost 2011; 9: 79-84.

26 Reeves BN, Key NS. Acquired hemophilia in malignancy. Thromb Res 2012; 129(Suppl. 1): S66-8.

27 Tiede A, Rand JH, Budde U, Ganser A, Federici AB. How I treat the acquired von Willebrand syndrome. Blood 2011; 117: 6777-85.

28 Sallah S, Wan JY, Nguyen NP, Hanrahan LR, Sigounas G. Disseminated intravascular coagulation in solid tumors: clinical and pathologic study. Thromb Haemost 2001; 86: 828-33.

29 Heit JA, Silverstein MD, Mohr DN, Petterson TM, O'Fallon WM, Melton LJ 3rd. Risk factors for deep vein thrombosis and pulmonary embolism: a population-based case-control study. Arch Intern Med 2000; 160: 809-15.

30 Khorana AA, Francis CW, Culakova E, Fisher RI, Kuderer NM, Lyman GH. Thromboembolism in hospitalized neutropenic cancer patients. J Clin Oncol 2006; 24: 484-90.

31 Prandoni P, Lensing AW, Piccioli A, Bernardi E, Simioni P, Girolami B, Marchiori A, Sabbion P, Prins MH, Noventa F, Girolami A. Recurrent venous thromboembolism and bleeding complications during anticoagulant treatment in patients with cancer and venous thrombosis. Blood 2002; 100: 3484-8.

32 Semrad TJ, O'Donnell R, Wun T, Chew H, Harvey D, Zhou H, White RH. Epidemiology of venous thromboembolism in 9489 patients with malignant glioma. $J$ Neurosurg 2007; 106: 601-8.

33 Wun T, White RH. Epidemiology of cancer-related venous thromboembolism. Best Pract Res Clin Haematol 2009; 22: 9-23.

34 Khorana AA, Francis CW, Culakova E, Kuderer NM, Lyman GH. Frequency, risk factors, and trends for venous thromboembolism among hospitalized cancer patients. Cancer 2007; 110: 2339-46.

35 Falanga A, Marchetti M. Anticancer treatment and thrombosis. Thromb Res 2012; 129: 353-9.

36 Lechner D, Weltermann A. Chemotherapy-induced thrombosis: a role for microparticles and tissue factor? Semin Thromb Hemost 2008; 34: 199-203.

37 Falanga A, Panova-Noeva M, Russo L. Procoagulant mechanisms in tumour cells. Best Pract Res Clin Haematol 2009; 22: 49-60.

38 Pickering W, Gray E, Goodall AH, Ran S, Thorpe PE, Barrowcliffe TW. Characterization of the cell-surface procoagulant activity of Tlymphoblastoid cell lines. $J$ Thromb Haemost 2004; 2: 459-67.
39 Fernandes RS, Kirszberg C, Rumjanek VM, Monteiro RQ. On the molecular mechanisms for the highly procoagulant pattern of $\mathrm{C} 6$ glioma cells. J Thromb Haemost 2006; 4: 1546-52.

40 Nadir Y, Brenner B, Gingis-Velitski S, Levy-Adam F, Ilan N, Zcharia E, Nadir E, Vlodavsky I. Heparanase induces tissue factor pathway inhibitor expression and extracellular accumulation in endothelial and tumor cells. Thromb Haemost 2008; 99: 133-41.

41 Kozwich DL, Kramer LC, Mielicki WP, Fotopoulos SS, Gordon SG. Application of cancer procoagulant as an early detection tumor marker. Cancer 1994; 74: 1367-76.

42 Molnar S, Guglielmone H, Lavarda M, Rizzi ML, Jarchum G. Procoagulant factors in patients with cancer. Hematology 2007; 12: 555-9.

43 Horstman LL, Jy W, Jimenez JJ, Bidot C, Ahn YS. New horizons in the analysis of circulating cell-derived microparticles. Keio $\mathrm{J}$ Med 2004; 53: 210-30

44 van Aalderen MC, Trappenburg MC, van Schilfgaarde M, Molenaar PJ, ten Cate H, Terpstra WE, Leyte A. Procoagulant myeloblastderived microparticles in AML patients: changes in numbers and thrombin generation potential during chemotherapy. $J$ Thromb Haemost 2011; 9: 223-6.

45 Auwerda JJ, Yuana Y, Osanto S, de Maat MP, Sonneveld P, Bertina RM, Leebeek FW. Microparticle-associated tissue factor activity and venous thrombosis in multiple myeloma. Thromb Haemost 2011; 105: 14-20.

46 Trappenburg MC, van Schilfgaarde M, Marchetti M, Spronk HM, ten Cate H, Leyte A, Terpstra WE, Falanga A. Elevated procoagulant microparticles expressing endothelial and platelet markers in essential thrombocythemia. Haematologica 2009; 94: 9118.

47 Kim HK, Song KS, Park YS, Kang YH, Lee YJ, Lee KR, Ryu KW, Bae JM, Kim S. Elevated levels of circulating platelet microparticles, VEGF, IL-6 and RANTES in patients with gastric cancer: possible role of a metastasis predictor. Eur J Cancer 2003; 39: 184-91.

48 Liu Y, Wang Z, Jiang M, Dai L, Zhang W, Wu D, Ruan C. The expression of annexin II and its role in the fibrinolytic activity in acute promyelocytic leukemia. Leuk Res 2011; 35: 879-84.

49 Garnier D, Magnus N, D’Asti E, Hashemi M, Meehan B, Milsom C, Rak J. Genetic pathways linking hemostasis and cancer. Thromb Res 2012; 129(Suppl. 1): S22-9.

50 Regina S, Valentin JB, Lachot S, Lemarie E, Rollin J, Gruel Y. Increased tissue factor expression is associated with reduced survival in non-small cell lung cancer and with mutations of TP53 and PTEN. Clin Chem 2009; 55: 1834 - 42.

51 Palumbo JS, Potter JM, Kaplan LS, Talmage K, Jackson DG, Degen JL. Spontaneous hematogenous and lymphatic metastasis, but not primary tumor growth or angiogenesis, is diminished in fibrinogendeficient mice. Cancer Res 2002; 62: 6966-72.

52 Lowe KL, Navarro-Nunez L, Watson SP. Platelet CLEC-2 and podoplanin in cancer metastasis. Thromb Res 2012; 129(Suppl. 1): S30-7.

53 Palumbo JS, Talmage KE, Massari JV, La Jeunesse CM, Flick MJ, Kombrinck KW, Jirouskova M, Degen JL. Platelets and fibrin(ogen) increase metastatic potential by impeding natural killer cell-mediated elimination of tumor cells. Blood 2005; 105: 178-85.

54 Rickles FR, Patierno S, Fernandez PM. Tissue factor, thrombin, and cancer. Chest 2003; 124: 58S-68S.

55 Ruf W. Tissue factor and PAR signaling in tumor progression. Thromb Res 2007; 120: S7-12.

56 Mohle R, Green D, Moore MA, Nachman RL, Rafii S. Constitutive production and thrombin-induced release of vascular endothelial growth factor by human megakaryocytes and platelets. Proc Natl Acad Sci USA 1997; 94: 663-8.

57 Liu Y, Kalen A, Risto O, Wahlstrom O. Time- and $\mathrm{pH}$-dependent release of PDGF and TGF-beta from platelets in vitro. Platelets 2003; 14: $233-7$. 
58 Uusitalo-Jarvinen H, Kurokawa T, Mueller BM, Andrade-Gordon $\mathrm{P}$, Friedlander M, Ruf W. Role of protease activated receptor 1 and 2 signaling in hypoxia-induced angiogenesis. Arterioscler Thromb Vasc Biol 2007; 27: 1456-62.

59 Kocaturk B, Versteeg HH. Tissue factor isoforms in cancer and coagulation: may the best isoform win. Thromb Res 2012; 129(Suppl. 1): $\mathrm{S} 69-75$.

60 Rak J. Microparticles in cancer. Semin Thromb Hemost 2010; 36: 888-906.

61 Klink M, Jastrzembska K, Nowak M, Bednarska K, Szpakowski M, Szyllo K, Sulowska Z. Ovarian cancer cells modulate human blood neutrophils response to activation in vitro. Scand J Immunol 2008; 68 328-36.

62 Falanga A, Vignoli A, Diani E, Marchetti M. Comparative assessment of low-molecular-weight heparins in cancer from the perspective of patient outcomes and survival. Patient Relat Outcome Meas 2011; 2: $175-88$.

63 Kuderer NM, Ortel TL, Francis CW. Impact of venous thromboembolism and anticoagulation on cancer and cancer survival. J Clin Oncol 2009; 27: 4902-11.

64 Noble S. Low-molecular-weight heparin and survival in lung cancer. Thromb Res 2012; 129(Suppl. 1): S114-8.

65 van Doormaal FF, Di Nisio M, Otten HM, Richel DJ, Prins M, Buller HR. Randomized trial of the effect of the low molecular weight heparin nadroparin on survival in patients with cancer. $J$ Clin Oncol 2011; 29: 2071-6.

66 Riess H, Pelzer U, Hilbig A, Stieler J, Opitz B, Scholten T, KauschatBruning D, Bramlage P, Dorken B, Oettle H. Rationale and design of PROSPECT-CONKO 004: a prospective, randomized trial of simultaneous pancreatic cancer treatment with enoxaparin and chemotherapy). BMC Cancer 2008; 8: 361.

67 Maraveyas A, Waters J, Roy R, Propper D, Fyfe D, Lofts F, Gardiner E, Sgouros J, Wedgwood K. Gemcitabine with or without prophylactic weight-adjusted dalteparin in patients with advanced or metatastatic pancreatic cancer (APC): a multicentre, randomised phase IIB trial (the UK FRAGEM study). Eur J Cancer Suppl 2009 7: 362.

68 Griffiths GO, Burns S, Noble SI, Macbeth FR, Cohen D, Maughan TS. FRAGMATIC: a randomised phase III clinical trial investigating the effect of fragmin added to standard therapy in patients with lung cancer. BMC Cancer 2009; 9: 355.

69 Spek CA, Arruda VR. The protein C pathway in cancer metastasis. Thromb Res 2012; 129(Suppl. 1): S80-4.

70 Horowitz NA. Mechanisms coupling thrombomodulin to tumor dissemination. Thromb Res 2012; 129(Suppl. 1): S119-21.

71 Falanga A, Marchetti M. Venous thromboembolism in hematologic malignancies. In: Khorana AA, Francis CW, eds. Cancer-Associated Thrombosis: New Findings in Translational Science, Prevention and Treatment. New York, NY: Informa Healthcare, 2008: $131-49$.

72 Landolfi R, Marchioli R, Kutti J, Gisslinger H, Tognoni G, Patrono C, Barbui T. Efficacy and safety of low-dose aspirin in polycythemia vera. $N$ Engl J Med 2004; 350: 114-24.

73 Streiff MB. The National Comprehensive Cancer Center Network $(\mathrm{NCCN})$ guidelines on the management of venous thromboembolism in cancer patients. Thromb Res 2010; 125(Suppl. 2) S128-33.

74 Mandala M, Falanga A, Piccioli A, Prandoni P, Pogliani EM, Labianca R, Barni S. Venous thromboembolism and cancer: guidelines of the Italian Association of Medical Oncology (AIOM). Crit Rev Oncol Hematol 2006; 59: 194-204.

75 Farge D, Bosquet L, Kassab-Chahmi D, Mismetti P, Elalamy I, Meyer G, Cajfinger F, Desmurs-Clavel H, Elias A, Grange C, Hocini H, Legal G, Mahe I, Quere I, Levesque H, Debourdeau P. 2008 French national guidelines for the treatment of venous thromboembolism in patients with cancer: report from the working group. Crit Rev Oncol Hematol 2010; 73: 31-46.
76 Mandala M, Falanga A, Roila F. Management of venous thromboembolism (VTE) in cancer patients: ESMO Clinical Practice Guidelines. Ann Oncol 2011; 22(Suppl. 6): vi85-92.

77 Lyman GH, Kuderer NM. Prevention and treatment of venous thromboembolism among patients with cancer: the American Society of Clinical Oncology Guidelines. Thromb Res 2010; 125(Suppl. 2) S120-7.

78 Bergqvist D, Agnelli G, Cohen AT, Eldor A, Nilsson PE, Le MoigneAmrani A, Dietrich-Neto F. Duration of prophylaxis against venous thromboembolism with enoxaparin after surgery for cancer. $N$ Engl J Med 2002; 346: 975-80.

79 Siragusa S, Armani U, Carpenedo M, Falanga A, Fulfaro F, Imberti D, Laurora R, Molinari AC, Prisco D, Silingardi M, Verso M, Visona A. Prevention of venous thromboembolism in patients with cancer: Guidelines of the Italian Society for Haemostasis and Thrombosis (SISET)(1). Thromb Res 2012; 129: e171-6.

80 Maraveyas A, Waters J, Roy R, Fyfe D, Propper D, Lofts F, Sgouros J, Gardiner E, Wedgwood K, Ettelaie C, Bozas G. Gemcitabine versus gemcitabine plus dalteparin thromboprophylaxis in pancreatic cancer. Eur J Cancer 2012; 48: 1283-92.

81 Agnelli G, Gussoni G, Bianchini C, Verso M, Mandala M, Cavanna L, Barni S, Labianca R, Buzzi F, Scambia G, Passalacqua R, Ricci S, Gasparini G, Lorusso V, Bonizzoni E, Tonato M. Nadroparin for the prevention of thromboembolic events in ambulatory patients with metastatic or locally advanced solid cancer receiving chemotherapy: a randomised, placebo-controlled, double-blind study. Lancet Oncol 2009; 10: 943-9.

82 Agnelli G, George DJ, Kakkar AK, Fisher W, Lassen MR, Mismetti P, Mouret P, Chaudhari U, Lawson F, Turpie AG. Semuloparin for thromboprophylaxis in patients receiving chemotherapy for cancer. N Engl J Med 2012; 366: 601-9.

83 Streiff MB, Bockenstedt PL, Cataland SR, Chesney C, Eby C, Fanikos J, Fogarty PF, Gao S, Garcia-Aguilar J, Goldhaber SZ, Hassoun H, Hendrie P, Holmstrom B, Jones KA, Kuderer N, Lee JT Millenson MM, Neff AT, Ortel TL, Smith JL, et al. Venous thromboembolic disease. J Natl Compr Canc Netw 2011; 9: 714-77.

84 Falanga A, Rickles FR. Management of Thrombohemorrhagic Syndromes (THS) in hematologic malignancies. Hematology Am Soc Hematol Educ Program 2007; 165-71.

85 Couban S, Goodyear M, Burnell M, Dolan S, Wasi P, Barnes D, Macleod D, Burton E, Andreou P, Anderson DR. Randomized placebo-controlled study of low-dose warfarin for the prevention of central venous catheter-associated thrombosis in patients with cancer. J Clin Oncol 2005; 23: 4063-9.

86 Cortelezzi A, Moia M, Falanga A, Pogliani EM, Agnelli G, Bonizzoni E, Gussoni G, Barbui T, Mannucci PM. Incidence of thrombotic complications in patients with haematological malignancies with central venous catheters: a prospective multicentre study. $\mathrm{Br} J$ Haematol 2005; 129: 811-7.

87 Carrier M, Le Gal G, Tay J, Wu C, Lee AY. Rates of venous thromboembolism in multiple myeloma patients undergoing immunomodulatory therapy with thalidomide or lenalidomide: a systematic review and meta-analysis. J Thromb Haemost 2011; 9: 653-63.

88 Palumbo A, Cavo M, Bringhen S, Zamagni E, Romano A, Patriarca F, Rossi D, Gentilini F, Crippa C, Galli M, Nozzoli C, Ria R, Marasca R, Montefusco V, Baldini L, Elice F, Callea V, Pulini S, Carella AM, Zambello R, et al. Aspirin, warfarin, or enoxaparin thromboprophylaxis in patients with multiple myeloma treated with thalidomide: a phase III, open-label, randomized trial. J Clin Oncol 2011; 29: 986-93.

89 Larocca A, Cavallo F, Bringhen S, Di Raimondo F, Falanga A, Evangelista A, Cavalli M, Stanevsky A, Corradini P, Pezzatti S, Patriarca F, Cavo M, Peccatori J, Catalano L, Carella AM, Cafro AM, Siniscalchi A, Crippa C, Petrucci MT, Yehuda DB, et al. Aspirin or enoxaparin thromboprophylaxis for patients with newly diagnosed multiple myeloma treated with lenalidomide. Blood 2012; 119: 933-9; quiz 1093 
90 Lyman GH, Khorana AA, Falanga A, Clarke-Pearson D, Flowers C, Jahanzeb M, Kakkar A, Kuderer NM, Levine MN, Liebman H, Mendelson D, Raskob G, Somerfield MR, Thodiyil P, Trent D, Francis CW. American Society of Clinical Oncology guideline: recommendations for venous thromboembolism prophylaxis and treatment in patients with cancer. J Clin Oncol 2007; 25: 5490-505.

91 Mandala M, Falanga A, Roila F. Venous thromboembolism in cancer patients: ESMO Clinical Practice Guidelines for the management. Ann Oncol 2010; 21(Suppl. 5): v274-6.

92 Palumbo A, Rajkumar SV, Dimopoulos MA, Richardson PG, San Miguel J, Barlogie B, Harousseau J, Zonder JA, Cavo M, Zangari M, Attal M, Belch A, Knop S, Joshua D, Sezer O, Ludwig H, Vesole D, Blade J, Kyle R, Westin J, et al. Prevention of thalidomide- and lenalidomide-associated thrombosis in myeloma. Leukemia 2008; 22: 414-23.

93 Khorana AA, Kuderer NM, Culakova E, Lyman GH, Francis CW. Development and validation of a predictive model for chemotherapyassociated thrombosis. Blood 2008; 111: 4902-7.

94 Ay C, Dunkler D, Marosi C, Chiriac AL, Vormittag R, Simanek R, Quehenberger P, Zielinski C, Pabinger I. Prediction of venous thromboembolism in cancer patients. Blood 2010; 116: 5377-82.

95 Zwicker JI, Liebman HA, Neuberg D, Lacroix R, Bauer KA, Furie $\mathrm{BC}$, Furie B. Tumor-derived tissue factor-bearing microparticles are associated with venous thromboembolic events in malignancy. Clin Cancer Res 2009; 15: 6830-40.

96 Meyer G, Marjanovic Z, Valcke J, Lorcerie B, Gruel Y, Solal-Celigny P, Le Maignan C, Extra JM, Cottu P, Farge D. Comparison of lowmolecular-weight heparin and warfarin for the secondary prevention of venous thromboembolism in patients with cancer: a randomized controlled study. Arch Intern Med 2002; 162: 1729-35.

97 Lee AY, Levine MN, Baker RI, Bowden C, Kakkar AK, Prins M, Rickles FR, Julian JA, Haley S, Kovacs MJ, Gent M. Low-molecular-weight heparin versus a coumarin for the prevention of recurrent venous thromboembolism in patients with cancer. $N$ Engl $\mathrm{J} \mathrm{Med}$ 2003; 349: 146-53.

98 Deitcher SR, Kessler CM, Merli G, Rigas JR, Lyons RM, Fareed J. Secondary prevention of venous thromboembolic events in patients with active cancer: enoxaparin alone versus initial enoxaparin followed by warfarin for a 180-day period. Clin Appl Thromb Hemost 2006; 12: 389-96.
99 Hull RD, Pineo GF, Brant RF, Mah AF, Burke N, Dear R, Wong T, Cook R, Solymoss S, Poon MC, Raskob G. Long-term low-molecular-weight heparin versus usual care in proximal-vein thrombosis patients with cancer. Am J Med 2006; 119: 1062-72.

100 Kearon C, Kahn SR, Agnelli G, Goldhaber S, Raskob GE, Comerota AJ. Antithrombotic therapy for venous thromboembolic disease: American College of Chest Physicians Evidence-Based Clinical Practice Guidelines (8th Edition). Chest 2008; 133: 454S$545 \mathrm{~S}$.

101 Hutten BA, Prins MH, Gent M, Ginsberg J, Tijssen JG, Buller HR. Incidence of recurrent thromboembolic and bleeding complications among patients with venous thromboembolism in relation to both malignancy and achieved international normalized ratio: a retrospective analysis. J Clin Oncol 2000; 18: 3078-83.

102 Carrier M, Le Gal G, Cho R, Tierney S, Rodger M, Lee AY. Dose escalation of low molecular weight heparin to manage recurrent venous thromboembolic events despite systemic anticoagulation in cancer patients. J Thromb Haemost 2009; 7: 760-5.

103 Panova-Noeva M, Falanga A. Treatment of thromboembolism in cancer patients. Expert Opin Pharmacother 2010; 11: 2049-58.

104 Schulman S, Kearon C, Kakkar AK, Mismetti P, Schellong S, Eriksson H, Baanstra D, Schnee J, Goldhaber SZ. Dabigatran versus warfarin in the treatment of acute venous thromboembolism. $N$ Engl J Med 2009; 361: 2342-52.

105 Buller H. EINSTEIN. European Society of Cardiology. Sep 2010 meeting 2010.

106 Verso M, Agnelli G. New and old anticoagulants in cancer. Thromb Res 2012; 129(Suppl. 1): S101-5.

107 Falanga A, Russo L, Tartari CJ. Pathogenesis and treatment of thrombohemorrhagic diathesis in acute promyelocytic leukemia. Mediterr J Hematol Infect Dis 2011; 3: e2011068.

108 Falanga A, Marchetti M, Barbui T. All-trans-retinoic acid and bleeding/thrombosis. Pathophysiol Haemost Thromb 2003; 33(Suppl. 1): 19-21.

109 de la Serna J, Montesinos P, Vellenga E, Rayón C, Parody R, León A, Esteve J, Bergua JM, Milone G, Debén G, Rivas C, González M, Tormo M, Díaz-Mediavilla J, González JD, Negri S, Amutio E, Brunet S, Lowenberg B, Sanz MA. Causes and prognostic factors of remission induction failure in patients with acute promyelocytic leukemia treated with all-trans retinoic acid and idarubicin. Blood 2008; 111: $3395-402$. 


\title{
Chapter 3
}

Mechanisms and risk factors of thrombosis in cancer.

\author{
Falanga $A$, Russo L, \\ Milesi V, Vignoli A. \\ Mechanisms and risk \\ factors of thrombosis in \\ cancer. Critical reviews in \\ Oncology/Hematology. \\ 2017;118:79-83.
}




\title{
Mechanisms and risk factors of thrombosis in cancer
}

\author{
Anna Falanga*, Laura Russo, Viola Milesi, Alfonso Vignoli \\ Department of Immunohematology and Transfusion Medicine \& the Hemostasis and Thrombosis Center, Hospital Papa Giovanni XXIII, Piazza OMS 1, 24127 Bergamo, \\ Italy
}

\section{A R T I C L E I N F O}

\section{Keywords:}

Cancer

Thrombosis

Hypercoagulable state

Thrombotic risk factors

Microparticles

Tissue factor

\begin{abstract}
A B S T R A C T
The close relationship between cancer and thrombosis is known since more than a century. Venous thromboembolism (VTE) may be the first manifestation of an occult malignancy in an otherwise healthy individual. Cancer patients commonly present with abnormalities of laboratory coagulation tests, indicating an ongoing subclinical hypercoagulable condition. The results of laboratory tests demonstrate that a process of fibrin formation and removal parallels the development of malignancy, which is of particular interest since fibrin and other clotting products are important for both thrombogenesis and tumor progression. Besides general clinical risk factors (i.e. age, previous VTE, immobility, etc.), other factors typical of cancer can increase the thrombotic risk in these patients, including the type of cancer, advanced disease stage, and cancer therapies. In addition, biological factors, including tumor cell-specific prothrombotic properties and the host cell inflammatory response to the tumor, play a central role in the pathogenesis of cancer-associated thrombosis. Cancer cells produce and release procoagulant and fibrinolytic proteins, as well as inflammatory cytokines. In addition, they are capable of directly adhering to host cells (i.e. endothelial cells, monocytes, platelets, and neutrophils), thereby stimulating additional prothrombotic properties of the host effector cells. Tumor-shed procoagulant microparticles also contribute to the patient hypercoagulable state. Finally, the changes of stromal cells of the tumor 'niche' induced by tissue factor (TF) highlight new interactions between hemostasis and cancer. Of interest, most of these mechanisms, besides activating the hemostatic system, also promote tumor growth and metastasis, and are regulated by oncogenic events. Indeed, molecular studies demonstrate that oncogenes responsible for the cellular neoplastic transformation drive the programs of hemostatic protein expression and microparticle liberation by cancer tissues. Human and animal experimental models demonstrate that activation of cancer-associated prothrombotic mechanisms parallels the development of overt thrombotic syndromes in vivo.
\end{abstract}

\section{Introduction}

Cancer patients may present many types of hemostatic disorders that significantly contribute to morbidity and mortality in this disease. A tight relationship exists between malignant disease, the occurrence of coagulation abnormalities and thrombosis. The relationship relies on the evidence that cancer induces a prothrombotic switch of the host hemostatic system, and in turn, blood clotting activation stimulates tumor growth and dissemination.

Cancer is associated with a four- to seven-fold increase in the risk of venous thromboembolism (VTE). However, even without thrombosis, the majority of cancer patients present with hemostatic alterations detectable by laboratory tests, which reveal different degrees of coagulation activation and characterize the hypercoagulable state of these subjects (Falanga and Russo, 2012).

Currently, it is fully recognized that cancer patients are at significant risk of developing thrombotic events, spanning from venous or arterial thrombosis to systemic syndromes, such as disseminated intravascular coagulation (DIC) with severe bleeding. Preventing these complications is clinically relevant because they considerably contribute to the morbidity and mortality of these patients (Falanga et al., 2014).

The pathogenesis of the cancer-associated coagulopathy is complex and multifactorial. Most importantly, tumor cells gain the capacity to activate the host hemostatic system, and this phenomenon is driven by the same oncogenes responsible for the cellular neoplastic transformation. By this process, cancer tissues become capable to express different procoagulant proteins (i.e. Tissue Factor [TF], Cancer Procoagulant [CP], Factor VII), which contribute to the occurrence of the overt symptomatic coagulopathy in vivo (Magnus et al., 2014a). The shedding of procoagulant microparticles [MPs] is also regulated by oncogenic events and further adds to the pathogenesis of the cancer-associated hypercoagulable state. Finally, the changes in the stromal cells of the tumor "niche" induced by tumor TF provide new evidence of the

\footnotetext{
* Corresponding author.

E-mail address: annafalanga@yahoo.com (A. Falanga).
} 
influence of the hemostasis system on cancer development.

To the other hand, many clinical factors influence the thrombotic risk of cancer patients, who definitely represent a high-risk category. Clinical factors include general cardiovascular risk factors, cancer specific risk factors, and anti-cancer therapies. Recent data confirm that the risk of developing VTE is increased up to seven-fold in these patients as compared to the general population (Timp et al., 2013). To help clinicians in the prevention and management of thrombotic events in cancer patients, a number of guidelines have been released from national and international scientific societies (Lyman et al., 2015).

This paper wishes to provide the most recent discoveries on the coagulopathy of cancer patients, the mechanisms underlying this phenomenon, and the risk assessment to predict thrombosis in the single patient.

\section{Pathogenesis of cancer-associated thrombosis}

The molecular and laboratory features of cancer-associated thrombosis are difficult to assess clinically; therefore, the weight of each of these factors on the overall thrombotic risk of the single patient is unknown at this time. The principal mechanisms of cancer-associated thrombosis include the expression of hemostatic proteins by tumor cells, the production of microparticles, inflammatory cytokines (i.e., tumor necrosis factor-alpha, interleukin-1b), and proangiogenic factors (vascular endothelial growth factor, basic fibroblast growth factor) by tumor and/or host cells, and the expression of adhesion molecules to bind platelets, endothelial cells, and leucocytes (Fig. 1). The same properties also contribute to tumor progression (Falanga et al., 2013).

\subsection{Cancer cell procoagulant factors}

Tumor cells can express hemostatic factors, including: (1) procoagulant proteins, (2) (MPs); and (3) fibrinolysis proteins.

Among procoagulant proteins, TF is the best characterized. Many solid tumors and hematologic malignancies constitutively express $\mathrm{TF}$, and the levels of TF expression tend to be associated with an aggressive pattern of the tumor. Tumor cell-derived TF plays a central role in the generation of thrombin in cancer but also contributes to tumor progression by directly influencing the expression of vascular endothelial growth factor by both malignant cells and host vascular cells. This property regulates tumor neo-vascularization and provides an important link between activation of coagulation, inflammation, thrombosis, and tumor growth and metastasis (Falanga et al., 2013).

Another tumor cell procoagulant is cancer procoagulant (CP) that, unlike TF, directly activates factor $\mathrm{X}$ independently of coagulation factor VII. CP has been detected in different malignant cells (Falanga et al., 1998), both from solid and hematologic tumors, but not in normal tissues. Of interest, in patients with acute promyelocytic leukemia (APL), CP is expressed by bone marrow blast cells at the onset of disease, but disappears at remission (Falanga et al., 1995). In addition, in APL blasts, CP expression paralleled the degree of malignant transformation and disappeared upon cellular differentiation with therapy with all-trans-retinoic-acid (ATRA). In contrast, cells resistant to ATRA maintained their malignant phenotype and continue to express CP. Similar observations have been reported for breast cancer (Falanga et al., 2002). The relative contribution of this factor to the overall cellular procoagulant activity and/or possible interactions with TF is unknown at this time.

Among other tumor cell procoagulant activities, the role of the enzyme heparanase is gaining much relevance. In particular, heparanase, apart from degrading the extracellular matrix, upregulates the expression of the blood coagulation initiator-TF and interacts with the tissue factor pathway inhibitor (TFPI) on the cell surface membrane of endothelial and tumor cells, leading to dissociation of TFPI and resulting in increased cell surface coagulation activity (Nadir and Brenner, 2016). Additionally, heparanase directly enhances TF activity, which led to increased factor Xa production and subsequent activation of the coagulation system (Nadir and Brenner, 2016).

Another emerging mechanism of tumor-promoted clotting activation resides in the tumor cell shed MPs. These small membrane vesicles carry high concentrations of procoagulant phosphatidylserine and TF (Falanga et al., 2012). The pathogenetic role of MPs in cancer-associated thrombosis is demonstrated by the development of a DIC-like syndrome in mice after intravenous injection of highly TF-positive MPs of tumor origin (Falanga et al., 2012). Elevated levels of circulating MPs have been described in cancer patients, with both solid and hematologic malignancies and play a role in the establishment of the hypercoagulable state (Falanga and Marchetti, 2009; Tilley et al., 2008; Del Conde et al., 2007; Kim et al., 2003). The production of MPs by cancer cells is possibly controlled by definite genetic events occurring in tumor genesis, including activating and inactivating mutations in oncogenes and tumor repressor genes (Garnier et al., 2012). Among hematologic malignancies, high levels of blast cells-derived MPs are described in patients with APL and other acute myeloid leukemias, and in patients with multiple myeloma and essential thrombocythemia.

Studies in animal models show that the intravenous injection into mice of MP derived from human tumor cells and expressing high levels of TF induces a TF-dependent activation of coagulation, which results in a DIC-like syndrome. TF-positive MPs are elevated in patients with solid tumors and VTE, including gastric and pancreatic cancers (Falanga et al., 2015a).

In the last decades, experimental models of human cancers (i.e. hepatoma, brain, and colon cancer) provide evidence in vivo that oncogene and repressor gene-mediated neoplastic transformation (i.e. activation of MET, loss of PTEN, induction of K-ras, and loss of p53) activates clotting as an integral feature of neoplastic transformation. Furthermore, a mutation in EGFR gene renders cancer cells hypersensitive to the action of coagulation proteins, such as TF. As a result, a microenvironment promoting tumor growth is generated (Magnus et al., 2014a). These data confirm that a reciprocal cancer-

\section{Blood clotting activation}

Thrombus formation

个

\section{Procoagulant activities}


Table 1

General risk factors.

\begin{tabular}{ll}
\hline Patient-related & Cancer-related \\
- Age & - Site of cancer (brain, pancreas, \\
• Gender: higher in female & kidney, stomach, lung, bladder, \\
- Race: higher in Africans- & gynecologic, hematologic malignancies) \\
Americans and lower in Asians & - Stage of cancer (advanced stage and \\
• Hospitalization & initial period after diagnosis) \\
- Prolonged immobility & - Surgery \\
• History of VTE & - Chemotherapy and hormonal \\
- Comorbid conditions (i.e. acute & therapy \\
infection, heart disease, respiratory & - Anti-angiogenic therapy \\
disease) & - Erythropoiesis stimulating agents \\
& - Central venous catheters \\
& - Blood transfusions \\
\hline
\end{tabular}

thrombosis connection exists, by which cancer cells support clot formation, and clotting proteins support cancer growth and dissemination. In the development of human cancers, cycles of micro environmental and genetic changes are increasingly manifest (Magnus et al., 2014b).

Finally, in this context, it is important to consider that tumor cells can also generate anticoagulant forces by interacting with the host fibrinolytic system. Indeed, they express fibrinolytic proteins such as the plasminogen activators (urokinase plasminogen activator and tissue plasminogen activator [tPA]), their inhibitors (plasminogen activator inhibitor-1 [PAI-1] and plasminogen activator inhibitor-2) [PAI-2], and receptors (i.e. urokinase-type plasminogen activator receptor, and annexin II, a co-receptor for plasminogen and tPA). In APL, the increased annexin II expression has been linked to an excessive activation of fibrinolysis (Liu et al., 2011). Likely, depending on which side, pro- or antifibrinolytic, prevails, the clinical manifestations may be quite different, from bleeding symptoms, as observed in leukemia, to VTE, as evidenced in solid tumors.

\subsection{Normal cell procoagulant properties elicited by cancer cells}

A strong interaction occurs between cancer cells and the host normal vascular cells, particularly endothelial cells, platelets, and leukocytes, which generally results in the induction of a procoagulant phenotype by normal cells and highlights the role of host tissue TF in the coagulopathy of cancer. The principal mechanisms by which cancer cells activate the procoagulant potential of host normal vascular cells include: (1) the release of soluble mediators, including inflammatory cytokines (i.e. TNF- $\alpha$, IL-1 $\beta$ ), proangiogenic and growth stimulating factors (i.e. VEGF, bFGF, G-CSF). and platelet aggregation agonists, including adenosine diphosphate and thrombin; and (2) the capacity to express surface adhesion molecules and/or their counter receptors by which cancer cells anchor other blood cells and attach to the vessel wall.

Very relevant appears the role of platelets, which maintain the vascular integrity within tumors and may represent a target for the specific destabilization of tumor vessels (Stegner et al., 2014). Tumor cells activate platelets by the direct cell-cell adhesion and the secretion of platelet-activating molecules. These mechanisms lead to platelet aggregation and is referred to as "tumor cell-induced platelet aggregation (TCIPA)." Platelet activation, coagulation, and thrombus formation are crucial events in limiting blood loss after tissue damage but are also major determinants of hematogenous tumor metastasis (Stegner et al., 2014). The increased platelet activation and aggregation correlate with the metastatic potential of cancer cells in both in vitro and in vivo models of experimental metastasis. Platelet aggregation protects tumor cell surface from immunological recognition in the circulation, as TICPA results in a "platelet coating" of cancer cells shielding them from natural killer (NK) cells (Palumbo et al., 2005). Some tumor cells may use podoplanin, a transmembrane sialoglycoprotein, to activate platelets (Raica et al., 2008). Podoplanin is present on the surface of certain tumor cells, including melanoma, squamous cell carcinoma, seminoma, and brain tumor cells (Raica et al., 2008). Increased levels of podoplanin are associated with tumor metastasis or malignant progression (Mishima et al., 2006). Therefore, podoplanin is a promising target for anti-metastatic therapy. Strategies are now being developed to inhibit PDPN-CLEC2 interactions in preclinical models of solid tumors (Chang et al., 2015).

Increased platelet adhesion and aggregation importantly contribute to thrombogenesis in vivo. In addition, adherent activated platelets release procoagulant MPs, which further contribute to fibrin deposition and microthrombi formation.

The role of both platelets and neutrophils as independent regulators of various processes in cancer has long been known, but it has quite recently emerged that the platelet-neutrophil interplay is yet a critical component of malignant disease. Neutrophils are present in large quantities in the tumor tissue where they release extracellular DNA traps [neutrophil extracellular traps (NETs)]. NETs provide a strong activation signal for platelets, promoting platelet aggregation and thrombosis. Conversely, platelets play an essential role as inducers of intravascular NETosis in response to lipopolysaccharide (LPS). Additionally, the formation of NETs in cancer may affect tumor growth and angiogenesis (Demers and Wagner, 2013). Furthermore, several reports describe that NETs contribute to cancer-associated pathology, by promoting processes responsible for cancer-related death such as thrombosis, systemic inflammation, and relapse of the disease.

\section{Risk factors and risk assessment in cancer patients}

Multiple clinical risk factors, i.e., patient-related or cancer-specific, concur to the activation of blood coagulation and importantly contribute to the thrombotic risk of cancer patients (Table 1) (Khorana and McCrae, 2014; Falanga et al., 2015b).

The clinical thrombotic risk factors, together with the biological procoagulant mechanisms expressed by cancer tissues, contribute to the occurrence of the procoagulant shift in the hemostatic balance of patients with cancer. Indeed, subclinical coagulation changes appear in almost all of these individuals, as shown by the detection of laboratory biomarkers of a hypercoagulable state.

About half of all patients with cancer, and as many as $90 \%$ of those with metastases, exhibit abnormalities in one or more routine coagulation parameters (Falanga, 2005). Laboratory tests with increased sensitivity to detect subtle alterations in the hemostatic system include the thrombin-antithrombin (TAT) complex, prothrombin fragment F1 + 2 (F1 + 2), fibrinopeptide A (FPA), PAI-1, and D-dimer. Levels of plasma markers of clotting activation tend to be universally elevated in patients with cancer (Rickles and Falanga, 2001), and worse with the start of antitumor therapies (Weitz et al., 2002).

Until recently, only few prospective studies have evaluated the utility of serial measurements of hemostatic markers for predicting the occurrence of VTE (as confirmed by objective test) in cancer patients (Falanga et al., 1993).

Current research is focusing on a number of thrombotic biomarkers that may be helpful in identifying cancer patients who are at high risk of developing thrombosis who might benefit from primary thromboprophylaxis. In addition, some of these markers have been incorporated in predictive models involving clinical and biological markers, which are to be validated in prospective clinical trials (Khorana et al., 2005; Ay et al., 2008, 2009).

Recently, plasma MPs are being investigated in connection with cancer progression and thrombosis development. MP levels are currently developed by ongoing clinical trials as a criterion to enroll high risk patients (Toth et al., 2008; Trappenburg et al., 2009; Zwicker et al., 2009).

In the last two decades, several hereditary risk factors (i.e. factor $\mathrm{V}$ Leiden or G20210A prothrombin gene mutation) for venous thrombosis have been identified. The influence of inherited thrombophilia in patients with cancer may be more difficult to demonstrate than in the 
general population, the risk of thrombosis due to cancer per se possibly outweighing the contribution of thrombophilic factors. Several studies evaluating the role of factor V Leiden or G20210A prothrombin gene mutation on the risk of thrombosis in patient with cancer have been published (Decousus et al., 2007). Overall, although conflicting results were obtained, it appears that patients with cancer and either of these mutations tend to exhibit a higher risk of thrombosis than patients with cancer without these mutations. In the largest study by Blom et al. the risk of VTE in patients with both cancer and factor V Leiden or prothrombin 20210A mutation was increased 12- and 17-fold, respectively, compared with patients without cancer and factor V Leiden (Blom et al., 2005).

\section{Assessment of the thrombotic risk in cancer patients}

Recently, the approach to risk assessment for thrombosis in cancer patients relies on the development of "risk assessment models" (RAM). The first was developed by Khorana specifically for cancer patients undergoing chemotherapy (Khorana et al., 2008). This RAM is based on five predictive variables, including cancer site, platelet count, hemoglobin level or the use of erythropoiesis-stimulating agents, leukocyte count, and body mass index. This model using a simple scoring system, is based on readily accessible baseline clinical and laboratory data, and has been shown to accurately predict the short-term risk of symptomatic VTE in patients undergoing chemotherapy-based treatments.

The Khorana score has been validated in both prospective and retrospective observational studies (Ay et al., 2010; Moore et al., 2011; Mandala et al., 2012; Verso et al., 2012). In the Vienna Cancer and Thrombosis Study (CATS) the score was expanded by adding two biomarkers (i.e., P-selectin and D-dimer), and the prediction of VTE was considerably improved. More recent, another modified Khorana risk assessment score (i.e., the Protecht score) was designed by adding platinum- or gemcitabine-based chemotherapy to the five predictive variables for identifying high-risk cancer patients in a post-hoc analysis of the Protecht clinical trial (Verso et al., 2012). In the setting of multiple myeloma, Palumbo et al. published a RAM, based on expert recommendation statements, for the prevention of thalidomide and lenalidomide-associated thrombosis in this disease (Palumbo et al., 2008). The availability of predictive models can facilitate the management of cancer-associated thrombosis by allowing the identification of patients at the highest thrombotic risk, who have the greatest benefit/risk ratio from receiving thromboprophylaxis.

Finally, the Ottawa Score has been developed to identify among patients with cancer and thrombosis those at highest risk of recurrent VTE, who may benefit from prolonged anticoagulant treatment (Louzada et al., 2012; den Exter et al., 2013).

The recent guidelines for prevention and treatment of VTE in cancer patients released by the American Society of Clinical Oncology remark that the thrombotic risk prediction cannot rely on the results of a single test. Instead, to assess the level of risk and identification of patients at high risk for thrombosis, the guidelines recommend including the detection of plasma thrombotic markers in "score systems" combining clinical and biological markers (Lyman et al., 2015).

\section{Conclusions}

Cancer is associated with an imbalance in the hemostatic system, which predisposes to thrombotic complications. Several procoagulant molecules, among which TF is the most important, are expressed by cancer cells or are induced by cancer cell in normal vascular tissues by both the release of soluble mediators and the direct cancer cell-host cell contact. TF exposure by endothelial cell, leukocyte, or circulating MPs of different origins plays a very important role. A very important advance in our knowledge has been the discovery that these cellular events are genetically driven in cancer. It is not surprising that commonly patients with cancer present with subclinical signs of clotting system activation, showing abnormalities of thrombotic biomarkers in the circulation, a condition known as a hypercoagulable state. The relevance of measuring these biomarkers to determine the patient thrombotic risk level is under active investigation. The goal is to identify the high-risk subgroups to establish more accurate and targeted anticoagulation strategies to prevent thrombosis in cancer patients. In the end, the clarification of specific molecular mechanisms triggering blood coagulation in specific cancer types may also indicate alternative ways to inhibit clotting activation in these conditions.

\section{Conflicts of interest}

There are no conflicts of interest.

\section{Acknowledgments}

The authors wish to thank the Associazione Italiana per la Ricerca sul Cancro (A.I.R.C.), grants "IG2013" n. 14505 and "5 per mille" n. ED12237, for its support.

\section{References}

Ay, C., Simanek, R., Vormittag, R., Dunkler, D., Alguel, G., Koder, S., Kornek, G., Marosi, C., Wagner, O., Zielinski, C., Pabinger, I., 2008. High plasma levels of soluble Pselectin are predictive of venous thromboembolism in cancer patients: results from the Vienna Cancer and Thrombosis Study (CATS). Blood 112 (7), 2703-2708.

Ay, C., Vormittag, R., Dunkler, D., Simanek, R., Chiriac, A.L., Drach, J., Quehenberger, P., Wagner, O., Zielinski, C., Pabinger, I., 2009. D-dimer and prothrombin fragment $1+2$ predict venous thromboembolism in patients with cancer: results from the Vienna Cancer and Thrombosis Study. J. Clin. Oncol. 27 (25), 4124-4129.

Ay, C., Dunkler, D., Marosi, C., Chiriac, A.L., Vormittag, R., Simanek, R., Quehenberger, P., Zielinski, C., Pabinger, I., 2010. Prediction of venous thromboembolism in cancer patients. Blood 116 (24), 5377-5382.

Blom, J.W., Doggen, C.J., Osanto, S., Rosendaal, F.R., 2005. Malignancies, prothrombotic mutations, and the risk of venous thrombosis. JAMA 293 (6), 715-722.

Chang, Y.W., Hsieh, P.W., Chang, Y.T., Lu, M.H., Huang, T.F., Chong, K.Y., Liao, H.R. Cheng, J.C., Tseng, C.P., 2015. Identification of a novel platelet antagonist that binds to CLEC-2 and suppresses podoplanin-induced platelet aggregation and cancer metastasis. Oncotarget $6(40), 42733-42748$.

Decousus, H., Moulin, N., Quenet, S., Bost, V., Rivron-Guillot, K., Laporte, S., Mismetti, P., 2007. Thrombophilia and risk of venous thrombosis in patients with cancer. Thromb. Res. 120 (Suppl 2), S51-S61.

Del Conde, I., Bharwani, L.D., Dietzen, D.J., Pendurthi, U., Thiagarajan, P., Lopez, J.A., 2007. Microvesicle-associated tissue factor and Trousseau's syndrome. J. Thromb. Haemost. 5 (1), 70-74.

Demers, M., Wagner, D.D., 2013. Neutrophil extracellular traps: a new link to cancerassociated thrombosis and potential implications for tumor progression. Oncoimmunology 2 (2), e22946.

den Exter, P.L., Kooiman, J., Huisman, M.V., 2013. Validation of the Ottawa prognostic score for the prediction of recurrent venous thromboembolism in patients with cancer-associated thrombosis. J. Thromb. Haemost. 11 (5), 998-1000.

Falanga, A., Ofosu, F.A., Cortelazzo, S., Delaini, F., Consonni, R., Caccia, R., Longatti, S., Maran, D., Rodeghiero, F., Pogliani, E., et al., 1993. Preliminary study to identify cancer patients at high risk of venous thrombosis following major surgery. Br. J. Haematol. 85 (4), 745-750.

Falanga, A., Iacoviello, L., Evangelista, V., Belotti, D., Consonni, R., D'Orazio, A., Robba, L., Donati, M.B., Barbui, T., 1995. Loss of blast cell procoagulant activity and improvement of hemostatic variables in patients with acute promyelocytic leukemia administered all-trans-retinoic acid. Blood 86 (3), 1072-1081.

Falanga, A., Consonni, R., Marchetti, M., Locatelli, G., Garattini, E., Passerini, C.G., Gordon, S.G., Barbui, T., 1998. Cancer procoagulant and tissue factor are differently modulated by all-trans-retinoic acid in acute promyelocytic leukemia cells. Blood 92 (1), 143-151.

Falanga, A, Toma, S., Marchetti, M., Palumbo, R., Raffo, P., Consonni, R., Marziali, S., Dastoli, G., Barbui, T., 2002. Effect of all-trans-retinoic acid on the hypercoagulable state of patients with breast cancer. Am. J. Hematol. 70 (1), 9-15.

Falanga, A., 2005. Thrombophilia in cancer. Semin. Thromb. Hemost. 31 (1), 104-110. Falanga, A., Marchetti, M., 2009. Venous thromboembolism in the hematologic malignancies. J. Clin. Oncol. 27 (29), 4848-4857.

Falanga, A., Russo, L., 2012. Epidemiology, risk and outcomes of venous thromboembolism in cancer. Hamostaseologie 32 (2), 115-125.

Falanga, A., Tartari, C.J., Marchetti, M., 2012. Microparticles in tumor progression. Thromb. Res. 129 (Suppl. 1), S132-S136.

Falanga, A., Marchetti, M., Vignoli, A., 2013. Coagulation and cancer: biological and clinical aspects. J. Thromb. Haemost. 11 (2), 223-233.

Falanga, A., Russo, L., Milesi, V., 2014. The coagulopathy of cancer. Curr. Opin. Hematol. 21 (5), 423-429.

Falanga, A., Schieppati, F., Russo, D., 2015a. Cancer tissue procoagulant mechanisms and 
the hypercoagulable state of patients with cancer. Semin. Thromb. Hemost. 41 (7), 756-764.

Falanga, A., Marchetti, M., Russo, L., 2015b. The mechanisms of cancer-associated thrombosis. Thromb. Res. 135 (Suppl. 1), S8-S11.

Garnier, D., Magnus, N., Lee, T.H., Bentley, V., Meehan, B., Milsom, C., Montermini, L., Kislinger, T., Rak, J., 2012. Cancer cells induced to express mesenchymal phenotype release exosome-like extracellular vesicles carrying tissue factor. J. Biol. Chem. 287 (52), 43565-43572.

Khorana, A.A., Francis, C.W., Culakova, E., Lyman, G.H., 2005. Risk factors for chemotherapy-associated venous thromboembolism in a prospective observational study. Cancer 104 (12), 2822-2829.

Khorana, A.A., Kuderer, N.M., Culakova, E., Lyman, G.H., Francis, C.W., 2008. Development and validation of a predictive model for chemotherapy-associated thrombosis. Blood 111 (10), 4902-4907.

Khorana, A.A., McCrae, K.R., 2014. Risk stratification strategies for cancer-associated thrombosis: an update. Thromb. Res. 133 (Suppl. 2), S35-S38.

Kim, H.K., Song, K.S., Park, Y.S., Kang, Y.H., Lee, Y.J., Lee, K.R., Kim, H.K., Ryu, K.W., Bae, J.M., Kim, S., 2003. Elevated levels of circulating platelet microparticles, VEGF, IL-6 and RANTES in patients with gastric cancer: possible role of a metastasis predictor. Eur. J. Cancer 39 (2), 184-191.

Liu, Y., Wang, Z., Jiang, M., Dai, L., Zhang, W., Wu, D., Ruan, C., 2011. The expression of annexin II and its role in the fibrinolytic activity in acute promyelocytic leukemia. Leuk. Res. 35 (7), 879-884.

Louzada, M.L., Carrier, M., Lazo-Langner, A., Dao, V., Kovacs, M.J., Ramsay, T.O., Rodger, M.A., Zhang, J., Lee, A.Y., Meyer, G., Wells, P.S., 2012. Development of a clinical prediction rule for risk stratification of recurrent venous thromboembolism in patients with cancer-associated venous thromboembolism. Circulation 126 (4), $448-454$.

Lyman, G.H., Bohlke, K., Khorana, A.A., Kuderer, N.M., Lee, A.Y., Arcelus, J.I., Balaban, E.P., Clarke, J.M., Flowers, C.R., Francis, C.W., Gates, L.E., Kakkar, A.K., Key, N.S., Levine, M.N., Liebman, H.A., Tempero, M.A., Wong, S.L., Somerfield, M.R., Falanga, A., American Society of Clinical, O., 2015. Venous thromboembolism prophylaxis and treatment in patients with cancer: american society of clinical oncology clinical practice guideline update 2014. J. Clin. Oncol. 33 (6), 654-656.

Magnus, N., D'Asti, E., Meehan, B., Garnier, D., Rak, J., 2014a. Oncogenes and the coagulation system-forces that modulate dormant and aggressive states in cancer. Thromb. Res. 133 (Suppl 2), S1-S9.

Magnus, N., Garnier, D., Meehan, B., McGraw, S., Lee, T.H., Caron, M., Bourque, G., Milsom, C., Jabado, N., Trasler, J., Pawlinski, R., Mackman, N., Rak, J., 2014b. Tissue factor expression provokes escape from tumor dormancy and leads to genomic alterations. Proc. Natl. Acad. Sci. U. S. A. 111 (9), 3544-3549.

Mandala, M., Clerici, M., Corradino, I., Vitalini, C., Colombini, S., Torri, V., De Pascale, A., Marsoni, S., 2012. Incidence, risk factors and clinical implications of venous thromboembolism in cancer patients treated within the context of phase I studies: the 'SENDO experience'. Ann. Oncol. 23 (6), 1416-1421.

Mishima, K., Kato, Y., Kaneko, M.K., Nishikawa, R., Hirose, T., Matsutani, M., 2006. Increased expression of podoplanin in malignant astrocytic tumors as a novel molecular marker of malignant progression. Acta Neuropathol. 111 (5), 483-488.

Moore, R.A., Adel, N., Riedel, E., Bhutani, M., Feldman, D.R., Tabbara, N.E., Soff, G., Parameswaran, R., Hassoun, H., 2011. High incidence of thromboembolic events in patients treated with cisplatin-based chemotherapy: a large retrospective analysis. J. Clin. Oncol. 29 (25), 3466-3473.

Nadir, Y., Brenner, B., 2016. Heparanase procoagulant activity in cancer progression. Thromb. Res. 140 (Suppl 1), S44-S48.

Palumbo, A., Rajkumar, S.V., Dimopoulos, M.A., Richardson, P.G., San Miguel, J., Barlogie, B., Harousseau, J., Zonder, J.A., Cavo, M., Zangari, M., Attal, M., Belch, A., Knop, S., Joshua, D., Sezer, O., Ludwig, H., Vesole, D., Blade, J., Kyle, R., Westin, J., Weber, D., Bringhen, S., Niesvizky, R., Waage, A., von Lilienfeld-Toal, M., Lonial, S., Morgan, G.J., Orlowski, R.Z., Shimizu, K., Anderson, K.C., Boccadoro, M., Durie, B.G., Sonneveld, P., Hussein, M.A., International Myeloma Working, G., 2008. Prevention of thalidomide- and lenalidomide-associated thrombosis in myeloma. Leukemia 22 (2), 414-423.

Palumbo, J.S., Talmage, K.E., Massari, J.V., La Jeunesse, C.M., Flick, M.J., Kombrinck, K.W., Jirouskova, M., Degen, J.L., 2005. Platelets and fibrin(ogen) increase metastatic potential by impeding natural killer cell-mediated elimination of tumor cells. Blood 105 (1), 178-185.

Raica, M., Cimpean, A.M., Ribatti, D., 2008. The role of podoplanin in tumor progression and metastasis. Anticancer Res. 28 (5B), 2997-3006.

Rickles, F.R., Falanga, A., 2001. Molecular basis for the relationship between thrombosis and cancer. Thromb. Res. 102 (6), V215-V224.

Stegner, D., Dutting, S., Nieswandt, B., 2014. Mechanistic explanation for platelet contribution to cancer metastasis. Thromb. Res. 133 (Suppl. 2), S149-S157.

Tilley, R.E., Holscher, T., Belani, R., Nieva, J., Mackman, N., 2008. Tissue factor activity is increased in a combined platelet and microparticle sample from cancer patients. Thromb. Res. 122 (5), 604-609.

Timp, J.F., Braekkan, S.K., Versteeg, H.H., Cannegieter, S.C., 2013. Epidemiology of cancer-associated venous thrombosis. Blood 122 (10), 1712-1723.

Toth, B., Liebhardt, S., Steinig, K., Ditsch, N., Rank, A., Bauerfeind, I., Spannagl, M., Friese, K., Reininger, A.J., 2008. Platelet-derived microparticles and coagulation activation in breast cancer patients. Thromb. Haemost. 100 (4), 663-669.

Trappenburg, M.C., van Schilfgaarde, M., Marchetti, M., Spronk, H.M., ten Cate, H., Leyte, A., Terpstra, W.E., Falanga, A., 2009. Elevated procoagulant microparticles expressing endothelial and platelet markers in essential thrombocythemia. Haematologica 94 (7), 911-918.

Verso, M., Agnelli, G., Barni, S., Gasparini, G., LaBianca, R., 2012. A modified Khorana risk assessment score for venous thromboembolism in cancer patients receiving chemotherapy: the Protecht score. Intern. Emerg. Med. 7 (3), 291-292.

Weitz, I.C., Israel, V.K., Waisman, J.R., Presant, C.A., Rochanda, L., Liebman, H.A., 2002 Chemotherapy-induced activation of hemostasis: effect of a low molecular weight heparin (dalteparin sodium) on plasma markers of hemostatic activation. Thromb. Haemost. 88 (2), 213-220.

Zwicker, J.I., Liebman, H.A., Neuberg, D., Lacroix, R., Bauer, K.A., Furie, B.C., Furie, B., 2009. Tumor-derived tissue factor-bearing microparticles are associated with venous thromboembolic events in malignancy. Clin. Cancer Res. 15 (22), 6830-6840. 
PART TWO

\section{Heparin Actions on \\ Endothelial Cell Hemostatic Properties}




\title{
Chapter 4
}

\author{
Differential effect of the \\ low-molecular-weight- \\ heparin, dalteparin, and \\ unfractionated heparin on \\ microvascular endothelial \\ cells hemostatic properties.
}

Vignoli A, Marchetti $M$, Balducci D, Barbui T, Falanga A. Differential effect of the lowmolecular-weight heparin, dalteparin, and unfractionated heparin on microvascular endothelial cell hemostatic properties. Haematologica. 2006;91(2):207-14. Erratum in:

Haematologica. 2006;91(5):620. 


\section{Differential effect of the low-molecular-weight heparin, dalteparin, and unfractionated heparin on microvascular endothelial cell hemostatic properties}

Alfonso Vignoli

Marina Marchetti

Donatella Balducci

Tiziano Barbui

Anna Falanga

Background and Objectives. Heparins, including unfractionated heparin (UFH) and lowmolecular-weight heparins (LMWH), are glycosaminoglycans that are largely used as anti-thrombotic drugs. While the mechanisms of their anticoagulant actions in blood have been extensively studied, their effects on the hemostatic properties of the endothelium are still under investigation. The aim of this study was to compare the antithrombotic effects of a LMWH, i.e. dalteparin, with UFH on both microvascular (human microvascular endothelial cells [HMEC-1]) and macrovascular (human umbilical vein endothelial cells [HUVEC]) endothelial cells.

Design and Methods. Endothelial cells were incubated with dalteparin or UFH and exposed to an inflammatory stimulus (i.e. lipopolysaccharide [LPS]). The following parameters were evaluated: tissue factor (TF procoagulant activity, antigen and mRNA), tissue factor pathway inhibitor (TFPI), and thrombomodulin (TM).

Results. In HMEC-1 and HUVEC, both heparins inhibited LPS-induced endothelial cell TF expression. However, in HMEC-1, dalteparin was significantly more effective than UFH. Both heparins increased TFPI antigen release in HMEC-1 and HUVEC. Dalteparin also reversed LPS-induced reduction of TM in HMEC-1, while UFH did not.

Interpretation and Conclusions. These data show that both dalteparin and UFH suppress inflammatory-mediated TF expression and increase the anticoagulant properties of macro- and micro-vascular endothelial cells. However, dalteparin has significantly greater effects than UFH in the microvascular endothelium, a site that plays a central role in many processes involved in inflammation and thrombosis.

Key words: heparin, low-molecular-weight heparin, endothelial cells, tissue factor, thrombomodulin, tissue factor pathway inhibitor.

Haematologica 2006; 91:207-214

(C2006 Ferrata Storti Foundation

All authors from the Department of Hematology-Oncology, Ospedali Riuniti di Bergamo, Bergamo, Italy.

\section{Correspondence:}

Anna Falanga, Department of Hematology-Oncology, Ospedali Riuniti di Bergamo, Largo Barozzi 1, 24128 Bergamo, Italy. E-mail: annafalanga@yahoo.com
U nfractionated heparin (UFH) and its low molecular weight (LMWH) derivatives are glycosaminoglycans used in clinical practice for the prevention and treatment of venous thromboembolism. ${ }^{1}$ Heparins exert anticoagulant effects by accelerating the rate of factor $\mathrm{Xa}$ and thrombin inhibition through binding to antithrombin. In addition, heparins possess a broad variety of biological activities, including anti-inflammatory, antihypertensive, and antitumor properties.,3 It appears that heparins may have important actions on the vascular endothelium, which plays a key role in numerous physio-pathological processes, including hemostasis, inflammation, leukocyte trafficking, angiogenesis and tumor metastasis. ${ }^{4}$ Under physiological conditions, endothelial cells generate an active antithrombotic surface that inhibits clotting activation and the adhesion of platelets and other circulating cells. However, when exposed to physical or biochemical stimuli, the endothelium undergoes a series of phenotypic changes that produce a shift to a prothrombotic condition. In particular, bacterial products (e.g. lipopolysaccharide, LPS), as well as inflammatory cytokines, stimulate endothelial cells to express procoagulant tissue factor (TF), downregulate anticoagulant thrombomodulin (TM), produce fibrinolytic inhibitors (e.g. plasminogen activator inhibitor1 [PAI-1]), and express cell adhesion molecules. These modifications can lead to the activation of the blood clotting system, which culminates in fibrin generation, in addition to increasing cellular adhesion processes, which can further stimulate localized coagulation. These phenomena are also involved in the progression of chronic inflammatory diseases, ${ }^{4,5}$ and are of particular relevance at the level of the microcirculation, where the interactions between the vascular wall and circulating cells are enhanced. In this context, it is of interest to determine the role of heparins at the microvascular level. Several in vitro studies have evaluated the impact of heparins on the hemostatic properties of the macrovascular endothelium, represented by human umbilical vein endothelial cells (HUVEC) ${ }^{6-9}$ However, no data are currently available regarding the effect of heparins on microvascular endothelial cells, which have different properties to HUVEC. ${ }^{10}$

The aims of the present study were: (i) to evaluate whether LMWH can counteract the prothrombotic phenotype of microvascular 
endothelial cells induced by a standard pro-inflammatory stimulus (i.e. LPS); (ii) to compare the responses of the microvascular endothelium with those of HUVEC; and (iii) to verify whether the effects of LMWH on the hemostatic properties of the two endothelial cell types differ from those of UFH. In particular, the effect of the LMWH, dalteparin, and UFH were compared in terms of the expression of endothelial TF procoagulant activity and anticoagulant properties (i.e. expression of TM and TF pathway inhibitor [TFPI]), in the presence and absence of LPS.

\section{Design and Methods}

\section{Endothelial cells}

The immortalized human microvascular endothelial cell line-1 (HMEC-1) was kindly supplied by Dr F.J.Candal (CDC, Centers for Disease Control and Prevention, Atlanta, GA, USA). To date, this is the best-characterized microvascular endothelial cell line." HMEC-1 were grown in RPMI 1640 medium supplemented with 10\% fetal calf serum (Gibco, Gaithersburg, MD, USA), $100 \mu \mathrm{g} / \mathrm{mL}$ streptomycin, $100 \mathrm{U} / \mathrm{mL}$ penicillin, $5 \mu \mathrm{g} / \mathrm{mL}$ amphotericin $\mathrm{B}$ (Bristol-Myers Squibb, Princeton, NJ, USA), $2 \mathrm{mmol} / \mathrm{L} \mathrm{L}$ glutamine (Gibco), $10 \mathrm{ng} / \mathrm{mL}$ epidermal growth factor (ICN, Costa Mesa, CA, USA) and $1 \mu \mathrm{g} / \mathrm{mL}$ hydrocortisone (ICN). HMEC-1 were serially passaged in T25 flasks (Falcon, Becton Dickinson, Mountain View, CA, USA) and, at passages 8 to 16 , seeded onto 24-well cell culture plates at the concentration of 30,000 cells/well, then grown to confluence in complete growth culture medium. ${ }^{12}$ The cells reached confluence in 3 to 4 days.

HUVEC were freshly isolated from human umbilical cord veins, as previously described, ${ }^{13}$ and grown in T25 flasks in RPMI 1640 medium supplemented with $20 \%$ fetal calf serum, $100 \mu \mathrm{g} / \mathrm{mL}$ streptomycin, $100 \mathrm{U} / \mathrm{mL}$ penicillin, $5 \mu \mathrm{g} / \mathrm{mL}$ amphotericin $\mathrm{B}$ and $2 \mathrm{mmol} / \mathrm{L} \mathrm{L}$-glutamine. Confluent primary cultures were harvested using $0.25 \%$ trypsin $/ 0.02 \%$ EDTA solution (Sigma, St Louis, MO, USA), seeded onto 24 -well cell culture plates pre-coated with $0.5 \%$ gelatin (Sigma) at the concentration of 30,000 cells/well and grown to confluence in complete growth culture medium. The cells reached confluence in 3 to 4 days. Both types of endothelial cells were grown in a humidified incubator in an atmosphere of $5 \% \mathrm{CO}_{2} / 95 \%$ air. At the end of each experiment, endothelial cells were counted by microscopy and the trypan blue exclusion test was used to determine cell viability. More than $95 \%$ of cells resulted viable in all experiments.

\section{Experimental system}

Confluent endothelial cell monolayers in 24-well plates were washed twice with RPMI 1640 medium and then incubated with RPMI 1640 medium (supplemented with $10 \%$ fetal calf serum and $2 \mathrm{mmol} / \mathrm{L}$ glutamine) containing either dalteparin (Fragmin ${ }^{\circledast}$, Pharmacia legacy, Sweden) or UFH (Vister ${ }^{\circledR}$, Parke-Davis, Lainate, Milan, Italy), at 0.01, $0.1,1$ and $10 \mathrm{IU} / \mathrm{mL}$ f.c., or saline (control cells) for 3 hours for TF mRNA measurement, 4-24 hours for TF activity and antigen assays, and up to 72 hours for TFPI and TM analysis. To evaluate the potential anti-inflammatory activity of both heparins, the study was also conducted in the pres- ence of $10 \mu \mathrm{g} / \mathrm{mL}$ LPS (Lipopolysaccharide endotoxin from Escherichia coli, Sigma) or saline (control cells). Heparin doses were selected on the basis of the plasma concentrations achieved in vivo during therapy of venous thromboembolism. After incubation, endothelial cell treatment media were collected and centrifuged for $10 \mathrm{~min}$ at 13,000 $\mathrm{rpm}$, the supernatants were then filtered through a $0.22 \mu \mathrm{m}$ filter to eliminate cell debris, and stored at $-40^{\circ} \mathrm{C}$ until assays. Endothelial cell monolayers were washed three times with phosphate-buffered saline ( $\mathrm{pH} 7.4$ ), to eliminate any heparin residues, and different endothelial cell samples were prepared as detailed below.

\section{TF procoagulant activity}

TF activity was evaluated in endothelial cell lysates $\left(5 \times 10^{5}\right.$ cells $/ \mathrm{mL}$ in phosphate-buffered saline), obtained after three cycles of freezing/thawing, by the one-stage recalcification assay of normal human plasma, as previously described. ${ }^{14}$ TF activity was identified and characterized as being associated with TF by the clotting assay of factor VII-, VIII- or X-deficient human plasmas (FVII-D, FVIII-D, FX-D, DADE Behring, Milan, Italy). In some experiments, TF activity was further characterized by incubating (15 min at $37^{\circ} \mathrm{C}$ ) endothelial cell samples with a purified polyclonal rabbit IgG antibody $(1 \mathrm{mg} / \mathrm{mL})$ directed against human TF (\#4502, American Diagnostica Inc., Greenwich, CT, USA) before the clotting assay. A normal non-immune rabbit IgG was the control in this assay. TF activity was referred to a calibration curve constructed with different dilutions (from $10^{-1}$ to $10^{-6}$ ) of a standard rabbit brain thromboplastin (RBT; Sigma). Results are expressed as standard thromboplastin arbitrary units (RBT units): 1 unit = the activity of $1 \mathrm{mEquiv} / \mathrm{mL}$ of RBT in the coagulation assay.

\section{TF antigen}

TF antigen levels were measured by ELISA (Imubind Tissue Factor ELISA Kit; American Diagnostica) in endothelial cells extracted in TRIS buffer $\left(5 \times 10^{5}\right.$ cells $/ \mathrm{mL}$ of $50 \mathrm{mmol} / \mathrm{L}$ Tris buffer, $100 \mathrm{mmol} / \mathrm{L} \mathrm{NaCl}$ and $1 \%$ Triton X100; pH 7.5) for 2 hours at $4^{\circ} \mathrm{C}$, followed by three cycles of freezing/thawing. The ELISA was performed according to the manufacturer's instructions. Results are expressed as pg/10 cells. $^{14}$

\section{TF mRNA}

Total cellular RNA was extracted using Trizol reagent (Life Technologies, Paisley, Scotland) according to the manufacturer's instructions. RNA was reverse-transcribed and used for parallel assays of TF and glyceraldehyde-3-phosphate dehydrogenase (GAPDH) mRNA by polymerase chain reaction (PCR) amplification. GAPDH acted as the internal control to normalize sample data to account for sample-sample differences. ${ }^{15}$ The following oligonucleotides were used: F1 (sense: bp 178 to 198) and R1 (antisense: bp 495 to 515 ) from the coding sequence of the human TF, and GF1 (sense: bp 64 to 86) and GR1 (antisense: bp 581 to 603) from the coding sequence of the human GAPDH (Laboratoires Eurobio, Les Ulis, France). Quantitative PCR was performed with $5 \mu \mathrm{L}$ of cDNA, as previously described. ${ }^{15}$ The PCR products from TF (317 bp) and GAPDH (528 bp) were analyzed by electrophoresis in a $2 \%$ agarose gel stained with ethidium bromide. Band 
intensities were quantified by densitometric analysis (ImageJ software, National Institutes of Health, Bethesda, $\mathrm{MD}$, USA). The results are expressed as the ratio of TF band intensity/GAPDH band intensity.

\section{TFPI antigen}

Antigenic levels of TFPI were measured in endothelial cell cultured media and cell extracts (prepared as for the TF antigen measurements) by ELISA using a commercially available kit (Imubind TFPI, American Diagnostica) according to the manufacturer's instructions. This ELISA measures both free and bound forms of TFPI. Results are expressed as $\mathrm{ng} / \mathrm{mL}$.

\section{TM antigen}

The levels of TM antigen were measured in endothelia cell extracts (prepared as for the TF antigen measurements) by a commercial ELISA kit (Asserachrom thrombomodulin, Roche Diagnostics), as previously described. ${ }^{16}$ Results are expressed as $\mathrm{ng} / 10^{5}$ cells.

\section{Statistical analysis}

The results are reported as mean \pm SD from at least five independent experiments performed in triplicate. Student's paired t-test was used for the determination of significance levels between treatments. Differences were considered statistically significant when $p$ values were $<0.05$

\section{Results}

\section{Effect of heparins on TF expression in stimulated EC (with LPS)}

In preliminary experiments, treatment of HMEC-1 and HUVEC with LPS induced a time-dependent increase in TF expression evaluated as activity, antigen, and mRNA, with a maximum effect at 4-6 hours and then a progressive decline towards basal values at 24-48 hours. In order to evaluate the activity of heparins on LPS-induced TF expression, we choose the 4- and 24- hour time points, i.e. when the effect of the LPS stimulus was maximum or when it was greatly reduced, respectively. Treatment of HMEC-1 with LPS for 4 hours induced a significant increase in TF activity (control: $14.5 \pm 1.3$, LPS: $46.2 \pm 5.2$ RBT units $/ 10^{5}$ cells; $p=0.001$ ). The incubation of endothelial cells with either dalteparin or UFH counteracted the LPS-induced TF activity (Figure 1). Particularly, dalteparin significantly inhibited TF activity, reaching a maximum inhibition of $96 \%$ at 1 $\mathrm{IU} / \mathrm{mL}\left(15.8 \pm 1.8 \mathrm{RBT}\right.$ units $/ 10^{5}$ cells, $p=0.031$ vs LPS) (Figure $1 \mathrm{~A})$, whereas UFH showed a maximum inhibitory effect of $55 \%$ with the dose of $10 \mathrm{IU} / \mathrm{ml}\left(28.6 \pm 2.8 \mathrm{RBT}\right.$ units $/ 10^{5}$ cells, $p=0.038$ vs LPS). Remarkably, TF inhibition by dalteparin was significantly greater than that of UFH at the doses of $0.1 \mathrm{IU} / \mathrm{mL}(0.012), 1 \mathrm{IU} / \mathrm{mL}(p=0.002)$ and 10 $\mathrm{IU} / \mathrm{mL}(p=0.031)$. As observed in HMEC-1, 4 hours of incubation with LPS induced a significant increase in TF activity also in HUVEC (control: 9.9 \pm 0.8 , LPS: 89.2 \pm 9.5 RBT units $/ 10^{5}$ cells; $p=0.001$ ). However, differently from what we found in HMEC-1, in these cells, heparins reduced LPSinduced TF activity to a similar extent (Figure 1B). In particular, at a concentration of $10 \mathrm{IU} / \mathrm{mL}$, dalteparin significant-

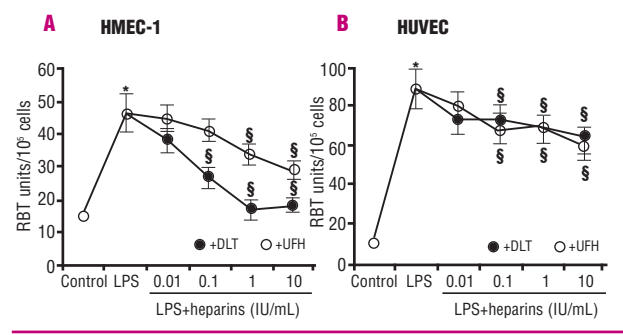

Figure 1. Effect of heparins on TF procoagulant activity expression by HMEC-1 (A) and HUVEC (B). TF activity was assayed in lysates of endothelial cells treated for 4 hours with LPS in the presence or absence of increasing doses of dalteparin (DLT) or UFH. The control was vehicle-treated endothelial cells. Data represent the mean $\pm S D$ of five independent experiments performed in triplicate. ${ }^{\star} p<0.05$ vs control; ${ }^{s} p<0.05$ vs LPS.

ly inhibited TF activity by $37 \%\left(62.3 \pm 6.4\right.$ RBT units $/ 10^{5}$ cells, $p=0.002$ ) compared with a significant reduction of 40 $\%$ for UFH (59.6 \pm 6.1 RBT units $/ 10^{5}$ cells; $\left.p=0.004\right)$.

The measurement of TF antigen levels in the same experimental conditions showed that, similarly to TF activity, in HMEC-1, the antigenic TF expression induced by LPS was significantly $(p=0.014)$ more inhibited by dalteparin ( $87 \pm 6 \%$ inhibition) than by UFH $(67 \pm 8 \%$ inhibition) (Figure 2A). In HUVEC, both heparins reduced LPS-induced TF antigen levels to the same extent, confirming the results obtained with TF activity (dalteparin vs UFH: $45 \pm 13 \%$ vs $43 \pm 5.7 \%$ inhibition; $p=n s$ ) (Figure $2 \mathrm{~B}$ ).

To evaluate whether the observed inhibition of TF activity and antigen expression was due to a possible effect of heparins on TF gene transcription, the levels of TF mRNA in HMEC-1 and HUVEC treated with heparins in the presence of LPS were evaluated by reverse transcriptase (RT)PCR. The TF-mRNA analysis showed that control samples of both HMEC-1 and HUVEC expressed very low levels of TF-mRNA (Figure 3). Treatment with LPS markedly increased mRNA levels compared with levels in control cells, but not in the presence of heparins. In HMEC-1, dalteparin was more effective than UFH, with a $96 \%$ mean inhibition of LPS-induced TF-mRNA, compared to $72 \%$ inhibition with UFH (Figure 3A). In HUVEC, no significant differences were observed between the two heparins, both of which caused about $75 \%$ inhibition of LPS-induced TFmRNA (Figure 3B). TF expression was also measured after 24 hours of heparin treatments (Table 1). In both cell types, the LPS-induced increase in TF expression remained significantly higher than that in control cells, although it was inferior to that observed after the 4-hour incubation. The increase in TF activity in both HMEC-1 and HUVEC was significantly inhibited by both dalteparin and UFH. However, in contrast to the observations after 4 hours of incubation, the degree of TF inhibition in HMEC-1 after 24 hours of incubation was comparable for the two heparins. Similar levels of TF inhibition were obtained with the assay of TF antigen levels (Table 1).

\section{Effect of heparins on TFPI in unstimulated endothelial cells (without LPS)}

To evaluate the effect of heparins on endothelial cell anti- 

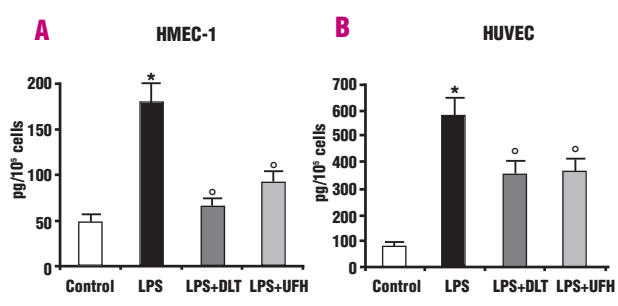

Figure 2. Effect of heparins on TF antigen levels in LPS-stimulated HMEC-1 (A) and HUVEC (B). TF antigen was measured in extracts of endothelial cells treated for 4 hours with LPS in the presence or absence of $10 \mathrm{IU} / \mathrm{mL}$ dalteparin or UFH. Data represent the mean $\pm S D$ of five independent experiments performed in triplicate. $p<0.05$ vs control; ${ }^{\circ} p<0.05$ vs LPS.

coagulant activity, the expression of TFPI by HMEC-1 and HUVEC was measured in basal condition (without LPS) and after stimulation with LPS. In unstimulated conditions, both heparins increased TFPI antigen levels in HMEC-1 cultured media at all the evaluated doses and all incubation times. The $1 \mathrm{IU} / \mathrm{mL}$ dose was the most effective for both heparins and produced a maximum effect on TFPI release after 72 hours of incubation (control: $34.7 \pm 2.9 \mathrm{ng} / \mathrm{mL}$; dalteparin: $62.5 \pm 6.7 \mathrm{ng} / \mathrm{mL}, p=0.048$; UFH: $70.5 \pm 8.3 \mathrm{ng} / \mathrm{mL}, p=0.021$ ) (Figure 4A). In parallel to the induction of TFPI release in HMEC-1 cultured media, heparins significantly reduced TFPI levels in HMEC-1 extracts starting from 4 hours of incubation (Figure 4B). The most effective dose was 1 $\mathrm{IU} / \mathrm{mL}$ for both heparins: at this dose, cell-associated TFPI levels were reduced $60 \%$ by dalteparin (control: $8.6 \pm 1.1$ $\mathrm{ng} / \mathrm{mL}$, dalteparin: $3.4 \pm 0.4 \mathrm{ng} / \mathrm{mL}, p=0.032$ vs control) and reduced $53.1 \%$ by UFH $(4.08 \pm 0.4 \mathrm{ng} / \mathrm{mL}, p=0.038$ vs control). This reduction was more marked after 24 hours of incubation, with mean reductions of $70 \%$ for dalteparin (control: $5.51 \pm 0.7 \mathrm{ng} / \mathrm{mL}$; dalteparin: $1.51 \pm 0.15 \mathrm{ng} / \mathrm{mL}, p=$ $0.032)$ and $72.1 \%$ for UFH $(1.2 \pm 0.11 \mathrm{ng} / \mathrm{mL}, p=0.019$ vs control). After incubation for 48 and 72 hours, significant differences persisted between TFPI levels in heparin-treated cells and control cells, although these were less pronounced. In HUVEC cultured media, an increase in TFPI antigen levels was observed for all incubation times with both dalteparin and UFH. As observed in HMEC-1, the $1 \mathrm{IU} / \mathrm{mL}$ was the most effective dose for both heparins, with a maximum increase in TFPI antigen levels observed after 48hour incubation, i.e. $97 \%$ by dalteparin and $142 \%$ by UFH (control: $6.3 \pm 0.71 \mathrm{ng} / \mathrm{ml}$; dalteparin: $12.4 \pm 1.4 \mathrm{ng} / \mathrm{mL}$, $p=0.005$; UFH: $15.2 \pm 1.81 \mathrm{ng} / \mathrm{mL}, p=0.002$ ) (Figure 4C). The increase in TFPI levels detected in the culture media of heparin-treated cells was much greater than the reduction observed in the levels of cell-associated TFPI. We could not perform the study in HUVEC extracts, because the levels of TFPI antigen in the extracts of these cells were below the detection limit of the ELISA (i.e.: $0.336 \mathrm{ng} / \mathrm{mL}$ ).

\section{Effect of heparins on TFPI in stimulated endothelial cells (with LPS)}

The results of TFPI modulation by heparins in LPS- stimulated conditions showed that LPS incubation (Figure 5A)

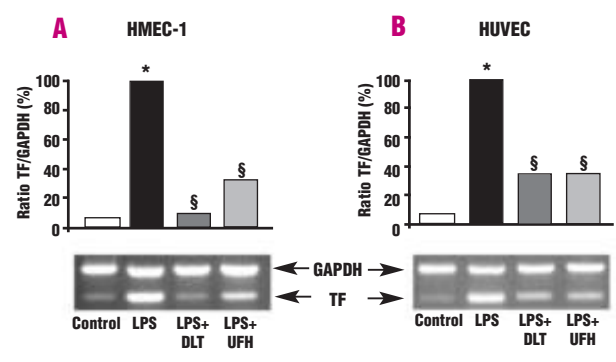

Figure 3. TF mRNA levels in HMEC-1 (A) and HUVEC (B) stimulated with LPS for 3 hours in the presence or absence of $10 \mathrm{IU} / \mathrm{mL}$ dalteparin or UFH. Quantification of the representative experiment is reported here, while statistical significances refer to the mean $\pm S D$ of three independent experiments. ${ }^{*} p<0.05$ versus control; ${ }^{\circ} p<0.05$ versus LPS.

Table 1. Levels of TF activity (RBT units $/ 10^{5}$ cells) and TF antigen (ng/10 $10^{5}$ cells) in HMEC-1 and HUVEC lysates after incubation for 24 hours with $10 \mu \mathrm{g} / \mathrm{mL}$ LPS in the presence or absence of $10 \mathrm{U} / \mathrm{mL}$ of dalteparin (DLT) or UFH.

\begin{tabular}{|c|c|c|}
\hline & \multicolumn{2}{|c|}{ HMEC-1 } \\
\hline $\begin{array}{l}\text { Control } \\
\text { LPS } \\
\text { LPS+DLT } \\
\text { LPS+UFH }\end{array}$ & $\begin{array}{l}10.5 \pm 1.3 \\
27.2 \pm 3.3^{*} \\
15.4 \pm 2.5^{\circ} \\
16.8 \pm 2.4^{\circ}\end{array}$ & $\begin{array}{l}40.2 \pm 10 \\
96.8 \pm 16^{*} \\
65.7 \pm 12^{\circ} \\
69.4 \pm 11^{\circ}\end{array}$ \\
\hline & TF activity & TF antigen \\
\hline $\begin{array}{l}\text { Control } \\
\text { LPS } \\
\text { LPS+DLT } \\
\text { LPS+UFH }\end{array}$ & $\begin{array}{c}4.8 \pm 0.7 \\
23.7 \pm 2.6^{*} \\
11.3 \pm 1.9^{\circ} \\
12.4 \pm 1.4^{\circ}\end{array}$ & $\begin{array}{c}81.1 \pm 15 \\
383 \pm 43^{*} \\
203 \pm 28^{\circ} \\
221 \pm 31^{\circ}\end{array}$ \\
\hline
\end{tabular}

${ }^{*} p<0.05$ versus control; ${ }^{\circ} p<0.05$ versus LPS. Data are expressed as mean $\pm S D$ of three independent experiments.

significantly increased TFPI levels in HMEC-1 cultured media, compared with vehicle-treated control cells, at all evaluated time points. The TFPI increase was maximum after 48 hours of incubation (control: $14.8 \pm 1.9 \mathrm{ng} / \mathrm{mL}$; LPS: $23.5 \pm 2.1 \mathrm{ng} / \mathrm{mL} ; p=0.001)$. Interestingly, in LPS-stimulated endothelial cells, heparins further increased TFPI release in culture media at all time points. As in unstimulated conditions, the heparin dose of $1 \mathrm{IU} / \mathrm{mL}$ was more effective than the $10 \mathrm{IU} / \mathrm{mL}$ for both heparins. After incubation for 72 hours, the following TFPI values were measured with the $1 \mathrm{IU} / \mathrm{mL}$ dose of heparin: LPS: $42.6 \pm 5.1 \mathrm{ng} / \mathrm{mL}$; dalteparin+LPS: $78.5 \pm 9.5 \mathrm{ng} / \mathrm{mL}, p=0.031$ vs LPS; UFH+LPS: $89.1 \pm 7.6 \mathrm{ng} / \mathrm{mL}, p=0.029$ vs LPS.

Differently from what observed in cultured media of HMEC-1, LPS incubation did not significantly affect the levels of cell-associated TFPI (Figure 5B). However, the presence of dalteparin or UFH significantly reduced cellassociated TFPI compared to LPS alone, with no significant differences between the various doses of heparins utilized. After 4-hour incubation, maximum cell-associated TFPI reductions were observed. Mean reductions at the $1 \mathrm{IU} / \mathrm{ml}$ dose were the following: dalteparin: $73 \pm 5.9 \%, p=0.019$ vs 


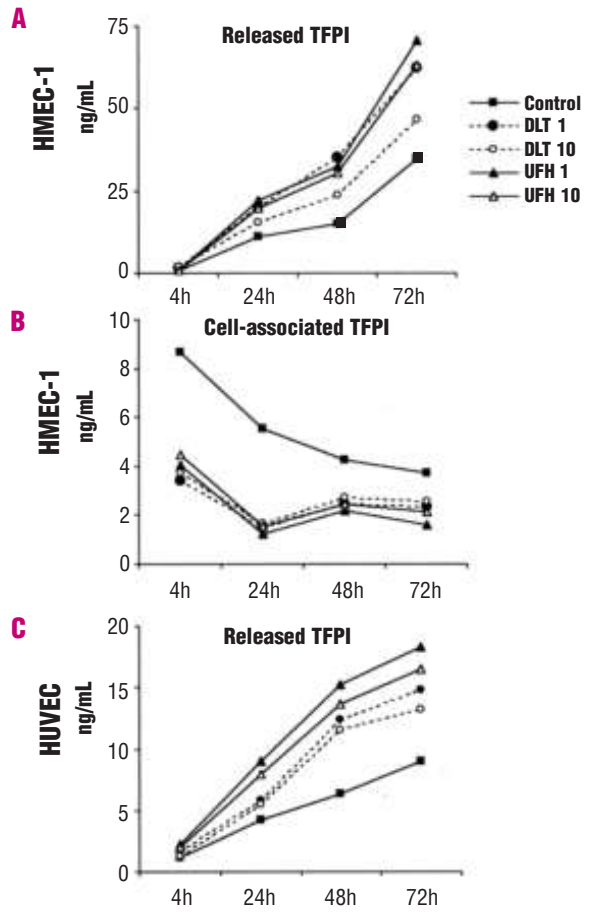

Figure 4. Effect of heparins on TFPI antigen expression by unstimulated endothelial cells (without LPS). TFPI was measured in cultured media $(A)$ or cell extracts $(B)$ of HMEC-1 or in cultured media of HUVEC (C), treated for 4, 24, 48 and 72 hours with 1 and 10 $\mathrm{IU} / \mathrm{mL}$ of dalteparin or UFH. The control cells were vehicle-treated endothelial cells. Data represent the mean values from five experiments performed in triplicate.

LPS; UFH: $65 \pm 6.6 \%, p=0.027$ vs LPS. LPS did not significantly affect TFPI levels in cultured media of HUVEC, and no additive effects were observed when HUVEC were incubated with LPS in the presence of dalteparin or UFH (Figure 5C).

\section{Effect of heparin on TM in unstimulated endothelial cells (without LPS)}

In order to evaluate the effect of heparins on another anticoagulant property of endothelial cells, measurements of endothelial TM expression were conducted in both unstimulated and LPS stimulated conditions. In unstimulated conditions, TM antigen levels were significantly increased in HMEC-1 treated with $10 \mathrm{IU} / \mathrm{mL}$ of dalteparin for 24 hours $(31 \pm 13 \%$ increase, $p=0.04), 48$ hours $(28 \pm 12.1 \%$ increase, $p=0.018)$ and 72 hours $(20 \pm 8.8 \%$ increase, $p=0.041$ ), compared with control cells (Figure 6A). No increases in TM antigen levels were evident when the cells were treated with lower concentrations of dalteparin. In contrast, TM expression was not significantly affected by UFH treatment after incubation periods of up to 72 hours at all doses. In HUVEC, no significant effect of

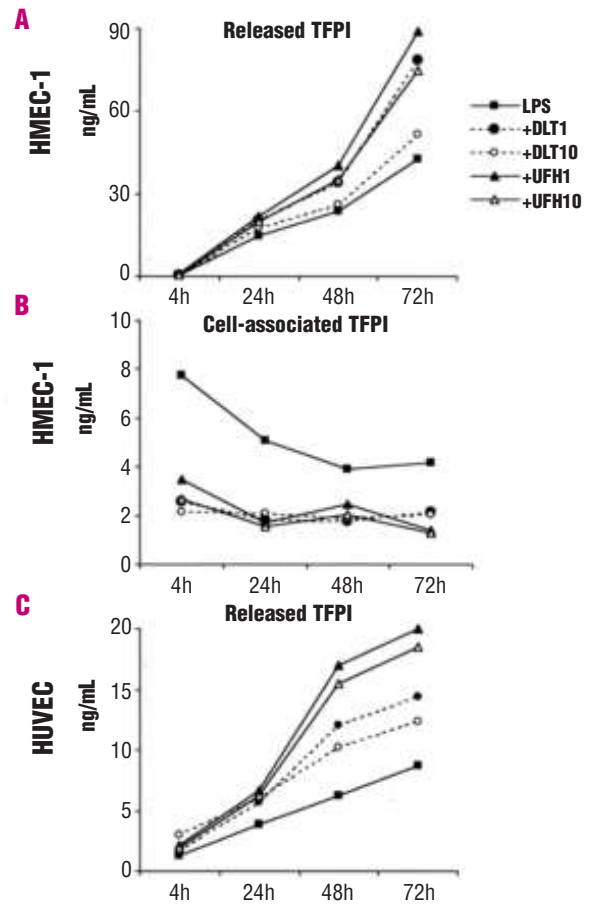

Figure 5. Effect of heparins on TFPI antigen expression by LPSstimulated endothelial cells. TFPI levels were measured in cultured media (A) or cell extracts (B) of HMEC-1, and in cultured media of HUVEC (C), treated for $4,24,48$ and 72 hours with 1 and $10 \mathrm{IU} / \mathrm{mL}$ of dalteparin or UFH in the presence of LPS. The control $10 \mathrm{IU} / \mathrm{mL}$ of dalteparin or UFH in the presence of LPS. The control
cells were vehicle-treated endothelial cells. Data represent the mean values from five experiments performed in triplicate.

heparins was observed up to 24 hours of incubation (Figure 6C). However, after 48- and 72-hour incubation, both dalteparin and UFH increased the cell TM antigen levels. These results reached statistical significance at the dose of $10 \mathrm{IU} / \mathrm{mL}$ for both heparins.

\section{Effect of heparins on TM in stimulated endothelial cells (with LPS)}

In HMEC-1, 24-hour incubation with LPS induced a significant reduction in TM levels $\left(11.8 \pm 1.0 \mathrm{ng} / 10^{5}\right.$ cells $)$ compared with levels control cells $\left(23 \pm 1.7 \mathrm{ng} / 10^{5}\right.$ cells; $\left.p<0.05\right)$ (Figure 6B). This effect of LPS was only observed after 24 hours of incubation, and not at other time points. This reduction in TM antigen levels was significantly counteracted by co-incubation of the cells with $10 \mathrm{IU} / \mathrm{mL}$ dalteparin, which prevented the LPS-induced reduction in TM antigen levels by $41 \%\left(16.4 \pm 1.31 \mathrm{ng} / 10^{5}\right.$ cells, $\left.p=0.01\right)$ (Figure 6B). As observed in unstimulated conditions, UFH did not show a significant effect on TM antigen levels in LPS-treated HMEC-1. LPS significantly reduced TM levels in HUVEC at all incubation times evaluated. Dalteparin and UFH prevented the reduction in TM levels, with no 


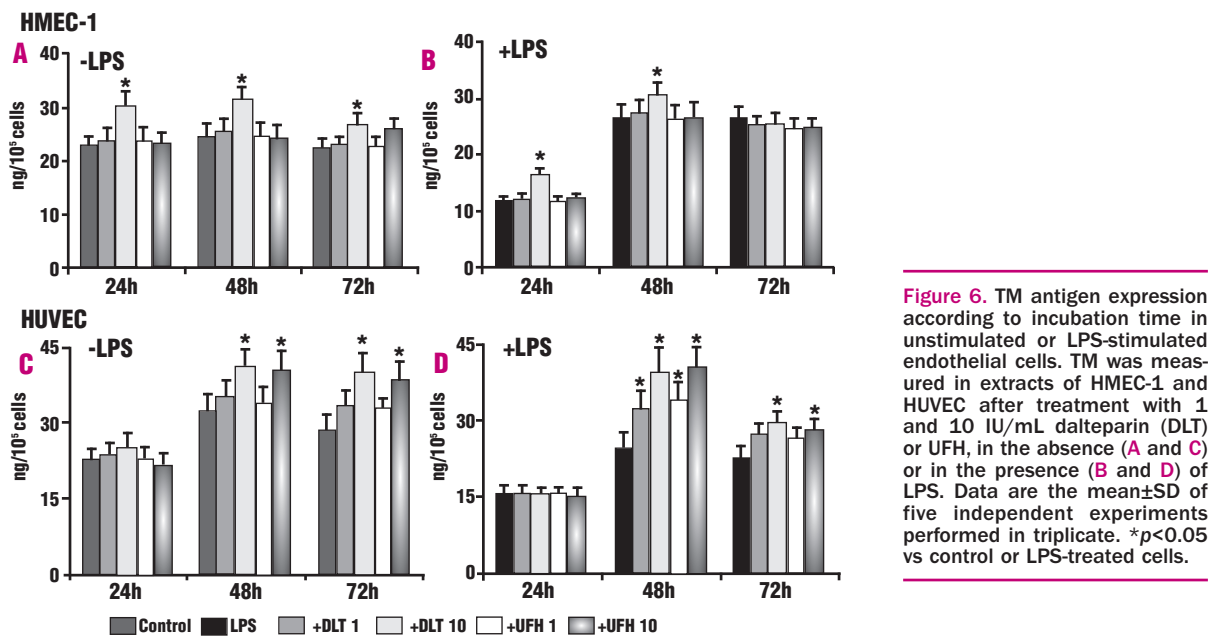

significant differences between the two agents, starting from 48-hour incubation (Figure 6D). At this time, the maximum effect was achieved with $10 \mathrm{IU} / \mathrm{mL}$ of dalteparin (control: $32.7 \pm 3 \mathrm{ng} / 10^{5}$ cells; LPS: $24.7 \pm 3.2 \mathrm{ng} / 10^{5}$ cells, dalteparin: $39.8 \pm 4.6 \mathrm{ng} / 10^{5}$ cells; $p=0.01$ vs LPS) or UFH (40.4 $\pm 3.8 \mathrm{ng} / 10^{5}$ cells; $p=0.009$ vs LPS).

\section{Discussion}

Heparins inhibit blood coagulation but also interfere with the physiological and pathological processes involved in inflammation and chronic diseases. ${ }^{2,17}$ The underlying mechanisms are likely to include an action of these agents on the prothrombotic and pro-angiogenic properties of the vascular endothelium. The present study is the first to evaluate the effect of heparins (the LMWH, dalteparin, and UFH) on the hemostatic properties of microvascular endothelial cells as compared to HUVEC. Our study indicates that both dalteparin and UFH have an antithrombotic effect on endothelial cells by suppressing inflammatory stimulus-mediated procoagulant TF expression and by enhancing anticoagulant TM expression and TFPI release. However, we found significant differences in responses to these two heparins between the two types of endothelial cells. With regard to TF modulation, we found that: (i) dalteparin and UFH inhibited LPS-induced TF activity and antigen in HMEC-1 to a greater extent than in HUVEC, (ii) in HMEC-1 dalteparin was more active than UFH, and (iii) in HUVEC the two heparins had comparable inhibitory activity. The differences between the two heparins on microvascular endothelial cell TF expression were observed after 4 hours of incubation but they did not persist after longer incubation (i.e. 24 hours). However, it should be noted that LPS-stimulated TF expression by HUVEC has been shown to be maximal after 4 to 8 hours of incubation, and it declines thereafter. ${ }^{22}$

Our data on HMEC-1 are consistent with these findings.
Our data show that dalteparin and UFH reduced TF activity and antigen levels, and also reduced TF mRNA levels in both endothelial cell types, suggesting that heparininduced inhibition of TF expression occurs, at least in part, at the transcriptional level. Heparin has been shown to inhibit cell proliferation by preventing the activation of the mitogen-activated protein kinase kinase-1 (MAPKK-1). ${ }^{23}$ Interestingly, MAPKK-1 activation in endothelial cells can be sensitive to LPS or cytokines, and is involved in the activation of the transcription factor complex NF- $\mathrm{KB}$. This transcriptional complex is implicated in TF gene transcription, ${ }^{24}$ and, as recently demonstrated, in TM repression by inflammatory cytokines. ${ }^{25}$

Previous studies have reported an inhibitory effect of heparins (both UFH and LMWH) on endothelial TF expression..$^{7-9}$ However, these studies were performed in different experimental conditions to those of the present study; different heparins were used and the experiments were conducted mainly in HUVEC. Cadroy et al. ${ }^{9}$ showed that UFH reduces LPS-induced TF activity in HUVEC. Another study in unstimulated HUVEC showed a reduction in cellular TF activity by UFH and the LMWH enoxaparin ${ }^{7}$ In that study, UFH produced significantly greater inhibition of TF activity than enoxaparin, although the heparins were only evaluated at one concentration (10 IU/mL). Interestingly, one study performed with the human endothelial cell line, EA.hy926, showed that dalteparin was more effective than UFH in reducing LPS-induced TF expression, and this is consistent with our observation in HMEC-1.

Our study also examined the effect of heparins on the antithrombotic properties of endothelial cells, in particular, on the expression of the two main inhibitors of blood coagulation expressed by the endothelium, TFPI and TM. TFPI is a potent inhibitor of the extrinsic coagulation pathway and is constitutively synthesized by the vascular endothelium. ${ }^{18}$ It acts by inhibiting the catalytic activity of factor Xa and of factor VIIa-TF complexes in the presence of factor $\mathrm{Xa}$. TFPI is released from the endothelium by heparins, a 
mechanism that contributes to the antithrombotic activity of this drug. ${ }^{19}$ In particular, heparins release the pool of TFPI bound to the negatively charged glycosaminoglycans located on the luminal surface of the endothelial cells. This heparin-releasable TFPI is mainly constituted by the free form, which possesses a higher anti-factor Xa inhibitory activity compared to the truncated forms, i.e. without the C-terminal region, which normally circulate in the blood. Our results show that dalteparin and UFH increase TFPI release into endothelial cell cultured media, both in HMEC1 and HUVEC. Similar effects have been described previously in HUVEC or other types of macrovascular endothelial cells, ${ }^{6,8,20,21}$ but this is the first time they have been observed in an endothelium of microvascular origin. This heparin effect on TFPI release is maximum at the dose of 1 $\mathrm{IU} / \mathrm{mL}$ and is associated with a reduction of the levels of this protein in cells, as we observed in HMEC-1 (in HUVEC, the study of cell-associated TFPI was not possible due to the low TFPI expression in cell extracts). In addition, we found that UFH was more effective than LMWH in this respect. Our study is the first to include an analysis of TFPI release in LPS-stimulated endothelial cells. In HMEC-1, both heparins were shown to further increase LPS-induced TFPI release. In contrast, LPS treatment did not affect TFPI release in HUVEC, a finding that is consistent with previous studies with this type of endothelial cell. ${ }^{26}$

Regarding the difference in the activity of heparins on TFPI release, in a study with HUVEC, ${ }^{20}$ dalteparin was found to be more effective than UFH in increasing TFPI release in endothelial cell cultured media. In contrast, in the endothelial cell line, EA.hy926, the release of TFPI was greater in the presence of UFH than in the presence of dalteparin. ${ }^{8}$ In addition, the TFPI increase in cultured media was accompanied by a concomitant reduction of cell-associated TFPI, and this is consistent with our findings. It has been suggested that the increase in TFPI release by heparins may also be due to enhanced transcriptional activity, as demonstrated by increased levels of TFPImRNA with heparin treatment. ${ }^{8,27}$ In addition to its antithrombotic activity, as a physiological inhibitor of the extrinsic pathway of coagulation, TFPI has biological functions as an anti-angiogenic and anti-inflammatory agent. Furthermore, TFPI has been shown to possess anti-proliferative and anti-migratory effects on cultured smooth muscle cells. ${ }^{28}$ Therefore, the release of TFPI by heparins likely mediates a role for these molecules in inflammation and atherosclerosis.

In the present study, we also demonstrated for the first time the effect of heparins on the other endothelial cellassociated coagulation inhibitor pathway, i.e. the expression of TM, a transmembrane protein expressed by vascular endothelial cells, which is a critical component of the anticoagulant protein $\mathrm{C}$ pathway. TM binds thrombin and alters its active site specificity to facilitate proteolytic activation of circulating protein $\mathrm{C}$. In concert with its cofactor protein $\mathrm{S}$, activated protein $\mathrm{C}$ enzymatically degrades factor Va and factor VIIIa of the clotting cascade, thereby suppressing further thrombin generation. ${ }^{29} \mathrm{TM}$ is downregulated in endothelial cells by various pro-inflammatory stimuli. ${ }^{16,30,31}$ Our results show that in HMEC-1, dalteparin upregulates TM expression and counteracts the LPS- induced suppression of TM expression, while UFH does not significantly affect the expression of this protein. In HUVEC, both LMWH and UFH stimulated the expression of the anticoagulant TM, and attenuated the LPS-induced suppression of TM. These data, therefore, add a novel function to the wide range of activities of heparins.

Our findings indicate that, at the level of the microvascular endothelium, dalteparin appears to exert a greater effect than UFH in the expression of an antithrombotic phenotype. On the other hand, UFH was more effective than dalteparin in increasing TFPI release in the cultured media of both endothelial cell types. In line with our results, other studies have reported that endothelial cells show different responses to UFH and LMWH..$^{6-8,20}$ One explanation for this difference may reflect differences in the chemical composition of individual heparins. Heparins are heterogeneous preparations derived from mammalian tissues, and contain polysaccharide chains of different lengths and molecular weights. UFH has a mean molecular weight of $12-15 \mathrm{kDa}$, with molecules ranging from 3 to $37 \mathrm{kDa}$ in weight. LMWH are derived from UFH by controlled enzymatic or chemical depolymerization, and have mean molecular weights ranging from 3 to $8 \mathrm{kDa}$. LMWH, therefore, have a much higher proportion of short chains than does UFH. This leads to an increased anti-Xa/anti-Ila activity ratio, a greater bioavailability, a lower effect on platelets, and a longer half life, compared with UFH.' It is possible that the different effects of heparins on endothelial cells observed in the present study might result from the different proportions of short and long polysaccharide chains within the two heparins. ${ }^{3,31}$ Based on this assumption, we suggest that the mechanisms involved in heparin-induced TFPI release might be more responsive to long polysaccharide chains, which are prevalent in UFH, whereas TF and TM modulation might be optimized by the short polysaccharide chains, which characterize dalteparin. However, little is known about the molecular mechanisms by which heparins modulate cellular pathways and this hypothesis would need further investigation. In conclusion, both dalteparin and UFH ameliorate a prothrombotic state in endothelial cells by suppressing inflammatory-mediated TF expression in microvascular and macrovascular endothelial cells, confirming that the vascular endothelium is an important site of action of heparins. Interestingly, dalteparin inhibited the induction of TF by LPS more effectively than did UFH, and increased TM expression, irrespective of the presence of LPS.

In contrast, no significant differences were observed between the two heparins on TF and TM expression in HUVEC. The findings that heparins inhibit the effects of LPS and directly stimulate TM and TFPI expression in microvascular endothelial cells are consistent with their observed anti-inflammatory effects.

All authors directly participated in the conception, design, experimental work, data analysis, article drafting, and critical revision, and approved the final version of the manuscript. This study was partially supported by a grant from the 'Italian Society for the Study of Hemostasis and Thrombosis' (SISET), Italy. The authors declare that they have no potential conflict of interest.

Manuscript received June 14, 2005. Accepted November 25 2005.

haematologica/the hematology journal | 2006; 91(2) | 213 | 


\section{References}

1. Hirsh J, Warkentin TE, Shaughnessy SG, Anand SS, Halperin JL, Raschke R, et al. Heparin and low-molecularweight heparin: mechanisms of action, pharmacokinetics, dosing, monitoring, efficacy, and safety. Chest 2001;119 Suppl 1:64S-94S

2. Zacharski LR, Ornstein DL. Heparin and cancer. Thromb Haemost 1998;80: 10-23.

3. Elsayed E, Becker RC. The impact of heparin compounds on cellular inflammatory responses: a construct for future investigation and pharmaceutical development. J Thromb Thrombocal development. J
lysis 2003; 15:11-8.

4. Cines DB, Pollak ES, Buck CA, Loscalzo J, Zimmerman GA, McEver RP, et al. Endothelial cells in physiology and in the pathophysiology of vascular and in the pathophysiology of vascu

5. Esmon CT. Inflammation and thrombosis. J Thromb Haemost 2003;1:13438.

6. Perez-Ruiz A, Montes R, Carrasco P, Rocha E. Effects of a low molecular weight heparin, bemiparin, and unfractionated heparin on hemostatic properties of endothelium. Clin Appl Thromb Hemost 2002;8:65-71.

7. Martinez-Sales V, Vila V, Reganon E, Oms JG, Aznar J. Effect of unfractionated heparin and a low molecular weight heparin (enoxaparin) on coagulant activity of cultured human endothelial cells. Haematologica 2003; 88:694-9.

8. Lupu C, Poulsen E, Roquefeuil S, Westmuckett AD, Kakkar VV, Lupu F. Cellular effects of heparin on the production and release of tissue factor pathway inhibitor in human endotheial cells in culture. Arterioscler Thromb Vasc Biol 1999; 19:2251-62.

9. Cadroy Y, Gaspin D, Dupouy D, Lormeau J'C, Boneu B, Sie P. Heparin reverses the procoagulant properties of stimulated endothelial cells. Thromb stimulated endothelial cell

10. Garlanda C, Dejana E. Heterogeneity of endothelial cells. Specific markers. Arterioscler Thromb Vasc Biol 1997; 17:1193-202

11. Ribeiro MJ, Phillips DJ, Benson JM, Evatt BL, Ades EW, Hooper WC. Hemostatic properties of the SV-40 transfected human microvascular endothelial cell line (HMEC-1). A representative in vitro model for microvascular endothelium. Thromb Res 1995 79:153-61.

12. Falanga A, Vignoli A, Marchetti M Barbui T. Defibrotide reduces procoagulant activity and increases fibrinolytic properties of endothelial cells. Leukemia 2003;17:1636-42.

13. Jaffe EA, Nachman RL, Becker CG, Minick CR. Culture of human endothelial cells derived from umbilical veins Identification by morphologic and immunologic criteria. J Clin Invest 1973; 52:2745-56

14. Falanga A, Marchetti M, Giovanelli S, Barbui T. All-trans-retinoic acid counteracts endothelial cell procoagulant activity induced by a human promyelocytic leukemia-derived cell line (NB4). Blood 1996;87:613-7.

15. Celi A, Pellegrini G, Lorenzet R, De Blasi A, Ready N, Furie BC, et al. Pselectin induces the expression of tis sue factor on monocytes. Proc Nat Acad Sci USA 1994; 91:8767-71.

16. Marchetti M, Vignoli A, Bani MR Balducci D, Barbui T, Falanga A. Alltrans retinoic acid modulates microvascular endothelial cell hemostatic properties. Haematologica 2003;88:895-905

17. Tyrrell DJ, Horne AP, Holme KR, Preus JM, Page CP. Heparin in inflammation potential therapeutic applications beyond anticoagulation. Adv Pharmacol 1999; 46:151-208.

18. Bajaj MS, Birktoft JJ, Steer SA, Bajaj SP Structure and biology of tissue factor pathway inhibitor. Thromb Haemost 2001. 86:959-72.

19. Sandset PM, Abildgaard U, Larsen ML. Heparin induces release of extrinsic coagulation pathway inhibitor (EPI) Thromb Res 1988:50:803-13.

20. Li Y, Rodriquez M, Spencer FA, Becker RC. Comparative effects of unfractionated heparin and low molecular weight heparin on vascular endothelial cell tissue factor pathway inhibitor release: a model for assessing intrinsic thromboresistance. J Thromb Thrombolysis 2002;14:123-9.

21. Westmuckett AD, Kakkar VV, Hamuro T, Lupu F, Lupu C. Bemiparin and fluid flow modulate the expression, activity and release of tissue factor pathway inhibitor in human endothelial cells in vitro. Thromb Haemost 2001;86:1547 54.

22. Crossman DC, Carr DP, Tuddenham
EG, Pearson JD, McVey JH. The regulation of tissue factor mRNA in human endothelial cells in response to endotoxin or phorbol ester. J Biol Chem 1990;265:9782-7.

23. Daum G, Hedin U, Wang Y, Wang T, Clowes AW. Diverse effects of heparin on mitogen-activated protein kinasedependent signal transduction in vascular smooth muscle cells. Circ Res 1997; 81:17-23.

24. Liu Y, Pelekanakis K, Woolkalis MJ. Thrombin and tumour necrosis factor alpha stimulate tissue factor expression in human endothelial cells: regulation through c-Fos and c-Jun. J Biol Chem 2004;279:36142-7.

25. Sohn RH, Deming CB, Johns DC, Champion HC, Bian C, Gardner K, et al. Regulation of endothelial thrombomodulin expression by inflammatory cytokines is mediated by activation of nuclear factor-k B. Blood 2005;105: 3910-7.

26. Ameri A, Kuppuswamy MN, Basu S, Bajaj SP. Expression of tissue factor pathway inhibitor by cultured endothelial cells in response to inflammatory mediators. Blood 1992;79:3219-26.

27. Hansen JB, Svensson B, Olsen R, Ezban M, Osterud B, Paulssen RH. Heparin induces synthesis and secretion of tissue factor pathway inhibitor from endothelial cells in vitro. Thromb Haemost 2000; 83:937-43.

28. Sato Y, Kataoka H, Asada Y, Marutsuka K, Kamikubo Y, Koono M, et al. Overexpression of tissue factor pathway inhibitor in aortic smooth muscle cells inhibits cell migration induced by tissue factor/factor VIIa complex. Thromb Res 1999;94:401-6

29. Bombeli T, Mueller M, Haeberli A. Anticoagulant properties of the vascular endothelium. Thromb Haemost 1997; 77:408-23.

30. Nan B, Lin P, Lumsden AB, Yao $Q$, Chen C. Effects of TNF- $\alpha$ and curcumin on the expression of thrombomodulin and endothelial protein $\mathrm{C}$ receptor in human endothelial cells. Thromb Res 2005; 115:417-26.

31. Khorana AA, Sahni A, Altland OD, Francis CW. Heparin inhibition of endothelial cell proliferation and organization is dependent on molecular weight. Arterioscler Thromb Vasc Biol 2003; 23:2110-5 


\section{PART THREE}

\section{Heparin Effects on Tumor Cell-Endothelial Cell Interactions}




\section{Chapter 5}

Heparins inhibit the endothelial prothrombotic features induced by tumor cells.

Vignoli A, Marchetti M, Falanga A. Heparins inhibit the endothelial prothrombotic features induced by tumor cells. Thrombosis Research

2017; 157:55-7. 
Letter to the Editors-in-Chief

\section{Heparins inhibit the endothelial pro-thrombotic features induced by tumor cells}

\section{Keywords:}

Heparin

Vascular endothelium

Tissue factor

Breast cancer

Acute promyelocytic leukemia

Tissue factor pathway inhibitor

\section{Introduction}

Patients with cancer are six times more likely to develop venous thrombotic events (VTE) compared to non-cancer subjects. In addition, cancer-associated thrombosis is linked with poor prognosis, and is the second leading cause of death in these patients [1].

The tumor cell capacity to interact with and activate the host hemostatic system plays an important role in the onset of the hypercoagulable state of cancer patients [2]. The production of procoagulant factors, fibrinolytic and antifibrinolytic proteins, pro-inflammatory and pro-angiogenic cytokines by tumor cells represents a group of cancer-specific pro-thrombotic mechanisms. In addition, the direct adhesion of tumor cells to host vascular cells promotes a vessel wall localized clotting activation and thrombus formation. In fact, tumor cells attached to endothelial cells (EC) release their cytokine content into a protected milieu that favors the pro-thrombotic and pro-angiogenic activities of EC. Along the same line, there is evidence that clotting activation supports cancer progression [2]. For example, tissue factor (TF) is also a signaling protein that regulates cancer cell migration, angiogenesis and metastasis [3]. This makes the inhibition of TF an important target for the design of new anti-tumor strategies.

Clinical evidences suggest that heparins, particularly low-molecularweight heparins (LMWH), may improve survival of cancer patients [4]. The biological mechanisms underlying this effect are still under investigation [5]. An important mechanism is attributed to the heparin actions at the vascular endothelium level, particularly the microvascular endothelium, importantly involved in numerous processes, including inflammation, leukocyte trafficking, wound healing, angiogenesis and tumor metastasis. We previously demonstrated that both LMWH and unfractionated heparin (UFH) are able to prevent the thrombogenic switch of EC induced by bacterial endotoxin stimulus [6], and to inhibit EC angiogenic activities triggered by tumor cells $[7,8]$. However, it is unknown whether heparins may interfere with EC prothrombotic features triggered by tumor cells. In this study we evaluate, in an 'in vitro' model, whether and to what extent two LMWHs and UFH affect the expression of TF and TFPI by EC challenged by tumor cells.

\section{Materials and methods}

Human microvascular endothelial (HMEC-1), human acute promyelocytic leukemia (NB4), and human breast cancer (MDA.MB231) cell lines were grown as described [7]. TCM were prepared as described [7]. TCM were assayed for the presence of VEGF, FGF-2, IL- $1 \beta$, TNF- $\alpha$ and IL- 8 by ELISA [7].

Confluent HMEC- 1 were incubated at $37{ }^{\circ} \mathrm{C}$ with TCM (f.c. $12.5 \%$ ) or $100 \mathrm{IU} / \mathrm{ml}$ standard IL- $1 \beta$, in the absence or presence of increasing concentrations (i.e. $0.01-0.1-1 \mathrm{IU} / \mathrm{ml}$ ) of $\mathrm{LMWH}$ (dalteparin sodium and enoxaparin sodium), or sodium UFH. Heparin concentrations were chosen on the basis of the therapeutic dose range. The TCM f.c. of $12.5 \%$ was selected after preliminary dose-response experiments showing that this dose is able to significantly induce TF expression without altering the integrity of EC monolayer, as previously experienced [7]. After $4 \mathrm{~h}$ of incubation, TF activity was measured by the one-stage recalcification assay of normal human plasma in EC lysates and TF antigen in EC extracts by ELISA, as described. TF activity was characterized by incubating EC samples with a purified polyclonal rabbit IgG antibody $(1 \mathrm{mg} / \mathrm{ml})$ directed against human TF before the clotting assay. A normal non-immune rabbit IgG was the control in this assay [6]. After $24 \mathrm{~h}$ incubation, TFPI antigen was measured in EC cultured media by ELISA [6]. The incubation times were selected based on time course experiments, showing that the expression of TF and TFPI antigens by EC stimulated with IL- $1 \beta$ up to $72 \mathrm{~h}$ was maximum after $4-6 \mathrm{~h}$ incubation for TF, and at $24 \mathrm{~h}$ incubation for TFPI. The integrity of the EC monolayer was microscopically verified at the end of each experiment. All experiments were done in triplicate, and each experiment was repeated $\geq 3$ times under independent conditions. Data were compared by one-way ANOVA analysis of variance for repeated measures and the Bonferroni's post-hoc test. p-Values $<0.05$ were considered significant. All statistical analyses were performed using SPSS ${ }^{\circ}$ statistical software.

\section{Results}

As shown in Fig. 1, at $4 \mathrm{~h}$ incubation with IL-1 $\beta$, EC TF activity significantly ( $p<0.01$ ) increased by $53 \%$ (Fig. 1 A) and TF antigen levels by $61 \%$ (Fig. 1B) as compared to unstimulated EC. Incubation of EC with heparins alone did not significantly affect TF expression (data not shown).

All heparins significantly counteracted the increase in EC TF activity elicited by IL-1 $\beta$ (Fig. 1A). At $1 \mathrm{IU} / \mathrm{ml}$, TF activity was $86 \%$ inhibited by dalteparin, $100 \%$ by enoxaparin, and $64 \%$ by UFH (all $\mathrm{p}<0.05$ ). Similarly, TF antigen was reduced by $72.5 \%$ with dalteparin, $100 \%$ with enoxaparin, and $70 \%$ with UFH; all $\mathrm{p}<0.05$ compared to IL- $1 \beta$ alone (Fig. 1B). Finally, IL-1 $\beta$ slightly increased EC TFPI antigen release, and this effect was significantly increased $(\mathrm{p}<0.01)$ by all heparins (Fig. $1 \mathrm{C})$.

The incubation of HMEC with TCM in the same experimental system also significantly increased TF levels as compared to control medium. Particularly, TF activity of HMEC- 1 was $16.3 \pm 3.4$ Units $/ 10^{5}$ cells in unstimulated conditions (control medium), and significantly increased 


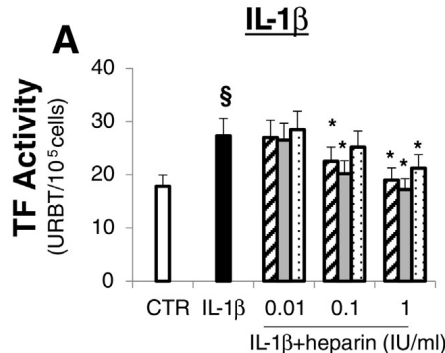

B
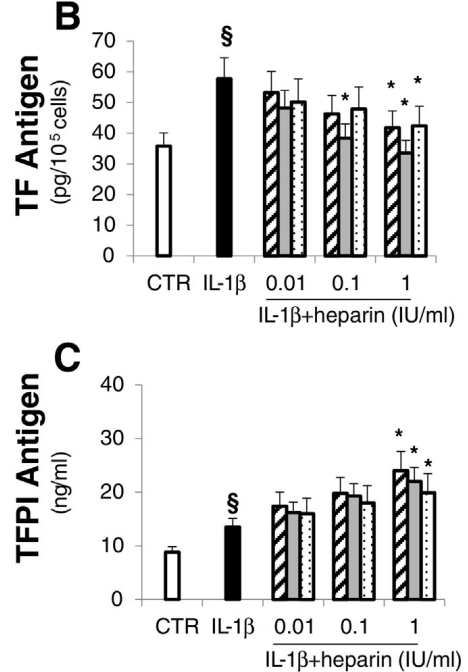

D

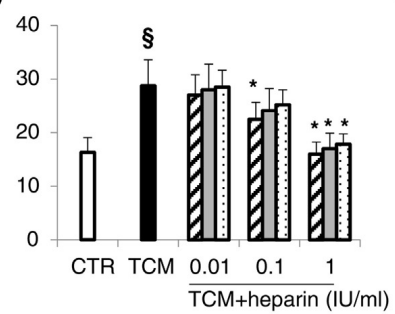

$\mathbf{E}$

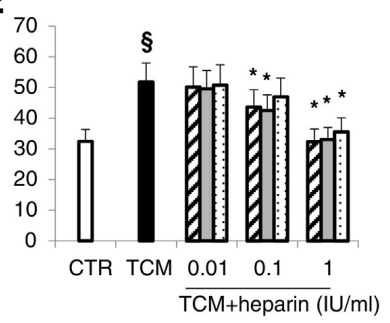

NB4 TCM

G

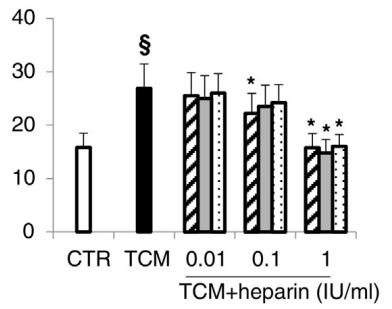

H

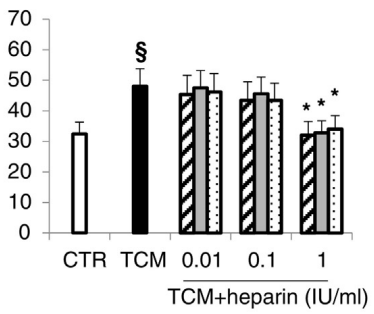

F

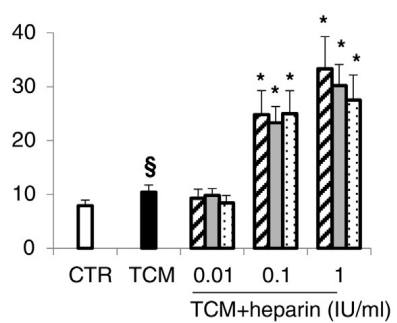

Fig. 1. Effect of heparins on the expression of TF (activity and antigen) and TFPI by HMEC-1 cells incubated with IL- $1 \beta$ or TCM. HMEC- 1 cells were incubated with IL-1 13 or TCM from breast cancer MDA.MB-231 and acute promyelocytic leukemia NB4 cells, in the absence or presence of increasing concentrations (0.01-0.1-1 IU/ml) of heparins (diagonal striped bars $=$ dalteparin, full grey bars = enoxaparin, dotted bars $=\mathrm{UFH}$ ). After $4 \mathrm{~h}$ incubation, TF activity was assayed in cell lysates, and TF antigen in cell extracts. After $24 \mathrm{~h}$ incubation, TFPl antigen was measured in EC supernatants. Data are mean \pm SD of 5 different experiments performed in triplicate. $\S=p<0.05$ vs control EC (CTR); ${ }^{*}=p<0.05$ vs IL- $1 \beta$ or TCM alone $\mathrm{TF}=$ tissue factor, TFPI = tissue factor pathway inhibitor, HMEC-1 = human microvascular endothelial cell line- 1 , IL- $1 \beta=$ interleukin- $1 \beta$, TCM $=$ tumor conditioned medium, $\mathrm{UFH}=$ unfractionated heparin, EC $=$ endothelial cells, URBT $=$ rabbit brain thromboplastin units.

to $28.7 \pm 4.5$ Units $/ 10^{5}$ cells and to $26.9 \pm 3.8$ Units $/ 10^{5}$ cells after exposure to TCM from MDA.MB-231 (Fig. 1D) and NB4 (Fig. 1G) cells, respectively. A concomitant increase in TF antigen levels paralleled the TF activity raise. MDA.MB-231 TCM increased TF antigen by $60 \%(51.8 \pm$ $6.3 \mathrm{pg} / 10^{5}$ cells, Fig. $\left.1 \mathrm{E}\right)$ and NB4 TCM by $48 \%\left(48.1 \pm 5.4 \mathrm{pg} / 10^{5}\right.$ cells, Fig. $1 \mathrm{H})$, compared to control HMEC-1 $\left(32.4 \pm 43 \mathrm{pg} / 10^{5}\right.$ cells; $\mathrm{p}<$ 0.05 ). All heparins dose-dependently counteracted the increase of EC TF expression elicited by TCM, both as activity (Fig. 1D and G) and antigen (Fig. $1 \mathrm{E}$ and $\mathrm{H}$ ), reaching a $100 \%$ inhibition at $1 \mathrm{IU} / \mathrm{ml}$.

Incubation of HMEC-1 with MDA.MB-231 TCM significantly increased TFPI levels in cultured media compared to control EC (28\% increment, $\mathrm{p}<0.05$; Fig. $1 \mathrm{~F}$ ). The addition of heparins to MDA.MB-231 TCM further increased TFPI release by EC, starting from the concentration of $0.1 \mathrm{IU} / \mathrm{ml}$ : at $1 \mathrm{IU} / \mathrm{ml}$, the increments observed towards TCM alone were $+232 \%$ with dalteparin, $+201 \%$ with enoxaparin, $+174 \%$ with UFH (all $\mathrm{p}<0.05$ vs TCM alone). Differently from MDA.MB.231 TCM, incubation of HMEC-1 with NB4 TCM significantly decreased TFPI release in culture medium $(2.26 \pm 0.31$ vs $7.81 \pm 1.14 \mathrm{ng} / \mathrm{ml}, \mathrm{p}<$ $0.05)$ (Fig. 1I). However, the addition of heparins to NB4 TCM significantly increased TFPI release by EC in a dose-dependent way. At $1 \mathrm{IU} / \mathrm{ml}$ heparin concentration, TFPI levels were above those of control cells. Heparins alone dose-dependently induced TFPI release by EC. At $1 \mathrm{IU} / \mathrm{ml}$ of heparins, TFPI was $20.8 \pm 2.8 \mathrm{ng} / \mathrm{ml}$ with DLT, $18.3 \pm$ $2.2 \mathrm{ng} / \mathrm{ml}$ with ENX, or $15.1 \pm 1.8 \mathrm{ng} / \mathrm{ml}$ with UFH.
The quantification of cytokines and growth factors in TCM showed VEGF as the most represented cytokine in both media (Table 1), with the greatest expression in MDA.MB-231 TCM. NB4 TCM contained the highest quantity of IL-8, while smaller amounts of IL-1 $\beta$, FGF-2 and TNF- $\alpha$ were detected in both TCM.

\section{Discussion}

In this study, we evaluated whether heparins may specifically counteract the procoagulant stimulus of tumor cells on EC. We employed the experimental system previously utilized to explore the anti-angiogenic activity exerted by heparins against tumor-derived angiogenic products $[7,8]$.

Table 1

Levels of cytokines and growth factors in TCM from MDA.MD.231 and NB4 cells. Data are mean \pm SD of measurements performed on at least 20 TCM collected in different dates for each cell line. ${ }^{*}=\mathrm{p}<0.05$ NB4 TCM vs MDA.MB-231 TCM.

\begin{tabular}{lll}
\hline & MDA.MB-231 TCM & NB4 TCM \\
\hline VEGF $(\mathrm{pg} / \mathrm{ml})$ & $1393 \pm 146$ & $641 \pm 65^{*}$ \\
FGF-2 $(\mathrm{pg} / \mathrm{ml})$ & $5.2 \pm 0.7$ & $10.1 \pm 1.3^{*}$ \\
IL-1 $(\mathrm{pg} / \mathrm{ml})$ & $35.2 \pm 4.6$ & $19.6 \pm 1.2^{*}$ \\
IL-8 $(\mathrm{pg} / \mathrm{ml})$ & $45.8 \pm 5.7$ & $62.2 \pm 9.2$ \\
TNF- $\alpha(\mathrm{pg} / \mathrm{ml})$ & $3.08 \pm 1.4$ & $20.1 \pm 2.7^{*}$ \\
\hline
\end{tabular}


First, we characterized the effect of heparins on EC on the expression of TF and release of TFPI elicited by the standard purified cytokine IL-1 $\beta$. This allowed us to study the activity of heparins in a calibrated condition. The results showed that the two LMWHs, as well as UFH, dosedependently inhibited the cytokine-induced TF expression by EC, both as activity and antigen. Thus, these findings confirm that these drugs possess an antithrombotic activity at the cellular level. This is in line with our previous finding demonstrating that the LMWH dalteparin and UFH inhibited the endothelium procoagulant profile elicited by bacterial endotoxin in both microvascular and macrovascular EC [6].

Next, we characterized the effects of breast and leukemia tumorderived product media on the EC procoagulant phenotype, and the capacity of LMWH and UFH to modulate this TCM procoagulant effect. The results show that TCM significantly induce TF expression by EC, similarly to what observed with standard IL-1 $\beta$. This observation provides support for the involvement of the vascular system not only in angiogenesis, but also in the onset of systemic hypercoagulability in malignancy.

In this setting, we found that heparins dose-dependently counteracted tumor cell-induced TF expression by EC and this occurred in a similar way with the three heparins, despite the different mean molecular weight. The downregulation of IL-1 $\beta$ - and TCM-induced TF activity and antigen levels by heparins probably occurs through a transcriptional mechanism, involving the inhibition of NF- $\kappa B$ activation, as described also for other endothelial inducible molecules $[6,9,10]$.

Another important finding is that the TF inhibition by heparin treatments was associated with a parallel increase in TFPI release by EC, as previously observed [6]. TFPI is an anticoagulant protein that inhibits early phases of the procoagulant response by abrogating the activity of the TF-FVIIa catalytic complex, and its reduction may further contribute to thrombosis [11]. It is well known that heparins are able to increase the release of TFPI by EC. For the first time here, we show that this effect is maintained also when EC are challenged by tumor products. Indeed, in this study, when heparins were used in combination with IL-1 $\beta$ and MDA.MB.231-TCM we observed a small additive effect, while, in combination with NB4-TCM we observed a prevention of TCM-induced TFPI reduction. This may represent another cell-specific antithrombotic mechanism of heparins in cancer. The characterization of the soluble mediators in TCM, revealed the presence of different cytokines and growth factors, including IL-1 $\beta$, VEGF, TNF- $\alpha$, and IL- 8 . All these molecules are known to be able to induce a procoagulant phenotype by EC.

To our knowledge, the present study demonstrates for the first time that heparins can act on the EC procoagulant properties elicited by tumor cells, particularly by inhibiting TF expression and stimulating TFPI release. This confers to heparins a specific cellular antithrombotic activity, a mechanism of great importance in cancer, where hypercoagulability is at least in part due to the stimulation of EC by tumor cells. Moreover, through these actions, heparins may interfere with cancer progression as well, since TF plays a role in favoring angiogenesis, while its specific inhibitor, TFPI, may counteract angiogenesis [2,12]. Taking into consideration that LMWH are able to inhibit also the proangiogenic activities of EC stimulated by tumor-derived products $[7,8]$, our data support the dual anti-thrombotic and anti-cancer activities of heparins observed in 'in vivo' studies [4], and highlight a role for these drugs in breaking the relationship between cancer and thrombosis.

\section{Conflicts of interest}

None.

\section{Acknowledgments}

This work has been partially supported by a grant of the Italian Association for Cancer Research (AIRC) (grant AIRC “5xMILLE” n. 12237).

\section{References}

[1] E. Donnellan, A.A. Khorana, Cancer and venous thromboembolic disease: a review, Oncologist 22 (2) (2017) 199-207.

[2] A. Falanga, M. Marchetti, A. Vignoli, Coagulation and cancer: biological and clinical aspects, J. Thromb. Haemost. 11 (2) (2013) 223-233.

[3] W. Ruf, N. Yokota, F. Schaffner, Tissue factor in cancer progression and angiogenesis, Thromb. Res. 125 (Suppl. 2) (2010) S36-S38.

[4] N. Zhang, W. Lou, F. Ji, L. Qiu, B.K. Tsang, W. Di, Low molecular weight heparin and cancer survival: clinical trials and experimental mechanisms, J. Cancer Res. Clin. Oncol. 142 (8) (2016) 1807-1816.

[5] A. Falanga, A. Vignoli, E. Diani, M. Marchetti, Comparative assessment of low-molecular-weight heparins in cancer from the perspective of patient outcomes and survival, Patient Relat. Outcome Meas. 2 (2011) 175-188.

[6] A. Vignoli, M. Marchetti, D. Balducci, T. Barbui, A. Falanga, Differential effect of the low-molecular-weight heparin, dalteparin, and unfractionated heparin on microvascular endothelial cell hemostatic properties, Haematologica 91 (2) (2006) 207-214.

[7] M. Marchetti, A. Vignoli, L. Russo, D. Balducci, M. Pagnoncelli, T. Barbui, A. Falanga, Endothelial capillary tube formation and cell proliferation induced by tumor cells are affected by low molecular weight heparins and unfractionated heparin, Thromb. Res. 121 (5) (2008) 637-645.

[8] A. Vignoli, M. Marchetti, L. Russo, E. Cantalino, E. Diani, G. Bonacina, A. Falanga, LMWH bemiparin and ULMWH RO-14 reduce the endothelial angiogenic features elicited by leukemia, lung cancer, or breast cancer cells, Cancer Investig. 29 (2) (2011) 153-161.

[9] X. Li, Z. Zheng, X. Li, X. Ma, Unfractionated heparin inhibits lipopolysaccharide-induced inflammatory response through blocking p38 MAPK and NF-kappaB activation on endothelial cell, Cytokine 60 (1) (2012) 114-121.

[10] Z.G. Luan, M. Naranpurev, X.C. Ma, Treatment of low molecular weight heparin inhibits systemic inflammation and prevents endotoxin-induced acute lung injury in rats, Inflammation 37 (3) (2014) 924-932.

[11] A. Dahm, A. Van Hylckama Vlieg, B. Bendz, F. Rosendaal, R.M. Bertina, P.M. Sandset, Low levels of tissue factor pathway inhibitor (TFPI) increase the risk of venous thrombosis, Blood 101 (11) (2003) 4387-4392.

[12] J. Wang, J. Xiao, D. Wen, X. Wu, Z. Mao, J. Zhang, D. Ma, Endothelial cell-anchored tissue factor pathway inhibitor regulates tumor metastasis to the lung in mice, Mol. Carcinog. 55 (5) (2016) 882-896.

Alfonso Vignoli

Marina Marchetti

Anna Falanga*

Department of Immunohematology and Transfusion Medicine, \& the Hemostasis and Thrombosis Center, ASST Papa Giovanni XXIII, Piazza O.M.S.

1, 24127 Bergamo, Italy

*Corresponding author.

E-mail address: annafalanga@yahoo.com.

19 April 2017

Available online 1 July 2017 


\section{Chapter 6}

Endothelial capillary tube formation and cell proliferation induced by tumor cells are affected by low molecular weight heparins and unfractionated heparin.

Marchetti M, Vignoli A, Russo L, Balducci D, Pagnoncelli M, Barbui T, Falanga A. Endothelial capillary tube formation and cell proliferation induced by tumor cells are affected by low molecular weight heparins and unfractionated heparin. Thrombosis Research 2008;121(5):637-45. 


\title{
Endothelial capillary tube formation and cell proliferation induced by tumor cells are affected by low molecular weight heparins and unfractionated heparin ${ }^{\text {is }}$
}

\author{
Marina Marchetti, Alfonso Vignoli, Laura Russo, Donatella Balducci, \\ Marcella Pagnoncelli, Tiziano Barbui, Anna Falanga*
}

Department of Hematology, Ospedali Riuniti di Bergamo, Largo Barozzi, 1-24128 Bergamo, Italy

Received 13 March 2007; received in revised form 5 June 2007; accepted 7 June 2007

Available online 10 August 2007

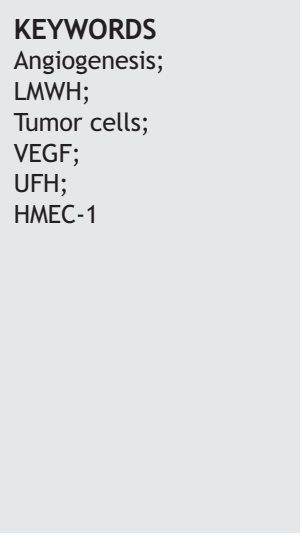

\begin{abstract}
Background: Clinical studies suggest a survival advantage in cancer patients receiving low molecular weight heparin (LMWH). A suggested mechanism for this beneficial effect may reside in the antiangiogenic activity of heparins.

Objectives: In this study we investigated whether two different LMWHs, i.e. enoxaparin and dalteparin, and unfractionated heparin (UFH), affect the angiogenic potential of human microvascular endothelial cells (HMEC-1) promoted by tumor cells.

Methods: HMEC-1 cells were incubated with tumor cell conditioned media (TCM) derived from human breast cancer and leukemic cells (i.e. MCF-7, MDA.MB.231, and NB4 cell lines) or recombinant cytokines (i.e. VEGF, FGF-2, TNF-alpha) \pm heparins. Capillary-like tube formation in Matrigel and cell proliferation were evaluated.

Results: All three TCM induced a significant $(p<0.05)$ increase in total length of tubes formed by HMEC-1 in Matrigel. These increases were significantly counteracted (62 to $100 \%$ mean inhibition) by enoxaparin and dalteparin, but were significantly less affected by UFH. Similarly, the tube formation induced by standard VEGF, FGF-2, or TNF-alpha was $100 \%$ inhibited by enoxaparin, and $70-90 \%$ by dalteparin, whereas minor or no inhibition
\end{abstract}

Abbreviations: EC, endothelial cells; ER-, estrogen receptor negative; ER+, estrogen receptor positive; FBS, fetal bovine serum; f.c., final concentration; FGF-2, fibroblast growth factor-2; HMEC-1, Human microvascular endothelial cells; HUVEC, human umbilical vein endothelial cells; kDa, KiloDalton; LMWH, Low molecular weight heparins; Mw, Molecular weight; O.D., optical density; SD, standard deviation; TCM, tumor cell conditioned medium; TF, Tissue Factor; TFPI, Tissue Factor Pathway Inhibitor; TNF-alpha, tumor necrosis factoralpha; UFH, unfractionated heparin; VEGF, vascular endothelial growth factor.

Research funding: Work supported by ISTH-Aventis Award 2001 to MM.

* Corresponding author. Tel.: +39035266 578; fax: +39035 266659.

E-mail address: annafalanga@yahoo.com (A. Falanga). 
was observed with UFH. VEGF was the most active cytokine in TCM of both breast cancer and leukemic cells. EC proliferation was significantly increased by standard angiogenic factors, and slightly affected by breast cancer TCM $(p=n s)$. The addition of heparins significantly counteracted the proliferative stimuli.

Conclusions: These results support a major role for LMWH compared to UFH in inhibiting the proangiogenic effect exerted by tumor cells or purified angiogenic factors on microvascular endothelium.

(c) 2007 Elsevier Ltd. All rights reserved.

\section{Introduction}

Low molecular weight heparins (LMWH) are glycosaminoglycans used in clinical practice for the prevention and treatment of venous thromboembolism [1]. They exert anticoagulant effects by accelerating the rate of inhibition of coagulation Factor $\mathrm{X}$ and thrombin by binding to antithrombin. In clinical studies of thrombosis, an advantage in survival was shown in patients with cancer receiving $\mathrm{LMWH}$, and these findings could not be explained solely by the prevention of venous thromboembolism [2]. Recently, the results of prospective randomized clinical trials specifically addressing the effect of LMWH on survival in patients with cancer, suggest a role for these drugs in cancer care, particularly in the early stages of the disease [3-6]. The possible mechanisms of LMWH interference with cancer biology are currently under investigation [7]. They may involve the inhibition of both coagulation-dependent and noncoagulation-dependent pathways of tumor progression [8-10]. Among the latter, an important role has been attributed to the action(s) of heparins on neoangiogenesis, i.e. the formation of new blood vessels from the host's existing vascular bed, which supports the expansion of a tumor and the formation of metastasis. The angiogenesis is a complex process constituted by multiple steps. It begins with the degradation of the basement membrane by proteases secreted by activated endothelial cells that will migrate and proliferate, leading to the formation of solid endothelial cell sprouts into the stromal space. Then, vascular loops are formed and capillary tubes develop with formation of tight junctions and deposition of new basement membrane.

It has been observed that heparins can inhibit capillary tube formation by human endothelial cells (EC) from the macrovascular bed (i.e. HUVEC) stimulated by standard proangiogenic factors [i.e. fibroblast growth factor-2 (FGF-2) and vascular endothelial growth factor (VEGF)], and that the heparin inhibitory capacity is dependent on the molecular weight of heparins used [11]. Furthermore, it has been shown that heparins can affect angiogenesis by modulating the binding of angiogenic growth factors to their cell receptors [12]. However, no studies have evaluated so far the interference of heparins on angiogenesis promoted by tumor cell derived products.

Therefore, in this study, we explored for the first time the effect of heparins on the interaction of tumor cells with human microvascular EC on two steps of angiogenesis: the EC proliferation and the capillary-tube formation by the matrigel assay, which evaluates the final differentiation of EC into capillary-like tubular structures.

We used EC of microvascular origin (i.e. HMEC-1) because: 1 . this is the EC type mainly involved in clinically relevant angiogenesis capillary sprouting in vivo $[13,14]$, and 2 . no in vitro studies have been performed so far to evaluate the effect of heparins on the angiogenesis of human microvascular EC in a matrigel-based assay. In our experimental system, the endothelial capillary formation was induced by two human breast cancer cell lines (i.e. MDA.MB-231 and MCF-7 cell lines), characterized by different expression of VEGF and metastatic potential in vivo, and by a human leukemic cell line (i.e. NB4) with well characterized procoagulant and proangiogenic properties [15-17]. Three heparins, largely utilized for the prevention and treatment of thrombosis in human subjects (including cancer patients), with different molecular weights and methods of preparation [i.e., two LMWH, dalteparin and enoxaparin, and an unfractionated heparin (UFH)] have been selected for the study.

\section{Materials and methods}

\section{Drugs}

Heparins used in this study were two LMWH, i.e. dalteparin sodium (Fragmin ${ }^{\circledR}$, gift of Pfizer, Rome, Italy; mean Mw $6.0 \mathrm{kDa}$ ) and enoxaparin sodium (Clexane $®$, gift of Aventis, Milan, Italy; mean MW $4.5 \mathrm{kDa}$ ), and a sodium unfractionated heparin ("UFH", Vister ${ }^{\circ}$, Parke-Davis, Lainate, Milan, Italy; mean Mw $15.0 \mathrm{kDa}$ ). The two LMWH are produced by the depolymerization of heparin derived from porcine mucosa. Particularly, dalteparin is prepared by benzylation and alkaline hydrolysis, and enoxaparin by nitrous acid depolymerization. The three heparins were in the form of their respective commercially available pharmaceutical products. The heparins were 
used at concentrations of $0.01,0.1$ and $1 \mathrm{lU} / \mathrm{ml}$, chosen on the basis of the therapeutic dose range utilized in clinics.

\section{Endothelial cell culture}

Human microvascular endothelial cells (HMEC-1) (kind gift from Dr. F.J. Candal, Centers for Disease Control and Prevention, Atlanta, GA, U.S.A.), were grown in RPMI1640 medium (Gibco, Gaithersburg, MD, U.S.A.) supplemented with $5 \%$ fetal bovine serum (FBS, Gibco), $2 \mathrm{mM}$ L-glutamine (Gibco), $10 \mathrm{ng} / \mathrm{ml}$ epidermal growth factor (ICN, Costa Mesa, CA, U.S.A.) and $1 \mu \mathrm{g} / \mathrm{ml}$ hydrocortisone (ICN), and maintained in a $5 \% \mathrm{CO}_{2} / 95 \%$ air atmosphere in a humidified incubator (Heraeus, Milan, Italy) at $37{ }^{\circ} \mathrm{C}$ [18]. Confluent monolayers of HMEC- 1 were passaged by trypsin/EDTA treatment $(0.25 \%$ trypsin-EDTA solution, Life Technologies, Inc., Rockville, MD, USA) at a 1:3 split ratio.

\section{Tumor cell culture and tumor cell conditioned medium (TCM) preparation}

Breast cancer conditioned media were obtained from two human cell lines, i.e. MDA.MB-231 and MCF-7, purchased from the American Type Culture Collection (ATCC; Manassas, VA, USA). MDA.MB-231 cells (ATCC cat. \#HTB-26), originally isolated from the pleura effusion of a 51-years female with adenocarcinoma [19], have a fibroblastic phenotype, are estrogen receptor negative (ER-), and are highly metastatic in vivo as established in mice [20].

MCF-7 cells (ATCC cat. \#HTB-22) have an epithelial phenotype, are ER positive $(E R+)$ and are low metastatic in vivo $[21,22]$.

Breast cancer cells were grown in Dulbecco's modified Eagle's medium (DMEM, Gibco) supplemented with 10\% FBS, 2 mM Lglutamine, $100 \mathrm{IU} / \mathrm{ml}$ penicillin, $100 \mu \mathrm{g} / \mathrm{ml}$ streptomycin and $1 \%$ non-essential amino acids (Gibco), in T75 flasks (Becton Dickinson, Mountain View, CA, USA), where they adhere to the plastic bottom forming a monolayer. At $100 \%$ confluence of cell monolayer, culture medium was removed, cells were washed three times with RPMI 1640 and incubated with $10 \mathrm{ml}$ serum-free RPMI1640 plus $2 \mathrm{mM} \mathrm{L-}$ glutamine. After $24 \mathrm{~h}$ incubation, TCM were collected, centrifuged for $10 \mathrm{~min}$ at $16,000 \times g$ to eliminate cell debris, then the supernatants were collected, $0.22 \mu \mathrm{m}$-filtered, and stored at $-40{ }^{\circ} \mathrm{C}$ until assayed.

Human promyelocytic leukemia NB4 cell line, established in vitro from an APL patient, was a kind gift from Dr. M. Lanotte (INSERM Unit 301, St Louis Hospital, Paris, France) and grown in suspension in RPMl1640 containing 10\% FBS, 2 mM L-glutamine, $100 \mathrm{IU} / \mathrm{ml}$ penicillin and $100 \mu \mathrm{g} / \mathrm{ml}$ streptomycin [15]. For the preparation of TCM, NB4 cells were collected, washed three times in RPMl1640, counted and resuspended at 500,000 cells $/ \mathrm{ml}$ in serumfree RPMI1640 plus $2 \mathrm{mM}$ L-glutamine. After $24 \mathrm{~h}$ incubation, the cells were sedimented by centrifugation ( $1500 \mathrm{~g}$ for $5 \mathrm{~min}$ ), and TCM collected and processed as described above for breast cancer cells.

Trypan blue exclusion dye test was used to determine HMEC-1 as well as tumor cells viability. Only cell cultures with more than $95 \%$ of viable cells were used for the subsequent experiments.

\section{Capillary-like tubule formation in Matrigel}

A Matrigel-based capillary-genesis assay was performed on HMEC-1 to assess the ability of these cells to form an organized tubular network [23]. The day before the experiment, confluent HMEC-1 were starved overnight at $37{ }^{\circ} \mathrm{C}$ with RPMI 1640 medium containing $1 \%$ FBS. Growth factor-reduced Matrigel ${ }^{\circledR}$ (Becton Dickinson) was thawed overnight at $4{ }^{\circ} \mathrm{C}$ on ice and, the day of the assay, plated on the bottom of 96 well-plates, and left at $37^{\circ} \mathrm{C}$ for $1 \mathrm{~h}$ for gelification. Starved HMEC- 1 were collected by enzymatic detachment $(0.25 \%$
trypsin-EDTA solution), counted and resuspended in RPMI1640 medium containing $0.5 \%$ FBS (f.c.). Then, 10,000 cell/well were seeded on Matrigel and incubated at $37^{\circ} \mathrm{C}$ and $5 \% \mathrm{CO}_{2}$ in a humidified atmosphere with TCM, or the following purified recombinant human angiogenic factors: $50 \mathrm{ng} / \mathrm{ml} \mathrm{VEGF}^{165}, 100 \mathrm{ng} / \mathrm{ml} \mathrm{FGF-2}$ and $100 \mathrm{ng} /$ $\mathrm{ml}$ TNF-alpha (R\&D Systems, Minneapolis, MN), in either the presence or in the absence of increasing doses of each heparin (i.e. $0.01-0.1-1 \mathrm{lU} / \mathrm{ml}$ ). Each treatment was performed in triplicate. After $24 \mathrm{~h}$ at $37{ }^{\circ} \mathrm{C}$ tubule formation was examined under an inverted light microscope (ZEISS, model 471202, Germany) at $100 \times$ magnification (objective lens numerical aperture $=0.22$ ). Digital images were obtained using a video camera system (Photosmart 318, Hewlett Packard) along with the microscope. Three images were randomly taken in different areas of the well, selecting those areas that were distinct and distant enough to not overlap each other, and then quantified by two observers blinded to treatment group. The total length of connected cells forming tubular structures on the matrigel surface was measured using the resulting images. Total tube length was determined by an image analysis software (Image J, National Institutes of Health, Bethesda, MD, USA). Results are expressed as $\mathrm{mm}$ tube length $/ \mathrm{cm}^{2}$ area. In some experiments, TCM were incubated for $2 \mathrm{~h}$ at $37^{\circ} \mathrm{C}$ prior to their use in the matrigel assay with the following neutralizing antibodies: polyclonal antihuman VEGF ${ }^{165}(2.5 \mu \mathrm{g} / \mathrm{ml}$, R\&D Systems), monoclonal antihuman TNF-alpha (4 ng/ml, R\&D Systems), and monoclonal antihuman FGF-2 (50 $\mu \mathrm{g} / \mathrm{ml}$, Upstate, Lake Placid, NY, USA). To optimize the antibody concentrations we conducted preliminary dose-response experiments with standard cytokines (data not shown). Capillary formation induced by standard angiogenic factors was completely inhibited by the respective neutralizing antibodies. Neutralizing antibodies alone did not affect endothelial cell tube formation (data not shown).

\section{EC proliferation}

EC proliferation was evaluated using the Crystal Violet staining method as described [24]. HMEC-1 were seeded in 96-well plates at the concentration of 10,000 cells/well. A calibration curve was prepared by seeding in duplicate the cells at the concentrations of $5,000,7,500,10,000,15,000$ and 20,000 cells/well: a series was utilized for Crystal Violet staining and the other for the trypan blue exclusion dye test. The cells were allowed to adhere and starved for $24 \mathrm{~h}$ in RPMl1640 medium at $1 \%$ FBS. The medium was then removed and HMEC- 1 were incubated with RPMI1640 medium (control cell wells and calibration curve wells) or TCM (12.5\% f.c. in RPMI 1640 medium+FBS $0.5 \%$ ), in the presence or absence of enoxaparin, dalteparin or UFH. After $24 \mathrm{~h}$ of incubation, the wells were washed three times with phosphate buffered saline (PBS; pH 7.4), and fixed with 3\% paraformaldehyde (Sigma) for $10 \mathrm{~min}$. Plates were washed three times with PBS, emptied and then allowed to dry by air. Then, $75 \mu$ l of Crystal Violet dye $\left(0.5 \%\right.$ in $\left.\mathrm{H}_{2} \mathrm{O}\right)$ was added to each well. After 5 min incubation, plates were rinsed extensively with PBS, and then $100 \mu \mathrm{l}$ of $0.1 \mathrm{M}$ sodium citrate in $50 \%$ ethanol was added. After crystal violet solubilization, the absorbance at $540 \mathrm{~nm}$ wavelength was read by a Multiskan Ascent reader (Titertek, Huntsville, AL, USA). The calibration curve was constructed by plotting the cell counts obtained by trypan blue exclusion dye test vs the correspondent optical densities (O.D.) obtained with the crystal violet assay.

\section{TCM cytokine quantification by ELISA}

TCM were assayed for the presence of the pro-angiogenic factors VEGF $^{165}$, FGF-2, and TNF-alpha by commercially available ELISA kits, i.e. human VEGF-A and human TNF-alpha ELISAs by BenderMedSystems (Vienna, Austria), and human FGF-2 ELISA by Chemicon 
International (Temecula, CA, USA). ELISAs were performed according to the respective manufacturers' instructions. Results are expressed as ng (TNF-alpha) or pg (VEGF and FGF-2) per $\mathrm{ml}$ of TCM, and represent the mean $\pm S D$ of 30 different TCM samples (i.e. collected in different days) for each tumor cell line.

\section{Statistical analysis}

The results are reported as mean $\pm S D$ of at least five independent experiments. Student's paired and unpaired $t$-test was used for the determination of significance levels between the different treatments. Differences were considered statistically significant when $p<0.05$.

\section{Results}

\section{TCM-induced formation of capillary-like tube structures in Matrigel}

HMEC -1 seeded on Matrigel invaded the underlying gel and formed capillary-like tube structures. In the presence of control medium alone, minor cell organization was observed and the mean overall length of tubular structures was $247 \pm 23 \mathrm{~mm} / \mathrm{cm}^{2}$.

To evaluate whether products released by tumor cells may also affect tube formation in this experimental system, TCM collected from human breast cancer cell lines, MCF-7 (ER+) and MDA.MB-231 (ER-), and from the NB4 promyelocytic leukemia cell line, were serially diluted with control medium (from 75 to $1.56 \%$ f.c.) and added to HMEC-1 seeded on matrigel. As shown in Fig. 1, TCM from the three cell lines induced a significant increase in HMEC-1 tube formation starting from $1.56 \%$ concentration and reached the maximum effect at $12.5 \%$ concentration of TCM; no further increase was observed with greater TCM concentrations. Particularly, the total length of the network formed after HMEC-1 incubation with $12.5 \%$ TCM was: $675 \pm 98 \mathrm{~mm} / \mathrm{cm}^{2}$ with MDA.MB.231, 502 $\pm 66 \mathrm{~mm} / \mathrm{cm}^{2}$ with MCF-7, and $708 \pm 89 \mathrm{~mm} / \mathrm{cm}^{2}$ with NB4, all $p<0.01$ compared with control medium $\left(238 \pm 28 \mathrm{~mm} / \mathrm{cm}^{2}\right)$. Similarly, a complex network developed in the presence of the pro-angiogenic factors: VEGF $\left(406 \pm 59 \mathrm{~mm} / \mathrm{cm}^{2}\right)$, FGF- $2(467 \pm$ $\left.61 \mathrm{~mm} / \mathrm{cm}^{2}\right)$, and TNF-alpha $\left(421 \pm 30 \mathrm{~mm} / \mathrm{cm}^{2}\right)$; all $p<0.01 \mathrm{vs}$ control medium.

\section{Heparins inhibit tube formation induced by TCM}

Subsequently, we studied the effect of heparins on TCM-induced capillary network formation. HMEC-1 were incubated for $24 \mathrm{~h}$ with control medium or TCM (12.5\% f.c.) in the presence of increasing concentrations of each heparin (i.e. $0.01,0.1,1 \mathrm{IU} / \mathrm{ml}$ ), then tube formation was evaluated. As shown in Fig. 2, the three heparins affected the capillary formation induced by either breast or leukemic cell TCMs to different extents. MDA.MB.231-TCM-induced capillary formation was dose-dependently inhibited by the three heparins (Fig. 2A). In particular, at the heparin concentration of $1 \mathrm{lU} / \mathrm{ml}$, the observed inhibitions (mean \pm SD) were: $35 \pm 6.3 \%$ by UFH $(p<0.01), 81 \pm 8.4 \%$ by enoxaparin $(p<0.01)$ and $75 \pm 8.8 \%$ by dalteparin $(p<0.01)$. At this concentration, the inhibitory effect of UFH was significantly $(p<0.05)$ lower than that of the two LMWH. Similarly, the MCF-7 TCM-induced tube formation was also dosedependently inhibited by heparins (Fig. 2B). In the range of drug concentrations between 0.01 and $1 \mathrm{IU} / \mathrm{ml}$, the inhibitory effect of UFH was significantly lower than that of both LMWH; specifically, at the heparin concentration of $1 \mathrm{IU} / \mathrm{ml}$, MCF-7 TCM induced-tube formation was $29 \pm 4.1 \%$ inhibited by UFH $(p<0.05), 62 \pm 7.2 \%$ by enoxaparin $(p<0.01)$ and $70 \pm 6.5 \%(p<0.01)$ by dalteparin. Finally, heparins counteracted in a dose-dependent manner tube formation induced by NB4 leukemic cell TCM (Fig. 2C). In this case, enoxaparin was the most effective drug, by completely preventing the proangiogenic stimulus at the $1 \mathrm{IU} / \mathrm{ml}$ concentration. At this dose, tube formation induced by NB4-TCM was $100 \%$ inhibited by enoxaparin $(p<0.01), 80 \pm 9.3 \%$ by dalteparin $(p<0.01)$ and 44 $\pm 5.6 \%$ by UFH $(p<0.01)$; a significant $(p<0.05)$ difference between the inhibition produced by either enoxaparin or dalteparin compared to UFH was also observed. Fig. 3 shows photographs of the capillary tube formation on matrigel from a representative experiment of heparin effects on TCM-induced capillary network formation.

\section{Heparins inhibit tube formation induced by standard angiogenic factors}

A series of experiments were performed to evaluate whether heparins may affect tube formation induced by standard human recombinant angiogenic factors. For this purpose, HMEC-1 were incubated for $24 \mathrm{~h}$ with VEGF, FGF-2 or TNF-alpha in either the presence or absence of each heparin (f.c. $1 \mathrm{IU} / \mathrm{ml}$ ).

As shown in Fig. 4, all the heparins significantly inhibited capillary tube formation induced by the three standard proangiogenic factors. However, the inhibitions achieved with the two LMWH were significantly higher than with UFH. Indeed, both enoxaparin and dalteparin $100 \%$ and $90 \pm 7.5 \%$ counteracted capillary tube formation induced by VEGF $(p<0.01), 100 \%$ and $70 \pm 8.2 \%$ by FGF- 2 $(p<0.01)$, and $100 \%$ and $75 \pm 7.4 \%$ by TNF-alpha $(p<0.01)$, respectively. Differently, UFH inhibited by $28 \pm 4.8 \%, 33 \pm$

$5.2 \%$ and $36 \pm 4.4 \%$ (all $p<0.05$ ) the capillary tube formation induced by VEGF, FGF-2 and TNF-alpha, respectively.

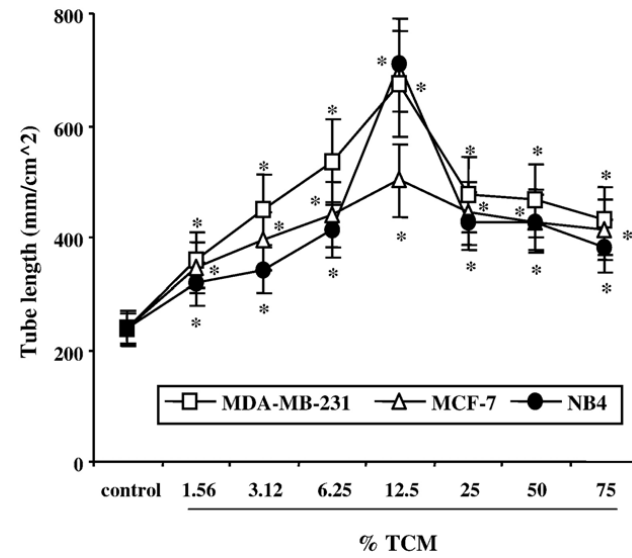

Figure 1 TCM induce HMEC-1 capillary-like tubule formation. HMEC-1 were exposed to increasing concentrations of TCM obtained from the two breast cancer cell lines (MDA.MB.231 and MCF-7) and from the leukemic NB4 cell line. After $24 \mathrm{~h}$ incubation, tube formation was quantified. For all three types of TCM, the maximum proangiogenic activity peaked at the $12.5 \%$ concentration. Data are reported as the mean \pm SD of 5 different experiments, each performed in duplicate. ${ }^{*}=p<0.05$ vs control. 


\section{Characterization of TCM growth factor content}

In order to identify the possible mediators of angiogenesis contained in breast cancer and leukemia cell TCM, quantitative assays (ELISA) for the main angiogenic factors, i.e. VEGF, FGF-2 and TNF-alpha, were performed. TCM from breast cancer cells contained significantly $(p<0.05)$ higher levels of VEGF (MDA.MB.231: $956 \pm 87 \mathrm{pg}$ / $\mathrm{ml}, \mathrm{MCF}-7: 647 \pm$

$70 \mathrm{pg} / \mathrm{ml})$ compared to NB4-TCM $(293 \pm 44 \mathrm{pg} / \mathrm{ml})$. All TCM were negative for the presence of FGF-2. No TNF-alpha was detected in breast cancer cell TCM, whereas a very small amount of this cytokine was found in NB4-TCM $(9.3 \pm 2.7 \mathrm{pg} / \mathrm{ml})$. Neutralizing antibody against VEGF was used in the matrigel assay to evaluate the relative proangiogenic role of this cytokine. The results show that the antiVEGF antibody significantly inhibited capillary-tube formation induced by TCM from MDA-MB.231 ( $98 \pm 10 \% ; p<0.01)$, MCF-7 (85 $\pm 14 \% ; p<0.01)$, and NB4 ( $80 \pm 18 \% ; p<0.01)$ (Fig. 5 ).

\section{HMEC-1 proliferation}

The effect of TCM and heparins on proliferation of HMEC-1 treated for $24 \mathrm{~h}$ with TCM (12.5\% f.c.) was explored. FGF-2, VEGF and TNFalpha were used as standard factors in this assay. The results (Fig. 6) show that after $24 \mathrm{~h}$ incubation, TCM from the two breast cancer cell lines produced a slight increase in HMEC-1 proliferation as compared with untreated cells $(8.5 \%$ and $9.2 \%$ increase for MDA-MB.231 and MCF-7, respectively; $p=n$.s. .). In contrast, the incubation of HMEC-1 with TCM from NB4 cells produced a slight decrease in EC proliferation compared to control (4.7\% decrease; $p=$ n.s.). The addition of heparins to TCM did not significantly affect cell proliferation.

After $24 \mathrm{~h}$ incubation HMEC-1 proliferation was $22 \%(p<0.05)$ increased by VEGF and $30 \%(p<0.05)$ by FGF-2 (Fig. 7$)$, while was unaffected by TNF-alpha (data not shown). All the three heparins significantly inhibited cell proliferation induced by VEGF and FGF-2 in a dose-dependent manner (Fig. 7), reaching a 100\% inhibition at the concentration of $1 \mathrm{lU} / \mathrm{ml}$ for all heparins. Similar results were obtained after $48 \mathrm{~h}$ incubation (data not shown).

\section{Discussion}

Angiogenesis, the formation of new vessels, has a major role in tumor growth, dissemination and metastasis in both solid and hematological tumors [25]. Angiogenesis is driven by microvascular EC, which upon activation by angiogenic growth factors degrade their basement membrane, migrate into the interstitial matrix, proliferate, and form new capillary-like structures [14]. The angiogenic switch in cancer is a highly complex event that involves several tumor-derived factors. Inhibition of angiogenesis is one of the proposed strategies to control cancer. Basic research and clinical data have shown anticancer effects of heparins, both UFH and LMWHs, suggesting a promising role for LMWHs in this setting $[7,26]$.

In the present study we evaluated whether heparins may affect the angiogenic properties of microvascular EC exposed to TCM. Two different LMWH, i.e. dalteparin and enoxaparin, and standard UFH were used. The two LMWH have been selected on the basis of their different molecular weight range
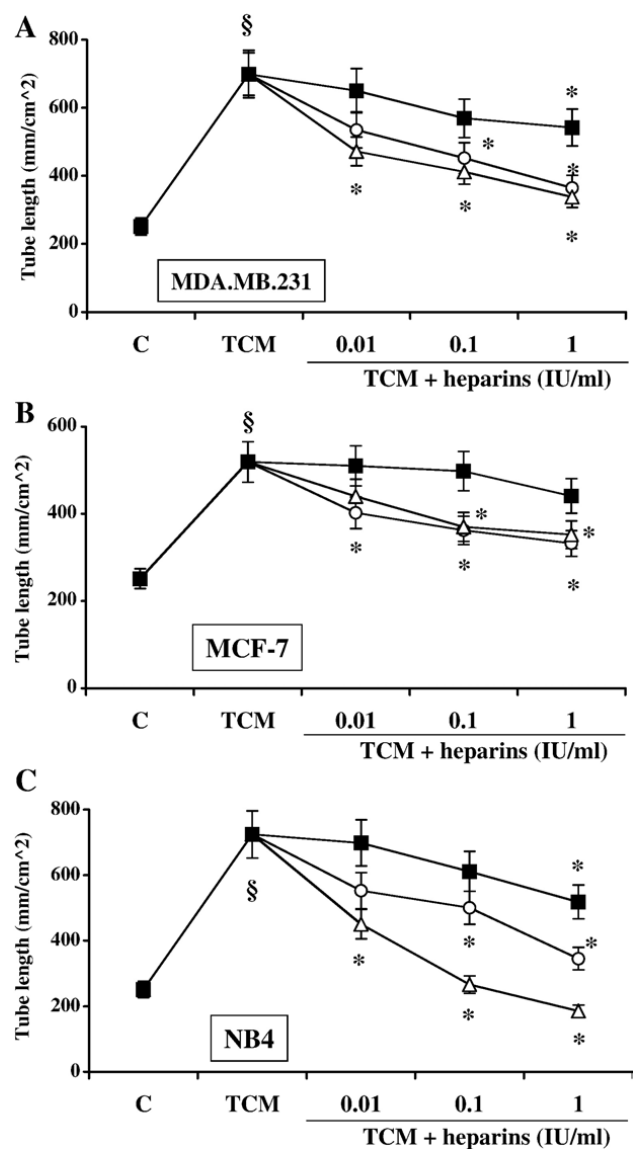

Figure 2 Heparins counteract HMEC-1 capillary-like tubule formation induced by TCM. HMEC-1 were incubated with TCM (f.c. $=12.5 \%$ ) obtained from MDA.MB.231 (panel A), MCF-7 (panel B), and NB4 (panel C) cell lines, in the absence or presence of increasing concentrations of heparins (Black square = UFH, Open triangle = Enoxaparin, Open circle = Dalteparin). After $24 \mathrm{~h}$ incubation, tube formation was quantified. Data are mean $\pm S D$ of 5 different experiments performed in duplicate. $\S=p<0.05$ vs control (C); ${ }^{*}=p<0.05$ vs TCM.

and type of preparations, as these characteristics are thought to affect their pharmacokinetic and biological properties [27]. In addition, these two LMWHs have been widely tested in clinical trials of thromboprophylaxis in patients with and without cancer and, recently, in clinical studies evaluating the effect on survival of patients with cancer [26].

Our results demonstrate that enoxaparin, dalteparin and UFH can inhibit microvascular EC capillarylike tube formation in matrigel when induced by 
human breast cancer and leukemia cells. The inhibition is dose-dependent and reaches a maximum effect with the concentration of $1 \mathrm{lU} / \mathrm{ml}$. In the interval of heparin concentrations between 0.1 and $1 \mathrm{IU} / \mathrm{ml}$, that is superimposable to the therapeutic dose range utilized in clinics, the two LMWH have superior inhibitory activity compared to UFH.

A number of tumor-derived products may be potential positive regulators of angiogenesis. Our results indicate an important role for VEGF in both breast cancer and leukemia cell-mediated capillary formation. Indeed, in our experimental conditions, a VEGF-neutralizing antibody mostly abrogated endothelial tube formation induced by the three TCM. Other proangiogenic factors may be released by tumor cells, i.e. FGF-2 and TNF-alpha, however, the screening of our TCM for these additional factors did not reveal significant amounts of these cytokines. In addition, neutralizing antibodies against these cyto- kines did not significantly inhibit TCM-induced angiogenesis. In the same tumor cell model of NB4, others have shown a major role for VEGF contained in the NB4 TCM in inducing the migration of HUVEC [17]. A role of this factor is confirmed also in our model, which is the first model studying the effect of NB4 cells on microvascular EC capillary-like tube formation.

It is noteworthy that the most potent tumorderived proangiogenic factors are heparin-binding proteins. We therefore explored the effect of heparins on angiogenesis induced by VEGF as well as by other standard proangiogenic factors, i.e.: FGF-2, and TNF-alpha. LMWH significantly inhibited capillary-like tube formation induced by these human recombinant factors, while a lower inhibitory effect was observed with UFH. Among the two LMWH, enoxaparin was more effective than dalteparin in inhibiting growth-factor induced capillary formation under these experimental conditions. Heparins, UFH

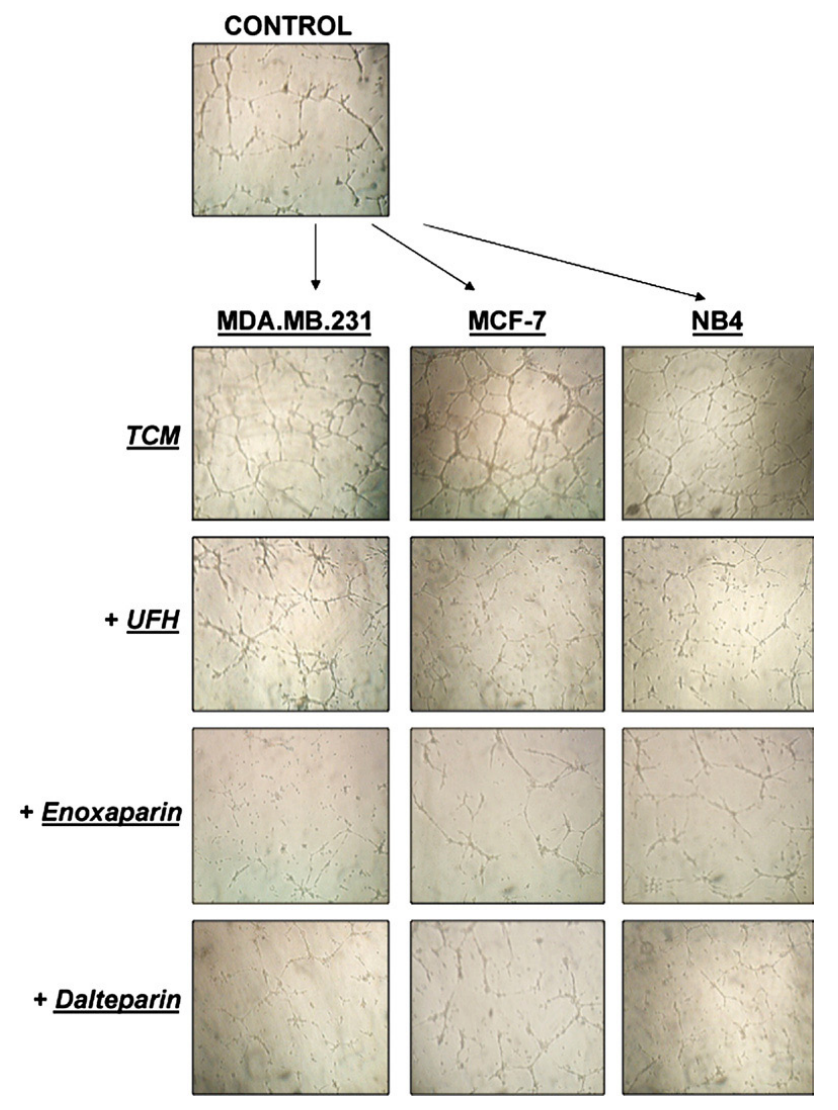

Figure 3 Pictures from a representative experiment showing that heparins affect HMEC-1 capillary-like tubule formation induced by the different TCM (f.c. $=12.5 \%$ ). The pictures (original magnification $=100 \times$ ) were squared and contrast $/$ brightness adjusted by the Adobe Photoshop 5.5 software. 


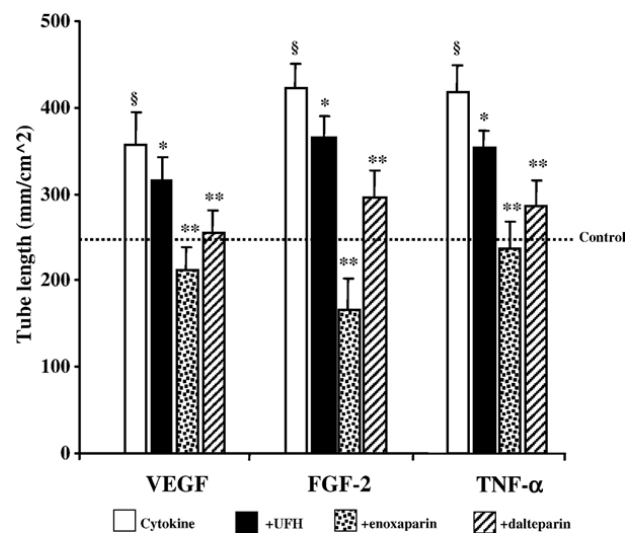

Figure 4 Heparins affect HMEC-1 tubule formation induced by standard proangiogenic factors. HMEC- 1 were incubated with the standard proangiogenic factors VEGF $(50 \mathrm{ng} / \mathrm{ml})$, FGF-2 $(100 \mathrm{ng} / \mathrm{ml})$, and TNF-alpha $(100 \mathrm{ng} / \mathrm{ml})$ in the absence or presence of $1 \mathrm{IU} / \mathrm{ml}$ heparins. After $24 \mathrm{~h}$ incubation, capillary like-tubule formation was quantified. Data are mean \pm SD of 5 different experiments performed in duplicate. $\S=p<0.05$ vs Control; ${ }^{*}=p<0.05$ vs No heparin.

and LMWH, are a heterogeneous mixture of glycosaminoglycan chains of different length and molecular weight. UFH has an average molecular weight of 13 to $15 \mathrm{kDa}$, whereas LMWHs are produced by UFH depolymerization and have a mean molecular weight between 3 and $6 \mathrm{kDa}$, depending on the manufacturing process. It has been demonstrated that heparin fragments with MWs of 4.8- to 5.4-kDa inhibit the in vitro binding of VEGF ${ }^{165}$ to its receptors on cultured

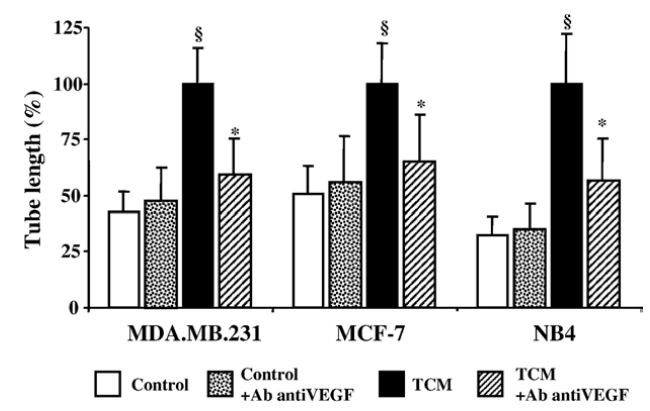

Figure 5 Neutralizing antibody against VEGF reduces HMEC-1 capillary-like tubule formation induced by TCM. TCM were preincubated for $2 \mathrm{~h}$ in the presence and absence of an antibody directed against VEGF (f.c. $=2.5 \mu \mathrm{g} / \mathrm{ml}$ ) at neutralizing concentration, and then used in the angiogenesis assay. After $24 \mathrm{~h}$ incubation, HMEC-1 capillary network was quantified. Data are mean $\pm S D$ of 5 different experiments, each performed in duplicate. $\S=p<0.05$ vs Control; ${ }^{*}=p<0.05$ vs TCM. bovine aortic arch EC, while fragments with MWs of more than $6.9 \mathrm{kDa}$ enhance the binding [28]. As a consequence of the lower mean molecular weight of the heparin fragments, it is possible that the LMWHs used in this study might prevent the binding of growth
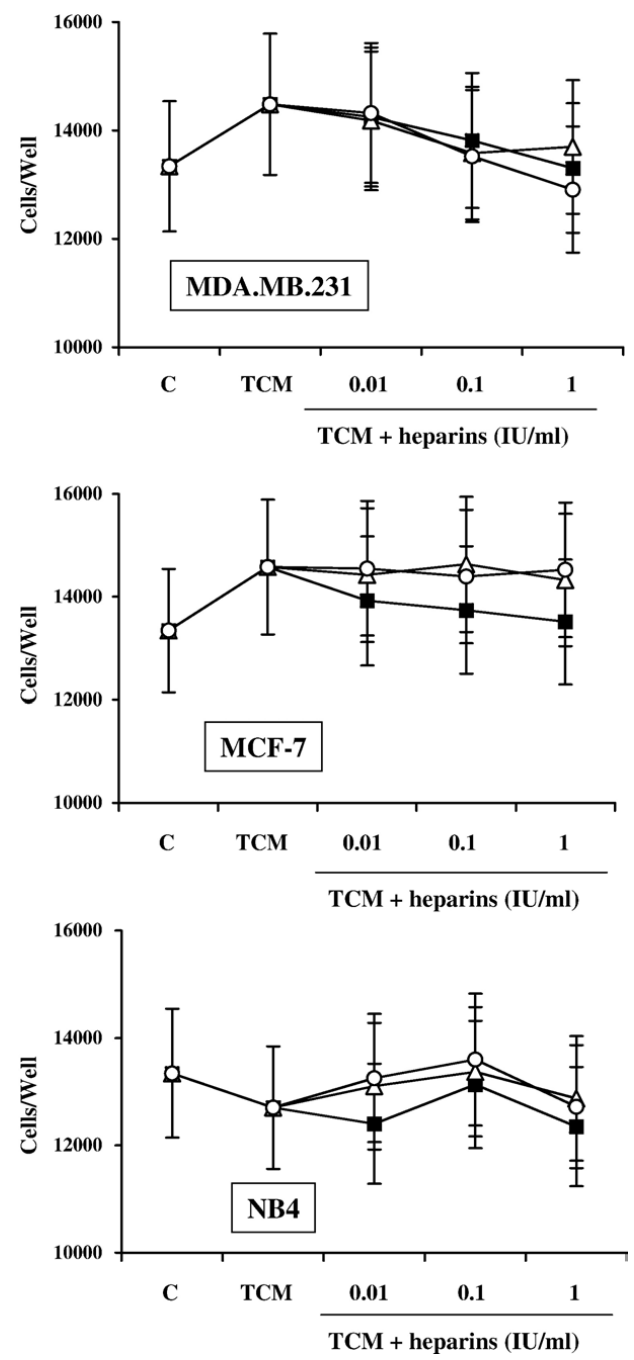

Figure 6 HMEC-1 proliferation in the presence of TCM heparins. HMEC-1 were exposed to the different TCM (f.c. = $12.5 \%$ ), in the presence and absence of heparins (Black square = UFH, Open triangle $=$ Enoxaparin, Open circle $=$ Dalteparin $)$, and after $24 \mathrm{~h}$ incubation cell proliferation was evaluated. No significant effect of TCM on HMEC-1 proliferation occurred. The addition of LMWHs or UFH did not induce significant modifications. The results are reported as mean \pm SD of 5 different experiments performed in triplicate. 
factors to their receptor on endothelial cells and thus inhibit their functions [12]. Based on these considerations, we can also hypothesize that the lower mean Mw of enoxaparin $(4.5 \mathrm{kDa})$ compared to dalteparin $(6.0 \mathrm{kDa})$ should be responsible for the major effect of enoxaparin over dalteparin in inhibiting capillary tube formation.

Our results are in line with those of other studies that have explored the effects of heparins on angiogenesis in different experimental in vivo and in vitro models. In an animal model of angiogenesis, it has been shown that FGF-2- and VEGF ${ }^{165}$-induced angiogenesis is more suppressed by a LMWH, or heparins enriched in $2.5 \mathrm{kDa}$ and $5.0 \mathrm{kDa}$ species, than by UFH and high-molecular-weight heparins
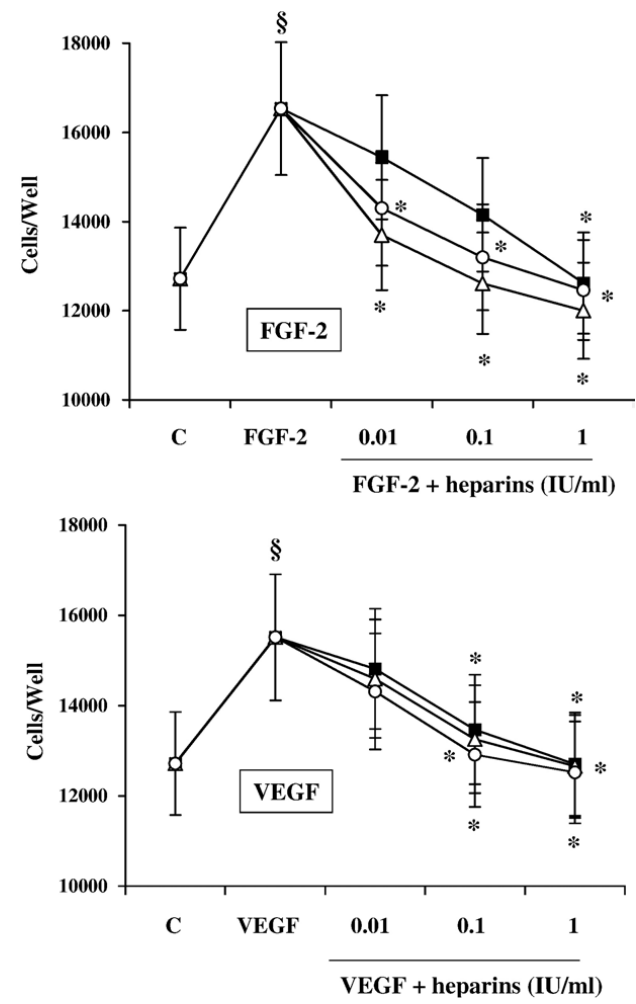

Figure 7 Heparins inhibit HMEC-1 proliferation induced by standard growth factors. Cell proliferation was evaluated in HMEC-1 exposed for $24 \mathrm{~h}$ to either FGF-2 $(100 \mathrm{ng} / \mathrm{ml})$ or VEGF $(50 \mathrm{ng} / \mathrm{ml})$ in the presence and absence of heparins (Black square $=U F H$, Open triangle $=$ Enoxaparin, Open circle $=$ Dalteparin). Both FGF-2 and VEGF significantly increased HMEC1 proliferation. The addition of LMWHs or UFH dose-dependently inhibited EC proliferation induced by either cytokine. The results are reported as mean \pm SD of 5 different experiments performed in triplicate.
$[29,30]$. Similarly, in the in vitro model of angiogenesis in HUVEC, LMWH in the range of 3-6 kDa significantly inhibited FGF-2- and VEGF-induced angiogenesis, whereas no inhibition was observed with UFH, tetrasaccharide, pentasaccharide and octasaccharide [11].

In our study we demonstrate that this occurs in the microvascular endothelial cell model, not only when EC are stimulated by standard proangiogenic factors, but also by tumor derived products. In these experimental conditions, a lower effect of UFH compared to $\mathrm{LMWH}$ in inhibiting angiogenesis is apparent.

The differential effect of LMWHs compared to UFH on angiogenesis has been observed also in studies of other EC activities. In a previous study we demonstrated that LMWH and UFH have different effects on the hemostatic properties of endothelial cells [31]. We could observe that LMWH (i.e. dalteparin) and UFH suppress LPS-mediated Tissue Factor (TF) expression and increase the anticoagulant properties of EC. In the microvascular setting (i.e. HMEC-1), dalteparin has a significantly greater effect than UFH in decreasing TF and increasing thrombomodulin and TF pathway inhibitor (TFPI) expression. We also observed that both UFH and LMWH reduced TF mRNA levels in HMEC1 [31]. As TF is involved in tumor angiogenesis through the regulation of VEGF expression [32], it could be hypothesized that heparins can interfere with the angiogenic process through TF downregulation as well.

In this work, we did not observe a significant effect of TCM on EC proliferation, indeed only TCM from breast cancer induced a very slight, statistically insignificant, increase of cell proliferation. Nor did we observe a significant effect of heparins on EC proliferation in the presence of TCM. Differently, the heparins significantly inhibited growth factor-induced proliferation. In this regard, our results are in agreement with those published by Collen et al. [33], who found a significant inhibition of FGF2- and VEGFinduced microvascular endothelial cell proliferation by UFH and by a commercial LMWH (i.e. reviparin), and with the data of Khorana et al. [11], who found a significant inhibition of FGF2-induced proliferation of HUVEC by both UFH and fractions of LMWH of 3 and $6 \mathrm{kDa}$.

Nevertheless, we must keep in mind that angiogenesis is a multi-step process. Indeed, endothelial cell proliferation and cell reorganization constitute two key moments for a successful formation of new vessels. The matrigel model of angiogenesis explores the capacity of cells to organize in tubular structure (i.e. migration and differentiation), and this event does not critically depend on endothelial proliferation. Therefore, we can hypothesize that the inhibitory activity of heparins against the proangiogenic stimulus of TCM is not mainly related to an inhibition of microvascular EC 
proliferation, but more likely to an intervention at the level of cell differentiation and reorganization induced by tumor cell derived products. Differently, the inhibition of EC proliferation and differentiation in tubule structures are both involved in the antiangiogenic activity of heparin against pure standard growth factor-induced angiogenesis.

In conclusion, we found that heparins can affect the angiogenic stimulus of tumor-derived products, as well as standard proangiogenic factors, and that LMWH are more effective than UFH in this process. The antiangiogenic activity of $\mathrm{LMWH}$, together with the known anticoagulant and antiinflammatory activities of these agents provides further basis for the beneficial clinical effects observed in the cancer setting.

\section{References}

[1] Hirsh J, Warkentin TE, Shaughnessy SG, Anand SS, Halperin JL, Raschke R, et al. Heparin and low-molecular-weight heparin: mechanisms of action, pharmacokinetics, dosing, monitoring, efficacy, and safety. Chest 2001;119(1 Suppl):64S-94S.

[2] Hettiarachchi RJ, Smorenburg SM, Ginsberg J, Levine M, Prins MH, Buller HR. Do heparins do more than just treat thrombosis? The influence of heparins on cancer spread. Thromb Haemost 1999;82:947-52.

[3] Kakkar AK, Levine MN, Kadziola Z, Lemoine NR, Low V, Patel $\mathrm{HK}$, et al. Low molecular weight heparin, therapy with dalteparin, and survival in advanced cancer: the fragmin advanced malignancy outcome study (FAMOUS). J Clin Oncol 2004;22:1944-8.

[4] Klerk CP, Smorenburg SM, Otten HM, Lensing AW, Prins MH, Piovella F, et al. The effect of low molecular weight heparin on survival in patients with advanced malignancy. J Clin Oncol 2005;23:2130-5.

[5] Lee AY, Rickles FR, Julian JA, Gent M, Baker RI, Bowden C, et al. Randomized comparison of low molecular weight heparin and coumarin derivatives on the survival of patients with cancer and venous thromboembolism. J Clin Oncol 2005;23: 2123-9.

[6] Altinbas M, Coskun HS, Er O, Eser B, Unal A, Cetin M, et al. A randomized clinical trial of combination chemotherapy with and without low molecular weight heparin in small cell lung cancer. J Thromb Haemost 2004; 2:1266-71.

[7] Zacharski LR, Ornstein DL. Heparin and cancer. Thromb Haemost 1998;80:10-23.

[8] Falanga A, Marchetti M, Vignoli A, Balducci D. Clotting mechanisms and cancer: implications in thrombus formation and tumor progression. Clin Adv Hematol Oncol 2003;1:673-8.

[9] Smorenburg SM, Van Noorden CJ. The complex effects of heparins on cancer progression and metastasis in experimental studies. Pharmacol Rev 2001;53:93-105.

[10] Prandoni P, Falanga A, Piccioli A. Cancer and venous thromboembolism. Lancet Oncol 2005;6:401-10.

[11] Khorana AA, Sahni A, Atland OG, Francis CW. Heparin inhibition of endothelial cell proliferation and organization is dependent on molecular weight. Arterioscler Thromb Vasc Biol 2003;23: 2110-5.

[12] Presta M, Leali D, Stabile H, Ronca R, Camozza M, Coco L, et al. Heparin derivatives as angiogenesis inhibitors. Curr Pharm Des 2003;9:553-66.

[13] Norrby K. Low-molecular-weight heparins and angiogenesis. APMIS 2006;114:79-102.
[14] Folkman J. Angiogenesis. Annu Rev Med 2006;57:1-18.

[15] Falanga A, Marchetti M, Giovanelli S, Barbui T. All-trans retinoic acid counteracts endothelial cell procoagulant activity induced by a human promyelocitic leukemia-derived cell line (NB4). Blood 1996;87:613-7.

[16] Falanga A, Consonni R, Marchetti M, Locatelli G, Garattini E, Passerini CG, et al. Cancer Procoagulant and Tissue Factor are differently modulated by all-trans-retinoic acid (ATRA) in acute promyelocytic leukemia cells. Blood 1998;92:143-51.

[17] Kini AR, Peterson LoAnn C, Tallman MS, Lingen MW. Angiogenesis in acute promyelocytic leukemia: induction by vascular endothelial growth factor and inhibition by all-trans retinoic acid. Blood 2001;97:3919-24.

[18] Marchetti M, Vignoli A, Bani MT, Balducci D, Barbui T, Falanga A. All-trans retinoic acid modulates microvascular endothelial cell hemostatic properties. Haematologica 2003;88:895-905.

[19] Cailleau R, Olive M, Cruciger QV. Long-term human breast carcinoma cell lines of metastatic origin: preliminary characterization. In Vitro 1978;14:911-5.

[20] Zhang RD, Fidler IJ, Price JE. Relative malignant potential of human breast carcinoma cell lines established from pleural effusions and a brain metastasis. Invasion Metastasis 1991;11: 204-15.

[21] Soule HD, Vazguez J, Long A, Albert S, Brennan M. A human cell line from a pleural effusion derived from a breast carcinoma. J Natl Cancer Inst 1973;51:1409-15.

[22] Shafie SM, Liotta LA. Formation of metastasis by human breast carcinoma cells (MCF-7) in nude mice. Cancer Lett 1980;11:81-7.

[23] Benelli R, Albini A. In vitro models of angiogenesis: the use of Matrigel. Int J Biol Markers 1999;14:243-6.

[24] Kueng K, Silfer E, Eppenberg V. Quantification of cells cultured on 96-well plates. Anal Biochem 1989;182:16-9.

[25] Carmeliet P, Jain RK. Angiogenesis in cancer and other diseases. Nature 2000;407:249-57.

[26] Falanga A, Piccioli A. Effect of anticoagulant drugs in cancer. Curr Opin Pulm Med 2005;11:403-7.

[27] Fareed J, Jeske W, Hoppensteadt D, Clarizio R, Walenga JM. Low molecular-weight heparins: pharmacologic profile and product differentiation. Am J Cardiol 1998;82:3L-10L.

[28] Soker S, Goldstaub D, Svahn CM, Vlodavsky I, Levi BZ, Neufeld $G$. Variations in the size and sulfation of heparin modulate the effect of heparin on the binding of VEGF165 to its receptors. Biochem Biophys Res Commun 1994;203:1339-47.

[29] Norrby K, Ostergaard P. Basic-fibroblast-growth-factormediated de novo angiogenesis is more effectively suppressed by low-molecular-weight than by high-molecularweight heparin. Int J Microcirc Clin Exp 1996;16:8-15.

[30] Norrby K. $2.5 \mathrm{kDa}$ and $5.0 \mathrm{kDa}$ heparin fragments specifically inhibit microvessel sprouting and network formation in VEGF165-mediated mammalian angiogenesis. Int J Exp Pathol 2000;81:191-8.

[31] Vignoli A, Marchetti M, Balducci D, Barbui T, Falanga A. Differential effect of the low-molecular-weight heparin, dalteparin, and unfractionated heparin on microvascular endothelial cell hemostatic properties. Haematologica 2006;91: 207-14 [Erratum in: Haematologica 2006;91:620].

[32] Abe K, Shoji M, Chen J, Bierhaus A, Danave I, Micko C, et al. Regulation of vascular endothelial growth factor production and angiogenesis by the cytoplasmic tail of tissue factor. Proc Natl Acad Sci U S A 1999;96:8663-8.

[33] Collen A, Smorenburg SM, Peters E, Lupu F, Koolwijk P, Van Noorden C, et al. Unfractionated and low molecular weight heparin affect fibrin structure and angiogenesis in vitro. Cancer Res 2000;60:6196-200. 


\section{Chapter 7}

LMWH Bemiparin and ULMWH RO14 reduce the endothelial angiogenic features elicited by leukemia, lung cancer, or breast cancer cells.

Vignoli A, Marchetti M, Russo L, Cantalino E, Diani E, Bonacina G, and Falanga A. LMWH bemiparin and ULMWH RO14 reduce the endothelial angiogenic features elicited by leukemia, lung cancer, or breast cancer cells. Cancer Investigation 2011; 29:153-61. 


\title{
LMWH Bemiparin and ULMWH RO-14 Reduce the Endothelial Angiogenic Features Elicited by Leukemia, Lung Cancer, or Breast Cancer Cells
}

\author{
Alfonso Vignoli, Marina Marchetti, Laura Russo, Elena Cantalino, Erika Diani, Gaia Bonacina, \\ and Anna Falanga
}

Division of Immunohematology and Transfusion Medicine, Department of Oncology-Hematology, Ospedali Riuniti di Bergamo, Bergamo, Italy

\begin{abstract}
Low-molecular-weight heparins (LMWH) are anticoagulant drugs that also possess antitumor properties. We evaluated whether "second generation" LMWH bemiparin and the Ultra-Low-MWH (ULMWH) RO-14 are able to inhibit in vitro the angiogenic response of microvascular endothelium stimulated by tumor-cell-conditioned media (TCM) from human leukemia, lung cancer, and breast cancer cells. Bemiparin and RO-14 dose dependently inhibited the increase of capillary-like tube formation (Matrigel-based assay) and endothelial migration (wound-healing assay) induced by TCM. Both drugs also inhibited angiogenic response elicited by purified VEGF and FGF-2. These findings support a possible role of these molecules as adjuvant drugs in cancer treatment.
\end{abstract}

Keywords: Heparins; LMWH; Angiogenesis; Endothelial cells; Cancer cells

\section{INTRODUCTION}

The association between cancer and thrombosis is well known since more than a century (1). It is a two-way association in that the presence of the tumor induces a hypercoagulable state in the host, predisposing the patient to thrombosis, while vice versa the activation of coagulation favors the tumor progression (1). It has been proposed that targeting this interaction may have a favorable impact on survival of cancer patients. In this respect, the heparin class of drugs has been intensely investigated. The glycosaminoglycan heparins are the most widely used parenteral anticoagulants in clinics for the prevention and treatment of thrombosis. They act by accelerating the rate of inhibition of blood coagulation factors X (FX) and II (FII) by antithrombin. Low-molecularweight heparins (LMWH) are largely utilized for thromboprophylaxis in oncological patients, who represent a population at high risk for both venous and arterial thrombosis (2). Interestingly, data from different randomized clinical trials suggest a beneficial effect of LMWH on survival in patients with several types of cancer (3). These effects are not completely explained by the prevention of thrombosis and have been attributed to a broad range of "nonanticoagulant" effects of heparins (4).

The first observation of a possible antineoplastic action of these drugs dates back to 1930 (5). Since then, a growing body of studies have demonstrated that heparins can affect the growth and metastasis of primary tumors, block the adhesion and migration of cancer cells, and affect tumor-induced neoangiogenesis $(4,6,7)$. The effects of heparins on angiogenesis have been actively investigated in both in vivo and in vitro systems (8). Some of these studies show that the size of heparins may influence their antiangiogenic properties (9). We recently demonstrated that two "first-generation" $\mathrm{LMWH}$, i.e., dalteparin and enoxaparin, with a mean $\mathrm{Mw}$ of 5.7 and $4.5 \mathrm{kDa}$, respectively, can prevent the formation of microvascular endothelial cell capillary-like tubes induced by breast cancer and leukemic-cell-conditioned media (10).

Recently, "second generation" LMWH have been made available. These new molecules are characterized by a lower mean molecular weight, a more precisely defined composition of polysaccharidic chains, a better anti-FXa/ anti-FIIa ratio, and possibly a better safety profile (i.e., reduced hemorrhagic risk). Bemiparin is one of these and has been recently evaluated in clinical trials of either thromboprophylaxis or adjuvant therapy in patients with cancer $(11,12$ ). RO-14 (mean $\mathrm{Mw} 2.2 \mathrm{kDa}$ ) is an ultralow MWH (ULMWH), obtained also by fractionation of heparin, that is currently in clinical developmental phase $(13,14)$.

In this study, we wanted to evaluate whether bemiparin $(11,12)$ and RO-14 may retain the antiangiogenic properties observed with first generation LMWH. Therefore, in an in vitro system of interaction of cancer cells with microvascular endothelial cells (HMEC-1), we investigated on the capacity of these molecules to inhibit the angiogenic features of the endothelium stimulated by leukemic, breast cancer, and small cell lung cancer cells, or by standard proangiogenic factors (i.e., VEGF and FGF-2). Particularly we evaluated whether bemiparin and/or RO-14 were able to prevent

Correspondence to: Anna Falanga, MD, Division of Immunohematology and Transfusion Medicine, Department of Oncology-Hematology, Ospedali Riuniti di Bergamo, Largo Barozzi 1, 24128 Bergamo, Italy. email: annafalanga@yahoo.com 
endothelial cell capillary-like tube formation, proliferation, and migration.

\section{MATERIALS AND METHODS}

\section{Drugs}

Heparins used in this study were the LMWH bemiparin sodium and the ULMWH RO-14 (both provided by Laboratorios Farmacéuticos ROVI, Madrid, Spain). Bemiparin and RO-14 are obtained from porcine mucosa through a depolymerization process called beta-elimination. Bemiparin has an average molecular mass of $3.6 \mathrm{kDa}$ (range: $3.0-4.2$ $\mathrm{kDa}$ ): typically, less than $35 \%$ of its oligosaccharides have a $\mathrm{Mw}<2.0 \mathrm{kDa}, 50 \%-75 \%$ of oligosaccharides have a $\mathrm{Mw}$ in the range $2.0-6.0 \mathrm{kDa}$, and less than $15 \%$ of oligosaccharides have a $\mathrm{Mw}>6.0 \mathrm{kDa}$. $\mathrm{RO}-14$ has an average molecular mass of $2.2 \mathrm{Da}$ (range: $1.8-3.0 \mathrm{kDa}$ ): $25 \%-45 \%$ of its oligosaccharides have a $\mathrm{Mw}<2.0 \mathrm{kDa}, 40 \%-75 \%$ of oligosaccharides have a $\mathrm{Mw}$ in the range $2.0-6.0 \mathrm{Da}$, and less than $15 \%$ of oligosaccharides have a $\mathrm{Mw}>6.0 \mathrm{kDa}$. Bemiparin was in the form of its respective commercially available preparation (25 [anti-Fxa] IU/mL), while RO-14 was provided to us as powder by the manufacturer, dissolved in sterile water at the concentration of $25 \mathrm{IU} / \mathrm{mL}$ and $0.22 \mu \mathrm{m}$ filtered. Both bemiparin and RO- 14 were previously analyzed by the manufacturer, according to the monograph of low-molecular-mass heparins of the European Pharmacopoeia (15), and, specifically, tests for bacterial endotoxins were performed in order to fulfill the criteria of less than $0.01 \mathrm{IU}$ per International Unit of anti-Xa activity.

For capillary-like tube formation and proliferation assays, bemiparin was utilized at the concentrations of $0.01,0.1$, and $1 \mathrm{IU} / \mathrm{mL}$, which cover the therapeutic dose range utilized in clinics, chosen on the basis of our previous work (10). For the wound-healing assay, it was utilized at the same concentrations plus also at the $10 \mathrm{IU} / \mathrm{mL}$ concentration. RO-14, for which the therapeutic plasma concentrations have not been established yet, was tested at the same concentrations as bemiparin.

\section{Human microvascular endothelial cell line-1 (HMEC-1) \\ HMEC-1 cells (kind gift from Dr. F.J. Candal, Centers for Dis- ease Control and Prevention, Atlanta, GA, USA) were grown in RPMI1640 medium (Gibco, Gaithersburg, MD, USA) sup- plemented with $5 \%$ fetal bovine serum (FBS, Gibco), 2 mM L- glutamine (Gibco), $10 \mathrm{ng} / \mathrm{mL}$ epidermal growth factor (ICN, Costa Mesa, CA, USA), and $1 \mu \mathrm{g} / \mathrm{mL}$ hydrocortisone (ICN) and maintained in a $5 \% \mathrm{CO}_{2} / 95 \%$ air atmosphere in a hu- midified incubator (Heraeus, Milan, Italy) at $37^{\circ} \mathrm{C}$. Conflu- ent monolayers of endothelial cells (EC) were passaged by trypsin/EDTA treatment $(0.25 \%$ trypsin-EDTA solution, Life Technologies, Inc., Rockville, MD, USA) at a 1:3 split ratio. \\ Tumor cell (TC) culture and TC-conditioned medium (TCM) preparation Human breast cancer cell line MDA.MB.231}

These cells (American Type Culture Collection, ATCCManassas, VA, USA, cat. no. HTB-26) have been originally isolated from the pleural effusion of a 51-year-old fe- male with adenocarcinoma (16), have a fibroblastic phenotype, are estrogen receptor negative (ER), and are highly metastatic in vivo as established in mice (17). MDA.MB.231 cells were grown in Dulbecco's modified Eagle's medium (DMEM, Gibco) supplemented with 10\% FBS, $2 \mathrm{mM} \mathrm{L-}$ glutamine, $100 \mathrm{IU} / \mathrm{mL}$ penicillin, $100 \mu \mathrm{g} / \mathrm{mL}$ streptomycin, and $1 \%$ nonessential aminoacids (Gibco), in T75 flasks (Becton Dickinson, Mountain View, USA), where they adhere to the plastic bottom forming a monolayer. At $100 \%$ confluence of cell monolayer, culture medium was removed, cells were washed three times with RPMI1640, and incubated with 10 $\mathrm{mL}$ serum-free RPMI1640 plus $2 \mathrm{mM}$ L-glutamine. After 24 $\mathrm{hr}$ incubation, TCM were collected, centrifuged for $10 \mathrm{~min}$ at $16,000 \mathrm{~g}$, then the supernatants were collected, $0.22 \mu \mathrm{m}$ filtered, and stored at $-40^{\circ} \mathrm{C}$ until assayed.

\section{Human small cell lung cancer (SCLC) cell line H69}

SCLC cell line H69 (ATCC, cat\# HTB-119) was grown in RPMI1640 medium supplemented with 10\% FBS in T75 flasks as a cell suspension (18). For TCM preparation, H69 cells have been collected from the flasks, centrifuged, and resuspended at 500,000 cells $/ \mathrm{mL}$ in serum-free RPMI1640. After $24 \mathrm{hr}$ incubation, cell suspensions have been centrifuged at $1,500 \mathrm{~g}$ for $5 \mathrm{~min}$, and the supernatants (i.e., TCM) collected, centrifuged again for $10 \mathrm{~min}$ at $16,000 \mathrm{~g}$ to remove residual cell debris, $0.22 \mu \mathrm{m}$-filtered, and stored frozen until assays.

\section{Human promyelocytic leukemia cell line NB4}

NB4 cell line, established in vitro from an APL patient, was a kind gift from Dr. M. Lanotte (INSERM Unit 301, St. Louis Hospital, Paris, France). This cell line was grown in suspension in RPMI1640 containing 10\% FBS, 2 mM L-glutamine, $100 \mathrm{IU} / \mathrm{mL}$ penicillin, and $100 \mu \mathrm{g} / \mathrm{mL}$ streptomycin (19). NB4 TCM has been prepared as for H69 cells.

Trypan blue exclusion dye test was used to determine HMEC-1 as well as cancer cells viability. Only cell cultures with more than $95 \%$ of viable cells were used for the subsequent experiments.

\section{Capillary-like tube formation in Matrigel}

A Matrigel-based capillary-genesis assay was performed on HMEC-1 to assess the ability of these cells to form an organized tubular network, as described (10). Briefly, confluent HMEC-1, starved overnight at $37^{\circ} \mathrm{C}$ with RPMI 1640 medium $+1 \%$ FBS, were collected by enzymatic detachment with trypsin-EDTA, counted, and resuspended in RPMI1640 medium $+0.5 \%$ FBS (f.c.). Then, 10,000 cells/well were seeded on growth-factor-reduced Matrigel (Becton Dickinson) and incubated at $37^{\circ} \mathrm{C}$ and $5 \% \mathrm{CO}_{2}$ in a humidified atmosphere with TCM, or the following purified recombinant human angiogenic factors: $50 \mathrm{ng} / \mathrm{mL} \mathrm{VEGF}^{165}$ or 100 $\mathrm{ng} / \mathrm{mL}$ FGF-2, in either the presence or in the absence of increasing doses (i.e., 0.01-0.1-1 IU/mL) of either bemiparin or RO-14. Each treatment was performed in triplicate. After 24 $\mathrm{hr}$ at $37^{\circ} \mathrm{C}$, tube formation was examined under an inverted 
light microscope (ZEISS, Oberkochen, Germany). Digital images were obtained using a video camera system along with the microscope. The total length of connected cells forming tubular structures on the Matrigel surface was measured, using the resulting images, by an image analysis software (Image J, National Institutes of Health, Bethesda, MD, USA). Results are expressed as $\mathrm{mm}$ tube length $/ \mathrm{cm}^{2}$ area. Preliminary experiments were conducted to assess the optimal TCM concentration. To this purpose, HMEC-1 were incubated with TCM at increasing concentrations (from $1.25 \%$ to $75 \%$, f.c.): $12.5 \%$ was the concentration at which all TCM induced the greatest tube formation (data not shown) and was then used for the subsequent experiments. In some experiments, TCM were incubated for $2 \mathrm{hr}$ at $37^{\circ} \mathrm{C}$, prior their use in the assay, with the polyclonal antihuman VEGF $^{165}$ neutralizing antibody (f.c. $2.5 \mu \mathrm{g} / \mathrm{mL}, \mathrm{R} \& D$ Systems, Minneapolis, MN, USA) (10).

\section{EC proliferation}

EC proliferation was evaluated using a colorimetric method as described (10). Briefly, HMEC-1 were plated at the concentration of 10,000 cells/well in 96-well plates. A calibration curve was also prepared by seeding HMEC-1 at increasing concentrations of cells per well. HMEC-1 were allowed to adhere and then starved for $24 \mathrm{hr}$ in RPMI1640 medium + $1 \%$ FBS. The medium was then removed, and HMEC-1 were incubated with RPMI1640 medium (control cell wells and calibration curve wells), TCM (f.c. $12.5 \%$ in RPMI 1640 medium $+0.5 \%$ FBS), or VEGF ${ }^{165}$ (f.c. $50 \mathrm{ng} / \mathrm{mL}$ ), in the presence or absence of bemiparin or RO-14 (0.01-0.1-1 $\mathrm{IU} / \mathrm{mL}$ ). After $24 \mathrm{hr}$ incubation, HMEC-1 were washed three times with PBS and fixed with $3 \%$ paraformaldehyde (SigmaAldrich, Milan, Italy) for $10 \mathrm{~min}$. Plates were washed three times with PBS, emptied, and allowed to dry by air. Then, $75 \mu \mathrm{L}$ of crystal violet dye $\left(0.5 \%\right.$ in $\left.\mathrm{H}_{2} \mathrm{O}\right)$ were added to each well. After $5 \mathrm{~min}$, crystal violet was solubilized with sodium citrate + ethanol solution and the absorbance read at $540 \mathrm{~nm}$ wavelength by a Multiskan Ascent reader (Titertek, Huntsville, AL, USA). The calibration curve was constructed by plotting the cell counts obtained by trypan blue exclusion dye test versus the correspondent optical densities (OD) obtained with the crystal violet assay.

\section{Wound-healing assay}

This test evaluates the combination of proliferating and migrating capacities of EC after an artificial wound. HMEC1 were grown to confluence at $37^{\circ} \mathrm{C}$ in a $5 \% \mathrm{CO}_{2}$ atmosphere in incubator. A hole in the monolayer was created in the center of each well by aspiration with a $10-\mu \mathrm{L}$ pipette tip. After three washes with RPMI1640, pretreatment images were taken using a LEICA DM IRB inverted microscope (Leica Microsystems GmbH, Wetzlar, Germany) at $5 \times$ magnification and an OPTIKAM PRO3 camera (M.A.D. Apparecchiature Scientifiche, Ponteranica, Italy). The medium was then removed and HMEC-1 were incubated with TCM, or $50 \mathrm{ng} / \mathrm{mL} \mathrm{VEGF}{ }^{165}$, in the presence or absence of bemiparin or RO-14 (f.c. $0.01-0.1-1-10 \mathrm{IU} / \mathrm{mL}$ for both), or with RPMI1640 medium (control cells). After $20 \mathrm{hr}$ incubation at $37^{\circ} \mathrm{C}$, posttreatment images were taken. For each well pretreatment and posttreatment images were compared, and the area occupied by migrating/proliferating cells (regrowth area) was calculated using the Image $1.42 \mathrm{q}$ software $(\mathrm{Na}$ tional Institutes of Health, Bethesda, MD, USA). Results are expressed as percentage of regrowth area, assuming the area occupied by control cells as $100 \%$ of regrowth.

Preliminary experiments were conducted to assess the optimal TCM concentration. To this purpose, HMEC-1 were incubated with TCM at increasing concentrations (from $1.25 \%$ to $75 \%$, f.c.). The most effective final concentrations of TCM were 25\% for both MDA.MB.231 and NB4 and 30\% for H69 (data not shown). These TCM concentrations were used in the subsequent experiments.

\section{TCM cytokine quantification by ELISA}

TCM were assayed for the presence of the proangiogenic factors VEGF ${ }^{165}$, FGF-2, and IL-1beta by commercially available ELISA kits (VEGF-A and IL-1beta ELISA, Bender MedSystems, Vienna, Austria; FGF-2 ELISA, Chemicon International, Temecula, CA, USA). ELISAs were performed according to the respective manufacturers' instructions. Results are expressed as pg of cytokine per $\mathrm{mL}$ of TCM and represent the mean $\pm S E$ of 30 different TCM samples (i.e., collected in different dates) for each tumor cell line.

\section{Statistical analysis}

Student's paired and unpaired $t$-test was used for the determination of significance levels between the different treatments. Differences were considered statistically significant when $p<.05$.

\section{RESULTS}

\section{Bemiparin and RO-14 counteract EC tube formation elicited by TCM}

The three different TCM induced a significant increase of EC capillary-like tube formation in Matrigel as compared to control medium (C). NB4 CM was the most effective in inducing network formation $(61.2 \% \pm 6.9 \%$ mean increase vs. C; $p<.01)$, followed by MDA.MB.231 CM $(50.6 \% \pm 5.9 \%$ mean increase; $p<.01$ vs. C), and H69 CM (43.5\% $\pm 4.8 \%$ mean increase; $p<.01$ vs. C).

The tube formation induced by MDA.MB.231, H69, and NB4 CM was dose dependently prevented by both bemiparin and RO-14. At the highest dose of heparins utilized, i.e., 1 $\mathrm{IU} / \mathrm{mL}$, both bemiparin and RO- 14 inhibited by $100 \%$ the increase of capillary tube formation induced by either $\mathrm{H} 69$ or MDA.MB.231 CM, while the mean inhibition observed for NB4 CM was $86.5 \% \pm 9.4 \%$ with bemiparin and $100 \%$ with RO-14 (Figure 1). No statistically significant differences were observed for any of the TCM utilized, between the effects of bemiparin and RO-14, at any concentration. Figure 2 shows representative pictures from selected experiments. 
Table 1. Levels of Proangiogenic Factors in TCM

\begin{tabular}{lccc}
\hline & H69 & MDA.MB.231 & NB4 \\
\hline VEGF $(\mathrm{pg} / \mathrm{mL})$ & $332 \pm 54$ & $1293 \pm 133$ & $543 \pm 72$ \\
FGF-2 $(\mathrm{pg} / \mathrm{mL})$ & $13.7 \pm 2.4$ & $4.3 \pm 0.8$ & $8.1 \pm 1.1$ \\
IL-1beta $(\mathrm{pg} / \mathrm{mL})$ & $63.7 \pm 8.3$ & $22.2 \pm 3.1$ & $8.7 \pm 1.5$ \\
\hline
\end{tabular}

Note: Data are expressed as mean \pm SE of ELISA assays performed on 30 TCM collected in different dates for each cell line.

\section{VEGF is the most represented proangiogenic factor in all TCM}

The levels of proangiogenic factors were measured in the TCM by ELISA. The results show that VEGF is the main cytokine contained in all three TCM, with the greatest amount found in the MDA.MB.231 CM (Table 1). Much lower amounts of FGF-2 and IL-1beta are present.

Since VEGF is the most represented proangiogenic factor in all TCM, we wanted to explore the role of this cytokine in TCM-induced tube formation. To this purpose, all TCM were preincubated with a neutralizing antibody against VEGF and then used in the Matrigel-based assay. The results show that the preincubation of TCM with anti-VEGF antibody abolished by $96.6 \% \pm 10.4 \%, 94.7 \% \pm 8.7 \%$, and $53.4 \% \pm 6.1 \%$ the capillary tube formation induced by MDA.MB.231, NB4, or H69, respectively (all $p<.05$ vs. control).

\section{Bemiparin and RO-14 counteract EC tube formation induced by VEGF and FGF-2}

We evaluated the capacity of bemiparin and RO-14 to inhibit the effect of purified proangiogenic cytokines. The results (Figure 3) show that bemiparin and RO-14 prevented, in a dose-dependent manner, EC tube formation induced by either VEGF (left panel) or FGF-2 (right panel). At the dose of $1 \mathrm{IU} / \mathrm{mL}$, bemiparin and RO-14 determined a significant $(p<.05)$ reduction of standard VEGF-induced tube formation of $78 \% \pm 8.5 \%$ and $74.7 \% \pm 6.6 \%$, respectively. Similar results were obtained in FGF-2-stimulated condition with a $86.8 \% \pm 9.7 \%$ and $79.2 \% \pm 8.8 \%$ reduction with bemiparin and RO-14, respectively ( $p<.05$ for both vs. FGF2 alone). No statistically significant differences between bemiparin and RO-14 were observed.
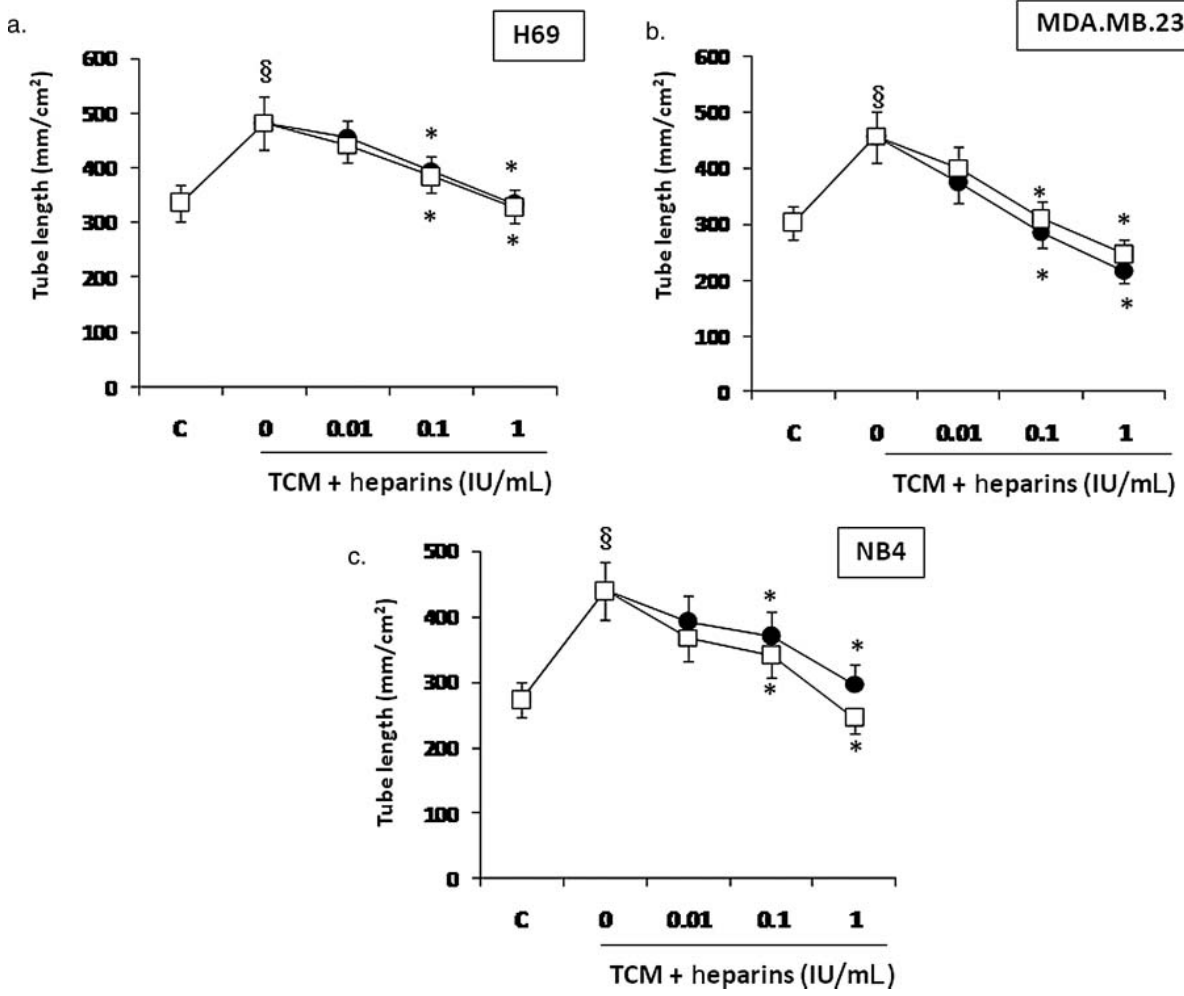

Figure 1. Bemiparin and RO-14 counteract HMEC-1 capillary-like tube formation induced by TCM. EC were incubated with each TCM (f.c. = $12.5 \%$ ) from H69, MDA.MB.231, and NB4 cells, in the presence or absence of increasing concentrations of heparins (bemiparin = full circle, RO-14 $=$ open square), for $24 \mathrm{hr}$, and then tube length evaluated. Both heparins completely inhibited the increase of tube formation induced by all TCM. Data are mean $+S D$ of 5 experiments performed in duplicate. ${ }^{*} p<.05$ vs. TCM; $p<.05$ vs. control medium (C) 


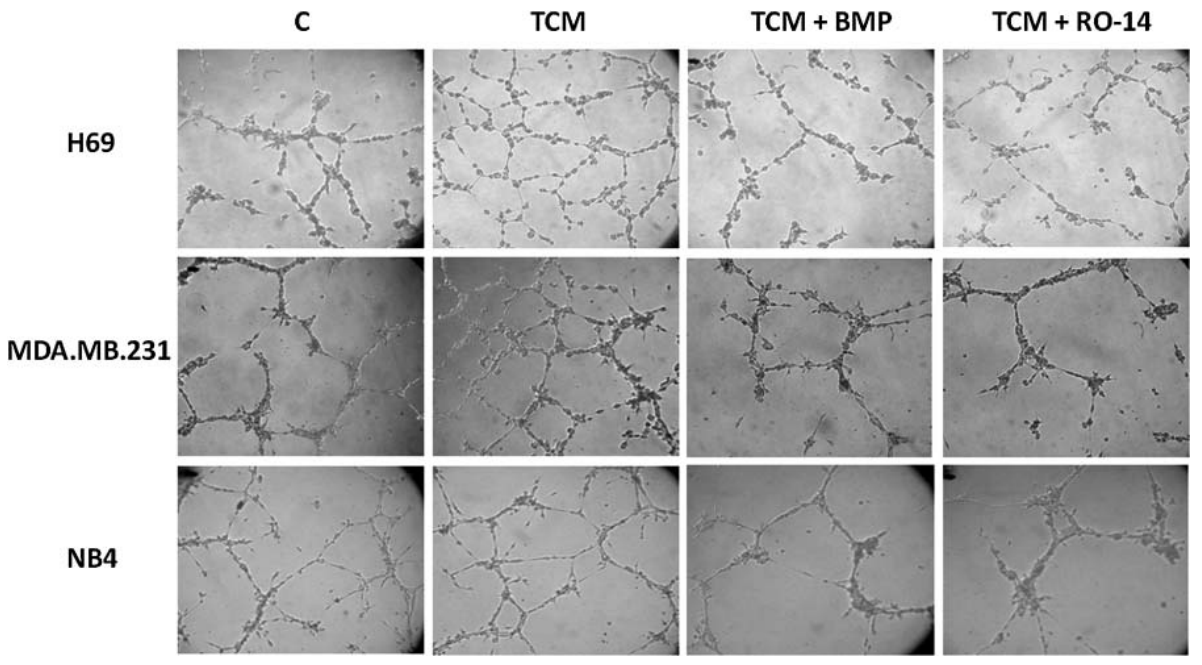

Figure 2. Representative pictures of selected experiments showing the inhibition of TCM-induced HMEC-1 capillary-like tube formation by bemiparin (BMP) and RO-14. EC were incubated with TCM (f.c. = 12.5\%) from H69, MDA.MB.231, and NB4 cells, in the presence or absence of 1 $\mathrm{IU} / \mathrm{mL}$ bemiparin or RO-14, for $24 \mathrm{hr}$, and then tube formation photographed. Pictures show that TCM increase the complexity of tube network and that this is counteracted by heparin addition. $\mathrm{C}=$ control medium.

\section{Bemiparin and RO-14 counteract EC proliferation induced by VEGF}

The incubation of HMEC-1 cells with H69, MDA.MB.231, or NB4 CM for $24 \mathrm{hr}$ did not significantly influence cell proliferation (data not shown), whereas incubation with standard VEGF induced a $25.2 \% \pm 4.2 \%$ increase of EC proliferation compared to control medium $(p<.01)$. Bemiparin dose dependently reduced VEGF-induced EC proliferation, reaching a $100 \%$ abolishment at the dose of $1 \mathrm{IU} / \mathrm{mL}$ (Figure 4). RO-14 also dose dependently counteracted EC
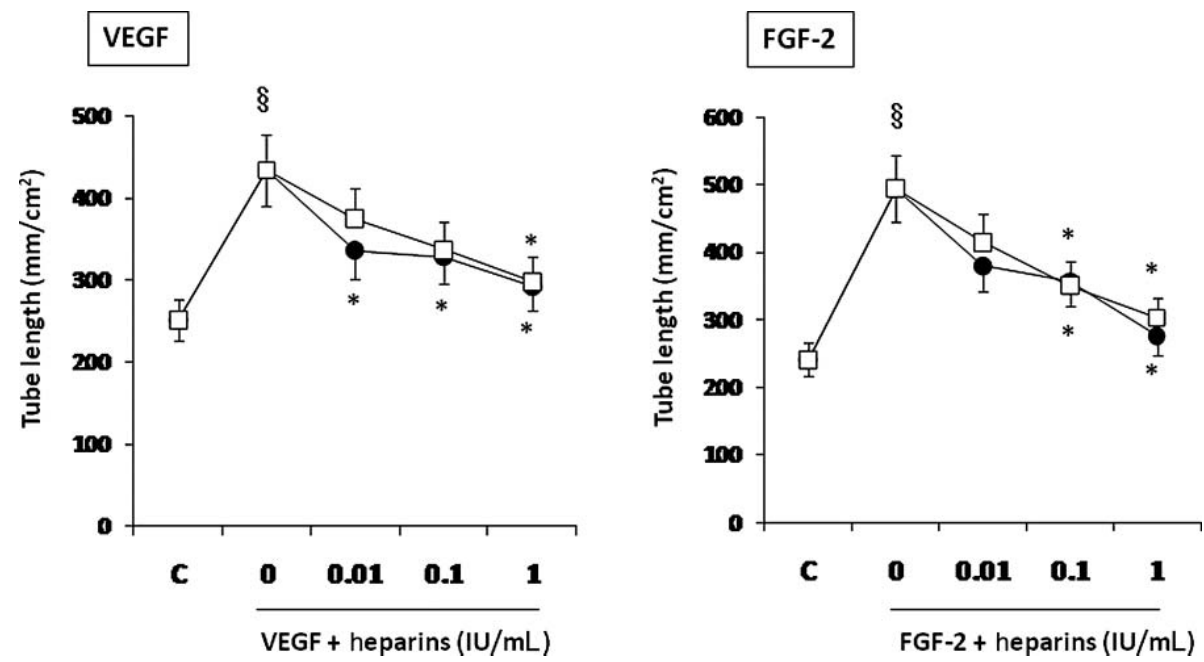

Figure 3. Bemiparin and RO-14 counteract HMEC-1 capillary-like tube formation induced by proangiogenic factors. EC were incubated with VEGF or FGF-2, in the presence or absence of increasing concentrations of heparins (bemiparin = full circle, RO-14 = open square) for 24 hr and then tube formation evaluated. Both heparins dose dependently inhibited the increase of tube formation induced by either VEGF or FGF-2. Data are mean $+S D$ of three experiments performed in duplicate. ${ }^{*} p<.05$ vs. $0 ; p<.05$ vs. control medium (C). 


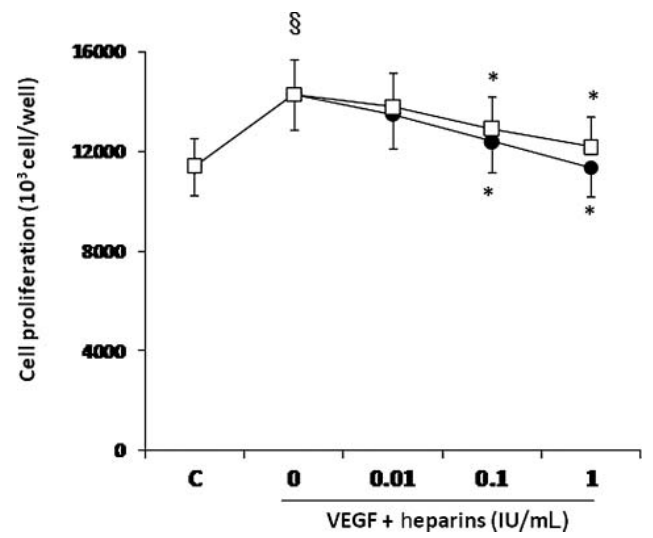

Figure 4. Bemiparin and RO-14 counteract HMEC-1 proliferation induced by VEGF. EC were incubated with VEGF, in the presence or absence of increasing concentrations of heparins (bemiparin $=$ full circle, RO-14 = open square) for $24 \mathrm{hr}$ and then cell proliferation evaluated. VEGF induced a significant increase of cell proliferation, which was inhibited by the addition of either bemiparin or RO-14. Data are mean $+S D$ of five experiments performed in triplicate. ${ }^{*} p<.05$ vs. 0 ; $p<.05$ vs. control (C).

proliferation induced by VEGF, although to a lesser extent, the inhibition observed at $1 \mathrm{IU} / \mathrm{mL}$ was $72.8 \% \pm 8.1 \%$ $(p<.05$ vs. VEGF alone) (Figure 4$)$. However, the difference between bemiparin and RO-14 was not statistically significant.

\section{Bemiparin and RO-14 counteract EC wound healing induced by TCM or VEGF}

All TCM (i.e., H69, MDA.MB.231, and NB4) induced a significant increase of EC repopulation in the wounded area. In particular, compared to control medium (set as the 100\%), regrowth areas induced by TCM were $195 \% \pm 10 \%$ by $\mathrm{H} 69$ CM, $210 \% \pm 13 \%$ by MDA.MB. $231 \mathrm{CM}$, and $180 \% \pm 8 \%$ by NB4 CM ( $p<.05$ for all TCM vs. control) (Figure 5, panels a, b, and c). Both LMWHs significantly counteracted the wound closure induced by TCM, in a dose-dependent way (Figure 5). At $10 \mathrm{IU} / \mathrm{mL}$, bemiparin and RO-14 significantly inhibited the migration induced by $\mathrm{H} 69 \mathrm{CM}$ (i.e., $55 \% \pm 7 \%$ and $85 \% \pm 8 \%$, respectively) and by NB4 CM (i.e., $44 \% \pm$ $6 \%$ and $61 \% \pm 5 \%$, respectively), while at the same dose both heparins inhibited by $100 \%$ the MDA.MB.231 CM-induced migration (Figure 5). Standard VEGF increased cell repopulation by $76.3 \% \pm 6.5 \%$ compared to control medium $(p<$ $.05)$. Both bemiparin and RO-14 dose dependently counteracted VEGF-induced migration (Figure 5, panel d), reaching at the dose of $10 \mathrm{IU} / \mathrm{mL}$, the inhibitions of $100 \%$ and $68.7 \% \pm$ $7.4 \%$, respectively $(p<.01)$. No statistically significant differences between the effects of bemiparin and RO-14 (at same concentrations) were observed with any TCM or standard VEGF. Figure 6 shows representative pictures from selected experiments.

\section{DISCUSSION}

LMWH are largely effective for the prevention and treatment of venous thrombosis in cancer patients. Some recent metaanalyses suggest that LMWH may also have a beneficial impact on survival of cancer patients $(20,21)$. This evidence has prompted the investigators to start randomized clinical trials aimed to specifically evaluate the impact of LMWH on cancer mortality. Some of these trials have recently been published, while others are ongoing (22).

The results of clinical studies are altogether promising; however, the mechanisms underlying the possible antitumor activity of LMWH are unknown. It has been hypothesized that other activities, besides inhibition of blood coagulation by these drugs, may be involved (4). Among these, an interference of LMWH with tumor-driven neoangiogenesis may be relevant. The effect of heparins on angiogenesis has been shown by a variety of in vivo and in vitro studies (8). However, the majority of studies have been conducted with unfractionated heparin (UFH) or "first generation" LMWH $(8-10,23)$. Recently, second generation LMWH, characterized by a lower mean molecular weight and a more precisely defined composition of polysaccharidic chains, have been made available. These properties may lead to a better efficacy/safety profile.

In this study, we describe the first "in vitro" characterization of the antiangiogenic activity of the second generation LMWH bemiparin, and of the ULMWH RO-14, in an in vitro model of tumor-induced angiogenesis.

Particularly, to elicit the proangiogenic phenotype, HMEC-1 were incubated with TCM from three different tumor cell types (leukemic, breast cancer, and SCLC). This approach was selected on the basis of our previous work utilizing the same experimental model of tumor cell/ endothelial cell interaction (10). In addition, the proangiogenic factors VEGF and FGF-2 were included into the study. The inclusion of purified growth factors allowed us to study the antiangiogenic activity of the two heparins in better standardized condition, compared to TCM.

Our data show that all three TCM significantly influenced the angiogenic phenotype of HMEC-1, by inducing an increase in the capillary-like tube formation and woundhealing capacity, without affecting endothelial cell proliferation. The potency of the three different TCM was similar and comparable to that of purified VEGF and FGF-2. The addition of either bemiparin or RO-14 significantly counteracted the proangiogenic potential of all TCM, as well as of VEGF and FGF-2. Indeed, a very strong inhibition of the endothelial cell capillary formation capacity (more than $90 \%$ for all TCM), together with a significant reduction in the migration ability (more than $60 \%$ for all TCM), occurred in the heparintreated conditions. These findings are of relevance as it has been variously reported that the nonanticoagulant effects of heparin differ greatly among the different heparin preparations (24). In our previous study, in the same model, we observed that the two first generation LMWH enoxaparin and dalteparin were more effective than UFH in inhibiting the 
a.

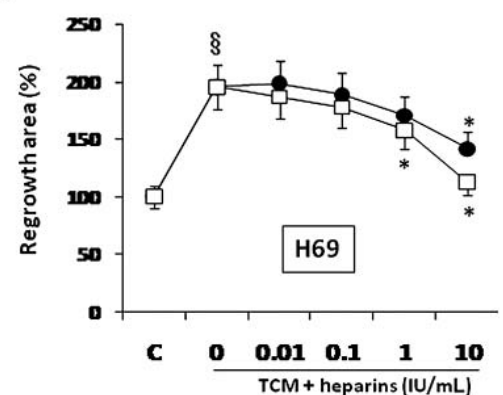

C.

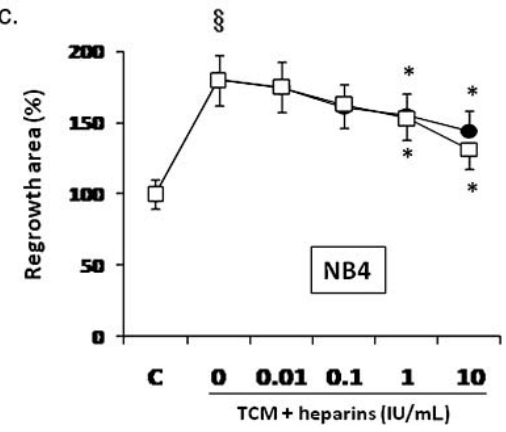

b.

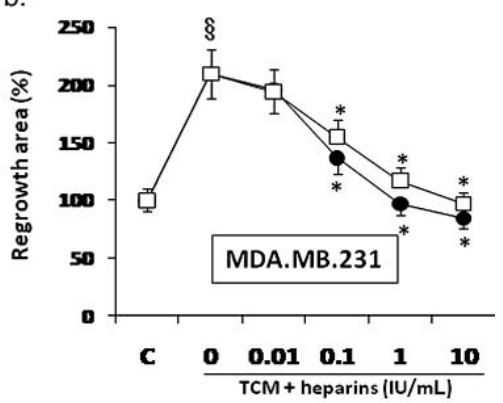

d.

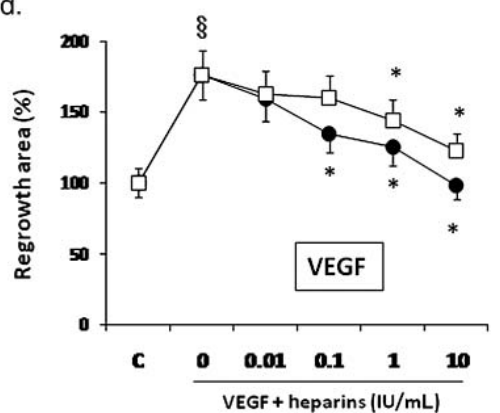

Figure 5. Bemiparin and RO-14 counteract HMEC-1 wound healing induced by TCM or VEGF. EC were wounded, then incubated with TCM from H69, MDA.MB.231, and NB4 cells, or VEGF in the presence or absence of increasing concentrations of heparins (bemiparin = full circle, RO-14 = open square), for $24 \mathrm{hr}$, and then regrowth area was evaluated. All TCM and VEGF induced a significant repopulation in the wounded area. The addition of either bemiparin or RO-14 dose dependently counteracted this effect. Data are mean $+S D$ of three experiments performed in quintuplicate. ${ }^{*} p<.05$ vs. $0 ; p<.05$ vs. control (C). C $=100 \%$.

capillary tube formation induced by purified proangiogenic factors (i.e., VEGF, FGF-2, and TNFalpha), while all heparins were equally effective in inhibiting TCM-induced capillary formation.

In the present work, we found that the antiangiogenic activities of bemiparin and RO-14 were comparable against both TCM and purified growth factors; however, different concentrations of the drugs were required to achieve significant inhibitions in the three different assays. Particularly, in the capillary-like tube formation assay, the concentration of $1 \mathrm{IU} / \mathrm{mL}$ of either bemiparin or RO-14 completely abolished the effect of the stimulus of all TCM. Differently, in the wound-healing assay, the effect of heparins on tumorinduced endothelial migration was maximal at the concentration of $10 \mathrm{IU} / \mathrm{mL}$, reaching a complete inhibition against MDA.MB.231 CM only. In the proliferation assay, the TCM did not significantly affect EC proliferation, confirming our previous findings (10), whereas purified VEGF induced a significant increase of cell proliferation, that was inhibited by more than $70 \%$ by the addition of either $1 \mathrm{IU} / \mathrm{mL}$ bemiparin or RO- 14 .

In agreement with other authors, we hypothesize that, in our experimental model, the antiangiogenic effect of heparins is related to their capacity to interfere with the binding of soluble proangiogenic molecules to their high-affinity signal-transducing receptors expressed by endothelial cell surface (8). It has been also demonstrated that this "antigrowth factor" effect is related to both the size and the proportion of the different heparin chains present in a particular drug formulation (9). Evidence exists that purified octasaccharides and decasaccharides are capable to significantly inhibit angiogenesis both "in vitro" and "in vivo" $(8,25,26)$. In this respect, bemiparin and RO-14 possess a high oligosaccharide content ranging from hexasaccharides to dodecasaccharides.

In this study, we found that all TCM contain various proangiogenic factors, but in different proportions. In particular, breast cancer cell CM contains more VEGF than the other two CM, while SCLC cell CM contains more FGF2 and IL-1beta than breast cancer and leukemia cell CM. To explore the role of VEGF in TCM-induced tube formation, we conducted a capillary-like tube formation assay after neutralizing VEGF in the TCM. The results of these experiments suggest that the role of VEGF is prominent in MDA.MB.231 and NB4 CM. Differently, in H69 CM the proangiogenic effect is likely due to a cooperation of different cytokines. We hypothesize that bemiparin and $\mathrm{RO}-14$ compete with proangiogenic cytokines contained in the TCM for their binding to the respective receptors and/or directly bind cytokines thus preventing their action. 


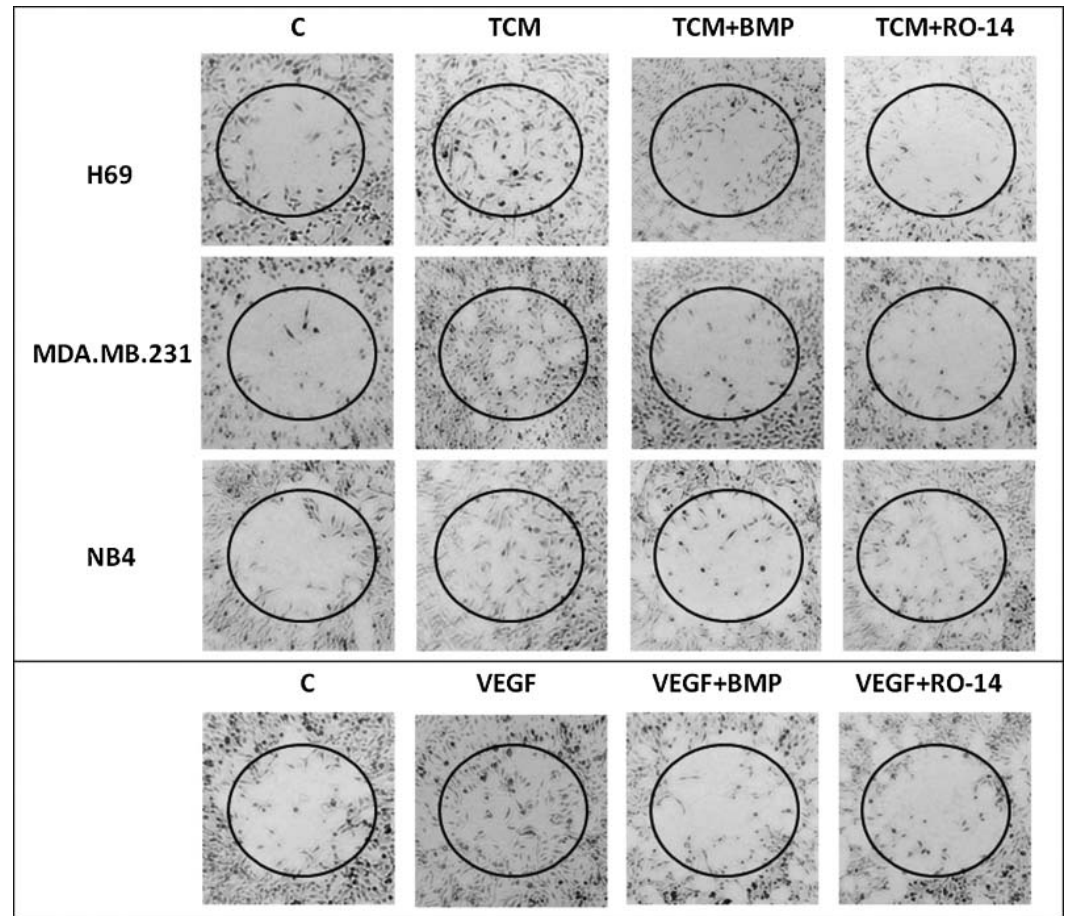

Figure 6. Representative pictures of selected experiments showing the inhibition of TCM- or VEGF-induced HMEC-1 wound healing by bemiparin and RO-14. EC were wounded, then incubated with TCM from H69, MDA.MB.231, and NB4 cells, or VEGF, in the presence or absence of 10 $\mathrm{IU} / \mathrm{mL}$ of bemiparin (BMP) or RO-14, for $24 \mathrm{hr}$, and then regrowth area was photographed. The photos show a lower number of cells migrated in the wounded area in the presence of bemiparin or RO-14, when compared to wells treated with TCM or VEGF in the absence of heparins. Control medium (C) or VEGF, by bemiparin and RO-14 (10 IU/mL). Black circles represent the wounded area.

However, other antiangiogenic mechanisms could be involved (27). Mousa et al. have shown that the LMWH tinzaparin can inhibit FGF-2-induced tube formation by mascrovascular EC through the release of tissue factor pathway inhibitor (TFPI), the main inhibitor of tissue factor, which is the most important activator of blood coagulation (23). Since it is known that bemiparin induces the release of TFPI by endothelium, as demonstrated in HUVEC (28) and in EA.hy926 cell line (29), and that HMEC-1 release TFPI under exposure to LMWH (dalteparin and enoxaparin) (30), we may not exclude that bemiparin and RO-14 may also counteract angiogenesis through this mechanism.

In conclusion, this study shows that both second generation LMWH and new ULMWH display an antiangiogenic activity against tumor derived products, as observed with classical LMWH and UFH. These findings support the hypothesis of a possible role of these molecules as adjuvant drugs in cancer treatment.

\section{ABBREVIATIONS}

LMWH, Low-Molecular-Weight Heparin ULMWH, Ultra-Low-Molecular-Weight Heparin

\section{SCLC, Small Cell Lung Cancer}

HMEC-1, Human Microvascular Endothelial Cell line-1 TCM, Tumor-Cell-Conditioned Medium

Mw, Molecular weight

VEGF, Vascular Endothelial Growth Factor

FGF-2, Fibroblast Growth Factor-2

IU, International Units

FX, coagulation Factor X

FII, coagulation Factor II

$\mathrm{kDa}$, kiloDalton.

\section{ACKNOWLEDGMENTS}

This study has been supported by an unrestricted grant from Laboratorios Farmacéuticos ROVI, and by a grant from the Italian Ministry of Health (Grant "Oncological Research" no. 29/07).

\section{DECLARATION OF INTEREST}

The authors report no conflict of interest. The authors alone are responsible for the content and writing of this paper. 


\section{REFERENCES}

1. Falanga A, Marchetti M, Vignoli A, Balducci D. Clotting mechanisms and cancer: implications in thrombus formation and tumor progression. Clin Adv Hematol Oncol 2003;1:673-678.

2. Khorana AA, Streiff MB, Farge D, Mandalà M, Debourdeau P, Cajfinger F, Marty M, Falanga A, Lyman GH. Venous thromboembolism prophylaxis and treatment in cancer: a consensus statement of major guidelines panels and call to action. J Clin Oncol 2009;27:4919-4926.

3. Gerotziafas GT, Papageorgiou C, Hatmi M, Samama MM, Elalamy I. Clinical studies with anticoagulants to improve survival in cancer patients. Pathophysiol Haemost Thromb 2008;36: 204-211.

4. Falanga A, Marchetti M. Heparin in tumor progression and metastatic dissemination. Semin Thromb Hemost 2007;33: 688-694.

5. Goerner A. The influence of anticlotting agents on transplantation and growth of tumor tissue. J Lab Clin Med 1930;16:369372.

6. Zacharski LR, Loynes JT. The heparins and cancer. Curr Opin Pulm Med 2002;8:379-382.

7. Coombe DR, Parish CR, Ramshaw IA, Snowden JM. Analysis of the inhibition of tumour metastasis by sulphated polysaccharides. Int J Cancer 1986;39:82-88.

8. Norrby K. Low-molecular-weight heparins and angiogenesis. Apmis 2006;114:79-102.

9. Khorana AA, Sahni A, Altland OD, Francis CW. Heparin inhibition of endothelial cell proliferation and organization is dependent on molecular weight. Arterioscler Thromb Vasc Biol 2003;23:2110-2115.

10. Marchetti M, Vignoli A, Russo L, Balducci D, Pagnoncelli M, Barbui T, Falanga A. Endothelial capillary tube formation and cell proliferation induced by tumor cells are affected by low molecular weight heparins and unfractionated heparin. Thromb Res 2008;121:637-645.

11. Kakkar VV, Balibrea JL, Martinez-Gonzalez J, Prandoni P, on behalf of the CANBESURE Study Group. Extended prophylaxis with bemiparin for prevention of venous thromboembolism after abdominal or pelvic surgery for cancer: the CANBESURE randomized study. J Thromb Haemost 2010;8:1223-1229.

12. Lecumberri R, Massuti B, Lopez Vivanco, Font A, Gonzalez Billalabeitia E, Rocha E, on behalf of the ABEL investigators, Adjuvan bemiparin in small cell lung cancer: results from the ABEL study [abstract]. Thromb Res 2010;125(Suppl. 2):S163.

13. Gómez-Outes A, Lecumberri R, Pozo C, Rocha E. New anticoagulants: focus on venous thromboembolism. Curr Vasc Pharmacol 2009;7:309-329.

14. Antonijoan RM, Rico S, Puntes M, Borrell M, Fontcuberta J, Monreal M, Martinez-Gonzalez J, Barbanoj MJ. Pharmacokinetics and safety of a novel ultra low molecular weight heparin (RO-14) in healthy volunteers-a first time in human (FTIH) single ascending dose study [abstract]. J Thromb Haemost 2009;7(Suppl. 2):PPWE-178.
15. Heparins, Low-Molecular-Mass (0828), Ph. Eur. 6th Ed. Strasbourg, France: Directorate for the Quality of Medicines of the Council of Europe., 2008.

16. Cailleau R, Olive M, Cruciger QV. Long-term human breast carcinoma cell lines of metastatic origin: preliminary characterization. In Vitro 1978;14:911-915.

17. Zhang RD, Fidler IJ, Price JE. Relative malignant potential of human breast carcinoma cell lines established from pleural effusions and a brain metastasis. Invasion Metastasis 1991;11:204-215.

18. Gazdar AF, Carney DN, Russell EK, Sims HL, Baylin SB, Bunn PAJ, Guccion JG, Minna JD. Establishment of continuous, clonable cultures of small-cell carcinoma of lung which have amine precursor uptake and decarboxylation cell properties. Cancer Res. 1980;40:3502-3507.

19. Falanga A, Marchetti M, Giovanelli S, Barbui T. All-trans-retinoic acid counteracts endothelial cell procoagulant activity induced by a human promyelocytic leukemia-derived cell line (NB4). Blood 1996;87:613-617.

20. Kuderer NM, Khorana AA, Lyman GH, Francis CW. A metaanalysis and systematic review of the efficacy and safety of anticoagulants as cancer treatment: impact on survival and bleeding complications. Cancer 2007;110:1149-1161.

21. Lazo-Langner A, Goss GD, Spaans JN, Rodger MA. The effect of low-molecular-weight heparin on cancer survival. A systematic review and meta-analysis of. J Thromb Haemost 2007;5:729-737.

22. Lee AYY. The roles of anticoagulants in patients with cancer. Thromb Res 2010;125(Suppl. 2):S8-S11.

23. Mousa SA, Mohamed S. Inhibition of endothelial cell tube formation by the low molecular weight heparin, tinzaparin, is mediated by tissue factor pathway inhibitor. Thromb Haemost 2004;92:627-633.

24. Ludwig RJ. Therapeutic use of heparin beyond anticoagulation. Curr Drug Discov Technol 2009;6:281-289.

25. Jayson GC, Gallagher JT. Heparin oligosaccharides: inhibitors of the biological activity of bFGF on Caco- 2 cells. $\mathrm{Br} \mathrm{J}$ Cancer 1997;75:9-16.

26. Hasan J, Shnyder SD, Clamp AR, McGown AT, Bicknell R, Presta M, Bibby M, Double J, Craig S, Leeming D, Stevenson K, Gallagher JT, Jayson GC. Heparin octasaccharides inhibit angiogenesis in vivo. Clin Cancer Res 2005;11:8172-8179.

27. Falanga A, Panova-Noeva M, Russo L. Procoagulant mechanisms in tumour cells. Best Practice Res Clin Haematol 2009;22:49-60.

28. Pérez-Ruiz A, Montes R, Carrasco P, Rocha E. Effects of a low molecular weight heparin, bemiparin, and unfractionated heparin on hemostatic properties of endothelium. Clin Appl Thromb Hemost 2002;8:65-71

29. Westmuckett AD, Kakkar VV, Hamuro T, Lupu F, Lupu C. Bemiparin and fluid flow modulate the expression, activity and release of tissue factor pathway inhibitor, in human endothelial cells in vitro. Thrombosis Haemostasis 2001;86:1547-1554.

30. Vignoli A, Marchetti M, Balducci D, Barbui T, Falanga A. Differential effect of the low-molecular-weight heparin, dalteparin, and unfractionated heparin on microvascular endothelial cell hemostatic properties. Haematologica 2006;91:207-214. 


\title{
Chapter 8
}

\author{
Comparative assessment of low- \\ molecular-weight-heparins in cancer \\ from the perspective of patient \\ outcome and survival.
}

Falanga A., Vignoli A., Diani E., Marchetti M. Comparative assessment of low-molecular-weight heparins in cancer from the perspective of patient outcomes and survival. Patient Related

Outcome Measures 2011;2:175-188. 


\section{Comparative assessment of low-molecular-weight heparins in cancer from the perspective of patient outcomes and survival}

\author{
Anna Falanga \\ Alfonso Vignoli \\ Erika Diani \\ Marina Marchetti \\ Division of Immunohematology \\ and Transfusion Medicine, Ospedali \\ Riuniti, Bergamo, Italy
}

\begin{abstract}
Patients with cancer are at high risk of developing venous thromboembolism (VTE), including deep venous thrombosis and pulmonary embolism. Compared to non-cancer patients, VTE in cancer is more frequently associated with clinical consequences, including recurrent VTE, bleeding, and an increase in the risk of death. Low-molecular-weight heparins (LMWHs) are commonly recommended for the prevention and treatment of VTE in cancer patients because of their favorable risk-to-benefit profile. Indeed, compared with vitamin K antagonists, LMWHs are characterized by a reduced need for coagulation monitoring, few major bleeding episodes, and once-daily dosing, which make these drugs more suitable in the cancer setting. Guidelines have been published recently with the aim to improve the clinical outcomes in cancer patients at risk of VTE and its complications. Coagulation activation in cancer may have a role not only in thrombosis but also in tumor growth and dissemination. Hence, inhibition of fibrin formation has been considered a possible tool against the progression of malignant disease. Clinical studies show that anticoagulant drugs may have a beneficial effect on survival in cancer patients, with a major role for LMWHs. Recently a number of prospective randomized clinical trials to test LMWHs to improve cancer survival as a primary endpoint in cancer patients have been conducted. Although the results are controversial, the interest in this research area remains high.
\end{abstract}

Keywords: venous thromboembolism, VTE, LMWH

\section{Introduction}

Tumor growth is associated with the development of a hypercoagulable state and an increased risk of thrombosis in the host. Thromboembolic disease can be the earliest clinical sign of a tumor, as originally reported by the French clinician Armand Trousseau over a century ago and recently confirmed by controlled prospective clinical trials. ${ }^{1,2}$ Conversely, patients already diagnosed with cancer have a significantly higher risk of developing "secondary" thrombosis in specific conditions. ${ }^{3,4}$ Important in this setting is the triggering role of antitumor therapies (ie, surgery, chemotherapy, radiotherapy, hormone therapy, and angiogenesis inhibitors) and of supportive therapies (ie, steroids, blood transfusion, white blood cell growth factors, and erythropoiesis-stimulating agents such as erythropoietin), which further increase the cancer-associated thrombotic risk. ${ }^{5,6}$

The interaction and relative effects of the risk factors associated with venous thromboembolism (VTE) in cancer patients is highly complex, making the pretreatment assessment of VTE difficult. Recently, a VTE risk-assessment model for patients undergoing chemotherapy was published and is based on five predictive variables in cancer patients, including cancer site, prechemotherapy platelet count, hemoglobin
Correspondence: Anna Falanga Division of Immunohematology and Transfusion Medicine, Ospedali Riuniti, Largo Barozzi I, 24I28 Bergamo, Italy Email annafalanga@yahoo.com 
levels or the use of erythropoiesis-stimulating agents, prechemotherapy leukocyte count, and body mass index. ${ }^{7}$

Even in the absence of overt thrombosis, cancer patients commonly present with abnormalities in laboratory coagulation tests, underlying a subclinical hypercoagulable condition, characterized by varying degrees of blood clotting activation. ${ }^{5,8,9}$ The results of laboratory tests demonstrate that there is a continuous process of fibrin formation and lysis during the development of malignancy. ${ }^{10-13}$ The pathogenesis of thrombophilia in cancer is multifactorial. An important role is attributed to the tumor cell capacity to interact with and activate the host hemostatic system through the expression of procoagulant factors (ie, tissue factor and cancer procoagulant), the production of inflammatory cytokines (ie, interleukin- $1 \beta$ and tumor necrosis factor- $\alpha$ ), and the direct adhesion to vascular cells, including platelets, endothelial cells, and monocytes. ${ }^{14,15}$

Treatment of VTE in cancer patients is challenging because of the high rates of anticoagulant-associated bleeding and treatment failures compared with patients with thrombosis and no cancer. ${ }^{16}$ According to a study of Prandoni et al, patients with cancer and VTE were approximately four times more likely to develop recurrent thromboembolic complications and twice as likely to develop major bleeding while receiving anticoagulant treatment than those without malignancy. ${ }^{17}$ Notably, cancer-associated VTE has important clinical and economic consequences, including increased morbidity consequential to hospitalization and anticoagulation use, bleeding complications, increased risk of VTE recurrences, and delays in cancer treatment. ${ }^{18}$

The standard treatment for acute VTE is an initial therapy with low-molecular-weight heparins (LMWHs), unfractionated heparin (UFH), or fondaparinux followed by long-term therapy with a vitamin $\mathrm{K}$ antagonist (VKA). However, this approach for long-term therapy is not highly effective in patients with cancer. ${ }^{17}$ Many aspects make problematic the administration of oral anticoagulant therapy in patients with cancer, including the frequent interruption of anticoagulant therapy due to invasive procedures and chemotherapy-induced thrombocytopenia, the difficulty of laboratory monitoring due to poor venous access, drug interactions, malnutrition, vomiting, and liver dysfunction. Altogether, these limitations can lead to unpredictable levels of anticoagulation and might be responsible for the increased risk of VTE recurrence and bleeding in cancer patients. Unlike VKA, LMWHs have predictable pharmacokinetic properties and drug interactions - the subcutaneous injection of LMWHs overcomes poor gastrointestinal absorption, and laboratory monitoring is not routinely required as the therapeutic dosage is based on the patient's weight. ${ }^{19}$ The rapid onset of action and the predictable clearance, render LMWHs suitable for patients frequently requiring interruptions of anticoagulant therapy. For all these reasons, LMWHs have been tested versus VKA in prospective randomized clinical trials (RCTs) of efficacy in the treatment of VTE in cancer patients. The results clearly show a superiority of LMWHs, which are now the drugs of choice for initial and long-term therapy of VTE in the cancer patient. ${ }^{20}$

\section{Overview of pharmacology and pharmacokinetics of LMWHs}

Heparin, a naturally occurring glycosaminoglycan, is a mixture of sulfated polysaccharide chains of different molecular weight. Heparins are synthesized by mast cells and distributed widely throughout the organs of mammalian species. In medicine, heparins are used as antithrombotic drugs. Heparin preparations are heterogeneous with respect to molecular size, anticoagulant activity, and pharmacokinetic properties. The molecular weight (MW) of UFH ranges from 3 to $30 \mathrm{kDa}$, with a mean MW of $15 \mathrm{kDa}$ (about 45 monosaccharide chains). Heparins exert their major anticoagulant activity in blood by binding to and potentiating the activity of the natural anticoagulant antithrombin (AT) through a unique glucosamine unit contained within a pentasaccharide sequence ${ }^{19}$ (Figure 1). Only about one-third of administered UFH binds to AT, and is responsible for most of its anticoagulant effect. The heparin-AT complex inactivates a number of coagulation enzymes, including activated factor II (thrombin), factor X, factor IX, factor XI, and factor XII. Thrombin and activated factor $\mathrm{X}(\mathrm{FXa})$ are the most responsive to inhibition, and human thrombin is about tenfold more sensitive than FXa to inhibition by the heparin-AT complex. For thrombin inhibition, heparin must bind to both the coagulation enzyme and AT, whereas binding of heparin to the enzyme is not required for inhibition of FXa. The formation of a ternary complex between AT, thrombin, and heparin results in the inactivation of thrombin. For this reason, heparin's activity against thrombin is size dependent, the ternary complex requiring at least 18 saccharide units for efficient formation. In contrast, anti-FXa activity requires only the pentasaccharide binding site. The heparin molecules with fewer than 18 saccharides lack the chain length to bridge between thrombin and AT and therefore are unable to inhibit thrombin. By inactivating thrombin, heparins not only prevent fibrin formation but also inhibit thrombin-induced activation of platelets and of factors V and VIII. In contrast, very small heparin fragments 


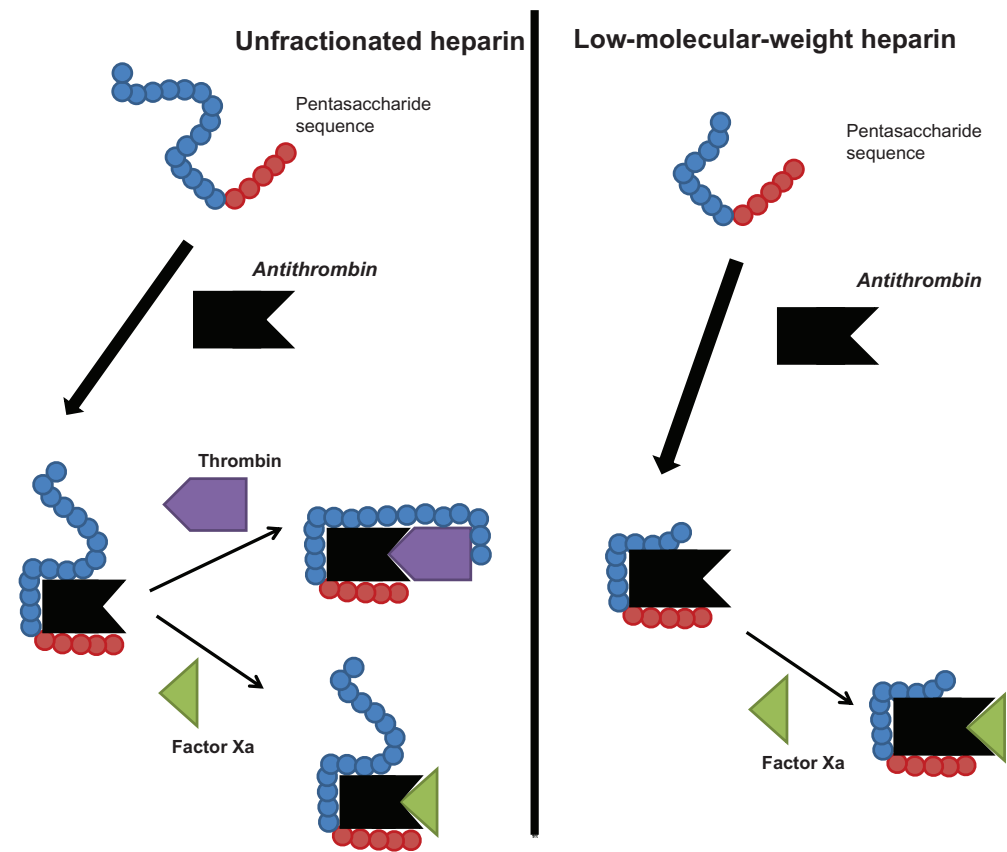

Figure I Anticoagulant mechanisms of unfractionated and low-molecular-weight heparins.

containing the high-affinity pentasaccharide sequence catalyze inhibition of FXa by AT. This size difference has led to the development of LMWHs and, more recently, to fondaparinux, a synthetic pentasaccharide, as anticoagulant drugs. LMWHs target FXa activity rather than thrombin (IIa) activity, with the aim of facilitating a more subtle regulation of coagulation and an improved therapeutic index.

After administration by intravenous infusion or by subcutaneous injection, UFH binds to a variety of plasma proteins, including histidine-rich glycoprotein, platelet factor 4 , vitronectin, and von Willebrand factor, thereby lowering its bioavailability and producing a variable anticoagulant response. Heparin exhibits complex pharmacokinetics and is cleared by two mechanisms. The rapid, saturable phase of elimination consists of receptor-mediated internalization of heparin by endothelial cells and macrophages, while the slower, nonsaturable mechanism is represented by renal elimination. The anticoagulant effect of heparin, therefore, is not linearly related to the dose when in the therapeutic range. The biologic half-life of heparin increases from 30 minutes following an intravenous bolus dose of $25 \mathrm{U} / \mathrm{kg}$ to 150 minutes following a bolus dose of $400 \mathrm{U} / \mathrm{kg}$.

LMWHs can be obtained by controlled chemical, enzymatic, physical, and radiochemical depolymerization of UFH. They possess a mean MW of between 3 and $6 \mathrm{kDa}$ and chain lengths of 12-18 saccharide units (Table 1).

Table I Primary prophylaxis in the cancer patient: recommendations

\begin{tabular}{lll}
\hline Patient group & Recommended & Not recommended \\
\hline Patients undergoing surgery & Prophylaxis with low-dose UFH or LMWH for at least 7-I0 days & Contraindication to anticoagulation: \\
& $\begin{array}{l}\text { Extended prophylaxis up to 4 weeks after discharge in patients } \\
\text { with high-risk features }\end{array}$ & consider mechanical methods alone \\
Hospitalized patients & VTE prophylaxis with anticoagulants & Contraindication to anticoagulation \\
Ambulatory patients receiving & Only patients with multiple myeloma receiving thalidomide or & All other patient categories \\
chemotherapy & lenalidomide prophylaxis with LMWH or adjusted dose warfarin & \\
\hline
\end{tabular}

Abbreviations: LMWH, low-molecular-weight heparin; UFH, unfractionated heparin; VTE, venous thromboembolism. 
Different LMWHs show distinct structural differences and MW component distribution, which determine differences in their chemical and biological activities, particularly, different anti-FXa and anti-FIIa activities, which translates to a particular anti-FXa/anti-FIIa ratio. ${ }^{21}$

Compared with UFH, LMWHs have an increased anti-Xa/ anti-IIa activity ratio, reduced plasma protein binding, lower tendency to bind to endothelial cells,${ }^{22}$ decreased interaction with platelets and platelet factor 4 , a prolonged half-life, and increased bioavailability after subcutaneous administration. All these characteristics translate to a consistent and predictable absorption rate and bioavailability patterns. Bioavailability of LMWHs is different according to molecule features, ranging from $87 \%$ to $98 \%{ }^{21-22}$ The apparent volume of distribution of the anti-FXa activity of LMWHs following subcutaneous injection is close to plasma or blood volume; the volume of distribution of enoxaparin $(5.3 \mathrm{~L})$ has been shown to be significantly lower than dalteparin $(7.7 \mathrm{~L})$ and nadroparin $(6.8 \mathrm{~L}) .^{23}$

UFH and LMWHs are metabolized by depolymerization and desulfation. ${ }^{22,24}$ After being degraded by the liver, heparins are eliminated by the kidneys as metabolites, retaining their biologic activity. ${ }^{24}$ The clearance of LMWHs does not change as a function of administered dose (unlike that of UFH, which is dose dependent), which may be attributed to the lower cellular uptake of LMWHs compared with UFH. ${ }^{25}$ The average apparent total body clearance of enoxaparin has been shown to be lower than that of $\mathrm{UFH},{ }^{25}$ and further differences also have been observed between enoxaparin, dalteparin, and nadroparin. ${ }^{26}$

\section{Management of VTE in cancer patients - focus on the use of LMWHs \\ Prophylaxis of VTE}

The efficacy of prophylactic strategies to prevent VTE in at-risk hospitalized patients has been well demonstrated. For example, pharmacological prophylaxis reduces the risk of pulmonary embolism (PE) by $75 \%$ in general surgical patients ${ }^{27}$ and by $57 \%$ in medical patients. ${ }^{28}$ However, VTE prevention in cancer patients is more complicated compared with non-cancer patients, as they are prone to greater recurrence rates and a higher incidence of bleeding complications. ${ }^{16,17}$ It has been shown that cancer patients undergoing surgery benefit from effective pharmacological prophylaxis, ${ }^{29}$ and that extended duration of thromboprophylaxis with LMWHs is beneficial to patients undergoing major abdominal or pelvic surgery. ${ }^{30}$ This is reflected in current guidelines, which recommend that all cancer patients undergoing major surgery should receive heparin-based prophylaxis for a minimum of 7-10 days, with supportive mechanical prophylaxis in those patients at highest risk. ${ }^{31}$ Clinical trials have demonstrated the benefit of VTE prophylaxis either with low-dose UFH or LMWHs in hospitalized general medical patients, including patients with cancer. In contrast to hospitalized cancer patients, the primary prevention of thrombosis in ambulatory cancer patients is still debated. Although there is evidence that LMWHs are effective in reducing VTE in selected outpatients receiving chemotherapy, the optimal dose, duration, and specific patient populations remain to be defined.

\section{Thromboprophylaxis in surgical cancer patients}

The most commonly used thromboprophylaxis regimens in general surgery consist of a single preoperative dose of UFH or LMWH followed by postoperative doses every 8-24 hours. UFH is typically administered at a prophylactic dose of 5000 IU twice or three times daily. A meta-analysis of eight trials that included patients undergoing surgery for cancer showed no differences in asymptomatic deep-vein thrombosis (DVT), clinical PE, death, and major bleeding between patients administered LMWH or UFH. ${ }^{27}$ The results of these studies provide evidence that once-daily LMWH is as safe and effective as several injections of UFH per day for the prevention of postoperative DVT in oncological patients. However, the risk of VTE complications is increased in patients who undergo cancer-related surgery for at least two reasons: (1) cancer-related surgery tends to be more extensive and often involves venous trauma, and (2) there is a tendency for these patients to be immobilized for prolonged periods. In addition, cancer treatments, the use of central venous catheters, and the hypercoagulable state associated with malignancy also heightens the VTE risk for cancer patients undergoing surgery. In a subgroup analysis of the MC-4 randomized trial, over 6000 surgical patients with malignant disease receiving perioperative UFH or LMWH certoparin, were compared with 17,000 surgical patients without malignancy. In this trial, despite the use of thromboprophylaxis, the rate of fatal PE was 3.7 times higher in patients with cancer than in non-cancer patients. ${ }^{32}$ The hypothesis that a higher dose of LMWH would be associated with a lower incidence of postoperative thromboembolic complications was tested in a study of over 2000 patients undergoing elective general surgery for malignant and benign abdominal disease. In this trial, increasing the dose of the LMWH dalteparin 
sodium from 2500 to 5000 IU once daily was associated with a reduction in the frequency of postoperative DVT in cancer surgery from $14.9 \%$ to $8.5 \%$, without significant increase in bleeding complications. ${ }^{33}$ Conversely, in patients without malignant disease, the reduction in postoperative DVT rate was associated with a significant increase in perioperative bleeding complications. ${ }^{33}$ In recent years, a number of trials have shown that LMWHs can reduce venographic DVT with extended out-of-hospital prophylaxis in patients undergoing major joint-replacement surgery. A meta-analysis of these trials has suggested that the rate of clinical DVT after hip replacement is also reduced with a longer treatment. ${ }^{34}$ On the basis of these results, the double-blind RCT ENOXACAN II evaluated the effect of extended prophylaxis in patients undergoing surgery for cancer. Particularly, patients undergoing planned curative open surgery for abdominal or pelvic cancer, received enoxaparin (40 mg subcutaneously) daily for 6-10 days and were then randomly assigned to receive either enoxaparin or placebo for another 21 days. ${ }^{30}$ Bilateral venography was performed at the end of treatment. There was a statistically significant reduction in DVT from $12 \%$ with placebo to $4.8 \%$ with extended prophylaxis, which persisted at 3 months of follow-up. There were no significant differences in the rates of bleeding or other complications. Similar results were provided by an open study of patients undergoing major abdominal surgery randomized to receive regular postoperative prophylaxis (7 days) or extended prophylaxis (28 days) with LMWH dalteparin. ${ }^{35}$ The results of the randomized, double-blind study CANBESURE have been published. In this study, patients admitted for abdominal or pelvic surgery for cancer received $3500 \mathrm{IU}$ of bemiparin for 8 days and then were randomized to receive either bemiparin or placebo for 20 additional days. This trial did not find an advantage of 4 weeks compared with 1 week of prophylaxis with bemiparin in reducing the primary composite efficacy outcome (ie, DVT, nonfatal PE, and all-cause mortality). However, a significant decrease of major VTE (4.6\% vs $0.8 \%, P=0.010$ ) was observed without concomitant increase in bleeding complications. ${ }^{36}$

\section{Thromboprophylaxis in medical cancer patients}

There are two main clinical situations in which to consider VTE prophylaxis in the medical patient with cancer: the first involves the patient who is hospitalized for an acute illness, and the second, the ambulatory patient who is receiving chemotherapy or radiation.

\section{Hospitalized cancer patients}

Clinical trials have demonstrated the benefit of VTE prophylaxis in hospitalized general medical patients. In particular, in the last few decades, the use of prophylaxis with LMWHs has been extensively explored. Although no studies have been designed ad hoc for cancer patients, different proportions of these subjects have been enrolled in the clinical trials conducted so far. The first important study was the MEDENOX study, ${ }^{37}$ a double-blind trial that randomly assigned 1102 hospitalized patients to receive $40 \mathrm{mg}$ of enoxaparin, $20 \mathrm{mg}$ of enoxaparin, or placebo once daily for 6-14 days. The incidence of VTE was significantly lower in patients randomized to $40 \mathrm{mg}$ of enoxaparin compared with placebo (5.5\% vs $14.9 \% ; P<0.001)$, while there were no significant differences between patients that received $20 \mathrm{mg}$ enoxaparin or placebo. A post-hoc analysis of this study demonstrated a $50 \%$ risk reduction ( $95 \%$ confidence interval [CI]: 0.14-1.72) of objectively confirmed VTE (either symptomatic and asymptomatic) in the subgroup of cancer patients receiving $40 \mathrm{mg}$ LMWH enoxaparin compared with placebo. ${ }^{38}$ These results were substantially confirmed by the PREVENT trial, which randomized acutely ill medical patients $(n=3706)$ to receive either LMWH dalteparin $5000 \mathrm{IU}$ daily or placebo for 14 days and followed up for 90 days. Overall, the incidence of VTE was reduced from $4.96 \%$ in the placebo group to $2.77 \%$ in the group treated with dalteparin. ${ }^{39}$ A retrospective post-hoc analysis revealed that in the subset of cancer patients, the VTE rate fell from $8.3 \%$ with placebo to $3 \%$ with LMWH (63\% risk reduction). ${ }^{40} \mathrm{~A}$ third study is the ARTEMIS trial on the efficacy and safety of $2.5 \mathrm{mg}$ oncedaily fondaparinux versus placebo in older acute medical inpatients at moderate to high risk of VTE. ${ }^{41}$ Of the 890 enrolled patients, about $15 \%$ of the patients had previous or current cancer. Fondaparinux reduced the incidence of VTE by $46.7 \%$ ( $P=0.029 \mathrm{vs}$ placebo $)$, with a same frequency of major bleeding $(0.2 \%$ in each group). Therefore, it would seem reasonable that patients with advanced malignancy who are bedridden should receive prophylaxis with either low dose UFH or LMWH.

\section{Ambulatory cancer patients}

The evidence on the primary prevention of thrombosis in ambulatory cancer patients is under investigation. The first evidence of the benefit of thromboprophylaxis in this setting came from a double-blind RCT, in which patients with metastatic breast cancer were given either very low-dose warfarin (1 mg for 6 weeks followed by an adjusted dose to a target prothrombin time international normalized ratio 
[INR]: of 1.3-1.9), or placebo, during chemotherapy. ${ }^{42}$ There was an $85 \%$ risk reduction in VTE rate in patients receiving warfarin, with no increase in bleeding. However, oncologists do not routinely use prophylaxis with oral anticoagulants in cancer patients receiving chemotherapy, for a series of reasons, including the concern for bleeding, an underestimation of the impact of the thrombotic complications, the logistics of laboratory monitoring, and dose adjustment in patients with cancer.

In the last decade, LMWHs, which possess many advantages over warfarin, have been tested in the ambulatory setting. The two most recent trials, conducted in patients with advanced pancreatic cancer who receive systemic chemotherapy, have shown positive results with LMWH prophylaxis. In particular, the CONKO-004 trial found a $87 \%$ risk reduction of VTE $(9.9 \%$ vs $1.3 \% ; P<0.01)$ using the LMWH enoxaparin at $1 \mathrm{mg} / \mathrm{kg}$ once daily for 3 months, compared with no prophylaxis; ${ }^{43,44}$ while the FRAGEM study reported a $61 \%$ risk reduction of VTE ( $31 \%$ vs $12 \%$; $P=0.02)$ using the CLOT $^{20}$ study therapeutic scheme of LMWH dalteparin. ${ }^{45}$

Results from the CONKO-004 and FRAGEM trials are, however, in contrast with other studies evaluating LMWHs given at prophylactic doses in ambulatory cancer patients. In particular, TOPIC-1 and TOPIC-2 RCTs, conducted to evaluate the effect of LMWH certoparin prophylaxis in patients with advanced breast cancer or non-small cell lung cancer (NSCLC), respectively, did not show statistically significant reduction of VTE rate with the use of LMWHs compared with placebo. ${ }^{46}$ In the PRODIGE study, the VTE rate in patients with malignant glioma treated with prophylactic doses of LMWH dalteparin ( $9 \%$ ) was lower compared with placebo (14.9\%) but not statistically significant. ${ }^{47}$

On the basis of these contrasting evidences, it seems that standard prophylaxis doses of LMWHs may be insufficient in patients with cancer to prevent thrombosis. Nevertheless, another interpretation is that thromboprophylaxis is beneficial in only certain tumor types. Recently, the results of a large Italian study (ie, the PROTECHT study) on the efficacy of thromboprophylaxis with LMWH nadroparin in reducing the rate of VTE in ambulatory cancer patients receiving chemotherapy have been published. ${ }^{48}$ Patients $(n=1150)$ with metastatic or locally advanced lung, gastrointestinal, pancreatic, breast, ovarian, or head and neck cancer were randomly assigned to receive LMWH nadroparin (3850 anti-Xa UI/day) or placebo for the overall duration of chemotherapy or up to a maximum of 4 months. The results showed that $15 / 769(2 \%)$ patients treated with nadroparin had thromboembolic events versus $15 / 381$ (3.9\%) patients treated with placebo. VTE accounted for 22 events, 14 of which occurred in patients with lung cancer. ${ }^{48}$ Overall, there is sound evidence that LMWHs are effective in reducing clinically important VTE in selected outpatients receiving chemotherapy, but the optimal dose, duration, and specific patient populations have to be further defined.

\section{Recommendations}

Based on the well-established VTE risk and emerging evidence showing the benefits of prophylaxis, a number of guidelines and consensus statements have been published on the use of VTE prophylaxis for cancer patients. Most noteworthy are those by the American College of Chest Physicians, ${ }^{49}$ the International Union of Angiology, ${ }^{50}$ the National Comprehensive Cancer Network, ${ }^{51}$ the Italian Association of Medical Oncology, ${ }^{52}$ the French National Federation of the League of Centers Against Cancer, ${ }^{53}$ the European Society of Medical Oncology, ${ }^{54}$ and the most recent guidelines from the American Society of Clinical Oncology. ${ }^{55}$ Table 2 summarizes the recommendations of the various guidelines in the different clinical settings. There is a broad agreement among the scientific panels on the importance of thromboprophylaxis in hospitalized patients with cancer, including prolonged prophylaxis in high-risk surgical patients. Prophylaxis is not currently recommended for ambulatory patients with cancer (with exceptions) or for central venous catheters. All of the panels agree that LMWHs are preferred for the long-term treatment of VTE in cancer. Areas that warrant further research include the

Table 2 Comparison of the main characteristics of the commercially available LMWH cited in the article

\begin{tabular}{lllll}
\hline LMWH & Method of depolymerization & Mean molecular weight (kDa) & Anti-Xa/anti-Ila ratio & Half-life (hours) \\
\hline Dalteparin & Nitrous acid & 6.0 & $1.9-3.2$ & $2.3-2.8$ \\
Enoxaparin & Alkaline & 4.5 & $3.3-5.3$ & $4.0-4.4$ \\
Nadroparin & Nitrous acid & 4.3 & $2.5-4.0$ & 3.7 \\
Tinzaparin & Enzymatic & 6.5 & $1.5-2.5$ & 3.0 \\
Certoparin & Isoamyl nitrite & 5.6 & $2.0-2.4$ & 3.5 \\
Bemiparin & Alkaline & 3.6 & 8.0 & $5.2-5.4$ \\
\hline
\end{tabular}

Abbreviation: LMWH, low-molecular-weight heparin. 
benefit of prophylaxis in the ambulatory setting, the riskbenefit ratio of prophylaxis for hospitalized patients with cancer, an understanding of incidental VTE, and the impact of anticoagulation on survival.

\section{Treatment of VTE}

The standard treatment regimen for a first acute VTE episode consists of initial therapy with heparins (either UFH, LMWHs, or fondaparinux), followed by long-term therapy with a VKA agent for 3-6 months. Today, the monotherapy with LMWHs is recommended for an established VTE event in the cancer patient. ${ }^{56,57}$

\section{Initial treatment}

LMWHs are at least as efficacious as UFH in reducing recurrent thrombosis and are associated with a lower risk of major bleeding, as demonstrated by different RCTs and meta-analyses of these trials. ${ }^{58}$ Data for cancer patients are limited; however, a meta-analysis of 11 studies shows a statistically significant reduction in mortality at 3 months of follow-up with LMWH compared with UFH. ${ }^{59}$ Fondaparinux shows similar efficacy and safety as heparins for the initial treatment of VTE in the general population. ${ }^{60,61}$ However, a recently published post-hoc, subgroup analysis of the 477 cancer patients in the MATISSE DVT and PE trials suggests that fondaparinux may be less effective than LMWHs but more effective than UFH. ${ }^{62}$ There were no statistically significant differences in bleeding among these parenteral agents for initial therapy in cancer patients. ${ }^{59}$

\section{Long-term treatment}

The effects of LMWHs have been compared with those of VKAs in different RCTs of long-term VTE therapy in patients with cancer. ${ }^{20,63-65}$ The largest of these trials, the CLOT study, randomized 676 cancer patients with acute proximal DVT, PE, or both to receive treatment with the LMWH dalteparin (200 IU/kg once daily) for 5-7 days and VKA for 6 months (target INR: 2.5) or dalteparin alone for 6 months (200 IU/kg once daily for 1 month, followed by a daily dose of approximately $150 \mathrm{IU} / \mathrm{kg}$ for 5 months $)^{20}$. The cumulative risk of recurrent VTE at 6 months was reduced from $17 \%$ in the VKA group to $9 \%$ in the dalteparin group, resulting in a statistically significant risk reduction of $52 \%$ ( $\log$-rank $P=0.002)$. Overall, there were no differences in bleeding and mortality between the two treatments. The other trials differ in design from the CLOT study, mainly in the type of LMWH (ie, enoxaparin and tinzaparin), the dose used, and/or duration of treatment ( 3 or 6 months). Although none of these trials, other than CLOT, demonstrated statistically significant differences between LMWHs and warfarin, there was a strong trend favoring LMWHs in all the studies. Based on published evidence, the use of LMWHs alone for the treatment of VTE in patients with cancer is endorsed by international guidelines, ${ }^{56,57}$ and the therapeutic scheme used in the CLOT study is currently the only LMWH regimen with regulatory approval for extended use in preventing recurrent VTE in cancer patients.

\section{Treatment of recurrent thrombosis}

Despite anticoagulation, up to $9 \%$ of patients with cancerassociated thrombosis treated with LMWHs or $20 \%$ treated with VKA can develop recurrent VTE. As suggested by some trials, the presence of metastasis, younger age, or a short interval between VTE and cancer diagnosis ( $<3$ months) are predictors of recurrent thrombosis during anticoagulant treatment. ${ }^{66,67}$ Data coming from RCTs to guide optimal management in oncology patients with recurrent thrombosis are lacking. Observational data and increasing clinical experience support the use of LMWHs in this setting. In patients who developed a recurrence while on warfarin therapy, the simple increase in warfarin administration is not recommended because it is associated with an augmented bleeding risk without a benefit in reducing recurrent VTE. Therefore, the recommended practice is to switch these patients to LMWHs. In addition, dose escalation of LMWHs is often effective in patients who develop a recurrence while on therapy with this drug. In a small cohort study of cancer patients with recurrent VTE while on LMWH or warfarin, escalating the dose of LMWH by $20 \%-25 \%$ or switching to LMWH, respectively, was effective in preventing further thrombotic episodes. ${ }^{68}$

\section{Impact of different LMWHs on patient- specific outcomes: focus on survival}

Since the early 1980s, a beneficial effect of heparins on overall survival has been reported by several retrospective evaluations of cohorts of cancer patients enrolled in RCTs of perioperative prophylaxis with UFH versus no prophylaxis; the one conducted by Kakkar et al being the most representative study. ${ }^{69}$ Lebeau et $\mathrm{al}^{70}$ evaluated, for the first time in a prospective manner, the effect of UFH on survival in patients with small cell lung cancer (SCLC) undergoing chemotherapy. The results of this RCT showed a higher complete response rate, median survival, and survival rates in patients receiving UFH together with chemotherapy, these being statistically significant differences only in the group of patients with limited disease $(P=0.03)$. However, a later systematic review 
of all methodologically correct clinical trials in cancer patients without VTE and comparing UFH with placebo or no treatment failed to provide convincing evidence of either positive or negative effects of UFH on cancer survival. ${ }^{71}$ Meanwhile, the use of LMWHs progressively increased and therefore data about the impact of these drugs on cancer survival started to arise. In 1999, a meta-analysis of all clinical trials testing the efficacy of LMWHs versus UFH for the initial treatment of VTE showed a pooled odds ratio for 3-month mortality in cancer patients of 0.61 (95\% CI: $0.40-0.93)$ in favor of LMWHs. ${ }^{72}$ Positive suggestions came also from the CLOT study; a post-hoc analysis of this trial found an advantage in survival in the subgroup of patients with limited disease receiving long-term LMWH dalteparin compared with warfarin. ${ }^{73}$ This indication, together with the known advantages of LMWH administration and the feasibility of long-term treatment, has prompted researchers to continue to investigate the potential role of LMWH as an antineoplastic agent. Prospective RCTs have therefore been designed to address as primary endpoint the survival of cancer patients receiving LMWHs. ${ }^{74}$ Table 3 summarizes the studies specifically designed for this purpose. The Fragmin Advanced Malignacy Outcome Study (FAMOUS) ${ }^{75}$ was a placebo-controlled RCT that examined the possible effects of the LMWH dalteparin on survival among patients with cancer without any evidence of thrombosis. Patients with different types of advanced solid malignant tumor were assigned to receive for 1 year either dalteparin (5000 IU/day, subcutaneously) or placebo along with standard cancer therapies. A statistically significant survival advantage at 2 and 3 years of randomization was found in those patients receiving dalteparin, with a relatively good prognosis at enrolment. The single-institution study by Altinbas et al revealed promising results on the benefit of a prophylactic administration of LMWH dalteparin (5000 IU/day, subcutaneously) given in combination with chemotherapy in patients with SCLC ${ }^{76}$ The results showed an overall tumor response rate significantly higher $(69.2 \%$ vs $42.5 \%$; $P=0.07)$, as well as the median progression-free survival ( 10 months vs 6 months; $P=0.01$ ) in patients receiving dalteparin. The randomized, placebo-controlled Malignacy and Low Molecular Weight Heparin Therapy (MALT) study evaluated the effect on survival of a therapeutic dose of the LMWH nadroparin in patients with metastatic or locally advanced solid malignancies, and no evidence of VTE ${ }^{77} \mathrm{~A}$ modest but significant survival benefit was observed among patients treated with LMWHs, particularly in those with a life expectancy at entry of at least 6 months. In 2006, another RCT evaluated the effect on survival of the LMWH dalteparin (5000 IU) in addition to standard clinical care in patients with advanced cancer. ${ }^{78}$ No statistically significant differences were found in the median survival time for the combined standard care and placebo groups (10.5 months) compared with the combined LMWH arm (7.3 months). Kuderer et al performed the first meta-analysis and systematic review of all RCTs on the efficacy and safety of anticoagulants (LMWHs, UFH, and VKA) in the treatment of patients with cancer without VTE. ${ }^{79}$ The results obtained from eleven eligible trials show that the administration of any sort of anticoagulation significantly decreased overall 1-year mortality with a relative risk of 0.905 (95\% CI: $0.85-0.97, P=0.003$ vs no anticoagulation). Interestingly, for LMWHs, the relative risk of mortality was 0.88 (95\% CI: $0.79-0.98, P=0.015)$, compared with a nonsignificant effect of warfarin, resulting in an absolute risk reduction of mortality of $8 \%$ for LMWHs, with also less major bleeding events in the LMWH group compared with warfarin. These findings have been confirmed in subsequent reviews. ${ }^{80}$

Table 3 Randomized clinical trials testing the effect of LMWHs on survival of cancer patients

\begin{tabular}{|c|c|c|c|c|}
\hline Study & Cancer type & Control & LMWH (regimen) & Effect on survival ${ }^{\mathrm{a}}$ \\
\hline Altinbas et $\mathrm{al}^{76}$ & SCLC & None & Dalteparin (5000 IU/day, I8 weeks) & + \\
\hline FAMOUS 75 & Advanced cancer & Placebo & Dalteparin (5000 IU/day, I year) & $\begin{array}{l}+/-(+ \text { patient with } \\
\text { better prognosis })\end{array}$ \\
\hline $\mathrm{MALT}^{77}$ & Metastasized and advanced cancer & Placebo & $\begin{array}{l}\text { Nadroparin (therapeutic dose } 2 \text { weeks + } \\
\text { half dose } 4 \text { weeks) }\end{array}$ & $\begin{array}{l}+/-(+ \text { patient with } \\
\text { better prognosis) }\end{array}$ \\
\hline Sideras et $\mathrm{al}^{78}$ & Advanced cancer & None & Dalteparin (5000 IU/day, 2 years) & + \\
\hline INPACT $^{82}$ & NSCLC, prostate, pancreatic & None & $\begin{array}{l}\text { Nadroparin (therapeutic dose } 2 \text { weeks }+ \\
\text { half dose } 4 \text { weeks, weight adjusted, followed } \\
\text { by up to six cycles) }\end{array}$ & None \\
\hline $\mathrm{ABEL}^{94}$ & Limited SCLC & None & Bemiparin (3500 IU/day, 26 weeks) & + \\
\hline $\begin{array}{l}\text { TILT (ongoing, } \\
\text { NCT 004775098) }\end{array}$ & NSCLC & Placebo & Tinzaparin (I00 IU/kg once-daily, I 2 weeks) & N/A \\
\hline
\end{tabular}

Notes: ${ }^{a}+$, positive effect of LMWH on survival; N/A, results not yet available; $+/-$, inconclusive.

Abbreviations: LMWH, low-molecular-weight heparin; NCT, National Clinical Trial; NSCLC, non-small cell lung cancer; SCLC, small cell lung cancer. 
Since then, other studies have been published or started. In a group of patients with pancreatic carcinoma, the addition of LMWH nadroparin (2850 IU/day) to chemotherapeutic regimen (gemcitabine plus cisplatinum) significantly increased the median time to progression and survival (13.0 vs 5.5 months, $P=0.0001$ ) for both metastatic and locally advanced carcinoma. ${ }^{81}$ However, this was a nonrandomized study performed in a very small group of patients $(n=69)$. In 2011, the results of the INPACT study, a multicenter, randomized, open-label study, did not show any survival benefit of nadroparin in addition to standard anticancer treatment in patients with different types of cancer (ie, NSCLC, hormonerefractory prostate cancer, or locally advanced pancreatic cancer) ${ }^{82}$ Ongoing studies on the effect of LMWHs on VTE prevention in cancer patients, including the CONKO-004, ${ }^{44}$ the FRAGEM,${ }^{45}$ and the FRAGMATIC trials, ${ }^{83}$ incorporate as secondary objective the effect of LMWHs on cancer survival. These results are yet unknown.

\section{Mechanisms of antitumor effect of heparins}

The suggestions coming from clinical trials of the beneficial effects of LMWHs on survival from cancer have triggered basic research to investigate on the potential antitumor effects of LMWHs in vitro and in animal models. Several different and possibly interrelated biological mechanisms have been proposed, including both coagulation-dependent and -independent activities (Figure 2). Indeed it has been demonstrated that heparin can interfere with tumor progression by inhibiting: (1) heparin-binding growth factors that drive

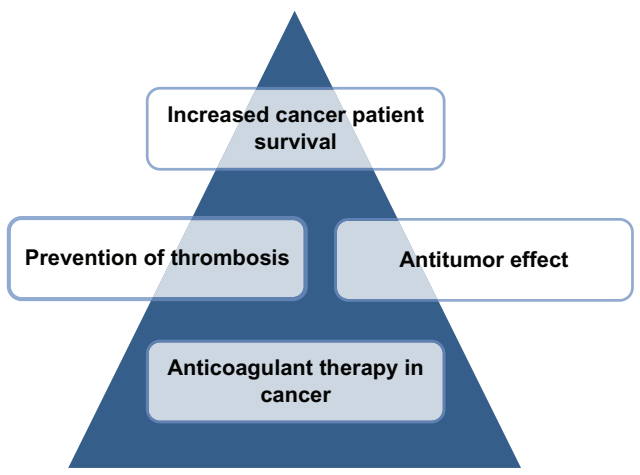

Figure 2 Antitumor properties of low-molecular-weight heparins. The rationale for an antitumor effect of anticoagulant drugs may rely on their capacity to inhibit blood coagulation. However, these agents, particularly heparins, exhibit the capacity to block hemostatic pathways specifically implicated in tissue malignant behavior, and show a number of coagulation-independent activities against cancer. malignant cell growth; (2) tumor angiogenesis; (3) tumor cell heparanase that mediates tumor cell invasion and metastasis; (4) cell surface selectin-mediated tumor cell metastasis; and (5) blood coagulation activation that may provide an environment leading to tumor growth.

Particularly, the inhibitory effects of heparins on angiogenesis have been actively investigated in both in vivo and in vitro systems. ${ }^{84}$ The molecular mechanisms involved in LMWH angiogenesis modulation include heparin binding to endothelial cells, induction of anti-angiogenic factors (such as tissue factor pathway inhibitor), and inhibition of proangiogenic factor release (such as tissue factor). Table 4 summarizes the most important studies conducted in vitro on the effects of LMWHs on endothelial cells exposed to angiogenic growth factors or tumor derived products. ${ }^{85-88}$ While it is well known that the anticoagulant properties of heparins are related to their chain length, the biochemical properties that could contribute to different in vitro antitumor efficacies are still not well elucidated. A study conducted by Khorana et al suggests that the different anti-proliferative and anti-angiogenic activities on endothelial cells of various commercial LMWHs, or purified heparin fractions, may be ultimately dependent on their mean MW and possibly by the sulfatation rate. ${ }^{86}$

Along this line of research, we have recently demonstrated that, in an in vitro system of interaction of cancer cells with microvascular endothelial cells, two LMWHs, ie, dalteparin and enoxaparin, prevents the formation of endothelial cell capillary formation induced by breast cancer and leukemic cells, and by standard proangiogenic factors (ie, vascular endothelial growth factor and fibroblast growth factor-2). ${ }^{85}$ Very recently, a similar anti-angiogenic activity has also been described for the "second generation" LMWH bemiparin and for the ultra-LMWH RO-14. ${ }^{87}$ The authors of this present paper are currently extending their studies by exploring the in vitro antitumor effect of LMWH on pancreatic cancer. This type of tumor carries the highest risk of thrombotic events amongst any other gastrointestinal cancers, with an incidence range of $17 \%-57 \% .{ }^{89}$ Furthermore, the diagnosis of VTE in pancreatic cancer is associated with poor overall survival. ${ }^{90}$ As shown in Figure 3, the LMWH dalteparin, bemiparin and the ultra-LMWH RO14 significantly prevented the capillarynetwork formation induced by a pancreatic cancer cell line. Interestingly, the anti-angiogenic effect was higher for the LMWH compared with the ultra-LMWH RO14. In addition, the same heparins showed a direct inhibitory effect on the migration of pancreatic cancer cells (Figure 4). Altogether, these in vitro data further contribute to support the evidence of a possible antitumor in vivo effect of LMWHs. 
Table 4 In vitro studies exploring the effect of LMWH on tumor-induced endothelial cell angiogenesis

\begin{tabular}{|c|c|c|c|c|}
\hline LMWH & Experimental model & Anti-angiogenic effect & LMWH mechanism proposed & Reference \\
\hline \multirow[t]{3}{*}{ Dalteparin } & TCM-stimulated HMEC-I & Inhibition of endothelial cell tube formation & Interference with bFGF and VEGF & Marchetti et $\mathrm{al}^{85}$ \\
\hline & and HUVEC & & binding to their receptors & \\
\hline & bFGF-stimulated HUVEC & $\begin{array}{l}\text { Inhibition of endothelial cell tube formation } \\
\text { and proliferation }\end{array}$ & $\begin{array}{l}\text { Interference with bFGF binding } \\
\text { to its receptor }\end{array}$ & Khorana et al ${ }^{86}$ \\
\hline Enoxaparin & bFGF-stimulated HUVEC & $\begin{array}{l}\text { Inhibition of endothelial cell tube formation } \\
\text { and proliferation }\end{array}$ & $\begin{array}{l}\text { Interference with bFGF binding } \\
\text { to its receptor }\end{array}$ & Khorana et al ${ }^{86}$ \\
\hline \multirow[t]{3}{*}{ Tinzaparin } & bFGF and TF/FVIla & Inhibition of endothelial cell tube formation & Increased release of TFPI & Mousa and \\
\hline & stimulated HUVEC & & & Mohamed $^{88}$ \\
\hline & bFGF-stimulated HUVEC & $\begin{array}{l}\text { Inhibition of endothelial cell tube formation } \\
\text { and proliferation }\end{array}$ & $\begin{array}{l}\text { Interference with bFGF binding } \\
\text { to its receptor }\end{array}$ & Khorana et al ${ }^{86}$ \\
\hline Bemiparin & TCM-stimulated HMEC-I & $\begin{array}{l}\text { Inhibition of endothelial cell tube formation, } \\
\text { proliferation, and wound healing }\end{array}$ & $\begin{array}{l}\text { Interference with angiogenic factor } \\
\text { binding to their receptor, increased } \\
\text { released of TFPI }\end{array}$ & Vignoli et $\mathrm{al}^{87}$ \\
\hline Nadroparin & - & - & - & N/A \\
\hline Certoparin & - & - & - & $\mathrm{N} / \mathrm{A}$ \\
\hline
\end{tabular}

Note: Selected works from the literature on the commercially available LMWH cited in the article.

Abbreviations: bFGF, basic fibroblast growth factor; HMEC-I, human microvascular endothelial cell line-I; HUVEC, human umbilical vein endothelial cells; LMWH, low-molecular-weight heparin; N/A, not applicable; TCM, tumor-conditioned medium; TF, tissue factor; FVIla, activated coagulation factor VII; TFPI, tissue factor pathway inhibitor; VEGF, vascular endothelial growth factor.

\section{Implications for future work and enhanced patient care}

Taken together, the results of the available evidence on the beneficial effect of LMWH on the survival of cancer patients are inconclusive. The majority of the studies described above included heterogeneous populations of cancer patients.
Future trials should be designed to study the effect of LMWHs in specific tumor types and stages.

Moreover, since emerging evidence shows that the use of specific angiogenesis inhibitors or erythropoiesis stimulating agents ${ }^{91}$ is associated with a further increase of VTE risk in cancer patients, it would be of interest to consider

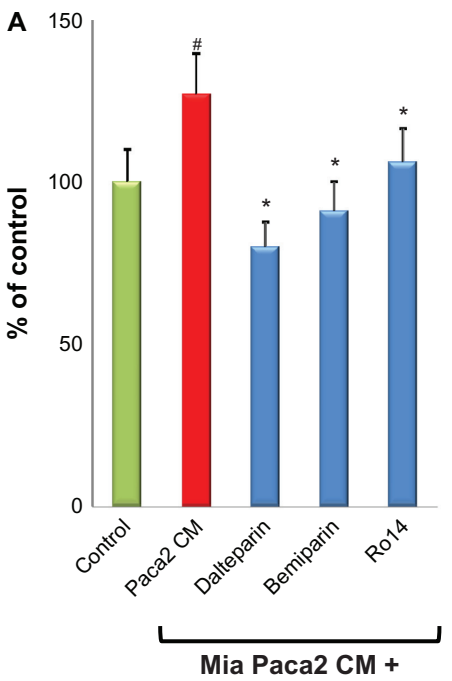

B

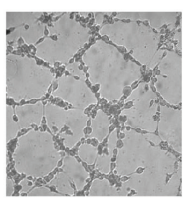

Paca2 CM

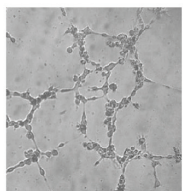

+Bemiparin

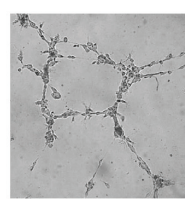

+Dalteparin

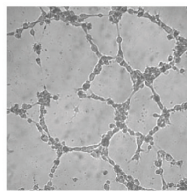

+ Ro14

Figure 3 LMWHs inhibit endothelial angiogenesis induced by conditioned medium from pancreatic tumor cells. Endothelial cells were incubated with TCM from a human pancreatic carcinoma (MIA Paca2) cell line, in the presence or absence of I IU/mL LMWH bemiparin, dalteparin, and the ultra-LMWH Rol4. After 24 hours incubation, capillary-like tube formation was evaluated as previously described. ${ }^{85}$ (A) The three heparins significantly inhibited the increase of tube formation induced by TCM. (B) Representative pictures of selected experiments showing the inhibition by the different heparins of pancreatic tumor cell-induced endothelial cell capillary-like tube. Notes: Data are means + standard deviations of three experiments performed in duplicate. ${ }^{\#} P<0.05$ vs control; $* P<0.05$ vs Paca 2 CM.

Abbreviations: LMWH, low-molecular-weight heparin; TCM, tumor-conditioned medium. 


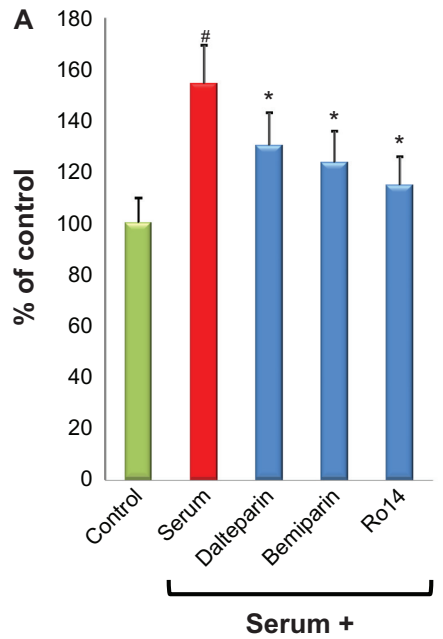

B

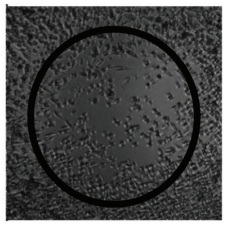

Serum

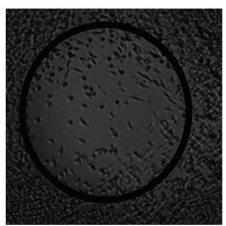

+Bemiparin

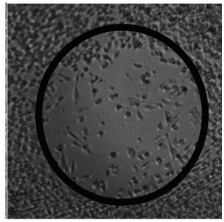

+Dalteparin

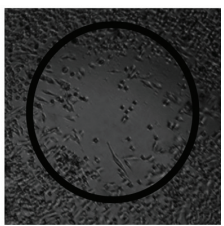

+ Ro14

Figure $4 \mathrm{LMWHs}$ inhibit the proliferation/migration of pancreatic tumor cells. The human pancreatic carcinoma (MIA Paca2) cells were grown to confluence at $37^{\circ} \mathrm{C}$ in a $5 \% \mathrm{CO}_{2}$ atmosphere in incubator, wounded, and grown in presence or absence of I IU/mL LMWH bemiparin, dalteparin, and the ultra-LMWH Rol4. After 48 hours of incubation, the rate of proliferation/migration was evaluated as previously described ${ }^{87}$ (A) Heparins significantly affect the proliferation/migration features of pancreatic cancer cells. (B) Representative pictures of selected experiments showing the inhibition by the different heparins of proliferation/migration of pancreatic tumor cells.

Notes: Data are means + standard deviations of three different experiments performed in duplicate and are expressed as percentage of regrowth area, assuming the area occupied by cells in absence of fetal calf serum as $100 \%$ of regrowth. $\# P<0.05$ vs control; $* P<0.05$ vs serum.

Abbreviation: LMWH, low-molecular-weight heparin.

ad-hoc trials to evaluate the potential beneficial role of LMWH prophylaxis on these therapeutic regimens.

Interestingly, new LMWHs characterized by a lower mean MW, and a more defined composition of polysaccharidic chain content, have been made available. These new heparins, called ultra-LMWHs, are characterized by a high anti-FXa activity and only residual anti-FIIa activity, thus the ratio anti-FXa/anti-FIIa is much greater compared with classical LMWHs. Some ultra-LMWHs are in clinical development. One of these, semuloparin, is currently being evaluated in cancer patients in the SAVE ONCO trial..$^{92}$ This is a double-blind study in patients with metastatic or locally advanced cancer of lung, colon-rectum, stomach, ovary, pancreas, or bladder, initiating a new chemotherapy course. Patients are randomized to receive semuloparin, or placebo, until change of chemotherapy. The primary efficacy outcomes are the composite of any DVT-, nonfatal PE-, and VTE-related death. The results of the 3212 patients enrolled so far demonstrate a $64 \%$ risk reduction of VTE (hazard ratio: $0.36,95 \%$ CI: $0.21-0.60$, $P<0.0001$ intention-to-treat analysis) with ultra-LMWH semuloparin (VTE incidence: $1.2 \%$ ) compared with placebo (3.4\%), with no significant difference in major bleeding (semuloparin $1.2 \%$ vs placebo $1.1 \%$ ).

\section{Conclusion}

Cancer patients present a high risk of developing VTE. All efforts must be made to prevent this potentially lifethreatening complication. As in noncancer patients, the first prophylactic and therapeutic approach was based on VKA, eg, warfarin. Then, UFH was increasingly used as an alternative to VKA. However, in the last few decades, there has been a progressive shift towards the use of LMWHs, which present some advantages compared with the parental drug UFH, which are now the drugs of choice for thromboprophylaxis and VTE prevention in cancer patients. Clinical data on the comparison of LMWHs is very limited. Even if the different LMWHs may show similar therapeutic profiles, it must be noted that they possess different molecular, pharmacokinetic, and functional patterns. ${ }^{21}$

Recent studies, although partially conflicting and inconclusive, suggest a beneficial impact of LMWHs on cancer patient survival, which cannot be explained with only the prevention of VTE, but may be attributable to an anticancer action of these drugs. ${ }^{93}$ Several trials are ongoing to understand which categories of cancer patients may better benefit from an adjuvant use of LMWHs, while the very recent availability of ultra-LMWHs may open even more promising perspectives. 


\section{Disclosure}

The authors have no financial or other conflicts of interest to declare in relation to this paper.

\section{References}

1. Piccioli A, Prandoni P. Venous thromboembolism as first manifestation of cancer. Acta Haematol. 2001;106:13-17.

2. Prandoni P, Lensing AW, Buller HR, et al. Deep-vein thrombosis and the incidence of subsequent symptomatic cancer. $N$ Engl J Med. 1992;327:1128-1133

3. Khorana AA, Francis CW, Culakova E, Fisher RI, Kuderer NM, Lyman GH. Thromboembolism in hospitalized neutropenic cancer patients. J Clin Oncol. 2006;24:484-490.

4. Khorana AA, Francis CW, Culakova E, Lyman GH. Risk factors for chemotherapy-associated venous thromboembolism in a prospective observational study. Cancer. 2005;104:2822-2829.

5. Rickles FR, Levine MN. Epidemiology of thrombosis in cancer. Acta Haematol. 2001;106:6-12.

6. Falanga A, Rickles FR. Management of thrombohemorrhagic syndromes (THS) in hematologic malignancies. Hematology Am Soc Hematol Educ Program. 2007:165-171.

7. Khorana AA, Kuderer NM, Culakova E, Lyman GH, Francis CW. Development and validation of a predictive model for chemotherapyassociated thrombosis. Blood. 2008;111:4902-4907.

8. Falanga A, Barbui T, Rickles FR, Levine MN. Guidelines for clotting studies in cancer patients. For the Scientific and Standardization Committee of the Subcommittee on Haemostasis and Malignancy International Society of Thrombosis and Haemostasis. Thromb Haemost. 1993;70:540-542.

9. Falanga A, Donati MB. Pathogenesis of thrombosis in patients with malignancy. Int J Hematol. 2001;73:137-144.

10. Falanga A, Iacoviello L, Evangelista V, et al. Loss of blast cell procoagulant activity and improvement of hemostatic variables in patients with acute promyelocytic leukemia administered alltrans-retinoic acid. Blood. 1995;86:1072-1081

11. Falanga A, Levine MN, Consonni R, et al. The effect of very-low-dose warfarin on markers of hypercoagulation in metastatic breast cancer: results from a randomized trial. Thromb Haemost. 1998;79:23-27.

12. Seitz R, Rappe N, Kraus M, et al. Activation of coagulation and fibrinolysis in patients with lung cancer: relation to tumour stage and prognosis. Blood Coagul Fibrinolysis. 1993;4:249-254

13. Wada H, Sase T, Yamaguchi M. Hypercoagulant states in malignant lymphoma. Exp Oncol. 2005;27:179-185.

14. Falanga A, Marchetti M, Vignoli A, Balducci D. Clotting mechanisms and cancer: implications in thrombus formation and tumor progression. Clin Adv Hematol Oncol. 2003;1:673-678.

15. Falanga A, Panova-Noeva M, Russo L. Procoagulant mechanisms in tumour cells. Best Pract Res Clin Haematol. 2009;22:49-60.

16. Hutten BA, Prins MH, Gent M, Ginsberg J, Tijssen JG, Buller HR. Incidence of recurrent thromboembolic and bleeding complications among patients with venous thromboembolism in relation to both malignancy and achieved international normalized ratio: a retrospective analysis. J Clin Oncol. 2000;18:3078-3083.

17. Prandoni P, Lensing AW, Piccioli A, et al. Recurrent venous thromboembolism and bleeding complications during anticoagulant treatment in patients with cancer and venous thrombosis. Blood. 2002;100:3484-3488.

18. Khorana AA. Cancer and thrombosis: implications of published guidelines for clinical practice. Ann Oncol. 2009;20:1619-1630.

19. Hirsh J, Warkentin TE, Shaughnessy SG, et al. Heparin and lowmolecular-weight heparin: mechanisms of action, pharmacokinetics, dosing, monitoring, efficacy, and safety. Chest. 2001;119:64S-94S.

20. Lee AY, Levine MN, Baker RI, et al. Low-molecular-weight heparin versus a coumarin for the prevention of recurrent venous thromboembolism in patients with cancer. $N$ Engl J Med. 2003;349:146-153.
21. Fareed J, Hoppensteadt D, Schultz C, et al. Biochemical and pharmacologic heterogeneity in low molecular weight heparins. Impact on the therapeutic profile. Curr Pharm Des. 2004;10:983-999.

22. Samama MM, Gerotziafas GT. Comparative pharmacokinetics of LMWHs. Semin Thromb Hemost. 2000;26 Suppl 1:31-38.

23. Eriksson BI, Soderberg K, Widlund L, Wandeli B, Tengborn L, Risberg B. A comparative study of three low-molecular weight heparins $(\mathrm{LMWH})$ and unfractionated heparin $(\mathrm{UH})$ in healthy volunteers. Thromb Haemost. 1995;73:398-401.

24. Frydman A. Low-molecular-weight heparins: an overview of their pharmacodynamics, pharmacokinetics and metabolism in humans. Haemostasis. 1996;26 Suppl 2:24-38.

25. Bara L, Samama M. Pharmacokinetics of low molecular weight heparins. Acta Chir Scand Suppl. 1988;543:65-72.

26. Collignon F, Frydman A, Caplain H, et al. Comparison of the pharmacokinetic profiles of three low molecular mass heparins - dalteparin, enoxaparin and nadroparin - administered subcutaneously in healthy volunteers (doses for prevention of thromboembolism). Thromb Haemost. 1995;73:630-640.

27. Mismetti P, Laporte S, Darmon JY, Buchmuller A, Decousus H. Meta-analysis of low molecular weight heparin in the prevention of venous thromboembolism in general surgery. Br J Surg. 2001;88: 913-930.

28. Dentali F, Douketis JD, Gianni M, Lim W, Crowther MA. Meta-analysis: anticoagulant prophylaxis to prevent symptomatic venous thromboembolism in hospitalized medical patients. Ann Intern Med. 2007;146:278-288.

29. Efficacy and safety of enoxaparin versus unfractionated heparin for prevention of deep vein thrombosis in elective cancer surgery: a double-blind randomized multicentre trial with venographic assessment. ENOXACAN Study Group. Br J Surg. 1997;84:1099-1103.

30. Bergqvist D, Agnelli G, Cohen AT, et al. Duration of prophylaxis against venous thromboembolism with enoxaparin after surgery for cancer N Engl J Med. 2002;346:975-980.

31. Khorana AA, Streiff MB, Farge D, et al. Venous thromboembolism prophylaxis and treatment in cancer: a consensus statement of major guidelines panels and call to action. J Clin Oncol. 2009;27:4919-4926.

32. Kakkar AK, Haas S, Wolf H, Encke A. Evaluation of perioperative fatal pulmonary embolism and death in cancer surgical patients: the MC-4 cancer substudy. Thrombos Haemost. 2005;94:867-871.

33. Bergqvist D, Burmark US, Flordal PA, et al. Low molecular weight heparin started before surgery as prophylaxis against deep vein thrombosis: 2500 versus $5000 \mathrm{XaI}$ units in 2070 patients. Br J Surg. 1995;82:496-501.

34. Hull RD, Pineo GF, Stein PD, et al. Extended out-of-hospital lowmolecular-weight heparin prophylaxis against deep venous thrombosis in patients after elective hip arthroplasty: a systematic review. Ann Intern Med. 2001;135:858-869.

35. Rasmussen MS, Jorgensen LN, Wille-Jorgensen P, et al. Prolonged prophylaxis with dalteparin to prevent late thromboembolic complications in patients undergoing major abdominal surgery: a multicenter randomized open-label study. J Thromb Haemost. 2006;4:2384-2390.

36. Kakkar VV, Balibrea JL, Martinez-Gonzalez J, Prandoni P. Extended prophylaxis with bemiparin for the prevention of venous thromboembolism after abdominal or pelvic surgery for cancer: the CANBESURE randomized study. J Thromb Haemost. 2010;8:1223-1229.

37. Samama MM, Cohen AT, Darmon JY, et al. A comparison of enoxaparin with placebo for the prevention of venous thromboembolism in acutely ill medical patients. Prophylaxis in Medical Patients with Enoxaparin Study Group. N Engl J Med. 1999;341:793-800.

38. Alikhan R, Cohen AT, Combe S, et al. Prevention of venous thromboembolism in medical patients with enoxaparin: a subgroup analysis of the MEDENOX study. Blood Coagul Fibrinolysis. 2003;14:341-346.

39. Leizorovicz A, Cohen AT, Turpie AG, Olsson CG, Vaitkus PT, Goldhaber SZ. Randomized, placebo-controlled trial of dalteparin for the prevention of venous thromboembolism in acutely ill medical patients. Circulation. 2004;110:874-879. 
40. Cohen AT, Turpie AG, Leizorovicz A, Olsson CG, Vaitkus PT, Goldhaber SZ. Thromboprophylaxis with dalteparin in medical patients: which patients benefit? Vasc Med. 2007;12:123-127.

41. Cohen AT, Davidson BL, Gallus AS, et al. Efficacy and safety of fondaparinux for the prevention of venous thromboembolism in older acute medical patients: randomised placebo controlled trial. BMJ. 2006;332:325-329.

42. Levine M, Hirsh J, Gent M, et al. Double-blind randomised trial of a very-low-dose warfarin for prevention of thromboembolism in stage IV breast cancer. Lancet. 1994;343:886-889.

43. Riess H, Pelzer U, Deutschinoff G, et al. A prospective, randomized trial of chemotherapy with or without the low molecular weight heparin (LMWH) enoxaparin in patients (pts) with advanced pancreatic cancer (APC): results of the CONKO 004 trial [abstract]. J Clin Oncol. 2009;27: abst LBA4506.

44. Riess H, Pelzer U, Hilbig A, et al. Rationale and design of PROSPECTCONKO 004: a prospective, randomized trial of simultaneous pancreatic cancer treatment with enoxaparin and chemotherapy. BMC Cancer. 2008;8:361.

45. Maraveyas A, Waters J, Roy R, et al. Gemcitabine with or without prophylactic weight-adjusted dalteparin in patients with advanced or metastatic pancreatic cancer (APC): a multicentre, randomised phase IIB trial (the UK FRAGEM study). Eur J Cancer Suppl. 2009;7:362.

46. Haas SK, Kakkar AK, Kemkes-Matthes B, et al. Prevention of Venous Thromboembolism with low-molecular-weight heparin in patients with metastatic breast or lung cancer - results of the TOPIC studies [abstract] J Thromb Haemost. 2005;3: abst OR059.

47. Perry JR, Julian JA, Laperriere NJ, et al. PRODIGE: a randomized placebo-controlled trial of dalteparin low-molecular-weight heparin thromboprophylaxis in patients with newly diagnosed malignant glioma. J Thromb Haemost. 2010;8:1959-1965.

48. Agnelli G, Gussoni G, Bianchini C, et al. Nadroparin for the prevention of thromboembolic events in ambulatory patients with metastatic or locally advanced solid cancer receiving chemotherapy: a randomised, placebocontrolled, double-blind study. Lancet Oncol. 2009;10:943-949.

49. Geerts WH, Bergqvist D, Pineo GF, et al. Prevention of venous thromboembolism: American College of Chest Physicians Evidence-Based Clinical Practice Guidelines (8th Edition). Chest. 2008; 133:381S-453S.

50. Prevention and treatment of venous thromboembolism. International Consensus Statement (guidelines according to scientific evidence). Int Angiol. 2006;25:101-161.

51. Streiff MB. The National Comprehensive Cancer Center Network (NCCN) guidelines on the management of venous thromboembolism in cancer patients. Thromb Res. 2010;125 Suppl 2:S128-S133.

52. Mandala M, Falanga A, Piccioli A, et al. Venous thromboembolism and cancer: guidelines of the Italian Association of Medical Oncology (AIOM). Crit Rev Oncol Hematol. 2006;59:194-204.

53. Farge D, Bosquet L, Kassab-Chahmi D, et al. 2008 French national guidelines for the treatment of venous thromboembolism in patients with cancer: report from the working group. Crit Rev Oncol Hematol. 2010;73:31-46.

54. Mandala M, Falanga A, Roila F. Venous thromboembolism in cancer patients: ESMO Clinical Practice Guidelines for the management. Ann Oncol. 2010;21 Suppl 5:v274-v276.

55. Lyman GH, Kuderer NM. Prevention and treatment of venous thromboembolism among patients with cancer: the American Society of Clinical Oncology Guidelines. Thromb Res. 2010;125 Suppl 2: S120-S127.

56. Lyman GH, Khorana AA, Falanga A, et al. American Society of Clinical Oncology guideline: recommendations for venous thromboembolism prophylaxis and treatment in patients with cancer. J Clin Oncol. 2007;25:5490-5505.

57. Kearon C, Kahn SR, Agnelli G, Goldhaber S, Raskob GE, Comerota AJ Antithrombotic therapy for venous thromboembolic disease: American College of Chest Physicians Evidence-Based Clinical Practice Guidelines (8th ed). Chest. 2008;133:454S-545S.
58. Van Dongen CJ, van den Belt AG, Prins MH, Lensing AW. Fixed dose subcutaneous low molecular weight heparins versus adjusted dose unfractionated heparin for venous thromboembolism. Cochrane Database Syst Rev. 2004;(4):CD001100.

59. Akl EA, Vasireddi SR, Gunukula S, et al. Anticoagulation for the initial treatment of venous thromboembolism in patients with cancer. Cochrane Database Syst Rev. 2011;(6):CD006649.

60. Buller HR, Davidson BL, Decousus H, et al. Subcutaneous fondaparinux versus intravenous unfractionated heparin in the initial treatment of pulmonary embolism. New Engl J Med. 2003;349:1695-1702.

61. Buller HR, Davidson BL, Decousus H, et al. Fondaparinux or enoxaparin for the initial treatment of symptomatic deep venous thrombosis: a randomized trial. Ann Intern Med. 2004;140:867-873.

62. Van Doormaal FF, Raskob GE, Davidson BL, et al. Treatment of venous thromboembolism in patients with cancer: subgroup analysis of the Matisse clinical trials. Thromb Haemost. 2009;101:762-769.

63. Meyer G, Marjanovic Z, Valcke J, et al. Comparison of low-molecularweight heparin and warfarin for the secondary prevention of venous thromboembolism in patients with cancer: a randomized controlled study. Arch Intern Med. 2002;162:1729-1735.

64. Deitcher SR, Kessler CM, Merli G, Rigas JR, Lyons RM, Fareed J. Secondary prevention of venous thromboembolic events in patients with active cancer: enoxaparin alone versus initial enoxaparin followed by warfarin for a 180-day period. Clin Appl Thromb Hemost. 2006;12:389-396.

65. Hull RD, Pineo GF, Brant RF, et al. Long-term low-molecular-weight heparin versus usual care in proximal-vein thrombosis patients with cancer. Am J Med. 2006;119:1062-1072.

66. Trujillo-Santos J, Nieto JA, Tiberio G, et al. Predicting recurrences or major bleeding in cancer patients with venous thromboembolism. Findings from the RIETE Registry. Thromb Haemost. 2008;100:435-439.

67. Lee AY, Parpia S, Julian J, Rickles FR, Prins M, Levine M. Risk factors for recurrent thrombosis and anticoagulant - related bleeding in cancer patients [abstract]. J Thromb Haemost. 2009;7: abst 107.

68. Carrier M, Le Gal G, Cho R, Tierney S, Rodger M, Lee AY. Dose escalation of low molecular weight heparin to manage recurrent venous thromboembolic events despite systemic anticoagulation in cancer patients. J Thromb Haemost. 2009;7:760-765.

69. Kakkar A, Hedges R, Williamson R, Kakkar V. Perioperative heparin-therapy inhibits late death from metastatic cancer. Int J Oncol. 1995;6:885-888.

70. Lebeau B, Chastang C, Brechot JM, et al. Subcutaneous heparin treatment increases survival in small cell lung cancer. "Petites Cellules" Group. Cancer. 1994;74:38-45.

71. Smorenburg SM, Hettiarachchi RJ, Vink R, Buller HR. The effects of unfractionated heparin on survival in patients with malignancy - a systematic review. Thromb Haemost. 1999;82:1600-1604.

72. Hettiarachchi RJ, Smorenburg SM, Ginsberg J, Levine M, Prins MH, Buller HR. Do heparins do more than just treat thrombosis? The influence of heparins on cancer spread. Thromb Haemost. 1999;82:947-952.

73. Lee AY, Rickles FR, Julian JA, et al. Randomized comparison of low molecular weight heparin and coumarin derivatives on the survival of patients with cancer and venous thromboembolism. J Clin Oncol. 2005;23:2123-2129.

74. Falanga A. The effect of anticoagulant drugs on cancer. J Thromb Haemost. 2004;2:1263-1265.

75. Kakkar AK, Levine MN, Kadziola Z, et al. Low molecular weight heparin, therapy with dalteparin, and survival in advanced cancer: the fragmin advanced malignancy outcome study (FAMOUS). J Clin Oncol. 2004;22:1944-1948.

76. Altinbas M, Coskun HS, Er O, et al. A randomized clinical trial of combination chemotherapy with and without low-molecular-weight heparin in small cell lung cancer. J Thromb Haemost. 2004;2:1266-1271.

77. Klerk CP, Smorenburg SM, Otten HM, et al. The effect of low molecular weight heparin on survival in patients with advanced malignancy. J Clin Oncol. 2005;23:2130-2135. 
78. Sideras K, Schaefer PL, Okuno SH, et al. Low-molecular-weight heparin in patients with advanced cancer: a phase 3 clinical trial. Mayo Clin Proc. 2006;81:758-767.

79. Kuderer NM, Khorana AA, Lyman GH, Francis CW. A meta-analysis and systematic review of the efficacy and safety of anticoagulants as cancer treatment: impact on survival and bleeding complications. Cancer. 2007;110:1149-1161.

80. Lazo-Langner A, Goss GD, Spaans JN, Rodger MA. The effect of low-molecular-weight heparin on cancer survival. A systematic review and meta-analysis of randomized trials. J Thromb Haemost. 2007;5:729-737.

81. Icli F, Akbulut H, Utkan G, et al. Low molecular weight heparin (LMWH) increases the efficacy of cisplatinum plus gemcitabine combination in advanced pancreatic cancer. J Surg Oncol. 2007;95:507-512.

82. Van Doormaal FF, Di Nisio M, Otten HM, Richel DJ, Prins M, Buller HR. Randomized trial of the effect of the low molecular weight heparin nadroparin on survival in patients with cancer. J Clin Oncol. 2011;29:2071-2076.

83. Griffiths GO, Burns S, Noble SI, Macbeth FR, Cohen D, Maughan TS. FRAGMATIC: a randomised phase III clinical trial investigating the effect of fragmin added to standard therapy in patients with lung cancer. BMC Cancer. 2009;9:355.

84. Norrby K. Low-molecular-weight heparins and angiogenesis. APMIS. 2006;114:79-102.

85. Marchetti M, Vignoli A, Russo L, et al. Endothelial capillary tube formation and cell proliferation induced by tumor cells are affected by low molecular weight heparins and unfractionated heparin. Thromb Res. 2008;121:637-645.
86. Khorana AA, Sahni A, Altland OD, Francis CW. Heparin inhibition of endothelial cell proliferation and organization is dependent on molecular weight. Arterioscler Thromb Vasc Biol. 2003;23:2110-2115.

87. Vignoli A, Marchetti M, Russo L, et al. LMWH bemiparin and ULMWH RO-14 reduce the endothelial angiogenic features elicited by leukemia, lung cancer, or breast cancer cells. Cancer Invest. 2011;29:153-161.

88. Mousa SA, Mohamed S. Inhibition of endothelial cell tube formation by the low molecular weight heparin, tinzaparin, is mediated by tissue factor pathway inhibitor. Thromb Haemost. 2004;92:627-633.

89. Khorana AA, Fine RL. Pancreatic cancer and thromboembolic disease Lancet Oncol. 2004;5:655-663.

90. Chew HK, Wun T, Harvey DJ, Zhou H, White RH. Incidence of venous thromboembolism and the impact on survival in breast cancer patients. J Clin Oncol. 2007;25:70-76.

91. Barbera L, Thomas G. Erythropoiesis stimulating agents, thrombosis and cancer. Radiother Oncol. 2010;95:269-276.

92. Agnelli G, George DJ, Fisher W, et al. The ultra-low molecualr weight heparin (ULMWH) semuloparin for prevention of venous thromboembolism (VTE) in patients with cancer receiving chemotherapy : SAVE ONCO study [abstract]. J Clin Oncol. 2011;29: abst LBA9014.

93. Falanga A, Marchetti M. Heparin in tumor progression and metastatic dissemination. Semin Thromb Hemost. 2007;33:688-694.

94. Lecumberri R, Massuti B, Lopez Vivanco G, Font A, Gonzalez Billalabeitia E, Rocha Eobot AI. Adjuvant bemiparin in small cell lung cancer: results from the ABEL study [abstract]. Thromb Res. 2010; 125(Suppl 2): abst S163.

\section{Publish your work in this journal}

Patient Related Outcome Measures is an international, peer-reviewed, open access journal focusing on treatment outcomes specifically relevant to patients. All aspects of patient care are addressed within the journal and practitioners from all disciplines are invited to submit their work as well as healthcare researchers and patient support groups. Areas covered will

\section{Dovepress}

include: Quality of life scores; Patient satisfaction audits; Treatment outcomes that focus on the patient; Research into improving patient outcomes; Hypotheses of interventions to improve outcomes; Short communications that illustrate improved outcomes; Case reports or series that show an improved patient experience; Patient journey descriptions or research.

Submit your manuscript here: http://www.dovepress.com/patient-related-outcome-measures-journal 


\section{Chapter 9}

Acute promyelocytic leukemia cell adhesion to vascular endothelium is reduced by heparins.

Vignoli A, Marchetti M, Falanga A. Acute promyelocytic leukemia cell adhesion to vascular endothelium is reduced by heparins. Ann Hematol.

2018;97(9):1555-62. 


\title{
Acute promyelocytic leukemia cell adhesion to vascular endothelium is reduced by heparins
}

\author{
Alfonso Vignoli ${ }^{1} \cdot$ Marina Marchetti $^{1} \cdot$ Anna Falanga $^{1}$ (D \\ Received: 6 November 2017 / Accepted: 21 April 2018 / Published online: 1 May 2018 \\ (C) Springer-Verlag GmbH Germany, part of Springer Nature 2018
}

\begin{abstract}
Adhesion of acute promyelocytic leukemia (APL) cells to endothelial cells (EC) is among the mechanisms of the APL-associated coagulopathy, responsible for early hemorrhagic deaths in affected patients. We compared the effects of dalteparin and enoxaparin, two low-molecular-weight heparins (LMWH), and unfractionated heparin (UFH), on APL NB4 adhesion to micro- (HMEC-1) and macro-vascular EC (HUVEC), in resting and interleukin-1 $\beta$ (IL-1 $\beta$ )-stimulated conditions. The heparin effect on EC adhesion molecule (ICAM-1, VCAM-1, E-selectin) expression was also assessed. In HMEC-1, dalteparin inhibited IL1 $\beta$-induced NB4 adhesion by $80 \%$, enoxaparin by $52 \%$, and UFH by $44 \%$. Similar results were obtained in HUVEC. This was associated with a significant decrease of VCAM-1 and ICAM-1 expression. In conclusion, we show that LMWH significantly counteract APL cell adhesion to the vessel wall, by modulating EC adhesion molecule expression. This property of heparins may represent one approach for hampering excess clotting activation and microthrombi deposition in APL.
\end{abstract}

Keywords Acute promyelocytic leukemia · Endothelium · Cell adhesion · Low-molecular-weight heparin · Cancer and thrombosis

\section{Introduction}

Acute promyelocytic leukemia (APL) is a distinct subtype of acute myeloid leukemia (M3) genetically characterized by the $t(15 ; 17)$ chromosomal translocation and the $P M L-R A R \alpha$ fusion gene. Blood coagulation abnormalities consistent with the diagnosis of disseminated intravascular coagulation (DIC) and thrombo-hemorrhagic symptoms [1, 2] are typically associated with the onset of this myeloid leukemia. Currently, the use of induction therapy with all-trans retinoic acid (ATRA)-based regimens yields complete remission rates of $>90 \%$ and long-term disease-free survival rates exceeding $80 \%$. However, the severe coagulopathy remains a relevant cause of early hemorrhagic death in these patients [3, 4].

Several leukemic cell-dependent pathogenic mechanisms are involved in clotting activation in APL [1] and include the following: (1) the production by APL cells of procoagulant

Anna Falanga

annafalanga@yahoo.com

Department of Immunohematology and Transfusion Medicine \& Hemostasis and Thrombosis Center, Hospital Papa Giovanni XXIII, Piazza O.M.S., 1, 24127 Bergamo, Italy factors, non-specific proteolytic enzymes, fibrinolytic proteins, and pro-inflammatory and pro-angiogenic cytokines [i.e., interleukin-1 $\beta$ (IL-1 $\beta$ ) and tumor necrosis factor $(\mathrm{TNF}-\alpha)]$; and (2) the direct interaction of leukemic cells with host vascular and blood cells (i.e., endothelial cells, leukocytes, and platelets) by means of adhesion molecules. The adhesion of APL cells to endothelial cells (EC) promotes localized clotting activation and thrombus formation. The leukemic cells attached to the endothelium can release their cytokine content into a protected milieu that favors their prothrombotic and pro-angiogenic activities [5-7]. Impairing APL cell-EC adhesion mechanism may be relevant for preventing the associated coagulopathy and organ infiltration by APL blasts.

Heparins, a group of glycosaminoglycans with a wide spectrum of biological activities [8], are widely used as anticoagulant drugs for the prevention and treatment of thrombosis in a variety of conditions, including cancer [9]. Heparins are known to have additional biological effects that are unrelated to their anticoagulant activity $[10,11]$. Experimental evidences suggest that heparins have the capability to interfere with mechanisms of tumor cell/EC interaction [12]. Along this line, our group could demonstrate that heparins (both unfractionated heparin (UFH) and low-molecular-weight 
heparins (LMWH) significantly counteract the pro-angiogenic and pro-thrombotic stimuli exerted by different tumor cells, including APL cells, on the endothelium [6, 13, 14]. In addition, both UFH and LMWH can inhibit leukocyte adhesion and infiltration in vitro and in vivo [11]. There are no studies evaluating the role of heparins on the adhesion of APL cells to the endothelium.

In this in vitro study, we investigate whether and to what extent two LMWH and UFH can interfere with the adhesion process of the human APL-NB4 cell line to EC monolayers. In particular, we evaluate the capacity of all three heparins to inhibit the APL cell to adhere to EC monolayer of two different origins, i.e., the microvascular (HMEC-1 cells) or macrovascular (HUVEC) beds, in both resting and IL-1 $\beta$ stimulated condition. We also assess whether the effects of LMWH on the adhesive properties of the two EC types differ from those of UFH.

\section{Methods}

\section{Drugs}

Heparins used in this study were two LMWH, i.e., dalteparin sodium (Pfizer, Milan, Italy; mean Mw $6.0 \mathrm{kDa}$ ) and enoxaparin sodium (Sanofi, Milan, Italy; mean $\mathrm{Mw}$ $4.5 \mathrm{kDa}$ ), and a sodium unfractionated heparin ("UFH", Parke-Davis, Lainate, Milan, Italy; mean Mw 15.0 kDa). The two LMWH are produced by the depolymerization of heparin derived from porcine mucosa. Particularly, dalteparin is prepared by nitrous acid depolymerization, and enoxaparin by benzylation and alkaline hydrolysis. The three heparins were in the form of their respective commercially available pharmaceutical products. The heparins were used at 0.1-1$10 \mathrm{IU} / \mathrm{ml}$, chosen on the basis of their plasma concentrations achieved in vivo during treatment of thrombosis or thromboprophylaxis [15].

\section{Cells and culture conditions}

The immortalized human microvascular EC line-1 (HMEC-1) was kindly supplied by Dr. F.J. Candal (CDC, Centers for Disease Control and Prevention, Atlanta, GA, USA). To date, this is the best-characterized microvascular EC line available [16]. HMEC-1 was grown in RPMI 1640 medium supplemented with $10 \%$ fetal calf serum (FCS, Gibco, Gaithersburg, MD, USA), $100 \mu \mathrm{g} / \mathrm{ml}$ streptomycin, $100 \mathrm{U} /$ $\mathrm{ml}$ penicillin, $5 \mu \mathrm{g} / \mathrm{ml}$ amphotericin-B (Bristol-Myers Squibb, Princeton, NJ, USA), 2 mM/l L-glutamine (Gibco), $10 \mathrm{ng} / \mathrm{ml}$ epidermal growth factor (ICN, Costa Mesa, CA, USA), and $1 \mu \mathrm{g} / \mathrm{ml}$ hydrocortisone (ICN). HMEC-1 was serially passaged in T25 flasks (Falcon, Becton Dickinson, Mountain View, CA, USA) and, at passages 8th to 16th, used for the assays [17]. Human umbilical vein EC (HUVEC) were freshly isolated from umbilical cord veins and grown in T25 flasks in RPMI 1640 medium supplemented with $20 \%$ FCS, $100 \mu \mathrm{g} / \mathrm{ml}$ streptomycin, $100 \mathrm{U} / \mathrm{ml}$ penicillin, $5 \mu \mathrm{g} / \mathrm{ml}$ amphotericin-B, and $2 \mathrm{mM} / 1 \mathrm{~L}-$ glutamine [18]. When confluent, HUVEC were harvested using $0.25 \%$ trypsin $/ 0.02 \%$ EDTA solution (Sigma, St Louis, MO, USA) and then used for the assays. Both endothelia were grown in a humidified incubator in an atmosphere of $5 \% \mathrm{CO}_{2} / 95 \%$ air.

The NB4 cell line established in vitro from an APL patient was a kind gift from Dr. M. Lanotte (INSERM Unit 301, St. Louis Hospital, Paris, France). These cells were continuously grown in suspension in RPMI1640 containing 10\% FBS, $2 \mathrm{mM}$ L-glutamine, $100 \mathrm{IU} / \mathrm{ml}$ penicillin, and $100 \mu \mathrm{g} / \mathrm{ml}$ streptomycin [5], in T75 flasks.

Trypan blue exclusion dye test was used to determine HUVEC, HMEC-1, and NB4 cell viability. Only cell cultures with more than $95 \%$ of viable cells were used for the subsequent experiments.

\section{Adhesion assay}

Adhesion of NB4 cells to EC was evaluated by a static assay. Confluent EC cultures were harvested by enzymatic detachment, washed in PBS, counted, resuspended in complete medium, and then seeded on the bottom of 8-well cell culture slide (Falcon). At confluence, EC were incubated with complete medium containing $100 \mathrm{IU} / \mathrm{ml}$ of recombinant human IL-1 $\beta$ (Sigma), as standard stimulus, in the absence or presence of $0.1-1-10 \mathrm{IU} / \mathrm{ml}$ of each heparin (i.e., dalteparin, enoxaparin, and UFH), for $24 \mathrm{~h}$ in cell incubator at $37{ }^{\circ} \mathrm{C}$. In preliminary experiments performed to establish the optimal IL-1 $\beta$ concentration, the maximum concentration of $100 \mathrm{IU} / \mathrm{ml}$ was the most effective in increasing NB4 cell adhesion to EC and therefore used in the subsequent experiments. Control EC were incubated, in the same conditions, with complete medium only. At the end of the incubation, EC monolayers were gently washed three times with warm medium so that the monolayer was not disturbed, NB4 cells were then seeded and left to adhere for $1 \mathrm{~h}$ in RPMI1640. Thereafter, nonadherent blast cells were removed by three washes with warm medium, and culture wells were examined at the microscope to verify the EC monolayer integrity. Then, the chamber of cell culture slide was removed, and NB4 cells and EC on slide surface were fixed and stained with Diff-Quick system (Medion Diagnostics, Düdingen, Germany). Adherent NB4 cells were counted in 20 different microscope fields (magnification $\times 100$; ZEISS model 467058, Germany), randomly selected, per each treatment of each experiment. Results are expressed as the mean number of adherent NB4 cells per field. 


\section{Flow cytometric analysis}

The expression of main adhesion molecules on HMEC-1, HUVEC, and NB4 cells was determined by direct immunofluorescence, using a FACSCanto flow cytometer (Becton Dickinson). Particularly, EC at 80-90\% confluence in T25 flasks were treated with $100 \mathrm{IU} / \mathrm{ml} \mathrm{IL}-1 \beta$, in the absence or presence of $10 \mathrm{IU} / \mathrm{ml}$ of each heparins (i.e., dalteparin, enoxaparin, and $\mathrm{UFH}$ ), for up to $24 \mathrm{~h}$ in the cell incubator at $37^{\circ} \mathrm{C}$. At the end of the incubation, EC were washed three times with PBS, collected by enzymatic detachment, washed with PBS by centrifugation, and resuspended in PBS at the concentration of $1 \times 10^{6}$ cells $/ \mathrm{ml}$. Then, cell suspension aliquots of $100 \mu$ were incubated with $20 \mu \mathrm{l}$ of fluorescein isothiocyanate (FITC)-conjugated monoclonal antibodies directed against human ICAM-1 (CD54), VCAM-1 (CD106), and E-selectin (CD62E) (BenderMedSystems, Vienna, Austria). NB4 cells at $24 \mathrm{~h}$ of culture were collected, washed three times with PBS, and resuspended in PBS at the concentration of $1 \times 10^{6}$ cells $/ \mathrm{ml}$. Then, $100 \mu \mathrm{l}$ aliquots of cell suspension were incubated for $20 \mathrm{~min}$ in the dark with $20 \mu \mathrm{l}$ of monoclonal antibodies (Becton Dickinson) directed against LFA1 (CD11a/CD18*FITC), MAC-1 (CD11b/CD18*PE), CD11c/CD18 (*FITC), very late antigen 4 or VLA4 (CD49dCD29*FITC), and ICAM-1 (CD54*FITC). IgG1 FITC- or IgG2 PE-conjugate isotypematched antibodies (Becton Dickinson) of irrelevant specificity were used as negative controls. At the end of incubation, EC and NB4 cells were centrifuged, resuspended in $100 \mu \mathrm{l}$ of PBS, and analyzed. Results are expressed as \% percentage of positive cells and mean fluorescence intensity (MFI). The MFI was calculated by subtracting the value of the mean fluorescence channel of the respective isotypic control from that value obtained from the sample incubated with adhesion molecule specific MAb.

\section{Statistical analysis}

All the experiments were performed at least in duplicate, and each experiment was repeated $\geq$ two times under independent conditions. Data from in vitro experiments and from morphometric analyses were compared by one-way ANOVA analysis of variance for repeated measures and the Bonferroni's post hoc test. The $p$ values $<0.05$ were considered significant. All statistical analyses were performed using SPSS $®$ software (SPSS, Chicago, IL, USA statistical software program).

\section{Results}

\section{NB4 cell adhesion to EC}

We first analyzed the interaction of NB4 cells with HMEC-1 and HUVEC monolayers (Fig. 1). In resting conditions, the number of NB4 cells attached to HUVEC was significantly greater compared to HMEC-1 $(9.39 \pm 5.39$ vs $5.07 \pm 0.78$ cell/ field; $p<0.05)$ monolayer. Incubation of HMEC-1 and HUVEC with IL- $1 \beta$ caused a significant increase in the number of leukemic cells adherent to both endothelia compared to resting conditions. This increment reached a maximum at $6-$ $8 \mathrm{~h}$ of stimulation and then started to decline. After $24 \mathrm{~h}$, we observed $11.4 \pm 2.45$ cells/field on HMEC-1 $(p<0.05)$ and $16.4 \pm 2.23$ cells/field on HUVEC $(p<0.05)$.

We then explored the effects of heparins on the NB4/EC interaction. Treatment of EC with heparins up to $24 \mathrm{~h}$, in the absence of IL-1 $\beta$ stimulus, did not significantly affect NB4 cell interaction with either EC type, at any time. Differently, we observed a lower number of NB4 cells adhered to endothelium treated with IL- $1 \beta$ in the presence of increasing doses of heparins, compared to IL-1 $\beta$ alone (Fig. 2). The effect was statistically significant $(p<0.01)$ after $24 \mathrm{~h}$ of incubation with the heparin concentration of $10 \mathrm{IU} / \mathrm{ml}$ in both endothelial types. Particularly, in HMEC-1 (Fig. 2a), a NB4 cell adhesion reduction of $80 \%$ was achieved with dalteparin, $52 \%$ with enoxaparin, and $44 \%$ with UFH, compared to IL- $1 \beta$ alone. Similarly, in HUVEC, dalteparin reduced IL- $1 \beta$-stimulated NB4 cell adhesion by $91 \%$, enoxaparin by $47 \%$, and UFH by $74 \%$ (Fig. 2 b).

\section{NB4 cell adhesion molecule expression}

The characterization of cell adhesion molecule on NB4 cell surface showed that $83.02 \pm 9.46 \%$ of cells were positive for VLA4, $19.78 \pm 9.23 \%$ for CD11b/CD18, $15.5 \pm 2.1 \%$ for CD11c/CD18, and $33.8 \pm 5 \%$ for ICAM-1, while CD11a/ CD118 was almost absent $(1.79 \pm 0.89 \%)$.

\section{Effect of heparins on EC adhesion molecule expression}

To explore whether the reduced adhesive properties towards NB4 cells of IL-1 $\beta$-stimulated HMEC-1 and HUVEC monolayer treated with heparins were related to a modification in the expression of cell adhesion molecules, both EC types were treated for $24 \mathrm{~h}$ with IL- $1 \beta$ in the presence and absence of the three heparins. Thereafter, expression of the main EC cell adhesion molecules was characterized by flow cytometry. As shown in Figs. 3a and 4a, under resting conditions, HMEC-1 cells presented significantly higher expression of ICAM-1 compared to HUVEC $(57.2 \pm 7.9$ vs $27.7 \pm 9.8 \%$ positive cells; $p<0.05)$. Differently, VCAM-1 levels were highest in HUVEC $(13.1 \pm 3.4 \%$, Fig. 4b) compared to HMEC-1 $(3.1 \pm$ $0.5 \% ; p<0.05$, Fig. 3b). E-selectin was detectable only in HUVEC (Fig. 4c), although at very low levels $(2 \pm 0.79 \%)$. Stimulation of EC with IL- $1 \beta$ caused a progressive increase in ICAM-1 and VCAM-1 levels by both HUVEC (ICAM-1 $93.4 \pm 5.7 \%$; VCAM-1 $58 \pm 8.3 \%$; Fig. 4) and HMEC-1 (ICAM-1 85.9 $\pm 10.2 \%$; VCAM-1 $12.1 \pm 2.4 \%$; Fig. 3), and 
Fig. 1 Time course experiments of NB4 cell adhesion to HMEC-1 (a) and HUVEC (b) monolayer in resting ("Control") and IL-1 $\beta$ stimulated conditions up to $24 \mathrm{~h}$ of incubation. Results are expressed as mean \pm SD of three independent experiments performed in duplicate. $\S p<0.05$ IL-1 $\beta$ vs Control

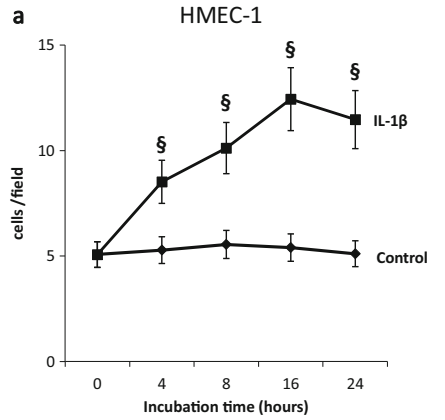

in E-selectin by HUVEC only (29.5 $\pm 4.1 \%$; Fig. 4c), over the $24 \mathrm{~h}$ incubation period. In these conditions, heparins counteracted IL- $1 \beta$-induced expression of cell adhesion molecules in both EC. Particularly, in HMEC-1, IL-1 $\beta$-induced expression of ICAM-1 was 70,54 , and $45 \%$ inhibited by dalteparin, enoxaparin, and UFH, respectively (Fig. 3a). The two LMWH, dalteparin and enoxaparin, also significantly $(p<0.05)$ reduced VCAM-1-induced expression by 38 and $28 \%$, respectively, while UFH did not (14\%; $p=$ n.s.) (Fig. $3 b)$. In HUVEC, all the heparins significantly $(p<0.05)$ reduced ICAM-1 (Fig. 4a) and VCAM-1 (Fig. 4b)-induced expression by IL-1 $\beta$ with $\%$ of inhibition ranging from 28 to $40 \%$, without affecting E-selectin levels (Fig. 4c).

\section{Discussion}

Early hemorrhagic deaths due to the severe thrombohemorrhagic coagulopathy associated with APL onset still remain an important cause of treatment failure in APL, an otherwise highly curable leukemia in the ATRA era. The interaction of APL cells with EC is one of leukemic celldependent pathogenic mechanisms involved in the clotting activation in APL, as it promotes localized clotting activation and thrombus formation by the release of cytokines and proangiogenic factors. Preventing leukemic cell-EC interactions may represent one approach for hampering excess clotting activation and microthrombi deposition. In this study, we evaluated in an in vitro model, whether heparins may directly interfere with APL cell adhesion to EC, and verified, in parallel, whether changes in the expression of EC adhesion molecules may occur by heparin treatment. Particularly, we employed the APL NB4 cell line, and two types of human EC of either micro- (HMEC-1) or macro-vascular (HUVEC) origins.

First, we analyzed the interaction of leukemic blast cells with the two types of endothelia in resting conditions, i.e., in the absence of both IL- $1 \beta$ and heparins. The results revealed a greater adhesion of NB4 cells to HUVEC compared to HMEC-1. Examination of the main EC surface adhesion molecules, i.e., ICAM-1, VCAM-1, and E-selectin, showed a different pattern of expression by the two endothelia. Particularly, ICAM-1 is expressed by both HMEC-1 and HUVEC, although HMEC-1 has a relatively higher baseline expression of ICAM-1 and lower expression of VCAM-1 compared to HUVEC, as previously observed [19]. The expression of E-selectin was detected in HUVEC-1 alone [19, $20]$. The analysis of leukemic cell ligands that bind adhesion molecules present on EC confirmed the presence on NB4 cell surface of CD11c and CD11b (all ligands of ICAM-1) and of
Fig. 2 Heparins inhibit the IL$1 \beta$-induced increase of NB4 adhesion to both HMEC-1 (a) and HUVEC (b) monolayer. Results are expressed as mean $\pm \mathrm{SD}$ of five independent experiments performed in triplicate. $\$ p<0.05$ vs Control $(\mathrm{C})$; $* p<0.05$ vs IL$1 \beta$. TC tumor cells, EC endothelial cells, DLT dalteparin (triangle symbol, full line), ENX enoxaparin (circle symbol, full line), UFH unfractionated heparin (square symbol, dashed line)

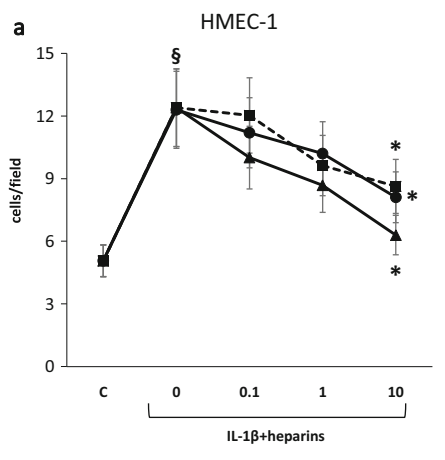

b HUVEC

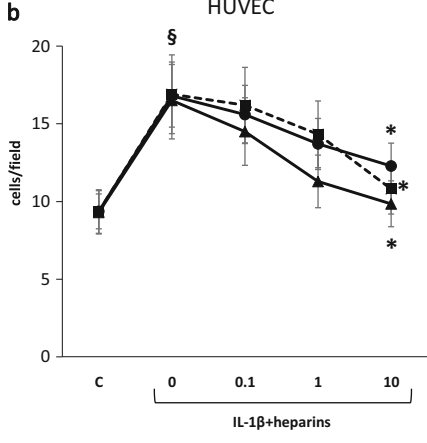


Fig. 3 Flow cytometric analysis of cell adhesion molecule expression, i.e., ICAM-1 (a) and VCAM-1 (b), by HMEC-1 after $24 \mathrm{~h}$ treatment with $\mathrm{IL}-1 \beta$ in the absence and presence of $10 \mathrm{IU} / \mathrm{ml}$ heparins. Results are mean $\pm \mathrm{SD}$ of five experiments performed in duplicate and are expressed as \% positive cells. $* p<0.05$ vs Control (C). DLT dalteparin,

ENX enoxaparin, UFH unfractionated heparin a

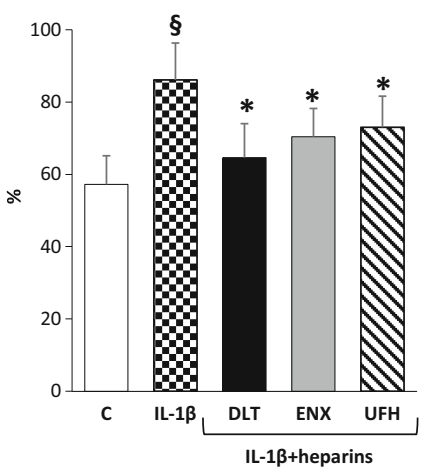

b

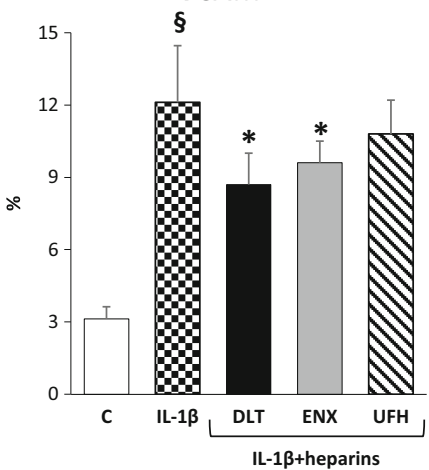

the $\alpha 4 \beta 1$ integrin VLA4 (the ligand of VCAM-1) [21, 22]. The different patterns of cell adhesion molecule expression on endothelia and the respective counter receptors on leukemic cells may well explain the higher adhesion potential of HUVEC compared to HMEC-1 towards NB4 cells. In our experimental system, treatment of HUVEC and HMEC-1 with IL-1 $\beta$ caused a significant increase in leukemic cell adhesion to both EC types. Adhesion molecule expression analysis showed a significant increase of ICAM-1 and VCAM-1 expression on IL- $1 \beta$-stimulated EC above the constitutive levels, although in HMEC-1, a relatively small expression of VCAM-1 was detectable. E-selectin significantly increased in HUVEC alone.

This is in line with data from other groups, who described the cytokine response by HMEC-1 in terms of low VCAM-1 and E-selectin induction [23]. Adhesion studies performed under static conditions by our and other groups have shown that NB4 cell adhesion to cytokine-activated HUVEC is mainly mediated by E-selectin, ICAM-1, and VCAM-1 [22, 24].

We then investigated the possible anti-adhesive effect of heparins in the same experimental conditions. In the absence of any cytokine stimulation, none of the heparins significantly affected leukemic cell-EC interaction. Differently, experiments performed with EC treated with heparins in the presence of IL- $\beta$ demonstrated that both LMWH and UFH are indeed effective in reducing NB4 cell adhesion. We hypothesize that heparins protect the endothelium from inflammatory stimulus and consequently reduce the expression of cell adhesion molecules. In agreement with that, previous studies showed that heparins might interfere with EC adhesion molecule expression [25-27]. However, in one of these studies, heparins (UFH and dalteparin) had an effect on cytokinestimulated ICAM-1 and E-selectin expression by HUVEC only when used at a very high concentration, i.e., $1000 \mathrm{IU} /$ $\mathrm{ml}$, well above the therapeutic range of these drugs (0.1-1 IU/ ml) [25]. In another study by Manduteanu et al., the LMWH enoxaparin could counteract LPS or TNF-induced adhesion of the monocyte-like cell line U937 and monocytes to valvular EC, by inhibiting E-selectin and ICAM-1 expression on EC [27].

In our study, we found that heparins produced a relevant inhibition of NB4 cell adhesion to IL- $\beta$-stimulated EC ( $>50 \%$ inhibition) which was associated to a significant reduction effect on the levels of adhesion molecules expression by EC.
Fig. 4 Flow cytometric analysis of cell adhesion molecule expression, i.e., ICAM-1 (a), VCAM-1 (b), and E-selectin (c), by HUVEC after $24 \mathrm{~h}$ treatment with IL- $1 \beta$ in the absence and presence of $10 \mathrm{IU} / \mathrm{ml}$ heparins. Results are mean \pm SD of five experiments performed in duplicate and are expressed as \% positive cells. $* p<0.05$ vs Control (C). DLT dalteparin, ENX enoxaparin, UFH unfractionated heparin

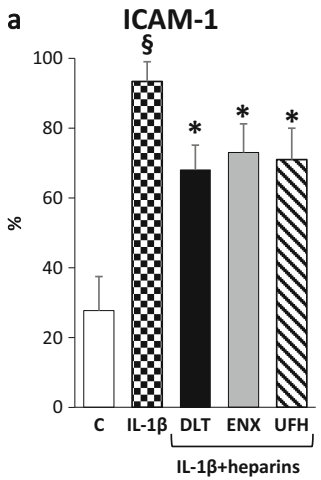

b

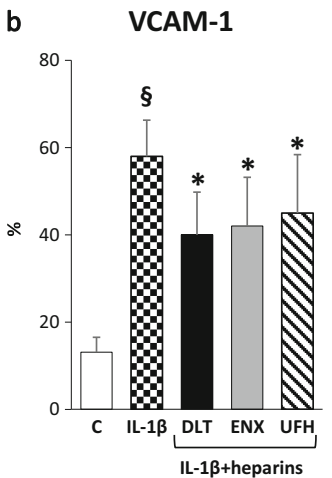

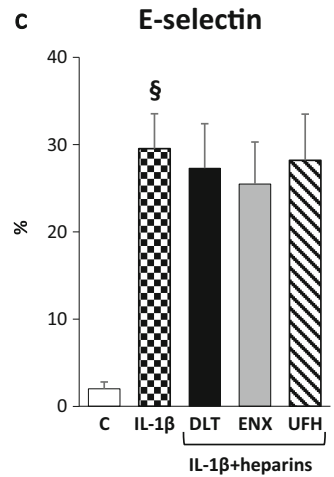


Therefore, the observed anti-adhesive mechanism of heparins appears to be at least partially linked to quantitative changes in EC surface adhesion molecule expression, as previously suggested [25]. We cannot exclude that other mechanisms related to the known capacity of heparins to bind to cell adhesion molecules, including P- and L-selectin, VLA-4 and $\beta 2$ integrins (i.e., CD11b and CD11c), interfered with the adhesion process [28]. It is possible that in our experimental system, EC adhesion molecules are bound to heparins, which prevents the adhesive interactions with their ligands on the APL cells. However, in our conditions, heparins are removed from EC by repeated washings before seeding NB4 cells. Furthermore, pre-activation of EC is necessary to exploit the anti-adhesive effects of heparins. In vivo activation of vascular endothelium in APL is a plausible situation sustained by the evidence that leukemic promyelocytes actively release proinflammatory cytokines, including IL- $1 \beta$, able to activate EC [6].

Although all three heparins counteracted NB4 cell adhesion, we could observe that the LMWH dalteparin was more effective than the other two heparins, particularly in microvascular HMEC-1. This is in line with results of our previous studies, demonstrating that this LMWH inhibits tumor cellinduced procoagulant [29] and proangiogenic [13] features of HMEC-1 more efficiently than other heparins.

The interference of heparins with APL cell adhesion to activated EC is important for many reasons. First, the role of heparins in the context of supportive therapy to reverse the coagulopathy associated to the onset of APL is unknown [2]. Old clinical studies, which used UFH, were small, retrospective, and uncontrolled [30, 31]. No systematic studies have been reported so far on the use of LMWH in these patients, who carry a very high bleeding risk. The relatively favorable safety profile of LMWH, together with their capacity to inhibit multiple mechanisms of microthrombi formation, including APL cell adhesion to EC, particularly in microcirculation, may encourage the design of clinical trials to test the efficacy of these molecules to affect early hemorrhagic deaths in APL. In the absence of these studies, lower doses of LMWH, individualized on the basis of the specific clinical and laboratory characteristics of APL patient, might be considered to switch off the prothrombotic and pro-inflammatory drive of leukemic cells [32]. In addition, the adherent cells may extravasate and infiltrate surrounding tissues, leading to organ distress and death. Further, adhesion of leukemic cells to endothelium strongly supports their survival, protects them from druginduced apoptosis, and extensively modifies their gene expression profile [33]. Therefore, interfering with leukemic cell-EC interaction is of relevance also in the setting of other hematological diseases characterized by hyperleukocytosis, leukostasis, and leukemic tissue infiltration [34]. Finally, in the case of APL, during treatment with ATRA, differentiating blasts may infiltrate several organs, particularly the lung, triggering the differentiation syndrome (DS) [35], a lifethreatening complication, characterized by respiratory distress, multiple organ failure, thrombo-hemorrhagic complications [36]. The first step of this phenomenon is necessarily the adhesion of the APL blasts to the vascular wall [21, 22].

One limitation of our work resides in that in vivo interaction is complex and difficult to replicate in the in vitro environment. It is possible that many other factors, absent in this setting, might modify the observed interactions between leukemic end endothelial cells. The addition of plasma in our system might be useful in exploring the activity of heparin as it occurs in vivo. However, studying this condition in our system is not possible. NB4 cells constitutively express TF, while EC express TF upon activation by proinflammatory stimuli (like IL-1 $\beta$ ), as also demonstrated by our group [6, 29]. Therefore, the plasma in contact with TF-bearing cells, becomes activated with subsequent thrombin generation and fibrin formation, which renders it difficult the evaluation of the cell adhesion phenomenon. In addition, it has to be considered that activated coagulation proteases can further interfere with the process.

Since heparins interference with APL cell adhesion in our system occurs when the endothelium is activated by inflammatory cytokines, one might think that other antiinflammatory agents, devoid of anticoagulant activity, might have a similar effect, without carrying a risk of bleeding. Along this line, it has been indeed demonstrated that steroids can counteract the increased expression of APL cell adhesion molecules induced by ATRA, thus potentially reducing APL cell adhesion to the endothelium [37]. However, we consider that, in the complex scenario of the APL coagulopathy, the anticoagulant activity of LMWH is very important by blocking the extreme activation of coagulation, which is mainly triggered by cellular TF in this condition. This is well demonstrated in experiments in rat models of DIC, where LMWH was effective in counteracting TF-induced DIC (as it occurs in APL) [38].

In conclusion, our study not only adds further background to the observed beneficial effect of heparins in cancer but also interestingly suggests that these drugs may play a role in different clinical settings, including the coagulopathy and organ failure of APL. Of course, this suggestion needs to be supported by further studies in both animal and human models, particularly aimed to evaluate the efficacy and safety of this approach.

Our group has previously shown that LMWH are able to inhibit the angiogenic activities of EC induced by tumorderived products, including those from NB4 cells [13, 14], and moreover, that these agents can effectively counteract the prothrombotic stimuli of APL cells towards EC [6]. Taken together, all these data provide strong evidence that heparins may affect the interactions of leukemic cells with the vascular endothelium. 
Acknowledgments This work is supported by grants of the Italian Association for Cancer Research ("Associazione Italiana per la Ricerca sul Cancro", AIRC) (grant no. IG14505 and AIRC "5 × 1000" no. 12237).

\section{Compliance with ethical standards}

Conflict of interest The authors declare that they have no conflict of interest.

\section{References}

1. Falanga A, Russo L, Tartari CJ (2011) Pathogenesis and treatment of thrombohemorrhagic diathesis in acute promyelocytic leukemia. Mediterr J Hematol Infect Dis 3(1):e2011068. https://doi.org/10. 4084/MJHID.2011.068

2. Falanga A (2017) Predicting APL lethal bleeding in the ATRA era. Blood 129(13):1739-1740. https://doi.org/10.1182/blood-201702-763490

3. Abla O, Ribeiro RC, Testi AM, Montesinos P, Creutzig U, Sung L, Di Giuseppe G, Stephens D, Feusner JH, Powell BL, Hasle H, Kaspers GJL, Dalla-Pozza L, Lassaletta A, Tallman MS, Locatelli F, Reinhardt D, Lo-Coco F, Hitzler J, Sanz MA (2017) Predictors of thrombohemorrhagic early death in children and adolescents with $\mathrm{t}(15 ; 17)$-positive acute promyelocytic leukemia treated with ATRA and chemotherapy. Ann Hematol 96(9):1449-1456. https://doi.org/ 10.1007/s00277-017-3042-6

4. Testa U, Lo-Coco F (2016) Prognostic factors in acute promyelocytic leukemia: strategies to define high-risk patients. Ann Hematol 95(5):673-680. https://doi.org/10.1007/s00277016-2622-1

5. Falanga A, Marchetti M, Giovanelli S, Barbui T (1996) All-transretinoic acid counteracts endothelial cell procoagulant activity induced by a human promyelocytic leukemia-derived cell line (NB4). Blood 87(2):613-617

6. Vignoli A, Marchetti M, Falanga A (2017) Heparins inhibit the endothelial pro-thrombotic features induced by tumor cells. Thromb Res 157:55-57. https://doi.org/10.1016/j.thromres.2017. 06.037

7. Gianni M, Norio P, Terao M, Falanga A, Marchetti M, Rambaldi A, Garattini E (1995) Effects of dexamethasone on pro-inflammatory cytokine expression, cell growth and maturation during granulocytic differentiation of acute promyelocytic leukemia cells. Eur Cytokine Netw 6(3):157-165

8. Tyrell DJ, Kilfeather S, Page CP (1995) Therapeutic uses of heparin beyond its traditional role as an anticoagulant. Trends Pharmacol Sci 16(6):198-204

9. Hirsh J, Warkentin TE, Shaughnessy SG, Anand SS, Halperin JL, Raschke R, Granger C, Ohman EM, Dalen JE (2001) Heparin and low-molecular-weight heparin: mechanisms of action, pharmacokinetics, dosing, monitoring, efficacy, and safety. Chest 119(Suppl. 1):64S-94S

10. Falanga A, Vignoli A, Diani E, Marchetti M (2011) Comparative assessment of low-molecular-weight heparins in cancer from the perspective of patient outcomes and survival. Patient related outcome measures 2:175-188. https://doi.org/10.2147/PROM.S10099

11. Lever R, Page CP (2012) Non-anticoagulant effects of heparin: an overview. Handb Exp Pharmacol 207:281-305. https://doi.org/10. 1007/978-3-642-23056-1 12

12. Falanga A, Marchetti M (2007) Heparin in tumor progression and metastatic dissemination. Semin Thromb Hemost 33(7):688-694. https://doi.org/10.1055/s-2007-991536
13. Marchetti M, Vignoli A, Russo L, Balducci D, Pagnoncelli M, Barbui T, Falanga A (2008) Endothelial capillary tube formation and cell proliferation induced by tumor cells are affected by low molecular weight heparins and unfractionated heparin. Thromb Res 121(5):637-645. https://doi.org/10.1016/j.thromres.2007.06.015

14. Vignoli A, Marchetti M, Russo L, Cantalino E, Diani E, Bonacina G, Falanga A (2011) LMWH bemiparin and ULMWH RO-14 reduce the endothelial angiogenic features elicited by leukemia, lung cancer, or breast cancer cells. Cancer Investig 29(2):153-161. https://doi.org/10.3109/07357907.2010.543217

15. Wei MY, Ward SM (2015) The anti-factor Xa range for low molecular weight heparin thromboprophylaxis. Hematol Rep 7(4):5844. https://oi.org/10.4081/hr.2015.5844

16. Ribeiro MJ, Phillips DJ, Benson JM, Evatt BL, Ades EW, Hooper WC (1995) Hemostatic properties of the SV-40 transfected human microvascular endothelial cell line (HMEC-1). A representative in vitro model for microvascular endothelium. Thromb Res 79(2): 153-161

17. Falanga A, Vignoli A, Marchetti M, Barbui T (2003) Defibrotide reduces procoagulant activity and increases fibrinolytic properties of endothelial cells. Leukemia 17(8):1636-1642. https://doi.org/10. 1038/sj.leu.2403004

18. Jaffe EA, Nachman RL, Becker GG, Minick CR (1973) Culture of human endothelial cells derived from umbilical veins. Identification by morphologic and immunologic criteria. J Clin Invest 52:27452756

19. Xu Y, Swerlick RA, Sepp N, Bosse D, Ades EW, Lawley TJ (1994) Characterization of expression and modulation of cell adhesion molecules on an immortalized human dermal microvascular endothelial cell line (HMEC-1). J Invest Dermatol 102(6):833-837

20. Ades EW, Candal FJ, Swerlick RA, George VG, Summers S, Bosse DC, Lawley TJ (1992) HMEC-1: establishment of an immortalized human microvascular endothelial cell line. J Invest Dermatol 99(6): 683-690

21. Brown DC, Tsuji H, Larson RS (1999) All-trans retinoic acid regulates adhesion mechanism and transmigration of the acute promyelocytic leukaemia cell line NB-4 under physiologic flow. Br J Haematol 107(1):86-98

22. Marchetti M, Falanga A, Giovanelli S, Oldani E, Barbui T (1996) All-trans-retinoic acid increases adhesion to endothelium of the human promyelocytic leukaemia cell line NB4. Br J Haematol 93(2):360-366

23. Lidington EA, Moyes DL, McCormack AM, Rose ML (1999) A comparison of primary endothelial cells and endothelial cell lines for studies of immune interactions. Transpl Immunol 7(4):239-246

24. Cavenagh JD, Gordon-Smith EC, Gibson FM, Gordon MY (1993) Acute myeloid leukaemia blast cells bind to human endothelium in vitro utilizing E-selectin and vascular cell adhesion molecule-1 (VCAM-1). Br J Haematol 85(2):285-291

25. Lever R, Hoult JR, Page CP (2000) The effects of heparin and related molecules upon the adhesion of human polymorphonuclear leucocytes to vascular endothelium in vitro. Br J Pharmacol 129(3): 533-540. https://doi.org/10.1038/sj.bjp.0703099

26. Miller SJ, Hoggat AM, Faulk WP (1998) Heparin regulates ICAM1 expression in human endothelial cells: an example of noncytokine-mediated endothelial activation. Thromb Haemost 80(3): 481-487

27. Manduteanu I, Voinea M, Capraru M, Dragomir E, Simionescu M (2002) A novel attribute of enoxaparin: inhibition of monocyte adhesion to endothelial cells by a mechanism involving cell adhesion molecules. Pharmacology 65(1):32-37

28. Bendas G, Borsig L (2012) Cancer cell adhesion and metastasis: selectins, integrins, and the inhibitory potential of heparins. Int $\mathrm{J}$ Cell Biol 2012:676731-676710. https://doi.org/10.1155/2012/ 676731 
29. Vignoli A, Marchetti M, Balducci D, Barbui T, Falanga A (2006) Differential effect of the low-molecular-weight heparin, dalteparin, and unfractionated heparin on microvascular endothelial cell hemostatic properties. Haematologica 91(2):207-214

30. Hoyle CF, Swirsky DM, Freedman L, Hayhoe FG (1988) Beneficial effect of heparin in the management of patients with APL. Br J Haematol 68(3):283-289

31. Rodeghiero F, Avvisati G, Castaman G, Barbui T, Mandelli F (1990) Early deaths and anti-hemorrhagic treatments in acute promyelocytic leukemia. A GIMEMA retrospective study in 268 consecutive patients. Blood 75(11):2112-2117

32. Squizzato A, Hunt BJ, Kinasewitz GT, Wada H, Ten Cate H, Thachil J, Levi M, Vicente V, D'Angelo A, Di Nisio M (2016) Supportive management strategies for disseminated intravascular coagulation. An international consensus. Thromb Haemost 115(5):896-904. https://doi.org/10.1160/TH15-09-0740

33. Poulos MG, Gars EJ, Gutkin MC, Kloss CC, Ginsberg M, Scandura JM, Rafii S, Butler JM (2014) Activation of the vascular niche supports leukemic progression and resistance to chemotherapy. Exp Hematol 42(11):976-986 e973. https://doi.org/10.1016/j. exphem.2014.08.003

34. Giammarco S, Chiusolo P, Piccirillo N, Di Giovanni A, Metafuni E, Laurenti L, Sica S, Pagano L (2017) Hyperleukocytosis and leukostasis: management of a medical emergency. Expert Rev Hematol 10(2):147-154. https://doi.org/10.1080/17474086.2017. 1270754

35. Luesink M, Jansen JH (2010) Advances in understanding the pulmonary infiltration in acute promyelocytic leukaemia. $\mathrm{Br} \mathrm{J}$ Haematol 151(3):209-220. https://doi.org/10.1111/j.1365-2141. 2010.08325.x

36. Frankel SR, Eardley A, Lauwers G, Weiss M, Warrell RP Jr (1992) The "retinoic acid syndrome" in acute promyelocytic leukemia. Ann Intern Med 117(4):292-296

37. Cunha De Santis G, Tamarozzi MB, Sousa RB, Moreno SE, Secco D, Garcia AB, Lima AS, Faccioli LH, Falcao RP, Cunha FQ, Rego EM (2007) Adhesion molecules and differentiation syndrome: phenotypic and functional analysis of the effect of ATRA, As2O3, phenylbutyrate, and G-CSF in acute promyelocytic leukemia. Haematologica 92(12):1615-1622. https://doi.org/10.3324/ haematol.10607

38. Asakura H, Aoshima K, Ichino T, Suga Y, Saito M, Morishita E, Yamazaki M, Ontachi Y, Mizutani T, Kato M, Miyamoto KI, Nakao S (2001) All-trans retinoic acid is partially effective against lipopolysaccharide-induced but not against tissue-factor-induced disseminated intravascular coagulation in rat models. Blood Coagul Fibrinolysis 12(4):301-306 


\section{Chapter 10}

General Discussion and Summary 
The presence of a tumor in a given subject predisposes the host to thrombotic complications, that have a negative impact on the patient's quality of life and life expectancy. Vice versa, the activation of the hemostatic system increases the risk of cancer progression, while a thrombosis may indeed be the first sign of an undiagnosed malignancy.

New therapeutic approaches, aimed to effectively disrupt this two-way connection, are strongly needed.

Heparins are well known drugs, widely used in the clinic for thromboprophylaxis and treatment of VTE, but these agents are also equipped with an array of potential anti-tumor properties. Among possible anti-tumor targets, the vascular endothelium is a fascinating target since it plays a role both in hemostasis and in tumor progression.

In the last decades, so-called low-molecular-weight heparins $(\mathrm{LMWH})$, obtained by fractionation of the classical "old" unfractionated heparin (UFH), have progressively replaced UFH in daily clinical use, due to some clinical and biological advantages [1]. While LMWH have been successfully introduced for the clinical management of a wide range of patients with thromboembolic disorders (both for prevention and treatment), conflicting evidence points to potential targets beyond anticoagulation, in particular related to improved survival of patients with cancer as summarized in the Chapter 2. However, the biological mechanisms 
underlying this dual action of heparins have not been completely clarified yet, as reported in Chapter 3 .

In the present thesis, we then aimed to verify whether heparins, both LMWH and UFH, can exert anticoagulant and antitumor effects by means of multiple actions on the vascular endothelium, so to impair the tumor-hemostasis mutual relationship.

As illustrated in Chapter 4, we started by demonstrating that both LMWH (dalteparin) and UFH have an antithrombotic effect on endothelial cells (EC) by suppressing bacterial endotoxin inflammatory stimulus-mediated procoagulant tissue factor expression and by enhancing anticoagulant thrombomodulin expression and tissue factor pathway inhibitor release. Previous studies have reported an inhibitory effect of heparins (both UFH and LMWH) on EC tissue factor expression. However, these studies were conducted mainly in macrovascular EC, while we included also microvascular $E C$, the endothelial type most involved in pathological processes. Although the effects reported in Chapter 4 may have impact on hemostatic activation, no tumor cell was involved in that system.

We then employed the same experimental model by exposing the vascular endothelium to products derived from breast cancer and leukemic cells. As shown in Chapter 5 , these tumor products elicit a rise in the procoagulant tissue factor expressed by the endothelium, but, similarly to what 
was observed with the standard bacterial endotoxin in Chapter 4 and interleukin- $1 \beta$ in the same Chapter 5 , heparins are able to counteract also this tumor cell-induced prothrombotic response.

Next step was to evaluate the interference of heparins on angiogenesis promoted by tumor cell derived products. In Chapter 6 we explored for the first time the effect of heparins on the interaction of tumor cells with human microvascular EC on two steps of angiogenesis: the EC proliferation, and the capillary-tube formation by the matrigel assay, which evaluates the final differentiation of EC into capillary-like tubule structures. HMEC-1 cells were incubated with tumor cell conditioned media (TCM) derived from human breast cancer and leukemic cells

or recombinant cytokines (i.e. VEGF, FGF-2, TNF- $\alpha$ ) in the absence and presence of heparins. Capillary-like tube formation in Matrigel and EC cell proliferation were evaluated. The results show that all TCM induced a significant increase in total length of tubes formed by HMEC1 in Matrigel, and that these increases were significantly counteracted (62 to $100 \%$ mean inhibition) by the LMWHs enoxaparin and dalteparin, but were significantly less affected by UFH. Similar results were obtained with the standard purified proangiogenic factors. Next, using the same experimental model (see Chapter 7), we observed a similar anti-angiogenic activity also for the "second 
generation" LMWH bemiparin and for the "ultra-LMWH" RO14. Ultra-LMWH are prepared by further heparin fractionation, and very few data are available about their biological activities.

We then extended our study by exploring the in vitro antitumor effect of LMWH on a pancreatic cancer cell line. This type of tumor carries the highest risk of thrombotic events amongst any other gastrointestinal cancers, with an incidence range of $17 \%-57 \%$. Furthermore, the diagnosis of venous thrombosis in pancreatic cancer is associated with a poor overall survival. As shown in Chapter 8, the LMWH dalteparin, the "second generation" bemiparin and the ultraLMWH RO-14 significantly prevented the capillary network formation induced by a pancreatic cancer cell line. Interestingly, the anti-angiogenic effect was higher for the LMWH compared with the ultra-LMWH RO-14. In addition, the same heparins showed a direct inhibitory effect on the migration of pancreatic cancer cells in vitro.

Finally, in Chapter 9, we report data about the interference of heparins in the adhesion of cancer cells to the vascular endothelium. The adhesion of tumor cells to the endothelium and its matrix, particularly in the microvascular bed, is a crucial step in the metastatic process [2] and organ infiltration. Here, we could demonstrate that heparins impair the adhesion of leukemic cells to endothelial monolayer, and that this is associated with a significant decrease of main 
endothelial surface adhesion molecule expression. We are currently extending our studies by exploring the in vitro antiadhesive effect of heparins on breast cancer cells. Altogether, these in vitro data further contribute to support the evidence of a possible antitumor in vivo effect of heparins, particularly LMWHs.

\section{Research perspectives}

The association between cancer and thrombosis was first described by Armand Trousseau in 1865 [3]. Since that time, it has become clear that cancer increases the risk of thrombosis [4]. We also know now that the activation of the clotting system may favour the progression of cancer [5-6]. In the last two decades, the research in this field has clarified many of the mechanisms that underlie the dialogue between the tumor and the hemostatic system. However, this has not led to significant improvements of the cancer patients' quality of life and life expectancy yet. This is likely because we first needed to reach a good comprehension of the biological pathways, before trying to hypothesize possible effective clinical strategies.

Antithrombotic agents, particularly heparins, are able to interfere with tumour cell proliferation and growth, angiogenesis, the development of distant metastases, resistance to chemotherapy and immune responses [7]. Therefore, it seemed feasible that antithrombotics with 
antineoplastic properties may improve cancer survival. A review of older trials comparing LMWH with UFH or oral anticoagulants for the treatment or prophylaxis of VTE revealed an advantage with respect to survival rates in patients receiving $\mathrm{LMWH}$, although these studies were not designed to evaluate the effect of the anticoagulants on cancer mortality [8]. More recent studies have been designed to assess the effect of LMWH on cancer survival rates, in addition to their efficacy in preventing VTE. However, data coming from these recent clinical trials are still insufficient/contradictory in terms of demonstrating a clear advantage given by heparins with regard to cancer patient survival. Particularly, it is unclear whether the possible beneficial effect of heparins is influenced by patient-related variables, such as tumor type, tumor stage and aggressiveness (metastatic or localized), or by administration timing, or by the intrinsic characteristics of the employed heparin preparation.

With our work we tried, on one hand to shed more light on the mechanisms underlying the possible beneficial effect of heparins in cancer, by studying the effect of these drugs on the vascular endothelium, on the other hand to understand whether these effects are restricted at particular tumor types and/or to some heparins. 
With regard to the question of whether heparins are able to interfere with the prothrombotic and protumor actions of vascular endothelium, the answer is affirmative. Our studies clearly show that heparins impair the EC prothrombotic switch and the neoangiogenesis process triggered by tumor cells. This does not appear restricted by tumor type or aggressiveness. Heparins show to be effective even against tumor cells derived from very aggressive breast and pancreatic cancers.

The second question we tried to answer is whether some heparins are more effective than others. In line with other studies [9], we have observed that EC show different responses to UFH and LMWH. One explanation for this difference may reflect differences in the chemical composition of heparins. Heparins are heterogeneous preparations, derived from mammalian tissues, containing polysaccharide chains of different lengths and molecular weights (MW). UFH has a mean molecular weight of 12-15 kDalton $(\mathrm{kDa})$, with molecules ranging from 3 to $37 \mathrm{kDa}$ in weight. LMWHs are derived from UFH by controlled enzymatic or chemical depolymerization, and have mean molecular weights ranging from 3 to $8 \mathrm{kDa}$. LMWHs are, therefore, characterized by a much higher proportion of short chains compared with UFH. This leads to an increased anti$\mathrm{Xa/anti-Ila}$ activity ratio, a greater bioavailability, a lower effect on platelets, and a longer half life, compared with UFH 
[10]. It is possible that the different effects of heparins on EC observed in the present studies might result from the different proportion of short and long polysaccharide chains within the two heparins as proposed by other authors [11]. It has been indeed demonstrated that heparin fragments with MWs of 4.8- to 5.4-KDa inhibit the in vitro binding of VEGF ${ }^{165}$ to VEGF ${ }^{165}$ receptors on cultured bovine aortic arch EC, while fragments with MWs of more than $6.9 \mathrm{kDa}$ enhance the binding [12]. As a consequence of the lower mean MW of the heparin fragments, it is possible that the LMWHs used here might prevent the binding of growth factors to their receptor on EC and thus inhibit their functions. As a consequence of these considerations, we can also hypothesize that the lower mean $\mathrm{Mw}$ of enoxaparin (4.5 kDa) compared to dalteparin (6.0 kDa) should be responsible for the major effect of enoxaparin over dalteparin in inhibiting capillary tube formation. Our results are in line with those of other studies that have explored the effects of heparins on angiogenesis in different experimental in vivo and in vitro models. In an animal model of angiogenesis, it has been shown that FGF2- and VEGF ${ }^{165}$-induced angiogenesis is more suppressed by a $\mathrm{LMWH}$, or heparins enriched in $2.5 \mathrm{kDa}$ and $5.0 \mathrm{kDa}$ species, than by UFH and high-molecular-weight heparins [13-14]. Similarly, in an in vitro model of angiogenesis in HUVEC, LMWH in the range of 3-6 kDa significantly inhibited FGF-2- and VEGF- induced angiogenesis, whereas no 
inhibition was observed with UFH, tetrasaccharide, pentasaccharide and octasaccharide [15].

So, we show here that LMWHs in low range of mean MW appear to be the most effective. However, during the course of our studies, heparins prepared by further fractionation of LMWH were made available by some pharma companies: these are called ultra-low molecular weight heparins (ULMWH). Since these ULMWH present an even higher anti$\mathrm{Xa}$ anti-Ila activity ratio (indeed anti-Ila acrivity is almost completelety absent in these preparations), that renders them very promising by the clinical point of view, we tested one representative of this new subclass of heparins in our models, i.e. the RO-14 (mean Mw $2.2 \mathrm{kDa}$ ), together with bemiparin, a "second-generation" LMWH characterized by a mean $\mathrm{Mw}$ of $3.6 \mathrm{kDa}$, that can be considered intermediate between the "first-generation" LMWH and the ULMWH. Our studies show that RO-14 and bemiparin possess an antiangiogenic activity similar to those shown by LMWH. RO-14 also possesses a direct inhibitory effect on the migration of the pancreatic cancer cells. Of note, in clinics these ULMWH are under consideration for thromboprophylaxis in a variety of clinical conditions, including cancer. Although they seem equally effective as LMWH for the prevention of thrombosis, with less bleeding complications, little is known about their effect on cancer patient survival. 
Our results provide background of, but also need for confirmation, by further studies.

The employment of tumor animal models would be of great help to further confirm the anticancer effects of heparins. Many approaches could be used. One of these could be the grafting of tumor in mice in the orthotopic site or by direct i.v. injection of tumor cells in the circulation as described by some authors [16-20]. Mice would then be treated with heparins. Many conditions could be explored: the drugs could be administered before tumor grafting, at the time of grafting, during malignant progression, or after the surgical removal of the primary tumor. Also, different tumor cell types could be employed (metastatic/non metastatic, different organ origin, etc.). Mice would then be monitored all along and sacrificed at the beginning and at the end of treatment, as well as after a period of drug washout. The rate of the primary tumor growth could be then evaluated. Metastatic dissemination could also be grossly monitored by optical imaging while at sacrifice the metastatized organs could be examined [17, 20]. Hemostatic activation of the mice could be analyzed in parallel to the oncologic study. In these models, all heparins studied for this thesis could be employed, particularly the new second-generation LMWH and the ULMWH. For the latter no data at all is available in cancer animal models. 
A next step of our studies could also be the evaluation, in our models, of the so-called "non-anticoagulant" heparins [21]. Indeed, some heparin preparations have been modified so that while they have lost the anticoagulant properties they still retain other features, including anti-cancer effects [21]. This could render these modified heparins of interest in the cancer setting, when one aims to target tumor progression without altering the hemostatic status of the host and thus avoiding heparin side-effects (namely hemorrhages).

The last step should be to understand how to translate the new and the future information into better clinical strategies. Indeed, those studies that have evaluated the benefits coming from the treatment with anticoagulants on survival of cancer patients show conflicting results [22]. However, the majority of these studies have evaluated the effects of anticoagulants in cancer patients that also had a thrombosis. We still lack studies in which the evaluation of the effect of anticoagulants on cancer progression is the primary target [23], independently from their effect in preventing the hemostatic system activation and thrombosis-related deaths. So, we strongly need this type of clinical studies. Data coming from in vitro research and animal models could help to design clinical trials of such type with narrow, clear targets. 


\section{References}

[1] G.J. Merli, J.B. Groce, Pharmacological and clinical differences between low-molecular-weight heparins: implications for prescribing practice and therapeutic interchange, P T 35(2) (2010) 95-105.

[2] F.W. Orr, H.H. Wang, Tumor cell interactions with the microvasculature: a rate-limiting step in metastasis., Surg Oncol Clin N Am 10 (2001) 357-381.

[3] E.S. Siegelman, L. Needleman, Venous thrombosis and cancer, N Engl J Med 328(12) (1993) 885; author reply 8867.

[4] P. Prandoni, A.W. Lensing, H.R. Buller, A. Cogo, M.H. Prins, A.M. Cattelan, S. Cuppini, F. Noventa, J.W. ten Cate, Deep-vein thrombosis and the incidence of subsequent symptomatic cancer, N Engl J Med 327(16) (1992) 1128-33. [5] F.R. Rickles, R.L. Edwards, C. Barb, M. Cronlund, Abnormalities of blood coagulation in patients with cancer. Fibrinopeptide A generation and tumor growth, Cancer 51(2) (1983) 301-7.

[6] G.J. Miller, K.A. Bauer, D.J. Howarth, J.A. Cooper, S.E. Humphries, R.D. Rosenberg, Increased incidence of neoplasia of the digestive tract in men with persistent activation of the coagulant pathway, J Thromb Haemost 2(12) (2004) 2107-14.

[7] A. Vignoli, M. Marchetti, L. Russo, E. Cantalino, E. Diani, G. Bonacina, A. Falanga, LMWH bemiparin and ULMWH 
RO-14 reduce the endothelial angiogenic features elicited by leukemia, lung cancer, or breast cancer cells, Cancer Invest 29(2) (2011) 153-61.

[8] R. Lecumberri, J.A. Paramo, E. Rocha, Anticoagulant treatment and survival in cancer patients. The evidence from clinical studies, Haematologica 90(9) (2005) 1258-66.

[9] A. Vignoli, M. Marchetti, D. Balducci, T. Barbui, A. Falanga, Differential effect of the low-molecular-weight heparin, dalteparin, and unfractionated heparin on microvascular endothelial cell hemostatic properties, Haematologica 91(2) (2006) 207-14.

[10] J. Hirsh, T.E. Warkentin, S.G. Shaughnessy, S.S. Anand, J.L. Halperin, R. Raschke, C. Granger, E.M. Ohman, J.E. Dalen, Heparin and low-molecular-weight heparin: mechanisms of action, pharmacokinetics, dosing, monitoring, efficacy, and safety., Chest 119(Suppl. 1) (2001) 64S-94S.

[11] A.A. Khorana, A. Sahni, O.D. Altland, C.W. Francis, Heparin inhibition of endothelial cell proliferation and organization is dependent on molecular weight, Arterioscler Thromb Vasc Biol 23(11) (2003) 2110-5.

[12] S. Soker, D. Goldstaub, C.M. Svahn, I. Vlodavsky, B.Z. Levi, G. Neufeld, Variations in the size and sulfation of heparin modulate the effect of heparin on the binding of VEGF165 to its receptors, Biochem Biophys Res Commun 203(2) (1994) 1339-47. 
[13] K. Norrby, P. Ostergaard, Basic-fibroblast-growth-factormediated de novo angiogenesis is more effectively suppressed by low-molecular-weight than by high-molecularweight heparin, Int J Microcirc Clin Exp 16(1) (1996) 8-15.

[14] K. Norrby, $2.5 \mathrm{kDa}$ and $5.0 \mathrm{kDa}$ heparin fragments specifically inhibit microvessel sprouting and network formation in VEGF165-mediated mammalian angiogenesis, Int J Exp Pathol 81(3) (2000) 191-8.

[15] M. Marchetti, A. Vignoli, L. Russo, D. Balducci, M. Pagnoncelli, T. Barbui, A. Falanga, Endothelial capillary tube formation and cell proliferation induced by tumor cells are affected by low molecular weight heparins and unfractionated heparin, Thromb Res 121(5) (2008) 637-45.

[16] R. Giavazzi, D.E. Campbell, J.M. Jessup, K. Cleary, I.J. Fidler, Metastatic behavior of tumor cells isolated from primary and metastatic human colorectal carcinomas implanted into different sites in nude mice, Cancer Res 46(4 Pt 2) (1986) 1928-33.

[17] M.R. Bani, A. Garofalo, E. Scanziani, R. Giavazzi, Effect of interleukin-1-beta on metastasis formation in different tumor systems, J Natl Cancer Inst 83(2) (1991) 119-23.

[18] M.R. Bani, A. Falanga, M.G. Alessio, E. Radice, R. Consonni, R. Giavazzi, M.B. Donati, Blood coagulation changes in nude mice bearing human colon carcinomas, Int J Cancer 50(1) (1992) 75-9. 
[19] M. Cesca, R. Frapolli, A. Berndt, V. Scarlato, P. Richter, H. Kosmehl, M. D'Incalci, A.J. Ryan, R. Giavazzi, The effects of vandetanib on paclitaxel tumor distribution and antitumor activity in a xenograft model of human ovarian carcinoma, Neoplasia 11(11) (2009) 1155-64.

[20] A. Silini, C. Ghilardi, C. Ardinghi, S. Bernasconi, P. Oliva, F. Carraro, A. Naldini, M.R. Bani, R. Giavazzi, Protease-activated receptor-1 (PAR-1) promotes the motility of human melanomas and is associated to their metastatic phenotype, Clin Exp Metastasis 27(1) (2010) 43-53.

[21] B. Casu, I. Vlodavsky, R.D. Sanderson, Nonanticoagulant heparins and inhibition of cancer, Pathophysiol Haemost Thromb 36(3-4) (2008) 195-203.

[22] I. Garcia-Escobar, C. Beato-Zambrano, J. Munoz Langa, E. Brozos Vazquez, B. Obispo Portero, D. Gutierrez-Abad, A.J. Munoz Martin, Pleiotropic effects of heparins: does anticoagulant treatment increase survival in cancer patients?, Clin Transl Oncol (2018).

[23] C. Tieken, H.H. Versteeg, Anticoagulants versus cancer, Thromb Res 140 Suppl 1 (2016) S148-53. 
Valorisation 
Cancer patients are at high risk of developing venous thromboembolism (VTE), including deep venous thrombosis and pulmonary embolism.

Indeed, in cancer patients VTE represents the second cause of death after the tumor itself, and significantly worsens their morbidity and the quality of life.

It is now well established that while the presence of a tumor predisposes the onset of VTE in the host, the activation of the hemostatic system in cancer may have a role not only in thrombosis but also in tumor growth and dissemination.

The effort of the current research aims to find valuable tools able to break down this mutual, vicious relationship.

In this respect, heparins, particularly the low molecular weight (LMWH) subcategory, are good candidates in that not only they are the drug of choice for the prophylaxis and treatment of VTE in a wide spectrum of pathological settings, including cancer, but they also appear to be endowed with direct and indirect anti-tumor features.

This has led to the development of a number of prospective randomized clinical trials to test LMWH to improve cancer survival as a primary end-point in cancer patients. Although the results are controversial, the interest in this research area remains high. Given the potential benefit of increased survival in oftentimes still fatal disease, any benefit, even small effects, may be clinically relevant. Therefore, it makes sense to dig deeper into the biology of cancer cells and to 
better establish the effects of different types of heparins, on growth and proliferation of tumor cells.

We choose to study the impact of heparins on the vascular endothelium, this because endothelial cells play multiple roles in several patho-physiological processes, including hemostatic activation and cancer progression, so they appear an ideal target when you aim to impair the cancer/thrombosis association.

We could demonstrate that heparins may prevent the prothrombotic switch of the endothelial cells when exposed to tumor-derived products, as well as standard cytokines. This is relevant because the inhibition of fibrin formation has been considered a possible tool against the progression of malignant disease.

Endothelial cells take also part in tumor-driven angiogenesis. We could observe that heparins are able to impair the tumorinduced formation of capillary-like tubules (a key step in the neo-angiogenesis process) by endothelial cells in the wellknown matrigel-based model. By counteracting the formation of new blood vessels, one could limit the tumor growth.

Then, we showed that heparins are able to counteract the direct adhesion of tumor cells to the vascular endothelium monolayer, by employing leukemic cells (but data are ongoing also with cells from solid tumor). This has important implications in that this effect may prevent tumor dissemination. We also showed that heparins counteract the 
migration of cells from pancreatic cancer, a very aggressive subtype of cancer.

It has to be noted that we employed only cells of human origin, with regard to both endothelium and tumor. In particular, we used in all studies endothelial cells of the microcirculation, the most involved type in the pathological conditions, while the majority of published studies with the vascular endothelium have utilized cells from the macrocirculation.

Moreover, in our studies, we used not only the classical unfractionated heparin (UFH) and various types of LMWH, but also one representative of the very new ultra-low molecular weight heparin (ULMWH) subclass, i.e. RO-14. These newest heparins are characterized by a lower mean $\mathrm{MW}$, and a more defined composition of polysaccharidic chain content. They are also characterized with a high antiFXa activity and only residual anti-Flla activity, thus the ratio anti-FXa/anti-Flla is much greater compared to classical LMWH [1], that means that they should be endowed with a better efficacy/risk ratio compared to LWMH. Some ultraLMWH are in clinical development [1-2]. However, little is known about their anti-cancer effects. Indeed, we first describe here that one of these ultra-LMWH i.e. RO-14 possess an anti-angiogenic activity similar to those shown by LMWH [3]. RO-14 also possesses a direct inhibitory effect on the migration of the pancreatic cancer cells. 
With all the limitations coming from being in vitro studies, taken together these data further contribute to support the evidence of a possible in vivo anti-tumor effect of LMWH.

They also provide ground for future extensive studies, both in animal models and in clinical trials, about a possible role for LMWH and ULMWH in the cancer/thrombosis setting.

In summary, the potential therapeutic benefit of heparin derivatives for patients with malignant disease, is still out of reach. This does not mean that the promising findings from in vitro and animal studies could not translate into effective therapies. The use of specific fractions, such as nonanticoagulant heparins with reduced bleeding potential, and the application of better experimental models of disease, should be able to advance our knowledge. This gain in knowledge should translate into feasible focused clinical trials in highly selected patients with cancer, as to obtain proof of principle data on efficacy and mechanisms of action. The use of biomarkers, both for cancer cell death, as well as for vascular damage, hypercoagulability and other markers of vascular disease related to cancer, should help to explore the underlying mechanisms further.

\section{References}

[1] Z. Liu, S. Ji, J. Sheng, F. Wang, Pharmacological effects and clinical applications of ultra low molecular weight heparins, Drug Discov Ther 8(1) (2014) 1-10. 
[2] G. Agnelli, D.J. George, A.K. Kakkar, W. Fisher, M.R. Lassen, P. Mismetti, P. Mouret, U. Chaudhari, F. Lawson, A.G. Turpie, Semuloparin for thromboprophylaxis in patients receiving chemotherapy for cancer, N Engl J Med 366(7) (2012) 601-9.

[3] A. Vignoli, M. Marchetti, L. Russo, E. Cantalino, E. Diani, G. Bonacina, A. Falanga, LMWH bemiparin and ULMWH RO-14 reduce the endothelial angiogenic features elicited by leukemia, lung cancer, or breast cancer cells, Cancer Invest 29(2) (2011) 153-61. 
Curriculum Vitae 
Alfonso Vignoli was born on January 22nd, 1970, in Vimercate, Italy.

After a 5-year course, in 1988 he obtained a Secondary School Diploma in Electrotechnical Engineering in Bergamo, Italy.

Then, he started his scientific training at the University of Milan, Italy: here, he obtained in 1998 the title of Master of Science in Biological Sciences, with a thesis prepared at the Hematology Department of the Bergamo Hospital (currently named "Papa Giovanni XXIII", formerly "Ospedali Riuniti"). Then, he continued his research activities at the Bergamo Hospital in the research laboratory led by Prof. Anna Falanga, first at the Hematology Department, and then at the Immunohematology and Transfusion Department, until today. In 2007 he obtained a Board Certification in Microbiology and Virology, after a 4-year course, at the University of Brescia, Italy.

In 2014, Dr. Vignoli became part of the permanent staff of the Immunohematology and Transfusion Department, where is still continuing his research activities in parallel to the ordinary duties typical of a blood bank.

In the last years he has also completed his studies related to the present $\mathrm{PhD}$ thesis, in the frame of the MaastrichtBergamo collaboration, under the supervision of Professor 
Hugo ten Cate for the Dutch side (from Maastricht University), and of Professor Anna Falanga for the Italian side (from Bergamo Hospital).

He has published about 20 full papers and more than 100 abstracts in International peer-reviewed scientific journals, along with books and book chapters, and he has presented his research data all over the world at the most relevant National and International Congresses. 
Publications 


\section{Papers}

1. Falanga $A$, Marchetti $M$, Evangelista $V$, Vignoli A, Licini $M$, Balicco M, Manarini S, Finazzi G, Cerletti C, Barbui T. Polymorphonuclear leukocyte activation and hemostasis in patients with essential thrombocythemia and polycythemia vera. Blood. 2000;96(13):4261-6.

2. Falanga A, Vignoli A, Marchetti M, Barbui T. Defibrotide reduces procoagulant activity and increases fibrinolytic properties of endothelial cells. Leukemia. 2003;17(8):163642.

3. Marchetti M, Vignoli A, Bani MR, Balducci D, Barbui T, Falanga A. All-trans retinoic acid modulates microvascular endothelial cell hemostatic properties. Haematologica. 2003;88(8):895-905.

4. Falanga A, Vignoli A. Venous thromboembolism in oncology. Eksp Onkol. 2004;26(1):11-4. Review.

5. Falanga A, Marchetti M, Vignoli A, Balducci D, Barbui T. Leukocyte-platelet interaction in patients with essential thrombocythemia and polycythemia vera. Exp Hematol. 2005;33(5):523-30.

6. Falanga A, Marchetti M, Vignoli A, Balducci D. Clotting mechanisms and cancer: implications in thrombus formation and tumor progression. Clin Adv Hematol Oncol. 2003;1(11):673-8. Review. 
7. Vignoli $A$, Marchetti $M$, Balducci $D$, Barbui $T$, Falanga $A$. Differential effect of the low-molecular-weight heparin, dalteparin, and unfractionated heparin on microvascular endothelial cell hemostatic properties. Haematologica. 2006;91(2):207-14. Erratum in: Haematologica. 2006;91(5):620.

8. Cella G, Marchetti M, Vignoli A, Randi ML, Saggiorato G, Pasetto L, Pagnan A, Barbui T, Falanga A. Blood oxidative status and selectins plasma levels in healthy donors receiving granulocyte-colony stimulating factor. Leukemia. 2006;20(8):1430-

9. Falanga A., Marchetti M., Vignoli A. Cancer and thrombosis in women: mechanisms. Thrombosis research 2007;119 (Suppl. 1):S33-S35.

10. Falanga A, Marchetti M, Vignoli A, Balducci D, Russo L, Guerini V, Barbui T. V617F JAK-2 mutation in patients with essential thrombocythemia: relation to platelet, granulocyte, and plasma hemostatic and inflammatory molecules. Experimental Hematology 2007;35(5):702-11. Erratum in: Exp Hematol. 2007 Sep;35(9):1476.

11. Marchetti M, Vignoli A, Russo L, Balducci D, Pagnoncelli M, Barbui T, Falanga A. Endothelial capillary tube formation and cell proliferation induced by tumor cells are affected by low molecular weight heparins and unfractionated heparin. Thrombosis Research 2008;121(5):637-45. 
12. Falanga $A$, Vignoli $A$, Marchetti $M$. Coagulation in Hematological Malignancies. Cancer Investigation 2009; 27: 1-10.

13. Cella G, Marchetti M, Vianello F, Panova-Noeva $M$, Vignoli A, Russo L, Barbui T, Falanga A. Nitric oxide derivatives and soluble plasma selectins in patients with myeloproliferative neoplasms. Thrombosis Haemostasis 2010;104(1):151-6.

14. Monreal Bosch M, Vignoli A, Lecumberri Villamediana R, Prandoni P. Bemiparin in oncology. Drugs. 2010;70 Suppl 2:35-42.

15. Vignoli A, Marchetti M, Russo L, Cantalino E, Diani E, Bonacina $G$, and Falanga $A$. LMWH bemiparin and ULMWH RO14 reduce the endothelial angiogenic features elicited by leukemia, lung cancer, or breast cancer cells. Cancer Investigation 2010; 29:153-61.

16. Falanga A., Vignoli A., Diani E., Marchetti M. Comparative assessment of low-molecular-weight heparins in cancer from the perspective of patient outcomes and survival. Patient Related Outcome Measures 2011;2:175188.

17. Falanga $A$, Marchetti $M$, Vignoli $A$. Coagulation and cancer: biological and clinical aspects. Journal Thrombosis Haemostasis 2013;11(2):223-33. Review. 
18. Vignoli A, Giaccherini $C$, Marchetti $M$, Verzeroli $C$, Gargantini C, Da Prada L, Giussani B, Falanga A. Tissue Factor Expression on Platelet Surface during Preparation and Storage of Platelet Concentrates. Transfusion Medicine Hemotherapy 2013;40(2):126-32.

19. Vignoli A, Marchetti M, Falanga A. Heparins inhibit the endothelial pro-thrombotic features induced by tumor cells. Thromb Res. 2017;157:55-57.

20. Falanga A, Russo L, Milesi V, Vignoli A. Mechanisms and risk factors of thrombosis in cancer. Critical reviews in Oncology/Hematology. 2017;118:79-83.

21. Vignoli A, Marchetti M, Falanga A. Acute promyelocytic leukemia cell adhesion to vascular endothelium is reduced by heparins. Annals of Hematology. 2018 Sep;97(9):15551562.

\section{Book}

Falanga A, Marchetti M, Balducci D, Vignoli A. Trombosi e Tumori. Springer, 2004. ISBN: 8847002931.

\section{Book chapter}

-Falanga A, Marchetti M, Vignoli A. Pathogenesis of thrombosis in cancer. In: Thrombosis and Cancer. Lugassy G, Falanga A, Kakkar AJ, and Rickles FR. (Eds). Martin Dunitz, London 2003, Chapter 2. 


\section{Acknowledgements}


I would like to express my heartfelt thanks to all the people who have accompanied me in my life as a researcher, and who have made possible the development and conclusion of this $\mathrm{PhD}$ thesis.

First of all my gratitude goes to Professor Anna Falanga, that welcomed me in her lab more than 20 years ago. In all this time, Professor Falanga has never made me miss her support and has always encouraged me not to give up my research activity.

In all these years I have also been lucky enough to work with Doctor Marina Marchetti, who taught me the basic principles of research.

Professor Falanga and Doctor Marchetti are the main architects of my research training, and I have shared and still share all my research with both.

I also thank all those colleagues with whom I have shared more or less long parts of my life as a researcher, particularly Donatella, Erika, Carmen, Sara, Cristina, Cinzia, Elena, Annamaria, and all those (too many to be mentioned here) that have followed other paths for the reasons of life. A special thank goes to Dr. Laura Russo, that will be at my side for the $\mathrm{PhD}$ defense. 
This is for the "Italian" side of the PhD preparation.

However, in the last years l've had the opportunity to get acquainted and work with many nice people from Maastricht in the Netherlands. I warmly thank all of them for their kindness, particularly Arina, Paola, Johan, Frauke, Henri, and Elisabetta (I apologize if I forget someone!). A special thank goes to Professor Hugo ten Cate, that has supervised this thesis and relentlessly supported me from the beginning to the very end of this adventure.

I also warmly thank Trees for her precious assistance and advices given for all the cumbersome administrative duties.

I thank all the prestigious members of my thesis assessment committee for their kind comments to my work, and their presence at the defense.

Last but not least my gratitude goes to my family, i.e. my parents and my brother: without their continuous support it would not have been possible to me to become and be a researcher for so many years. My parents aren't in this world anymore, but I'm certain they are still following me in this and other adventures of life. 
